\title{
ADVANCED MICROTURBINE SYSTEMS
}

Final Report for Tasks 1 Through 4 and Task 6

\author{
T. Rosfjord, Program Manager \\ W. Tredway, Deputy Program Manager
}

A. Chen, J. Mulugeta, and T. Bhatia

\section{United Technologies Research Center \\ East Hartford, CT 06118}

March 26, 2007

Prepared for

The U.S. Department of Energy, Office of Distributed Energy

Award No. DE-FC26-00CH11060

Report Number DOE/CH/11060-1 


\section{DISCLAIMER}

This report was prepared as an account of work sponsored by an agency of the United States Government. Neither the United States Government nor any agency thereof, nor any of their employees, makes any warranty, express or implied, or assumes any legal liability or responsibility for the accuracy, completeness, or usefulness of any information, apparatus, product, or process disclosed, or represents that its use would not infringe privately owned rights. Reference herein to any specific commercial product, process, or service by trade name, trademark, manufacturer, or otherwise does not necessarily constitute or imply its endorsement, recommendation, or favoring by the United States Government or any agency thereof. The views and opinions of authors expressed herein do not necessarily state or reflect those of the United States Government or any agency thereof. 


\section{Executive Summary}

In July 2000, the United Technologies Research Center (UTRC) was one of five recipients of a US Department of Energy contract under the Advanced Microturbine System (AMS) program managed by the Office of Distributed Energy (DE). The AMS program resulted from several government-industry workshops to improve customer choice and value for electrical power with reduced pollutants. The Advanced Microturbine System program goals were:

- System $\operatorname{cost}=\$ 500 / \mathrm{kW}$

- Electrical efficiency $=40 \%$

- 11,000 hour between major overhaul

- $\mathrm{NOx}=7$ PPM@15\% O2

- Multi-fuel capable

UTRC formulated an RD\&D program around an integrated microturbine/bottoming cycle system concept. The program executed the following four tasks:

- Task 1 Preliminary Design - Cycle and system analyses identified technology options. The desired AMS system balanced performance, cost, and technical risk.

- Task 2 and 6 Subsystem Component Development - Ceramic turbine, low emission combustor, EBC coatings and Organic Rankine Cycle (ORC) component designs were developed to mitigate AMS risks.

- Task 3 \& 4 System Integration and Performance Demonstration -A C200/ORC system was integrated and tested to achieve $38 \%$ electrical efficiency.

The primary Conclusions from this AMS program were:

- A viable approach to a $40 \%$ electrical efficiency AMS with very low emissions is to integrate high-performing microturbine and Organic Rankine Cycle systems.

- Ceramic turbine components - vane ring, integrally bladed rotor, and shroud - can be designed and $\mathrm{EBC}$ coated to meet realistic microturbine performance and life targets.

- A statically and dynamically stable natural-gas-fired microturbine combustor can be designed to achieve ultra-low emissions over a wide turndown range.

- A high performance, adaptable, affordable Organic Rankine Cycle system can be achieved through the use of components produced by HVAC suppliers.

In addition to the findings supporting the above Conclusions, the UTRC AMS program provided significant technical leverage:

- The ORC system technology was commercialized by UTC Power as the PureCycle $^{\mathrm{TM}}$ product to recycle energy from any waste heat stream into electrical power without any pollutant production. The PureCycle ${ }^{\mathrm{TM}}$ system appears well aligned with conversion renewable geothermal energy into electricity.

- Other US Government sponsored efforts to use ceramic turbine components, such as the Advanced Small Turbine Technologies Demonstration effort for unmanned aerial vehicles, are benefiting from the AMS accomplishments. Developed methods for ceramic component designs that achieve life while preserving 
performance, and for production of complex prototype parts, are being applied in this US Army program. 


\section{Acknowledgements}

This Topical Report presents work, accomplishments, and conclusions from Tasks 1 through 4 and Task 6 of the UTRC Advanced Microturbine System collaboration with the Office of Distributed Energy of the US Department of Energy under contract DEFC26-00CH11060. The authors and other UTRC engineers benefited from the many useful discussions with the DOE team, led by Debbie Haught and supported by Donald Geiling and Steven Waslo.

The breadth of the microturbine system solution required the talents and efforts of many researchers beyond the report authors, including: John Holowczak, Jun Shi, Venkata Vedula, Connie Bird, Luca Bertuccioli, Scott Ochs, Tania Bhatia, Ellen Sun, Sonia Tulyani, Catalin Fotache, Donald Kendrick, John Stufflebeam, Louis Chiapetta, Scott Liljenberg, Karen Teerlinck, Daniel Mosher, Bruce Biederman, Duane McCormick, Thomas Radcliff, Frederick Cogswell, Stephen Jones, and several UTRC support staffs, were responsible for the significant and high quality findings and accomplishments of the collaboration. 


\section{Table of Contents}

Executive Summary

Acknowledgements

Table of Contents

List of Figures

List of Tables

Section 1.0 Introduction and Advanced Microturbine System Study

1.1 Introduction

1.2 Advanced Microturbine System Study

\section{Section 2.0 Advanced Microturbine System Technology Studies}

2.1 Ceramic Turbine Technology Development

2.2 Low Emissions Combustor Technology Development

2.3 Organic Rankine Cycle (ORC) Technology Development

Section 3.0 Integration and Test of Advanced Microturbine System

3.1 System Integration, Installation, and Instrumentation

3.2 C200 Performance

3.3 ORC System Performance

3.4 Integrated Advanced Microturbine System Performance

Section 4.0 Ceramic Technology Development

4.1 Ceramic Component Design

4.2 Development of Environmental Barrier Coating for silicon nitride

4.3 Spin Testing

Section 5.0 Conclusions, Program Leverage, and Recommendations

5.1 Conclusions

5.2 Program Leverage

5.3 Recommendations

Appendix 


\section{Table of Figures}

\section{Figure number and title}

1.2.1 Rankine Cycle process

1.2.2 High efficiency AMS cycle

1.2.3 Effects of pressure ratio on AMS performance for fixed T7

1.2.4 Relative contribution to achieve $40 \%$ electrical efficiency

1.2.5 T4-T7 relationship for AMS cycle

1.2.6 Payback years for alternative recuperator technologies

2.1.1 Relative Mach distribution for ceramic vane/rotor Gen 1 design

2.1.2 Steady-state full-power heat transfer coefficients

2.1.3 Sample endwall contouring of blade platform

2.1.4 Convection heat transfer coefficient distribution on blade surface

2.1.5 Circumferentially-averaged convective heat transfer coefficient and driving temperature on the shroud

2.1.6 Cold-day startup transient

2.1.7 Maximum thermal stress in the vane during transient shutdown

2.1.8 Temperature gradients and thermal stress during steady-state

2.1.9 Thermal stress during tip shutdown after $8 \mathrm{sec}$

2.1.10 Design concept for slotted ceramic shroud

2.1.11 Temperature distribution and thermal stress of the shroud under hot streak conditions

2.1.12 Radial deflection and maximum principle stress for a spinning disk only

2.1.13 Temperature and maximum principle stress for rotor with blade pull

2.1.14 Self sustaining radius determination for ST5+ rotor disk

2.1.15 Cold spin distribution of rotor maximum principle stress

2.1.16 Cold spin rim hoop and radial stress

2.1.17 Hot spin temperature and maximum principle stress

2.1.18 Hot spin radial and hoop rim stress

2.1.19 Startup midspan blade sink temperature and rotor speed in time

2.1.20 Startup rotor maximum principle stress

2.1.21 Emergency shutdown blade and midspan sink temperature and rotor speed in time

2.1.22 Emergency shutdown maximum principle stress with time

2.1.23 Partitioning of IBR FEA into representative data sets for CARES analysis

2.1.24 Predicted cT blade recession over 25,000 hours of microturbine operation

2.1.25 Brazed attachment and wedge attachment

2.1.26 Brazed-Wedge attachment concept

2.1.27 Brazed-Wedge attachment FEA results

2.1.28 Brazing trials specimens

2.1.29 Effect of zirconia TBC spall impact on rotor blade at $100 \%$ speed

2.1.30 ST5 andST5+ leading edge FOD impact results

2.1.31 Multi-axis machined vane ring at Kyocera

2.1.32 Multi-axis machined silicone nitride vane rings

2.1.33 Typical defects seen in "reject" vane ring

2.2.1 Isometric view of combustor assembly 
2.2.2 Cross-section of tapered ceramic combustor liner

2.2.3 EBC coating

2.2.4 EBC in the ID surface of 6 in. Hexaloy cylinder

2.2.5 Multi-point premixer for Low emissions cylindrical combustor

2.2.6 PLIF imaging for the axial swirler nozzle

2.2.7 Representative nozzle boundary conditions

2.2.8 Predicted CO levels

2.2.9 Scroll impedance measurement setup

2.2.10 Impedance at various flow rates

2.2.11 Thermo-acoustic instability model predictions

2.3.1 19XR225 compressor

2.3.2 09DK094 Carrier air cooled condenser

2.3.3 Gen 1 ORC evaporator

2.3.4 Gen 1 ORC test system

2.3.5 Gen 1 ORC evaporator performance

2.3.6 Mach number profiles for turbine nozzles and gap

2.3.7 Turbine impellor and generator shaft with roller element bearings

2.3.8 Long term lubricant stability test results

2.3.9 Motor and oil cooling circuits and management systems

2.3.10 Motor and oil cooling circuit performance

2.3.11 Validation of condenser capacity and pressure drop

2.3.12 Over speed protection

2.3.13 Generation 2 ORC

2.3.14 Safe turbine operating zone

2.3.15 Modified-cascade closed-loop controller

3.1.1 Installation and integration of C200/ORC AMS

3.1.2 Instrumentation for integrated C200/ORC AMS

3.1.3 Microturbine measurements for exhaust and lost energy

3.2.1 C200 electrical efficiency

3.2.2 Measured C200 exhaust characteristics

3.3.1 Predicted ORC design point performance

3.3.2 Measured ORC system performance with C200 exhaust

3.3.3 ORC performance characteristics

3.3.4 ORC condenser performance

3.3.5 ORC recuperator pressure drop

3.3.6 ORC evaporator performance

4.2.1 Study of the feasibility of thermal spraying an integral vane ring.

4.2.2 Calculation of residual stress in $\mathrm{Si}$ layer on monolithic $\mathrm{Si}_{3} \mathrm{~N}_{4}$.

4.2.3 Various architectures considered to drive down residual stress in the Si-layer of the coating.

4.2.4 EBC coating microstructure and digitized image for OOF analysis

4.2.5 (a) Retained strength of silicon nitride using an oxide interlayer between silicon nitride and Si bond coat. (b) Microstructure of the bond coat system that retains baseline substrate strength

1.2.7 Strength of samples fractured in four point bending shown as Weibull distribution 
4.2.6 (a) Fracture surface of as received silicon nitride that failed at $86.6 \mathrm{ksi}$ in bend test. (b) Fracture surface of as silicon nitride coated with the compliant later and Si that failed at $81.4 \mathrm{ksi}$ in bend test

4.2.7 Relative high temperature steam resistance of candidate EBC top layer materials

4.2.8 Dip coated $\mathrm{HfO}_{2}$ on CVD Si. (a) Top view and (b) Cross section

4.2.9 Coating trials aimed at producing a "full EBC" system.

4.2.10 A yttrium silicate coating was applied to a NT154 silicon nitride airfoil via dip coating. The optical micrograph on the right shows a section of the leading edge with a uniform layer of the coating.

4.2.11 Slurry coated SN282 blade. (a) Before and (b) After burner rig testing to $2400 \mathrm{~F}$ (50 cycles)

4.2.12 Coating of integral vane ring to demonstrate scalability of the process

4.3.1 Spin tested microturbine rotor. (a) Uncoated rotor, (b) Coated rotor before spin test and (c) Coated rotor after spin 


\section{Table of Tables}

\section{Table number and title}

1.2.1 Current natural gas microturbine product characteristics

1.2.2 Recuperator material/cost trades

2.1.1 Design changes and transient stress

2.1.2 Design changes and resulting clearances

2.1.3 NT154 strength and weibull modulus

2.1.4 Rotor modal analysis

2.2.1 Predicted vs measured NOx and CO (previous nozzle)

3.2.1 Energy loss from C200 \#4

3.2.2 Energy loss form C200 \#3

3.3.1 Performance of C200/ORC Advanced Microturbine System

4.2.1 Variation of coating thickness as a function of position and section on blade A 


\section{Section 1.0 Introduction and Advanced Microturbine System Study}

\subsection{Introduction}

In July 2000, the United Technologies Research Center (UTRC) was one of five recipients of a US Department of Energy contract under the Advanced Microturbine System (AMS) program managed by the Office of Distributed Energy (DE). The AMS program resulted from several government-industry workshops that recognized that microturbine systems could play an important role in improving customer choice and value for electrical power. That is, the group believed that electrical power could be delivered to customers more efficiently and reliably than the grid if an effective distributed energy strategy was followed. Further, the production of this distributed power would be accomplished with less undesirable pollutants of nitric oxides (NOx) unburned hydrocarbons (UHC), and carbon monoxide (CO).

In 2000, the electrical grid delivered energy to US customers at a national average of approximately $32 \%$ efficiency. This value reflects a wide range of powerplants, but is dominated by older, coal burning stations that provide approximately $50 \%$ of US electrical power. The grid efficiency is also affected by transmission and distribution (T\&D) line losses that can be significant during peak power usage. In some locations this loss is estimated to be $15 \%$. Load pockets can also be so constrained that sufficient power cannot be transmitted without requiring the installation of new wires. New T\&D can be very expensive and challenging as it is often required in populated regions that do not want above ground wires. While historically grid reliability has satisfied most customers, increasing electronic transactions and the computer-controlled processes of the "digital economy" demand higher reliability. For them, power outages can be very costly because of transaction, work-in-progress, or perishable commodity losses.

Powerplants that produce the grid electrical power emit significant levels of undesirable NOx, UHC, and CO pollutants. The level of emission is quoted as either a technology metric or a system-output metric. A common form for the technology metric is in the units of PPM@15\% O2. In this case the metric reflects the molar fraction of the pollutant in the powerplant exhaust when corrected to a standard exhaust condition as containing 15\% (molar) oxygen, assuring that the PPM concentrations are not altered by subsequent air addition or dilution. Since fuel combustion consumes oxygen, the output oxygen reference is equivalent to a fuel input reference. Hence, this technology metric reflects the moles of pollutant per mole of fuel input, but not the useful output of the powerplant - i.e. the power. The system-output metric does embrace the useful output and is often termed an output-based metric. A common form for the output-based metric is in the units of $1 \mathrm{~b} / \mathrm{MWh}$. This is a system metric relating the pounds of pollutant to output energy (e.g., MWh) of the powerplant. The two emission metrics are quantitatively related through the efficiency:

$$
\begin{aligned}
& \text { A (lb/MWh) = K x B (PPM @ 15\% O2) / Eta (\%) } \\
& \text { Where: } \\
& \qquad \mathrm{A}=\text { pollutant magnitude in output-based units }
\end{aligned}
$$


$\mathrm{B}=$ pollutant magnitude in fuel-input based units

Eta $=$ electrical efficiency $(\%)$

$\mathrm{K}=$ constant for units conversion and fuel-related properties

In 2000, the US national average for grid power output-based NOx was $3.0 \mathrm{lb} / \mathrm{MWh}$. Using an electrical efficiency of $32 \%$, this metric corresponds to approximately $70 \mathrm{PPM}$ NOx @ 15\% O2. This level is $5 \mathrm{X}$ higher than typically achieved with natural-gas gas turbine power generators such as shown below in Table 1.2.1 for current microturbines. Hence, microturbines contain the combustor technology to reduce pollutants from power generation.

In a distributed energy strategy, power generation devices would be located at or near the customer to improve delivered electrical efficiency and reliability. The electrical efficiency of these devices must exceed the grid efficiency to save energy. Moreover, their efficiency must significantly exceed the grid efficiency to provide a cost of electricity (COE) attractive to customers. That is, in simple terms, COE depends on equipment cost and life, fuel cost, system efficiency, and maintenance cost according to:

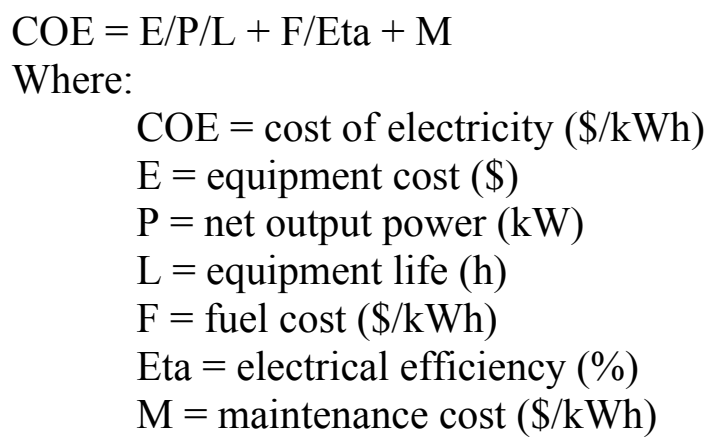

COE is much more than converting fuel price via electrical efficiency. This concept applies to electricity delivered by the grid or by distributed devices. For the grid, economies of larger scale, and long lifetimes, beneficially reduce grid COE despite the low grid efficiency. On the other hand, the smaller scale of distributed power devices results in more costly equipment and maintenance per unit output. Therefore they require a higher efficiency "Eta" to reduce the fuel price contribution and thereby offset the equipment and maintenance price. By placing the units at the user, power reliability can be enhanced as issues such as associated with weather influences will be eliminated. While it is expected that most distributed power generation would operate parallel to the grid (i.e. provide an alternative power supply that offsets purchases of grid power), local power generation may also be configured to also provide back-up power capability (i.e., dual mode configuration - grid parallel or independent mode). This feature further enhances customer power reliability.

Consideration such as these led to a set of goals for the Advanced Microturbine System program to foster the attractiveness of microturbines as a distributed powerplant. The goals addressed contributing factors to $\mathrm{COE}$ such as equipment price, life, and efficiency, 
while promoting reliability, low environmental impact, and fuel flexibility. The targeted goals for the AMS were:

- System cost $=\$ 500 / \mathrm{kW}$

- $\quad$ Electrical efficiency $=40 \%$

- 11,000 hour between major overhaul

- NOx=7 PPM@15\% O2

- Multi-fuel capable

UTRC formulated an RD\&D program around a system concept that was predicted to meet most of these objectives. The program consisted of the following six tasks and high-level statements of accomplishments:

- Task 1 Preliminary Design - Cycle and system analyses were performed to identify technology options that achieved the AMS goals. The desired system properly balanced performance, cost, and technical risk to ensure that an AMS would be demonstrated. Preliminary component designs were generated.

- Task 2 Subsystem Component Development - Component designs were finalized, fabricated, and evaluated to mitigate AMS risks.

- Task 3 \& 4 System Modification and Performance Demonstration - UTRC integrated an Organic Rankine Cycle (ORC) with an enhanced performance microturbine and achieved 38\% electrical efficiency.

- Task 5 Durability Demonstration - Full-scale test and verification of an integrated AMS system was planned but deleted during the course of the program.

- Task 6 Ceramic Turbine Technology - Added task in 2005 for risk reduction to reap benefits ceramic technology towards improving electrical efficiency to over $40 \%$.

As described more fully below, the UTRC preferred AMS integrated an enhanced performance microturbine with an electrical efficiency of approximately $33 \%$, with an Organic Rankine Cycle (ORC) subsystem to convert the microturbine exhaust into additional electrical power. The original pathway for the microturbine was to enhance the $400 \mathrm{~kW}$ ENT400 microturbine under development by DTE Energy Technologies and powered by the Pratt \& Whitney Canada ST5 engine. ENT400 development was stopped in 2002 because of technical and financial issues. In later 2002, UTC announced a Strategic Alliance with the Capstone Turbine Corporation, shifting the microturbine focus for the UTRC AMS to the Capstone C200. Final execution of Tasks 2, 3, 4 and 6 were adapted to this new Alliance.

This report details the accomplishments of Tasks 1 through 4 and Task 6 . The following portions of Section 1.0 establish the characteristics of existing microturbines and of the UTRC preferred system to achieve the AMS goals. Section 2.0 describes the technology developments that contributed toward that system, with Section 3.0 describing the integration and testing of the AMS.. Section 4.0 describes technology developments and risk reduction in the area of environmental barrier coatings and ceramics. Section 5.0 provides Conclusions, Program Leverage, and Recommendations. 


\subsection{Advanced Microturbine System Study}

\subsubsection{System Study Perspective and Methods}

A microturbine is a small-scale electrical power generation system that typically consists of a low pressure-ratio recuperated gas turbine engine driving a generator. The typical fuel is natural gas although some designs are qualified for liquid fuel or opportunity fuels such as landfill gas. An electrically driven fuel gas booster is often included to deliver the fuel pressure required by the engine, but its power usage is usually not included in the system performance ratings.

Microturbine system manufacturers use a low pressure-ratio gas turbine engine to avoid the costs associated with multiple turbomachinery stages and/or specialized cooling as may be required for high pressure-ratio engines. However, the thermal efficiency of a low pressure-ratio engine (shaft power/input fuel energy rate) is less than $15 \%$. A recuperator, which is high temperature heat exchanger that transfers energy from the turbine exhaust flow to the compressor discharge flow, is used to reduce the thermal energy exhausted by the system and thereby increase thermal efficiency to over $25 \%$.

Generator designs include induction or permanent magnet devices that are rotated by the engine either directly or through a geared connection. The permanent magnet design is operated either synchronous to the electrical grid or at high speed in which case an inverter transforms the rectified generator output to high-quality power at desired characteristics (frequency, voltage, etc).

The Capstone Turbine Corporation, Energy Systems of the Ingersoll-Rand Company, and Elliott Energy Systems, Inc currently sell commercial products with power outputs ranging from $30 \mathrm{~kW}$ to $250 \mathrm{~kW}$ at ISO ambient conditions (59F, Sea Level, $60 \% \mathrm{RH}$ ). Table 1.2.1 depicts ratings of current natural gas fueled offerings. As indicated, LHV electrical efficiencies range $26 \%$ to $30 \%$, most units have very low NOx emissions, and most integrate an exhaust heat recovery heat exchanger. Such devices have become common to produce another energy stream valued by the customer.

UTRC performed a system trade-off study to determine affordable pathways to achieve the AMS goals. These goals were considered together as the desirable AMS must achieve a competitive COE, a combination of first cost, electrical efficiency, maintenance cost, and life. In general, lower first cost and much higher electrical efficiency than offered by current microturbine systems must be simultaneously achieved. It was accepted that the lean, premixed combustion strategy currently in use (e.g. Capstone) would be adopted and extended to lower NOx emissions. Fuel flexibility was not included in the high priority design constraints, and a natural gas fired system was sought.

UTRC analyzed over 200 cycles representing combinations of Brayton-cycle gas turbine systems and Rankine cycle systems for performance and cost. A Rankine cycle is a heat engine that accepts energy at a high temperature, converts some of the input to useful 
work such as a turbine driving an electrical generator, and rejects the balance of energy at a low temperature. In particular, as illustrated on Figure 1.2.1, the input energy (Qh) vaporizes a high pressure working fluid that expands across a turbine and performs work (Wt), removes energy to condense the lower pressure and temperature vapor to liquid (Qc), and then pumps the liquid (Wp) up to the evaporator condition. The working fluid must be matched to the temperature of the source energy, and can be water or hydrocarbons. The systems analyzed focused on the use refrigerants as the working fluid, and this bottoming cycle was termed an Organic Rankine Cycles (ORC).

Table 1.2.1 Current natural gas microturbine product characteristics

\begin{tabular}{|c|c|c|c|c|c|c|}
\hline Manufacturer & & Capstone & Capstone & Elliott & IR & IR \\
\hline Model & & $\mathrm{C} 30$ & C60 iCHP & TA100CHP & $70 \mathrm{~L}$ & 250 \\
\hline Power@ISO & $\begin{array}{l}\text { kWe } \\
\text { w/o FGB }\end{array}$ & 30 & 60 & 100 & 70 & 250 \\
\hline $\begin{array}{l}\text { LHV Efficiency } \\
\text { (a) ISO }\end{array}$ & $\begin{array}{l}\% \\
\text { w/o FGB }\end{array}$ & 26 & 28 & 29 & 29 & 30 \\
\hline NOx & $\begin{array}{l}\text { PPM } \\
15 \% \text { O2 }\end{array}$ & $<9$ & $<9$ & 24 & $<9$ & $<9$ \\
\hline & $\begin{array}{l}\text { LbNOx/ } \\
\text { MWeh }\end{array}$ & & & & & \\
\hline $\begin{array}{ll}\text { Fuel } & \text { Gas } \\
\text { Booster } & \\
\end{array}$ & & Option & External & Integrated & Integrated & Integrated \\
\hline Generator & & $\begin{array}{l}\mathrm{PM} \\
\mathrm{w} / \text { Inverter }\end{array}$ & $\begin{array}{l}\mathrm{PM} \\
\mathrm{w} / \text { Inverter }\end{array}$ & $\begin{array}{l}\mathrm{PM} \\
\mathrm{w} / \text { Inverter }\end{array}$ & Induction & $\begin{array}{l}\text { Synch } \\
\text { PM }\end{array}$ \\
\hline Lubrication & & Air & Air & Oil & Oil & Oil \\
\hline $\begin{array}{ll}\text { Exhaust } & \text { Heat } \\
\text { Recovery } & \\
\end{array}$ & & None & Integrated & Integrated & Integrated & Integrated \\
\hline
\end{tabular}

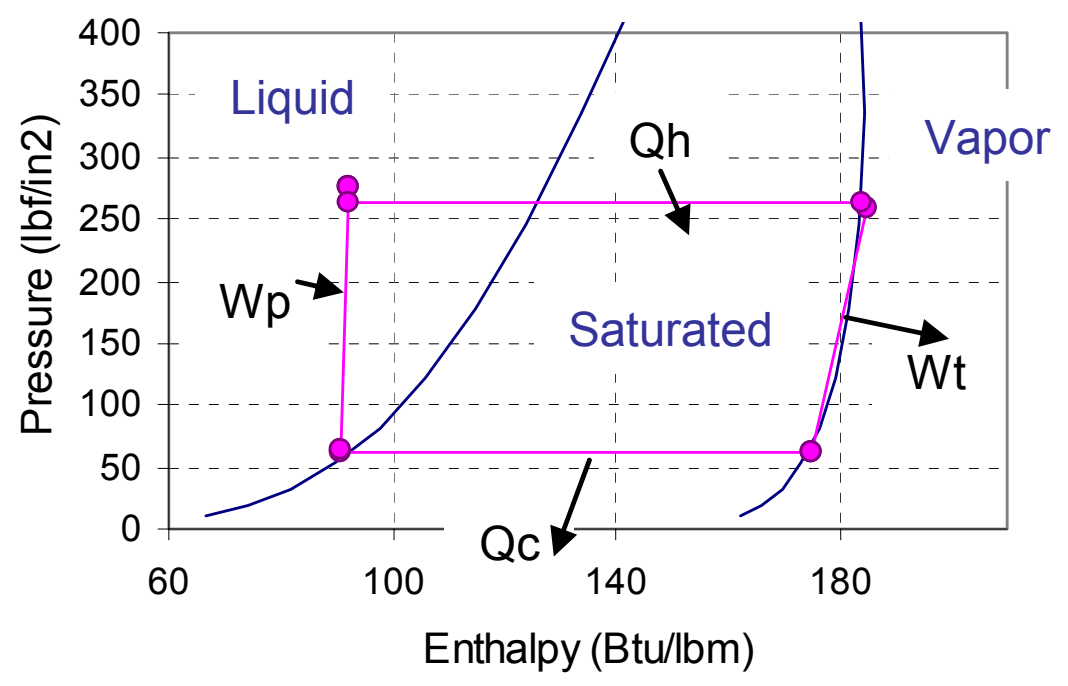

Figure 1.2.1 Rankine Cycle processes 
The design-point Brayton-cycle analysis employed the Keenan and Kaye gas properties for air and for the products of combustion. 'Design point' implied that component performance is given, not computed from component performance maps. The component performance figures used were based on component performance predictions generated for the ST5 engine and, where no formal performance prediction capability existed, on engineering judgment. In addition to the component efficiencies, it was important to include duct and heat exchanger pressure losses and engine bleeds, and parasitic power losses in order to accurately assess the performance of a complex cycle such as a recuperated Brayton-cycle with a bottoming cycle.

The design point Rankine-cycle analysis used working fluid properties collated by NIST and published as the RefProp program. The working fluids investigated are hydrofluourocarbons that have previously been evaluated for use in refrigeration cycles, hence the acronym, RefProp. The ORC consists of the standard Rankine cycle components - pump, evaporator, turbine, feed heater, and condenser.

\subsubsection{System Study Conclusions}

1. System electrical efficiencies greater than $40 \%$ are compatible with cost effectiveness using combined recuperated-gas-turbine-engine/ORC-bottoming cycle configurations.

Figure 1.2.2 shows a cycle diagram for a system that employs a recuperator capable of operating at $1250 \mathrm{~F}$ with a ceramic turbine that requires $4 \%$ less compressor bleed for cooling than would a metallic turbine. The $1250 \mathrm{~F}$ recuperator operating temperature is between 70 and 100F higher than current technology. Based on available information on recuperator cost, it was assumed that an advanced material would be required which would increase the recuperator cost by $40 \%$ above that of the baseline. The turbine entrance temperature is less than $100 \mathrm{~F}$ above the level used in the baseline. Even though small, this increase will require a more capable material than used in the baseline in order to achieve the required lifetime. It was assumed that a ceramic material, requiring less cooling and costing $10 \%$ less to fabricate, would be available.

The performance analysis tools were used to examine variants of the cycle illustrated in Figure 1.2.2. A re-examination of the effect of cycle pressure ratio was performed for this specific cycle as illustrated in Figure 1.2.3. Note that in these analyses, recuperator technology was kept constant with $\mathrm{T} 7=1250 \mathrm{~F}$. This presentation is in contrast with the more usual analysis in which turbine technology, as represented by T4, is kept constant. Low pressure-ratio (PR) systems require high recuperator use temperature to benefit from them. If T7 is limited, low PR systems perform worse than high PR systems. Some benefit to cycle efficiency was observed in increasing PR above $8: 1$, but the efficiency increase was not found to be sufficient to offset the cost associated with developing the new compressor design. 


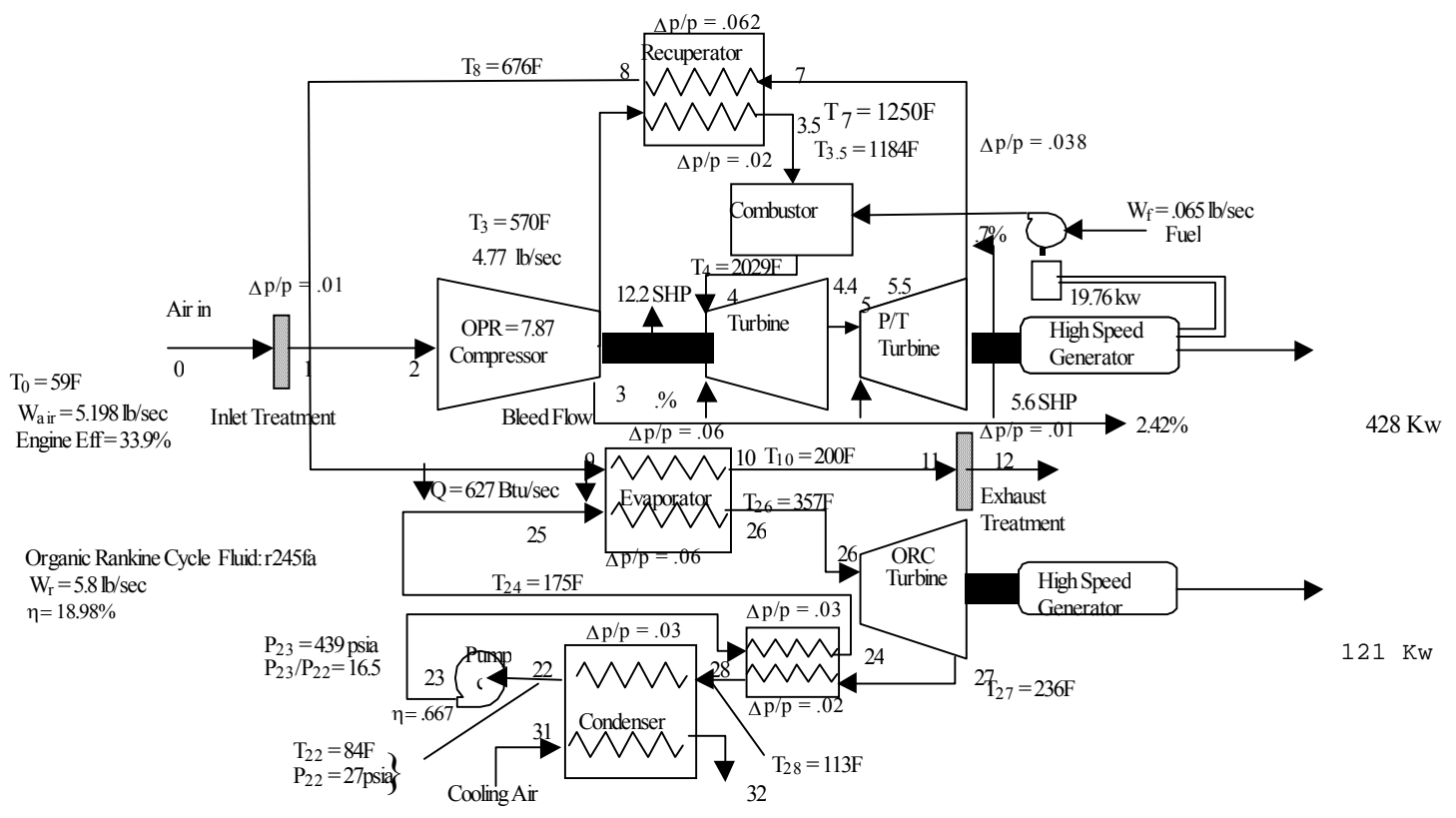

Figure 1.2.2 High-efficiency AMS cycle

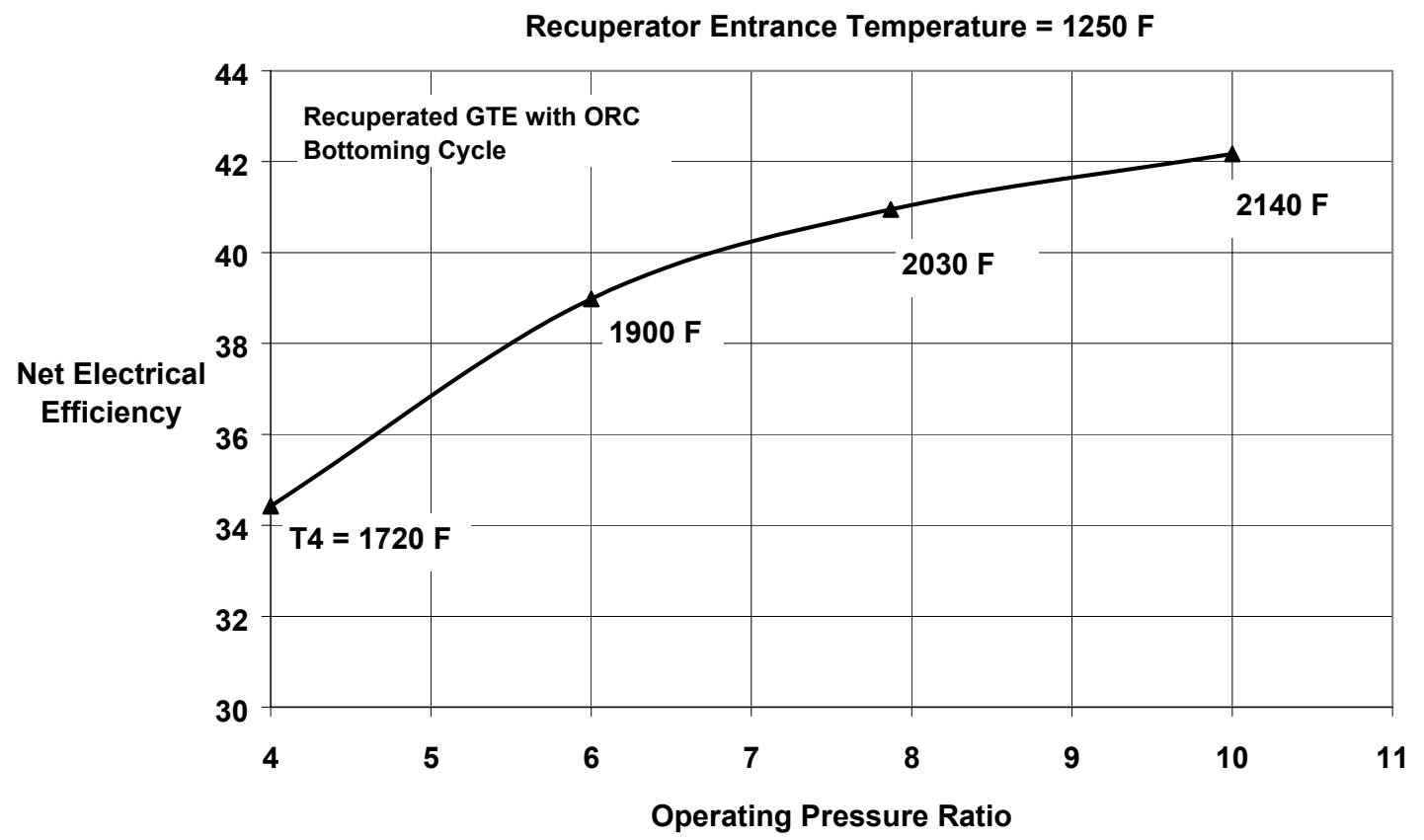

Figure 1.2.3 Effect of pressure ratio on AMS performance for fixed T7

2. The ORC bottoming cycle is the key to achieving high electrical efficiency.

Higher efficiencies are achieved by using hotter cycles, improving electrical efficiency and utilizing waste heat. The results of UTRC studies indicated that hotter cycles realized only modest efficiency gains in affordable systems - the cost of the recuperator 
quickly becomes prohibitive (see below). On the other hand, little or no advancement in materials technology and component performance appears to be required to implement an ORC.

The key to the ORC is the capability of the organic working fluid. The fluid must be safe, non-toxic, environmentally safe, thermally stable, affordable, and have thermodynamic properties suitable for low temperature $(<500 \mathrm{~F})$ cycles. The studies conducted focused on the use of fluids currently available in commercial quantities. The cycle illustrated above is based on the use of R245fa, which based on available data is considered non-toxic, not an ozone scavenger, non-flammable, stable to temperatures above $350 \mathrm{~F}$, and reasonably priced. As shown in Figure 1.2.2, for the cycle analyzed, the evaporator exit temperature is $357 \mathrm{~F}$ and the maximum pressure is 440 psia. The minimum temperature differential (the temperature 'pinch' in a counterflow exchanger) was kept above $25 \mathrm{~F}$ in the three exchangers.

For this advanced cycle, the contributions of each of the strategies for improving efficiency are illustrated in Figure 1.2.4. The ORC contributes 6.4 points in efficiency. The assumed improvement in electrical generator/inverter performance contributes 1.7 points in efficiency, while the combined effect of the modestly hotter recuperator and the ceramic turbine with its reduced cooling requirement contributes 2.8 points.

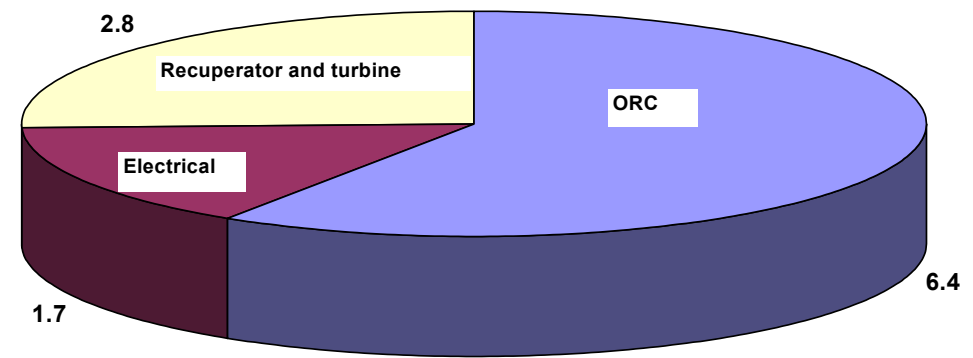

\section{Figure 1.2.4 Relative contribution to achieve 40\% electrical efficiency}

3. Recuperator cost limits gas turbine cycle temperature.

For a given engine cycle, there is a monotonic relationship between turbine entrance temperature and recuperator operating temperature. Whereas improvements in turbine cooling schemes and the development of advanced metallics and ceramics offered promise of higher turbine operating conditions, affordable recuperators capable of handling the increased temperatures were not identified. For the cycle of interest, the relationship between turbine entrance temperature and recuperator entrance temperature is shown in Figure 1.2.5. Current technology is characterized by metallic turbines operating in the $\mathrm{T} 4$ range of $1900-2000 \mathrm{~F}$, requiring recuperators capable of operating in the $\mathrm{T} 7$ range of $1150-1250 \mathrm{~F}$ for this combined cycle system. If an aggressive ceramic turbine technology were pursued to allow T4 levels of 2000-2300F, recuperator operation 
at T7 of $1350-1450 \mathrm{~F}$ would be required. According to UTRC analyses of materials capabilities, such high T7 levels required the use of advanced materials that greatly increased the recuperator price. An assessment of recuperator material capability (for a 32,000 -hour life) and the relative recuperator cost is shown in Table 1.2.2.

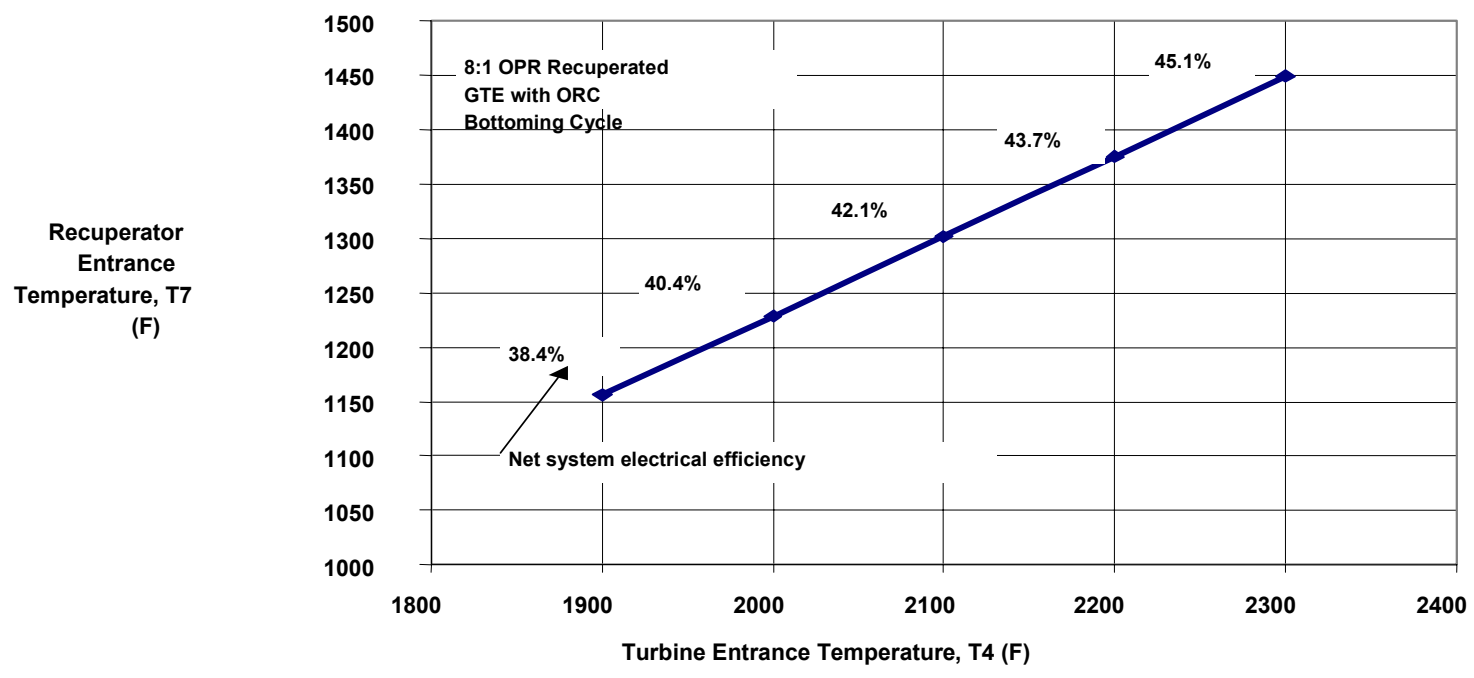

Figure 1.2.5 T4 - T7 relationship for the AMS cycle

Table 1.2.2 Recuperator material/cost trades

\begin{tabular}{|l|l|l|}
\hline Max gas temperature $(\mathrm{F})$ & Material & Relative Cost \\
\hline 1180 & Type 347 stainless steel & 1.0 \\
\hline 1250 & Advanced austenitic ss. & 1.4 \\
\hline 1300 & Inconel 625 & 3.5 \\
\hline 1350 & Haynes 230 & 5.5 \\
\hline
\end{tabular}

The relative payback period of AMS system is an alternative economic metric to COE; payback also combines first price, efficiency, and maintenance price. The net effect on system payback for using these various materials in a primary surface recuperator (PSR) is shown in Figure 1.2.6. The left-hand bar represented the DTE ENT4000 - a nominal $30 \%$ electrical efficiency system. The next four bars show the payback period for three higher-temperature cycles that required higher-capability recuperator materials. As seen, the improved efficiency of a highest temperature system is offset by the higher recuperator cost. The advanced austenitic stainless steel recuperator used in conjunction with a ceramic turbine produces the most attractive economics. The advantages offered by the ceramic turbine are higher T4 capability with slighter lower cost and a reduced turbine cooling air relative to a metallic turbine. However for the affordable AMS system, it is not possible to take full advantage of the higher ceramic turbine capability 
because of recuperator price. These results illustrate that recuperator capability drives the cycle selection process.

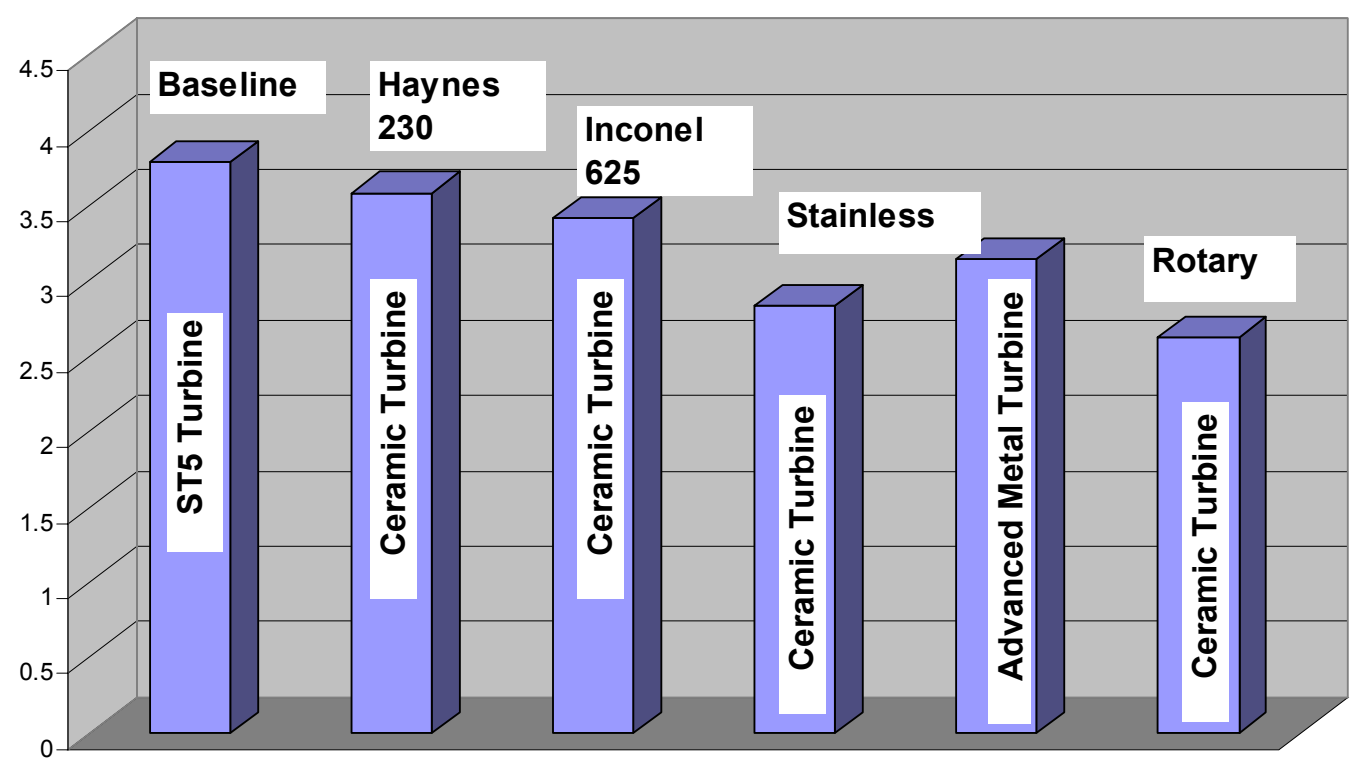

Figure 1.2.6 Payback years for alternative recuperator technologies

Alternative recuperator design concepts were also considered. The right-hand bar of Figure 1.2.6 reflects the projected price of a system employing a rotary recuperator (regenerator) that has the temperature capability of a Haynes 230 PSR, but the cost of a Type 347 device. Rotary recuperators were not favored for moderate pressure ratio (8:1) cycles because of the challenge to provide a reliable seal between the high-pressure and low-pressure gases within moving compartments. The analysis used to generate the results shown in Figure 1.2.6 assumed a 4\% leak rate for the rotary recuperator and a $0 \%$ leak rate for the PSR. It is apparent that under these assumptions, the rotary device could be a viable candidate.

\subsubsection{System Study Summary and Enabling Technologies}

As a consequence of these system analyses and conclusions, the desired AMS was a combination of an enhanced microturbine and an ORC that converted the exhaust into additional electrical power. The enhanced microturbine used ceramic turbine technology and modestly higher recuperator materials to permit a hotter, more efficient Brayton cycle. Improved generator/inverter components were assumed, but lean premixed combustion technology had to be adapted for the hotter cycle. Therefore, enabling technologies for:

- ceramic turbines

- low emission combustors

- ORC systems

were targeted for development and risk reduction in Task 2 of the program. 


\section{Section 2.0 Advanced Microturbine System Technology Studies}

\subsection{Ceramic Turbine Technology Development}

The development of a ceramic intensive turbine was broken into several tasks, including aerodynamic design, design of silicon nitride turbine components (cT vane ring, integrally bladed rotor (IBR), and turbine shroud), attachment development for silicon nitride IBRs, assessment of environmental barrier coatings (EBCs) for ceramic turbine components, manufacturing development, and FOD resistance analytical development. This section of the report will summarize key progress in these areas. The majority of the design activity was completed prior to strategic redirection of the program away from the ST5; in those cases where the activity was incomplete, it is so noted in the report. Also, several papers on the ceramic component design activity were presented at major conferences during the timeframe of the AMS contract. Three of these papers for which manuscripts were prepared and submitted are included in the report Appendix for additional documentation.

\subsubsection{Aerodynamic Design}

This task focused on aerodynamic design of Foreign Object Damage (FOD) resistant axial flow ceramic turbine vanes and rotor blades. The aerodynamic profiles of the cT turbine vanes and blades were altered to reduce blade count and thicken airfoil cross sections for improved producibility in silicon nitride and silicon carbide ceramics. The improved rotor blade shape and count were incorporated into the design for a ceramic IBR to replace the baseline ST5 rotor design. The baseline ST5 design incorporates uncooled, individual, single crystal superalloy blades. A silicon nitride ceramic IBR allowed for higher $\mathrm{T} 4$ temperatures while reducing overall systems cost by reducing parts count.

Initial efforts focused on aerodynamic design of FOD resistant vanes and rotor blades, and structural design of a ceramic rotor hub. A meanline optimization was performed that resulted in a first-stage design consisting of 15 vanes and 27 blades. Axial chords were held to those of the baseline ST5 design to limit airfoil aspect ratios and the associated profile losses, while reaction was limited to $45 \%$ to reduce blade exit flow angle and Mach number, and the associated transition duct losses. This reaction is a substantial increase over that of the baseline, which was held to $25 \%$ to reduce the effects of combustion gas temperature on the uncooled single crystal superalloy vanes. Blade trailing edge thickness was increased for FOD resistance. The meanline optimization resulted in a design with an increase in aerodynamic stage efficiency of between 1 and 2 $\%$-points over that of the baseline.

The meanline data was converted to an initial three-dimensional design, which was optimized for pressure distribution using a steady, inviscid flow solver. The relative Mach number distribution at mid-span of this design can be seen in Figure 2.1.1. The initial aerodynamic design was then converted to CAD format and combined with the 
vane ring and IBR disk designs to be analyzed for structural integrity and ceramic manufacturability.

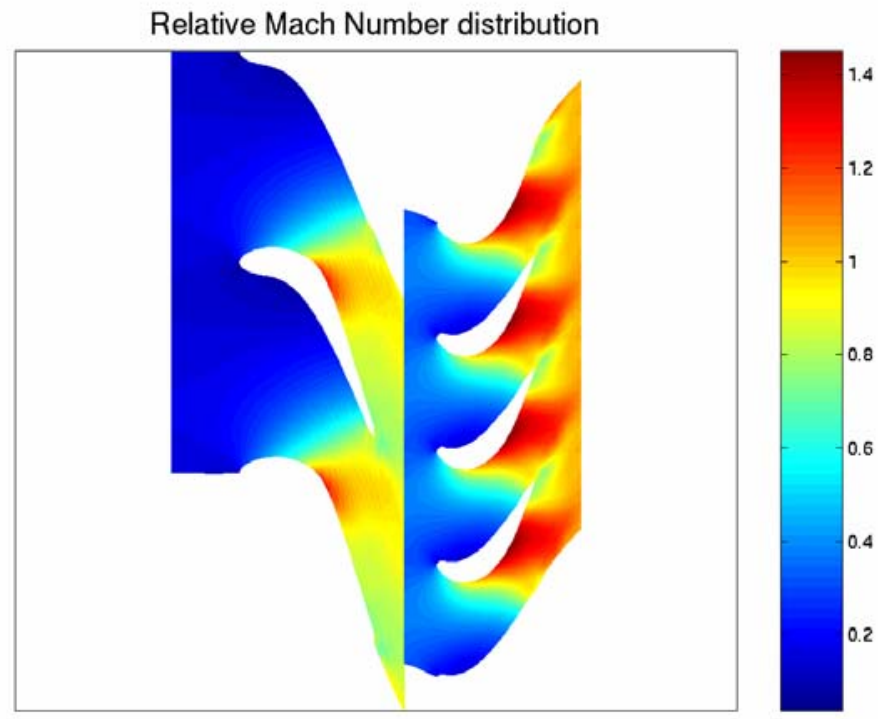

Figure 2.1.1 Relative Mach distribution for ceramic vane/rotor "Gen 1" design

Aerodynamic design continued by optimizing the three-dimensional vane and blade geometries for pressure distribution using a steady, inviscid flow solver. Fine-grid Navier-Stokes analyses were performed with both average and hot-streak inlet conditions to obtain boundary temperatures and heat-transfer coefficients for structural analysis. Vane heat-transfer coefficients are shown in Figure 2.1.2. Navier-Stokes computations were also performed on combined ST5 vane / ST5+ blade geometries, and vice-versa, to determine the usefulness and feasibility of rig-testing these combinations of components.

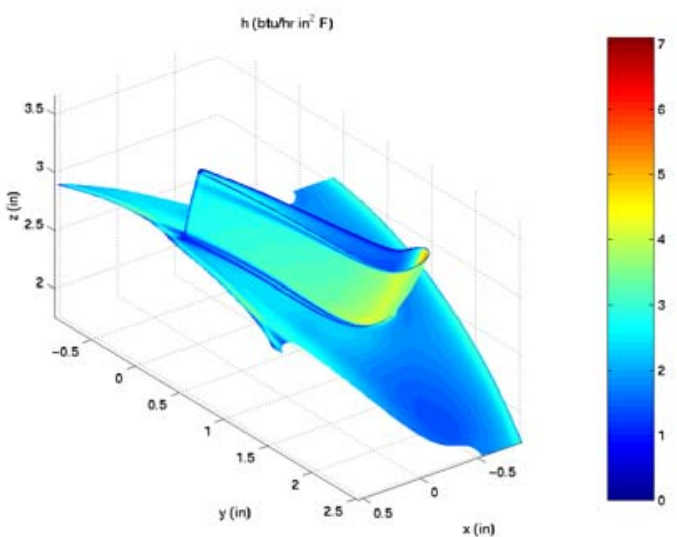

Average

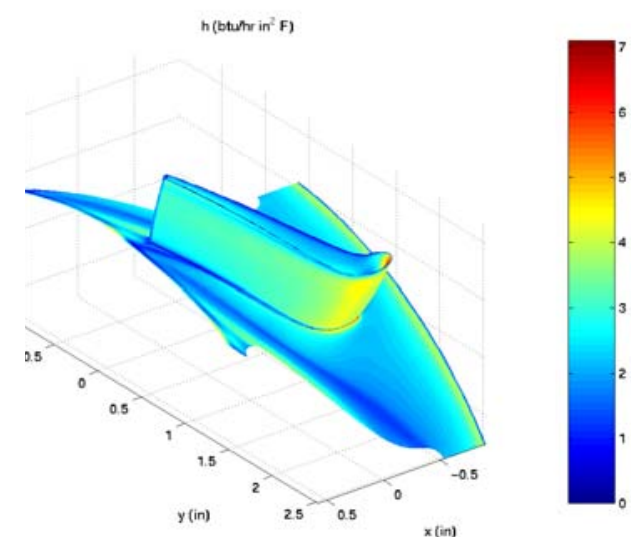

Hot-Streak

Figure 2.1.2 Steady-state full-power heat transfer coefficients 
Three-dimensional vane and blade geometries, which were optimized for pressure distribution while meeting all design constraints, were obtained using a steady, inviscid flow solver. The results were then validated with a viscous flow solver. Endwall contouring of the vane and blade platforms was examined as a mechanism to increase efficiency, reduce circumferential flow distortion, and potentially increase structural strength. Endwall contouring as applied to the blade platform can be seen in Figure 2.1.3. Both two-dimensional and three-dimensional models were used to analyze the stress levels in the rotor using end wall contouring. Unexpected high hoop stress developed around the troughs and under the platform. Attempts to add mass under the rim resulted in an increase in bore stress, and did not relieve the stress on the upper surface of the platform. End wall contouring as a method of reducing bore stress was abandoned.

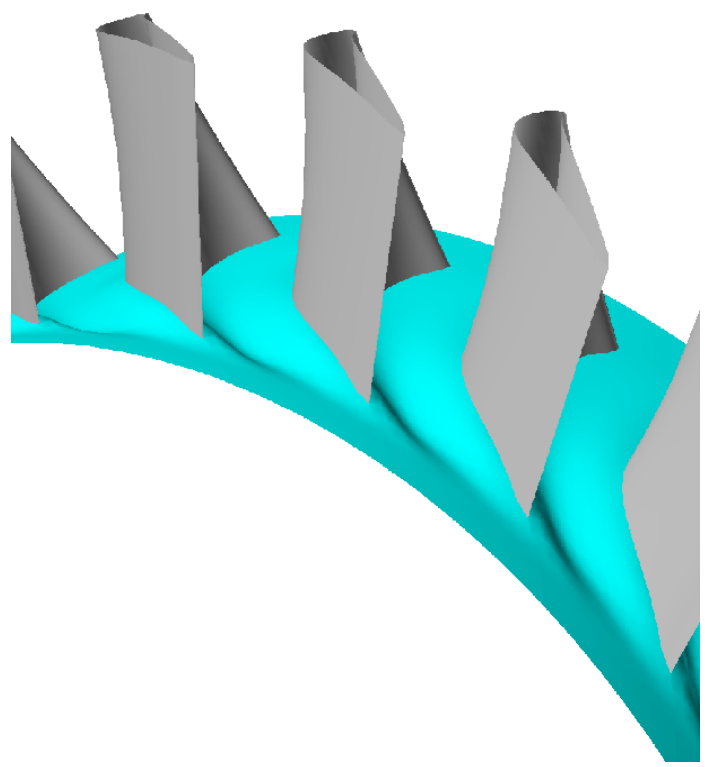

Figure 2.1.3 Sample endwall contouring of blade platform

The primary focus of the aerodynamic team turned to aerothermal analysis of the high pressure turbine stage including the effect of tip clearance, and more detailed transient analyses of both vane and blade for cold-day start-up and standard-day load-shed emergency shutdown conditions. The primary objective of the aerothermal analysis was to provide temperature and convective heat transfer coefficient boundary conditions for the structural analysis of the shroud. Earlier analyses of the turbine had been run without tip clearance since this greatly reduces the computational complexity of the problem. However, modeling of the tip flow is critical to an accurate assessment of the heat transfer to the shroud. In order to accurately resolve the flow in this region, an additional computational sector must be added to the model and the grids near the tip must be significantly refined. Because of this increase in the model size the run time increased to approximately 10 days with the model running in parallel on four processors. As in previous analyses, cases with both adiabatic and constant wall temperature boundary conditions were run to derive the local values of the convective heat transfer coefficient 
and driving temperature. Figure 2.1 .4 below shows the convective heat transfer coefficient distribution on the blade surface.

The convective heat transfer coefficient and driving temperature on the shroud must be circumferentially averaged since a fixed point on the shroud will experience time varying unsteady conditions as successive blade passages pass it. The circumferentially averaged results are shown in Figure 2.1.5.

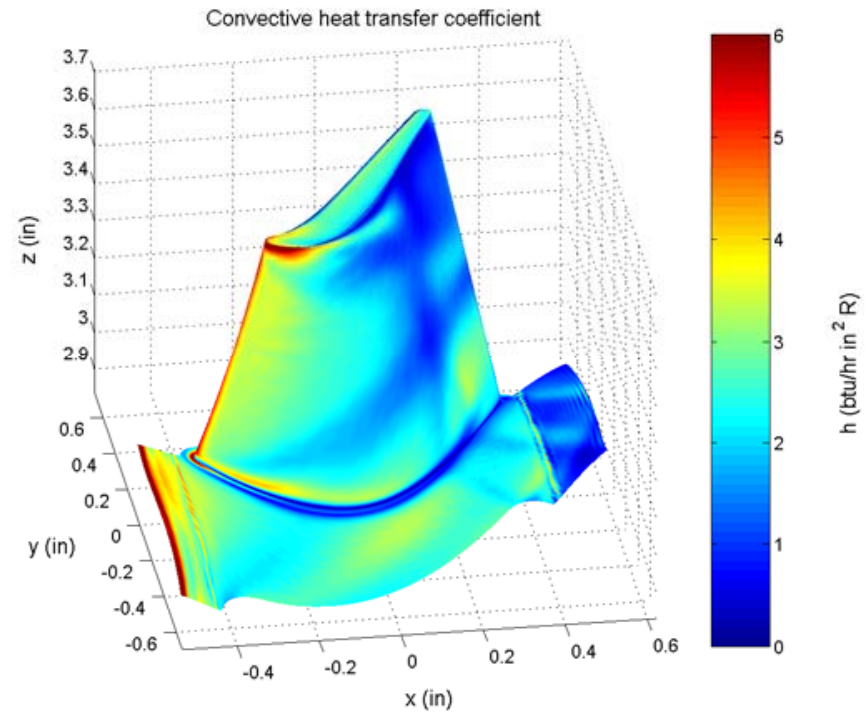

Figure 2.1.4 Convective heat transfer coefficient distribution on blade surface

The second activity was a refined transient analysis of both cold-day start up and standard-day load-shed emergency shutdown. In lieu of scaled engine test data, the results of a transient engine cycle deck (SOAPP transient performance deck) were used. Cycle data for the ST5+ were provided to the PWC Performance Analysis group who modified the existing transient deck for the baseline ST5 engine to reflect the new cycle design point. The results of PWC's transient analysis were post-processed to yield the relevant time histories (driving temperatures, heat transfer coefficients) that are the necessary boundary conditions for the transient structural analysis. Sample results for the cold-day start-up transient are shown in Figure 2.1.6. 


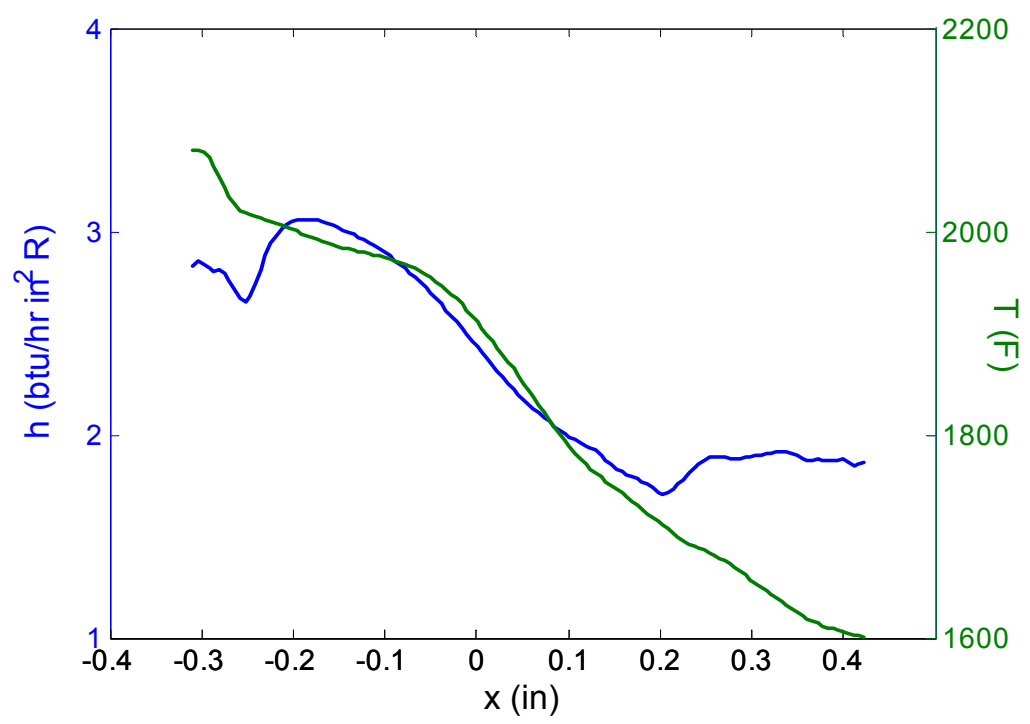

Figure 2.1.5 Circumferentially-averaged convective heat transfer coefficient and driving temperature on the shroud

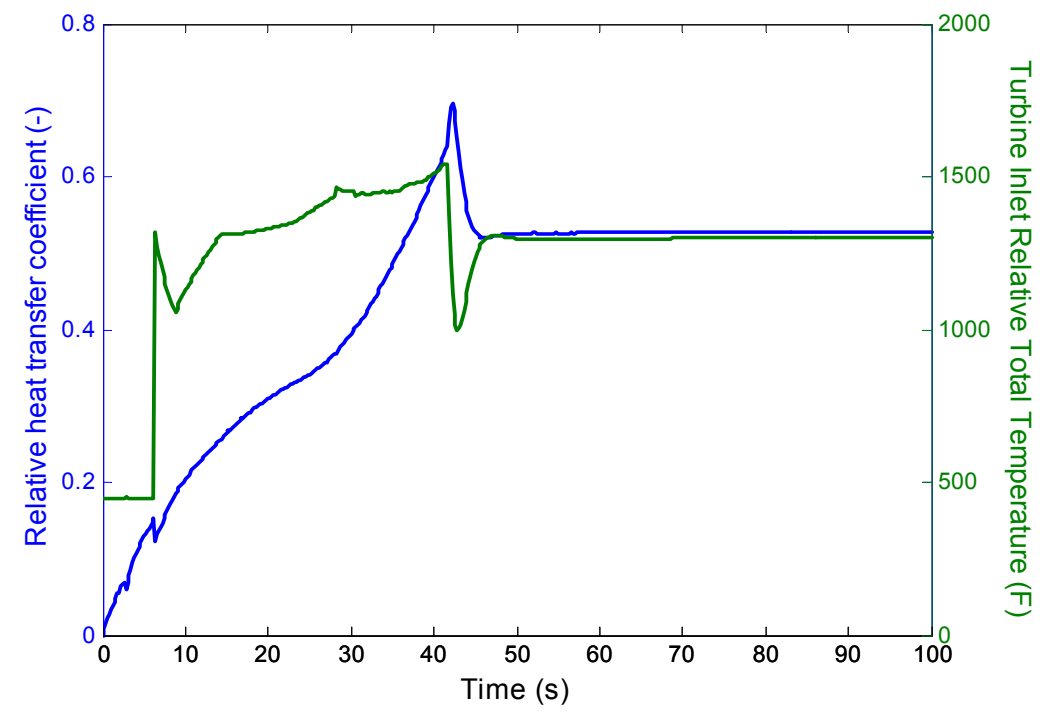

Figure 2.1.6 Cold-day startup transient

\subsubsection{Design of Ceramic Turbine Components}

The purpose of this task was to design and structurally analyze uncooled ceramic turbine components (vane ring, shroud, and rotor) for use in the ST5+ version of the Pratt Canada ST5 microturbine. Design and analysis of each component are discussed separately. 


\subsubsection{Ceramic Vane Ring}

The thermal gradients and the resulting thermoelastic stresses in the vane cascade were estimated using finite element analysis. The ST5 metal design, if manufactured as a single part from silicon nitride, was used for this initial analysis. Finite element analysis was performed for the complete vane ring (13 vanes) by ABAQUS using 4-node tetrahedral elements. Thermal boundary conditions for ST5 vanes were obtained from Pratt \& Whitney Canada (PWC) and were used in the analysis. The maximum and minimum temperatures in the vane assembly were 2018 and $1642^{\circ} \mathrm{F}$ respectively and the maximum principal stress was $25.8 \mathrm{ksi}$ at the inner surface of the inner platform. The analysis was performed for several different boundary conditions that result in more severe gradients and stresses. It was found that the thermal stresses could be as high as $63 \mathrm{ksi}$ depending on the severity of the heat transfer coefficients and sink temperatures.

FEA was performed to predict the steady state thermal gradients and the resulting thermoelastic stresses in a Gen 2 vane design consisting of 15 vanes. A count of 15 vanes was consistent with the aero meanline analysis, and was selected to avoid resonance with the 27 bladed rotor, while providing for the ability, if necessary, to use 5 vane triplets, or 3 five vane sections, to minimize parts count and sealing issues. The analysis indicated that the steady state stresses at the trailing edge of the vane were $\sim 16$ and $26 \mathrm{ksi}$ for the average inlet and hot-streak conditions respectively. CARES analysis indicated that the corresponding probabilities of failure were $5.3 \times 10-6$ and $8.9 \times 10-5$, respectively, suggesting that these thermal stresses were acceptable for both conditions. The hoop stresses in the outer ring were less than $10 \mathrm{ksi}$, indicating that an integral continuous vane ring was viable.

Transient analysis of the vane ring was performed for a variety of shutdown conditions. Initially, it was considered that the worst case scenario would be an instantaneous drop of $\mathrm{T} 4$ gas temperature to $1182 \mathrm{~F}$ (recuperator output) from $2100 \mathrm{~F}$. The analysis of this case showed that the maximum stresses in integral vane and separate outer platform designs were 37.2 and $29.8 \mathrm{ksi}$ respectively. The analysis was also performed for the case when the gas temperature dropped to $1182 \mathrm{~F}$ in $1 \mathrm{sec}$. For this case the stresses in the integral vane design and separate outer platform were 39.8 and 46.4 ksi respectively (Figure 2.1.7). In all cases, the transient stresses are highest at the trailing edge fillets. The reason for this is that the trailing edge cools much faster than the platforms resulting in a high temperature gradient at the fillets.

Subsequently, mass flow data was obtained from PWC and was scaled by the aeroanalysis to predict the variation of $\mathrm{T} 3, \mathrm{~T} 3.5$, and $\mathrm{T} 4$ as a function of time. This data was used to predict the thermal stresses in the vane assembly. It was found that maximum stresses were higher than those predicted for step changes. The maximum stresses were 59 and $70 \mathrm{ksi}$ for integral vane ring and separate outer platform designs, respectively. The corresponding probability of failure was $\sim 20 \%$. 

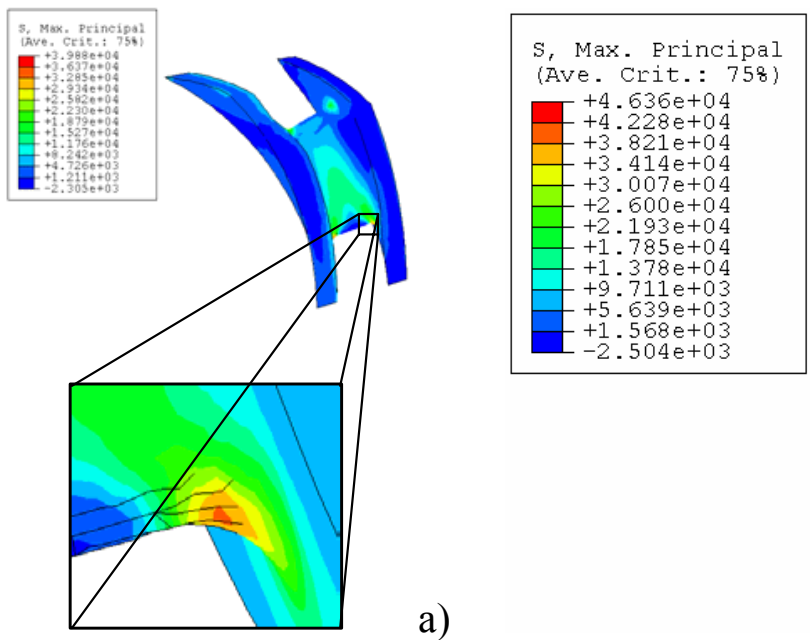

a)

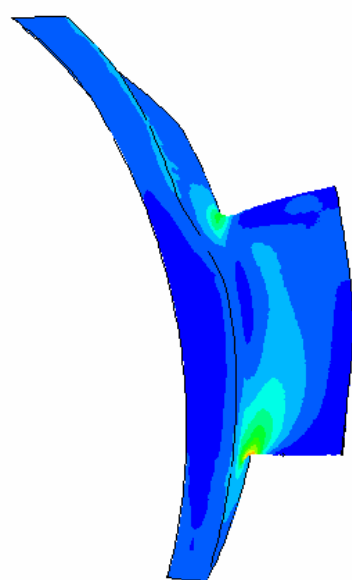

(b)

Figure 2.1.7 Maximum thermal stress in the vane during transient shutdown (a) integral vane ring at $t=4 \mathrm{sec}$ and (b) separate outer platform designs at $t=5 \mathrm{sec}$

Because of this high failure probability, the focus of the vane design activity turned towards making design modifications that would reduce the high stresses during transient conditions. The effects of platform thickness, attachment ring location, and end-wall contouring on transient stresses were evaluated. Table 2.1.1 lists the various design changes that were made and the resulting transient stress. The analysis was also repeated to account for the presence of environmental barrier coating (EBC) on the vane. A significant reduction in the transient stress from $59 \mathrm{ksi}$ to $28.5 \mathrm{ksi}$ was achieved when the attachment ring was relocated towards the trailing edge and the outer platform cooling was modified.

Table 2.1.1 Design changes and transient stress

\begin{tabular}{lc}
\hline Design Changes & $\begin{array}{c}\text { Maximum Principal } \\
\text { Stress (ksi) }\end{array}$ \\
\hline Platform Modifications & 59.0 \\
Baseline & $>59$ \\
Separate outer platform & $<59$ \\
Additional rings & $<59$ \\
Thinner platforms & \\
& \\
Attachment Location & 48.3 \\
Baseline & $<48$ \\
No attachment ring & $>48$ \\
Move $0.2 "$ to TE & $<48$ \\
Fillets: 0.05 and $0.05 "$ & $<48$ \\
Fillets: 0.2 and $0.17 "$ & $<48$ \\
Fillets: 0.1 and $0.1 "$ & \\
Endwall Contour & \\
Revise Cooling & 34.1 \\
Baseline & $<30$ \\
Use effective $\mathrm{h}$ & \\
\hline
\end{tabular}


Detailed transient and steady state thermal analysis were then performed on the revised vane aero-optimized designs. The steady state and transient thermal stresses in the vane ring were found to be acceptable for both average inlet and hot-streak conditions. The hot-streak and average inlet steady state stresses were found to be 25.3 and $13.9 \mathrm{ksi}$, respectively. Figure 2.1.8 shows the thermal gradients and resulting stresses in the vane ring. The transient stress peaked to $25.9 \mathrm{ksi}$ at the trailing edge fillet on the inner platform, 8 seconds into trip shut-down (Figure 2.1.9). Ceramic reliability analysis using CARES predicted a probability of failure of $\sim 1$ in 1,000,000 vanes. Scaling the analysis to the entire vane ring predicted a failure probability of 1 in 100,000 . The structural analysis was repeated to include the attachment tab (and the pressure loading on it) on the inner platform of the vane ring. The internal tab led to an increase in the stress to 34.5 ksi and the resulting probability of failure was predicted as 1.4 in 10,000 vane rings.

Based on the analysis, the vane ring design was released to Kyocera Industrial Ceramics Corporation (KICC) to commence prototype manufacturing trials. The results of this manufacturing development activity are summarized in a subsequent section. 
Temperature (F)

\section{Average-inlet}

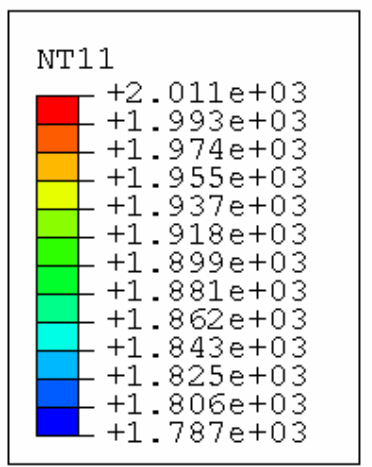

Temperature (F)

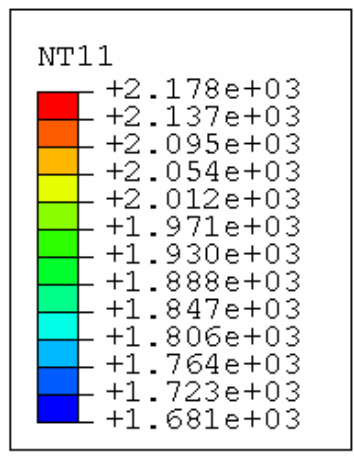

Hot Streak

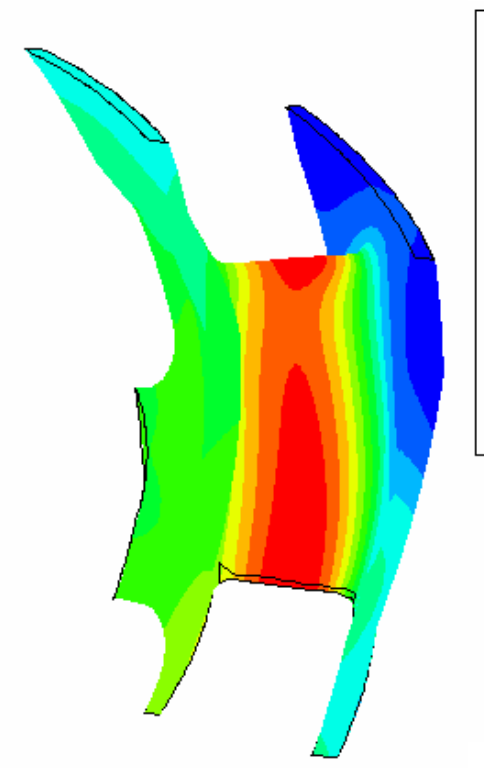

Max. principal stress (psi)

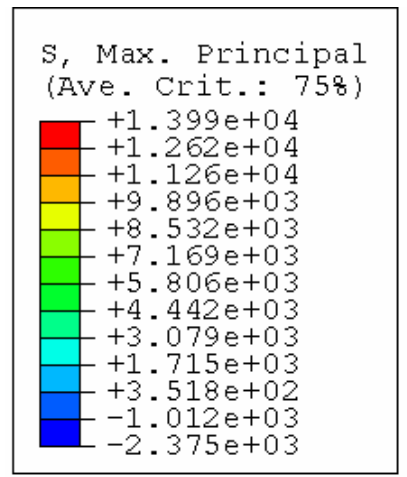

Max. principal stress (psi)

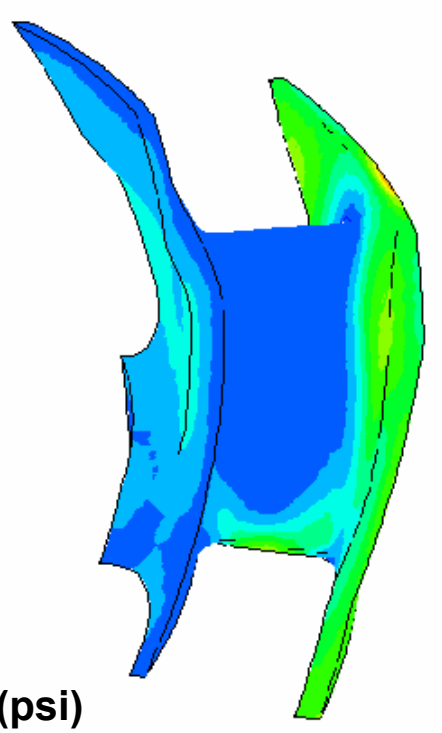

GEN4

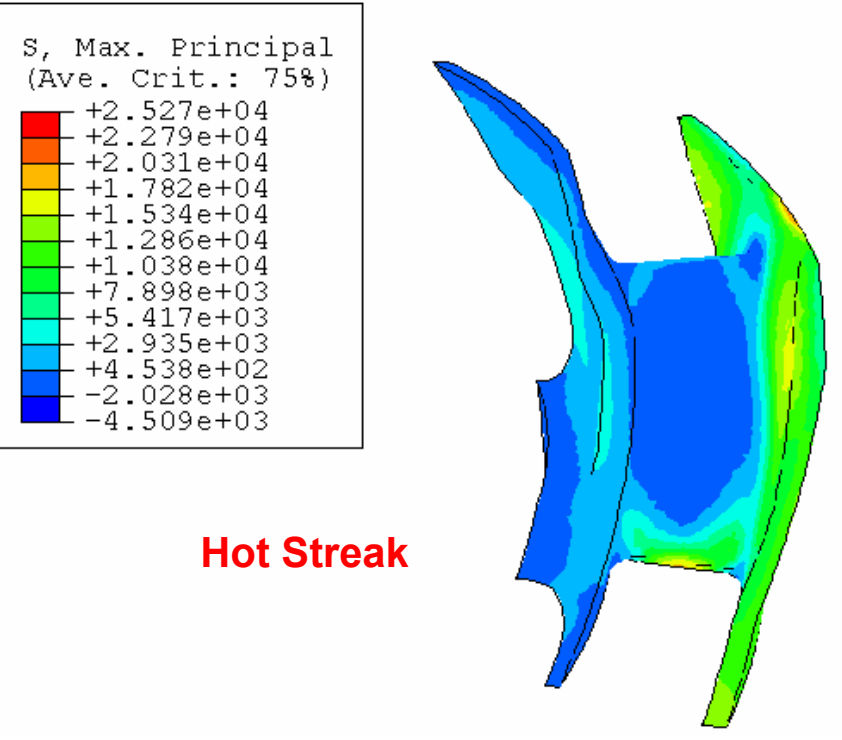

Figure 2.1.8 Temperature Gradients and Thermal Stresses During Steady State (average-inlet and hot-streak conditions) 
Max. principal stress (psi)
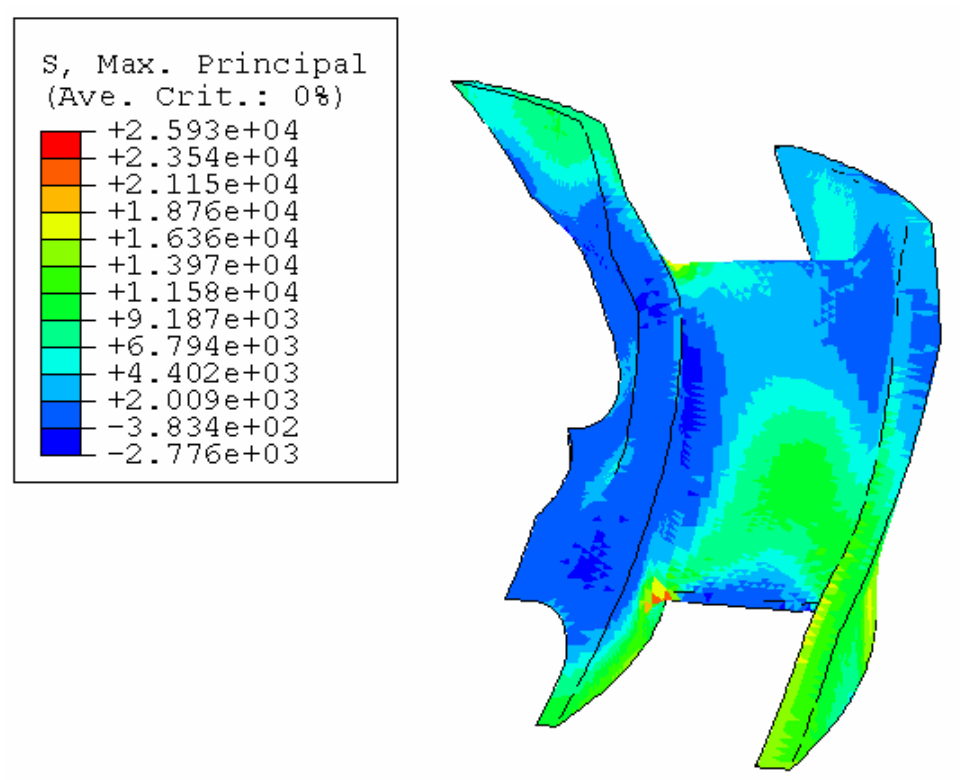

GEN4

Figure 2.1.9 Thermal stress during trip shutdown after 8 sec 


\subsubsection{Ceramic Shroud}

Due to the low thermal expansion of silicon nitride materials, the ceramic IBR the of ST5+ was expected to grow thermally approximately $1 / 3$ that of the metallic ST5 compressor turbine rotor. In addition, the low density and high stiffness of the ceramics makes the ST5+ ceramic expand less than the ST5 rotor due to centrifugal forces. Combining these two factors together, a large gap was expected between the ceramic IBR and the metal shroud. This gap would lead to severe blade tip flow losses and consequent low turbine and engine efficiency.

To assess the effect of such loss, a tip clearance analysis was conducted for three shrouds: metal shroud, SiC, and Si3N4 shrouds. These analyses included checking pinch points, where clearance might go to zero or interference, during startup. Aerothermal heat transfer to the shroud, and its effect on shroud absolute temperature was also determined and added to the analysis. The findings are summarized in Table 2.1.2 below.

Table 2.1.2 Design changes and resulting clearance

\begin{tabular}{|c|c|c|c|c|}
\hline Rotor Type & ST5 & \multicolumn{3}{|c|}{ ST5+ Ceramic rotor } \\
\hline Shroud Type & ST5 & ST5 & SiC & Si3N4 \\
\hline Ave. Running Clearance & $0.0078 ”$ & $0.0261 ”$ & $0.0085 "$ & $0.0062 "$ \\
\hline
\end{tabular}

It was evident from these data that if a metal shroud was used with the ceramic rotor excessive leakage would ensue due to the large tip clearance of 0.0261 ". However, use of a ceramic shroud reduced the tip clearance to 0.0085 " for SiC and 0.0062 " for Si3N4. Only Si3N4 provided any real benefit over the baseline ST5 metal engine in terms of tip clearance control. For small engines such as ST5+, a 1 mil tip clearance equated to $\sim 0.3 \%$ turbine efficiency. Therefore, use of a Si3N4 shroud was predicted to result in a $0.45 \%$ increase in turbine efficiency.

Design concepts for ceramic shrouds were developed and one of the concepts is shown in Figure 2.1.10. This design included a slot arrangement to locate the shroud with respect to the vane outer platform. A total of four ceramic design concepts were developed for the turbine shroud, which were subsequently down selected to two. Detailed thermal and stress analyses were performed to determine which of the two concepts would be better as the final design. Due to the high rotation speed of the rotor blades, heat transfer coefficients for the shroud were determined as a function of the engine axial length only. Sink temperature variation in the circumferential direction assumed the same profile as predicated by CFD at the exit of the scroll. Considering the averaging effect resulting from the rotor blade rotation, such a profile represents a worst case. 


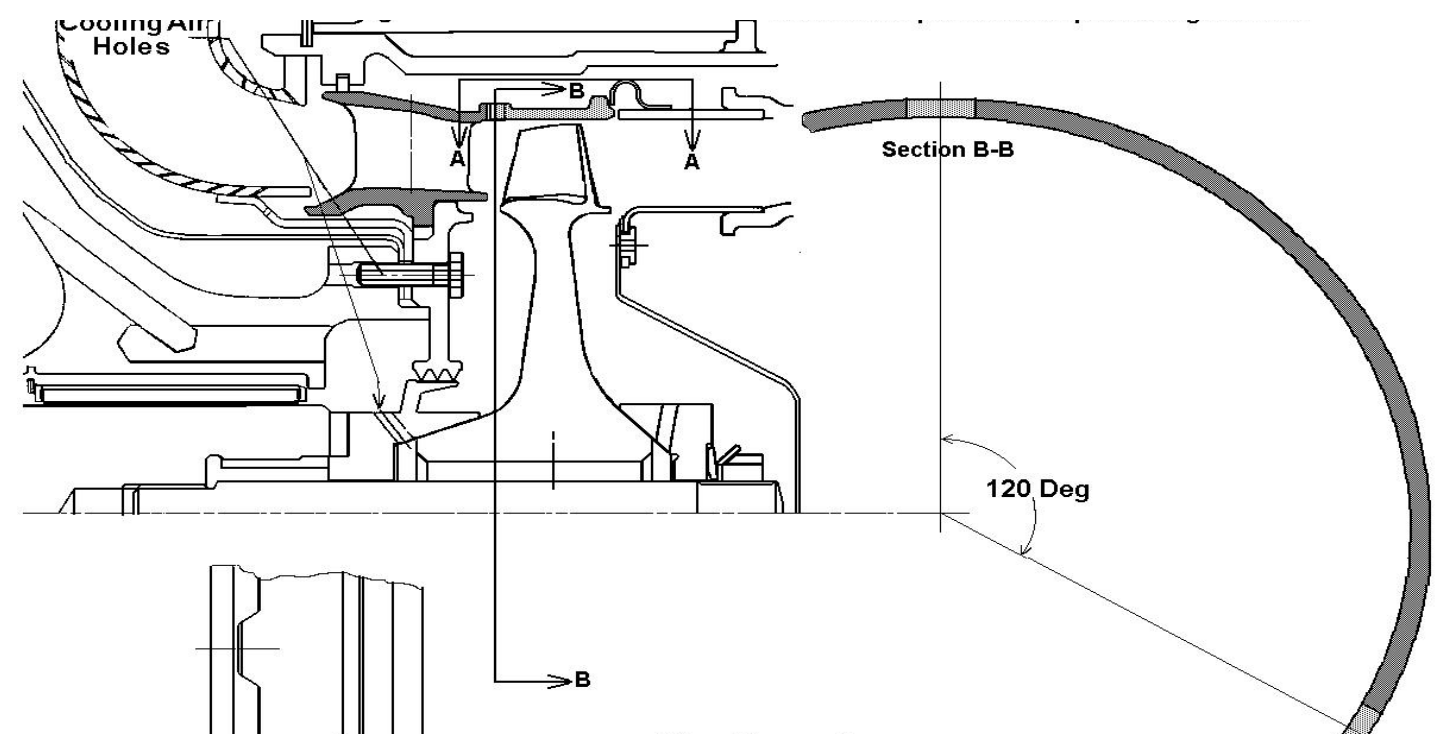

Figure 2.1.10 Design concept for slotted ceramic shroud

Thermal distortion of the shroud support, i.e., the turbine support casing or the vane ring outer platform, strongly influences thermal stress in the shroud. Steady state thermal analysis showed that the OD platform of the vane grows radially by 0.0158 " under hot streak conditions and 0.014 " under average inlet conditions. This means the maximum vane ring outer platform distortion is 0.0018 ", comparable to the 0.0015 " turbine support casing distortion. Therefore, either design was acceptable. Under the worst thermal loading case, i.e. the hot streak conditions, the peak thermal stress was just over $10 \mathrm{ksi}$ in the shroud (see Figure 2.1.11).
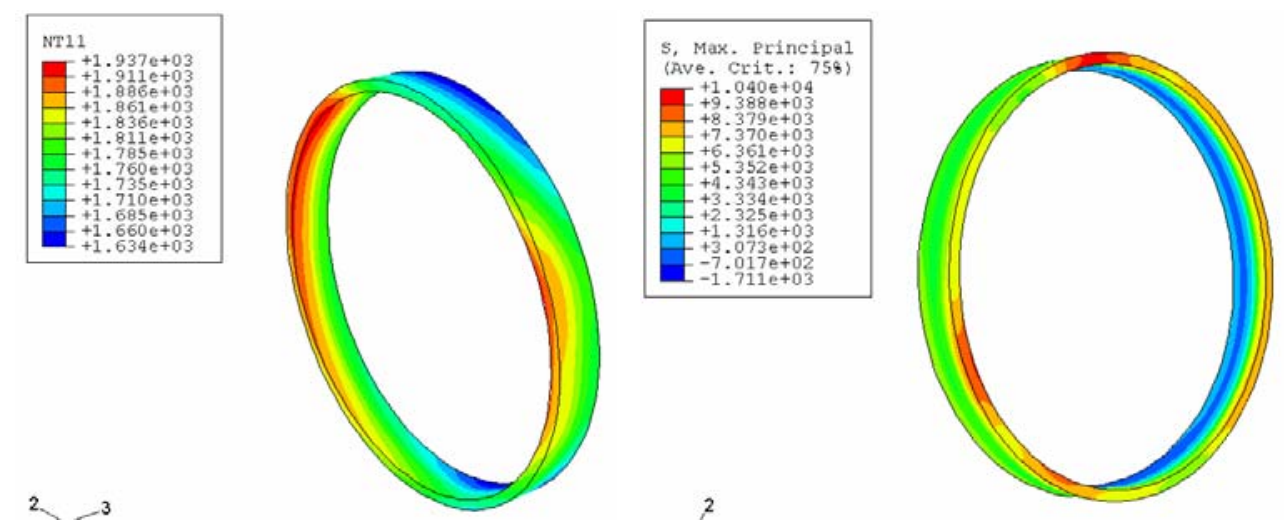

Figure 2.1.11 Temperature distribution (left side) and thermal stress distribution (right side) of the turbine shroud under hot streak conditions

A second major design concern was the relative thermal deformation between the shroud and its support during transient engine operation. To analyze this, thermal growth of the casing and the ceramic shroud during startup and shutdown was predicted. During the $10 \mathrm{~F}$ cold start, the turbine support casing was expected to shrink 0.015 " more than the ceramic shroud, which meant that a cold build clearance of at least 0.015 " was needed. 
At steady state, the casing grows 0.010 " more than the shroud, while during shut-down, the thin shroud reacts to gas temperature drop quickly, widening the gap between the shroud and the casing to 0.025 ". Therefore the overlap between the tab on the shroud and the slot on the casing should be greater than 0.015 " to maintain shroud support by the casing. There were pros and cons for both designs and a final design was not selected prior to the conclusion of the design activity.

\subsubsection{Ceramic Turbine Rotor}

Two-dimensional disk only models were used to analyze the stress levels in the rotor, and the rotor bore. The $2 \mathrm{D}$ model was run repeatedly to arrive at an optimum disk shape that minimized bore and web stresses. Additionally it was desired to make the disk as symmetric as possible. Some material was added in the under rim fillet to balance the rim deflection.

A solid disk design (with no bore) would have reduced disk stress, but the bore was required to allow for a path way for cooling air exiting from the air bearing to pass to the back side of the rotor. A 1" bore diameter was selected. Figure 2.1.12 shows 2D plots of the final disk design. The disk was reshaped to balance the rim radial deflection and to decrease web stress. The CARES code was used to predict probability of survival of the initial 3D design iteration. Those results indicated that high stress in the rim contributed more to the probability of failure than high stress in the bore. Based on this direction the disk was redesigned to allow for more bore stress and to reduce rim deflection.
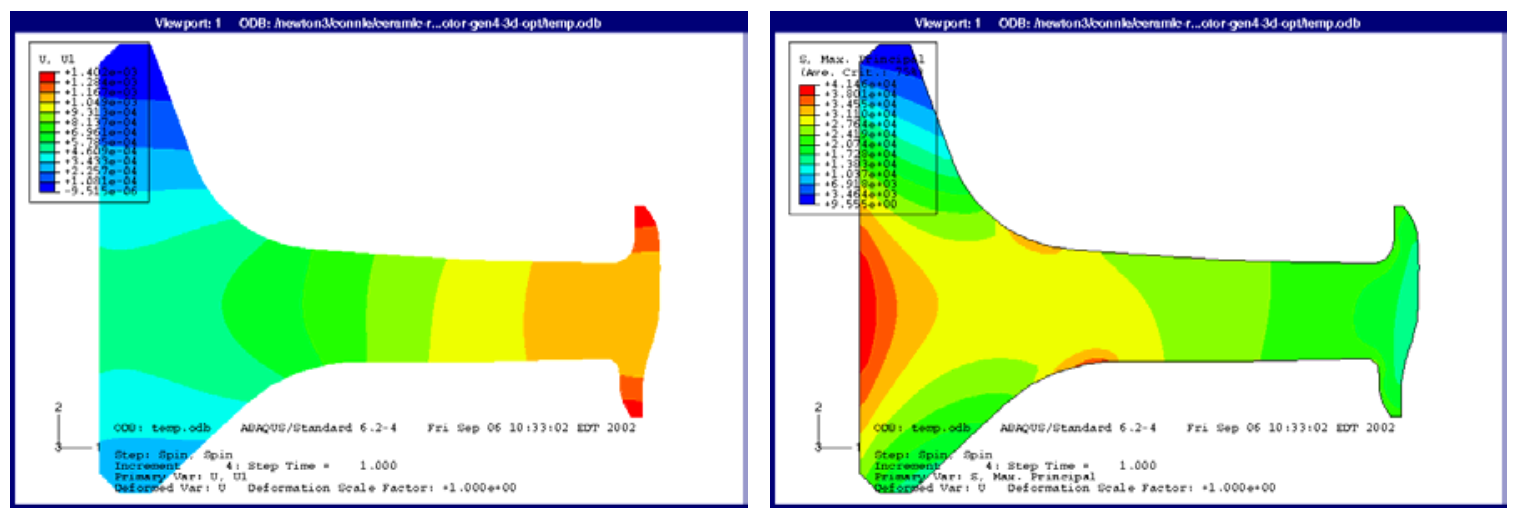

Figure 2.1.12 Radial deflection and maximum principle stress for a spinning disk only analysis

The blade pull and thermal stress were than added to the 2D analysis. Figure 2.1.13 shows plots of temperature and maximum principal stress. It can be seen from the plot of maximum principal stress that the blade pull intensified the lower web stress more than the bore stress. The stress in the web is balanced. Stress in the lower web area is more tolerable that web stress near the rim due to increasing disk temperature from the bore to rim. The 2D blade pull and thermal effect model predicts bore stress of 61,000 psi. 

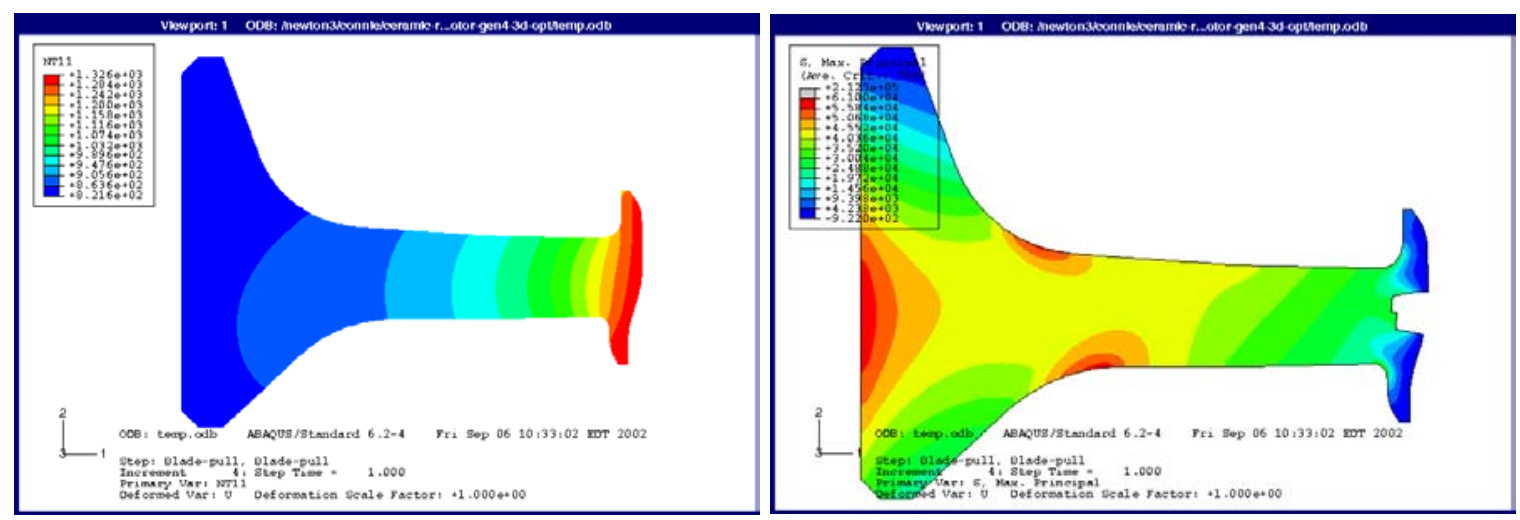

Figure 2.1.13 Temperature and maximum principal stress for the rotor with blade pull

Figure 2.1.14 is a plot of the self-sustaining radius that was produced for this rotor design. The self-sustaining radius is defined as the radius where the axial growth of the disk equals the radial growth of a free spinning ring. The free ring displacement is a calculated value based on rpm, material density, radius, and Young's modulus. The displacement due to thermal growth was added to this value. The disk displacement was obtained from the FEA model of the rotor. The self-sustaining radius is where these two lines intersect. Adding disk material outboard of the self-sustaining radius will increase bore stress. Adding material inboard of the self-sustaining radius can potentially reduce bore stress. For this design the area inboard of the self-sustaining radius was specifically shaped for the attachment design. As an exercise the area below the self-sustaining radius was significantly widened and the bore stress was reduce by $2,000 \mathrm{psi}$.

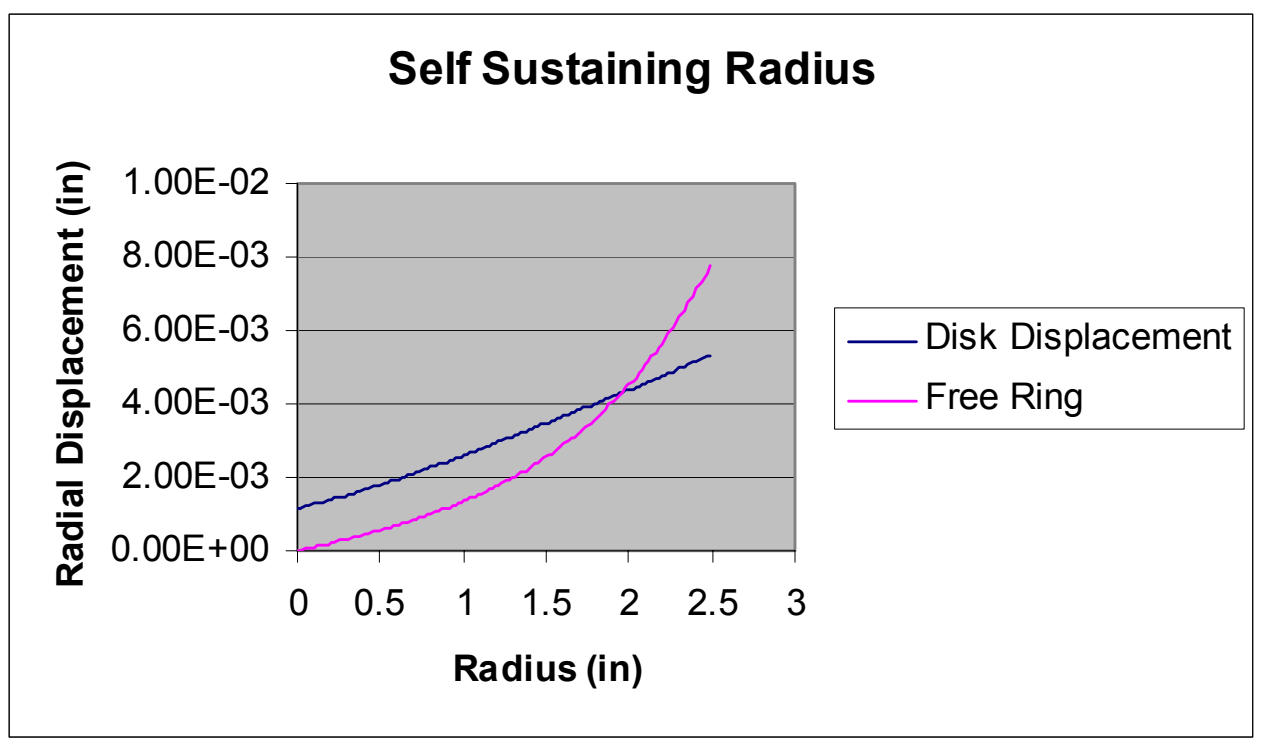

Figure 2.1.14 Self sustaining radius determination for the ST5+ rotor disk

A 1/27th cyclic symmetry model was developed and cyclic symmetry boundary conditions were applied to the cut disk faces. The rotor was constrained at one point in 
the axial direction and allowed to spin at 54,900 rpm. Figure 2.1.15 is a plot of maximum principal stress with the disk spinning at a uniform $70^{\circ} \mathrm{F}$. The maximum stress occurs in the bore and is predicted to be 55,000 psi.

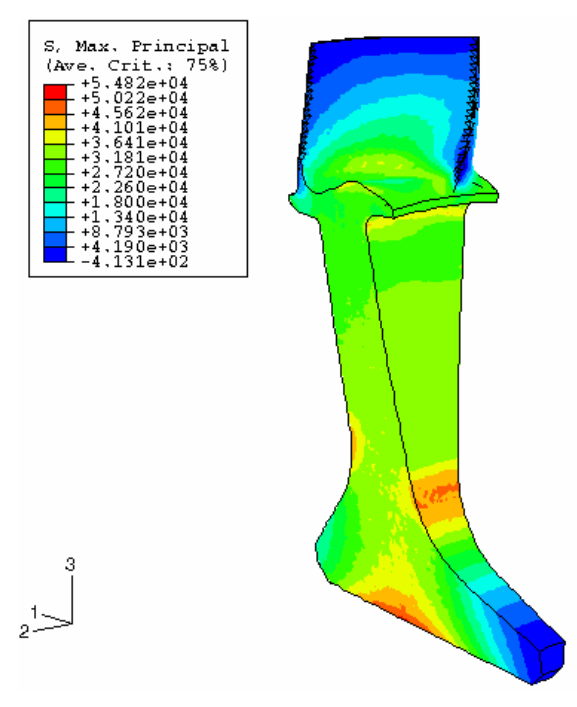

\section{Figure 2.1.15 Cold spin distribution of rotor maximum principal stress}

Figure 2.1.16 contains plots of the rim stress in the radial and hoop directions. Plots of radial stress were used to center the blade pull under the blade as much as possible. The blade was initially stacked so the center of gravity of each blade section lied on a radial line. The radial line was then leaned 0.020 " in the positive axial direction.

An examination of the hoop stress plot showed large areas of tensile stress in the leading edge fillet. Many attempts were made to reduce this stress but no design change that could significantly reduce the stress was found. The maximum radial blade pull was 30,000 psi while the maximum hoop stress was 40,000 psi.

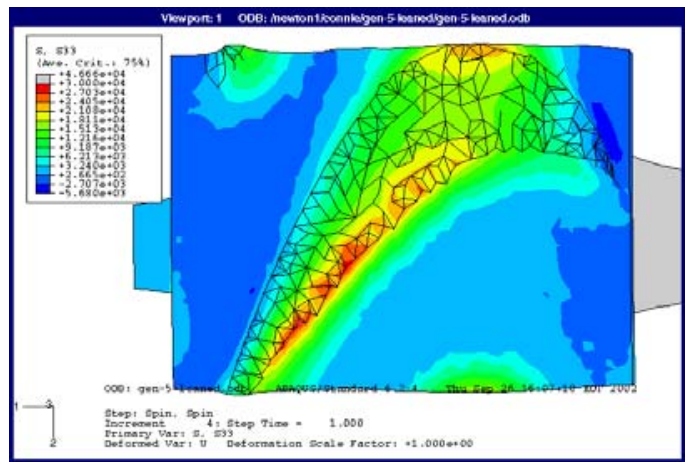

Radial Stress Stress

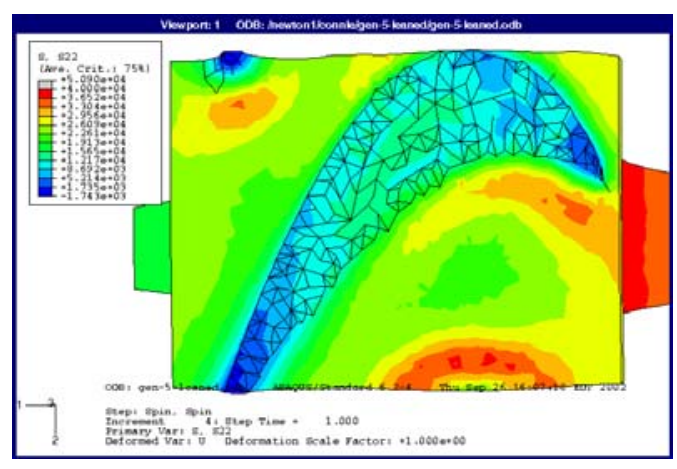

Hoop Stress Stress

Figure 2.1.16 Cold spin rim hoop and radial stress

Figure 2.1.17 contains plots of the temperature and maximum principal stress distribution in the hot spinning rotor. Convective heat transfer coefficients and sink temperatures 
were output from the aero-analysis. The thermal boundary conditions from the aero analysis were mapped onto the rim and surface of the blade. A bleed flow analysis was completed and the thermal boundary conditions on the disk faces and bore were imposed using user subroutines. The aerodynamic pressure load was added to the blade and disk free surfaces.
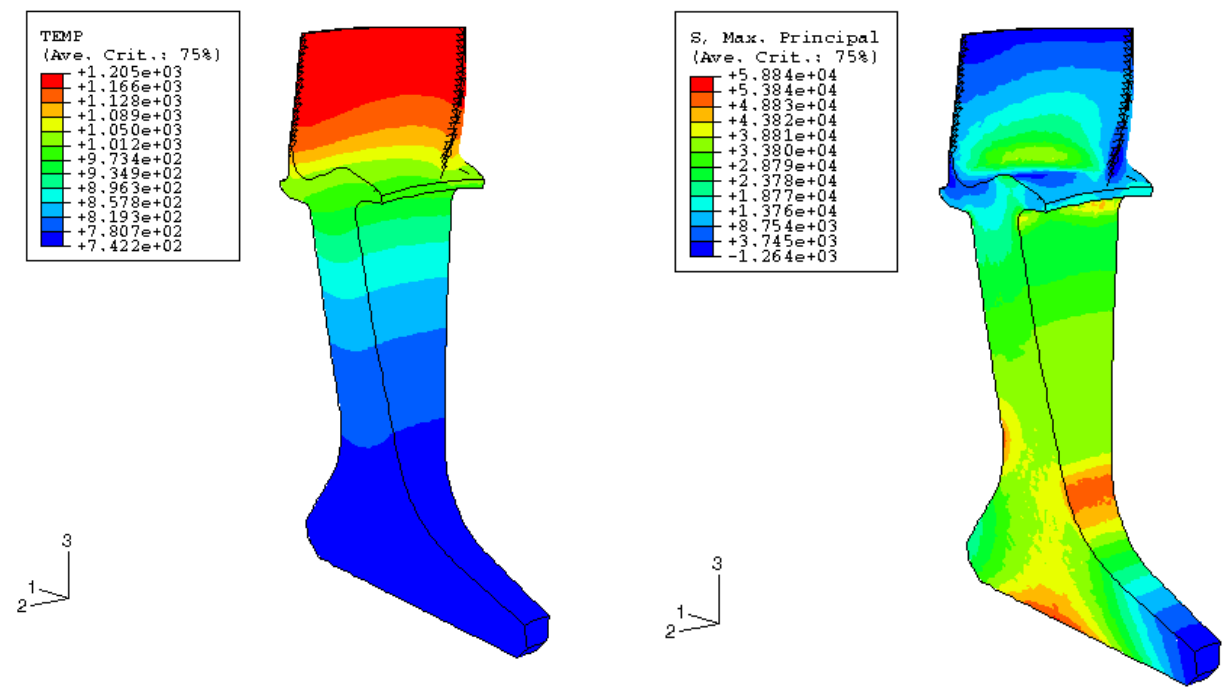

Figure 2.1.17 Hot spin temperature and maximum principal stress plots

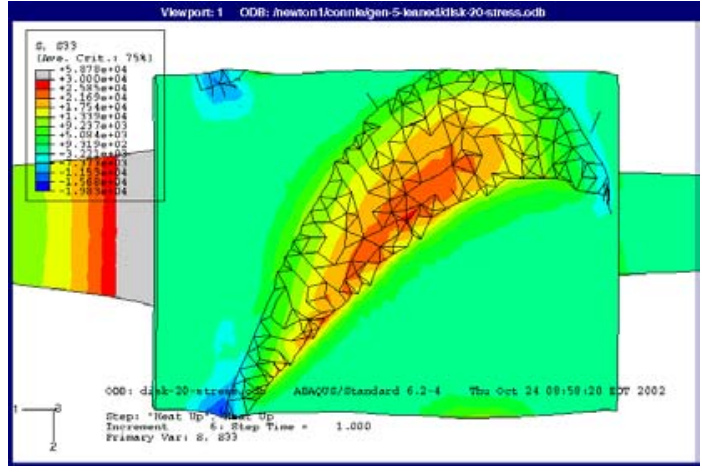

Radial Stress Stress

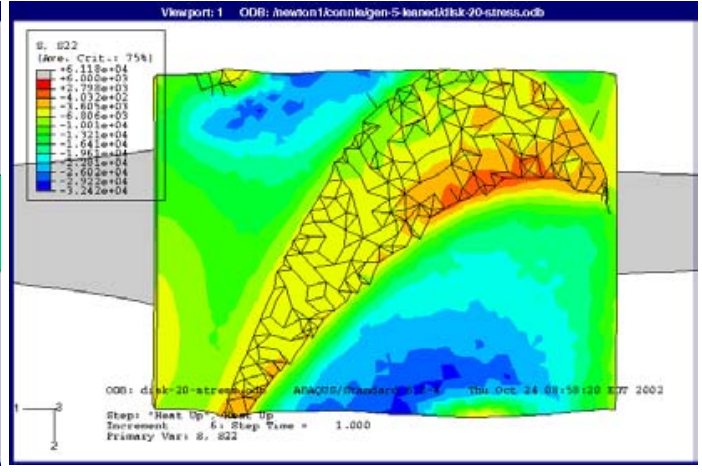

Hoop Stress Stress

\section{Figure 2.1.18 Hot spin radial and hoop rim stress}

Figure 2.1.8 contains plots of radial and hoop stress for the rim under hot spin conditions. The maximum rim stress due to blade pull is $30,000 \mathrm{psi}$ and in the hot condition the blade pull is well centered. The maximum hoop stress has been drastically reduced (under $1000 \mathrm{psi}$ ) by the introduction of a thermal gradient in the disk. The bore stress went from 55,000 psi cold to 59,000 psi hot. The $2 \mathrm{D}$ model predicted a maximum bore stress of 61,000 psi. The $2 \mathrm{D}$ model was a good predictor of bore stress, but did not capture the hoop stress in the rim. 
An aero analysis was performed for both a cold start up and emergency trip shut down. Aero analysis data for convective heat transfer coefficients provided blade sink temperature at tip, mid-span and root, and rotational velocity as a function of time. Transient structural analyses were performed using this data. The results were examined for thermal transients that may cause locally high stress.

The cold startup analysis assumed that all hardware had an initial temperature of $-10^{\circ} \mathrm{F}$. Figure 2.1.19 shows blade midspan sink temperature and shaft rotation as a function of time. Data for the first 100 seconds of operation were provided and simulated. The simulated start up is from a stationary rotor to idle (not full power). The final rotor rpm is $50 \%$ of max power and the idle blade sink temperature is approximately $1200^{\circ} \mathrm{F}$ lower than maximum power. Figure 2.1.20 contains a plot of rotor maximum principle stress as a function of start up time.
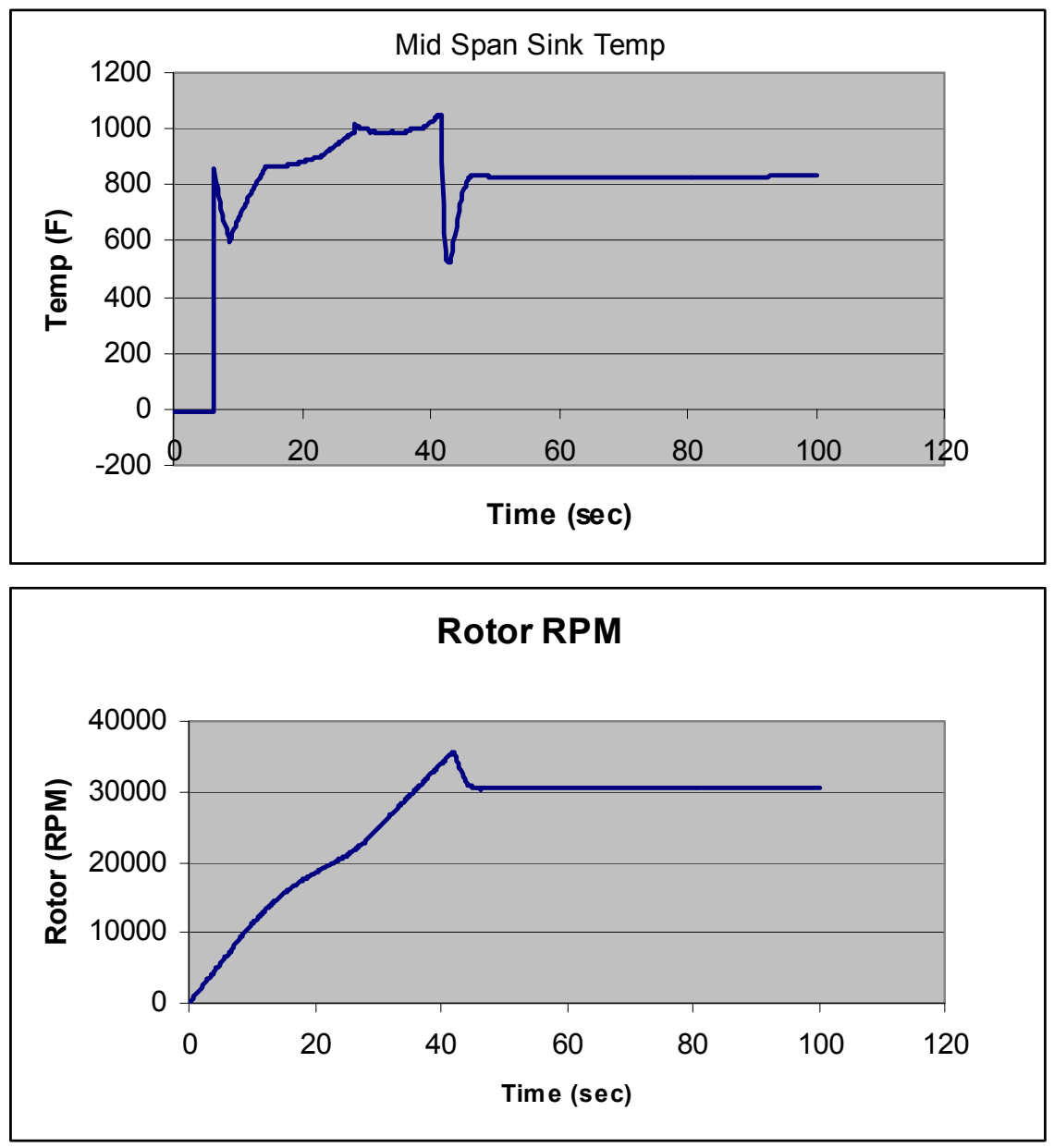

Figure 2.1.19 Startup midspan blade sink temperature and rotor speed as a function of time 


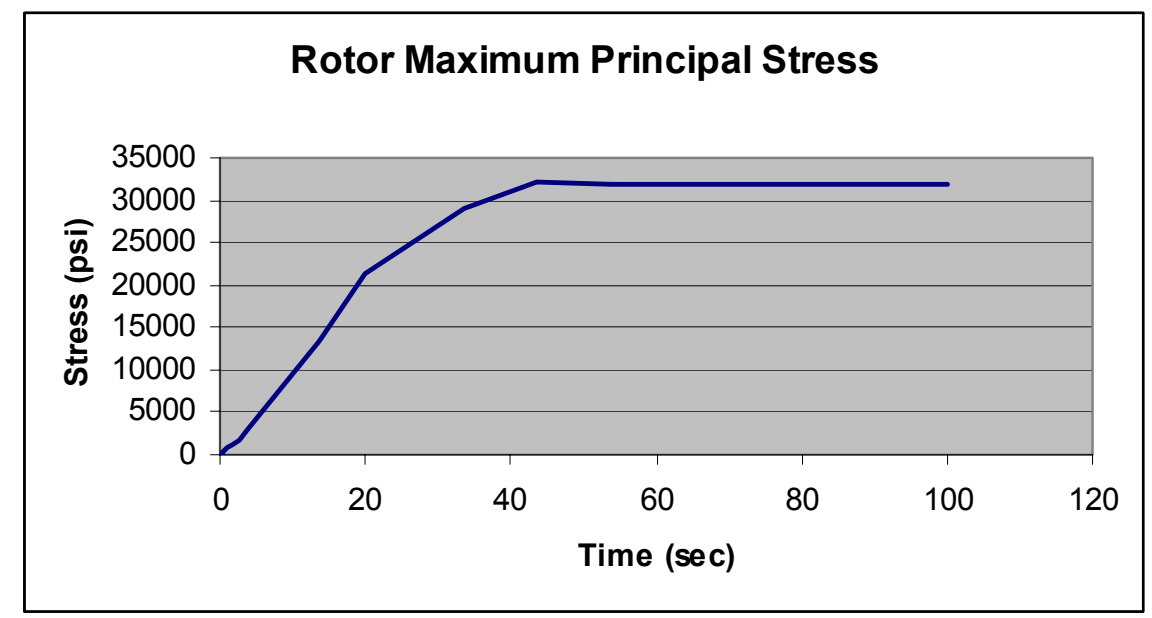

Figure 2.1.20 Startup rotor maximum principal stress

In the emergency trip shutdown analysis, the rotor was operating at full power at the start of the simulation prior to fuel shut off. Figure 2.1.21 is a plot of blade mid span sink temperature and rotor speed as a function of time. The initial blade mid span sink temperature was $1902^{\circ} \mathrm{F}$. The initial rotor speed was $50,352 \mathrm{rpm}$ at the maximum power condition. This was $9 \%$ less that the steady state hot spin case because the hot spin case was an over speed condition. Figure 2.1.22 is a plot of maximum principle stress as a function of time. It was clear that the initial state was the highest stress state. The stress diminished as the rotational speed decreased and the thermal gradients reduced. Any increase in stress due to thermal gradients was far outweighed by the decreased stress as the rotor slowed down. 

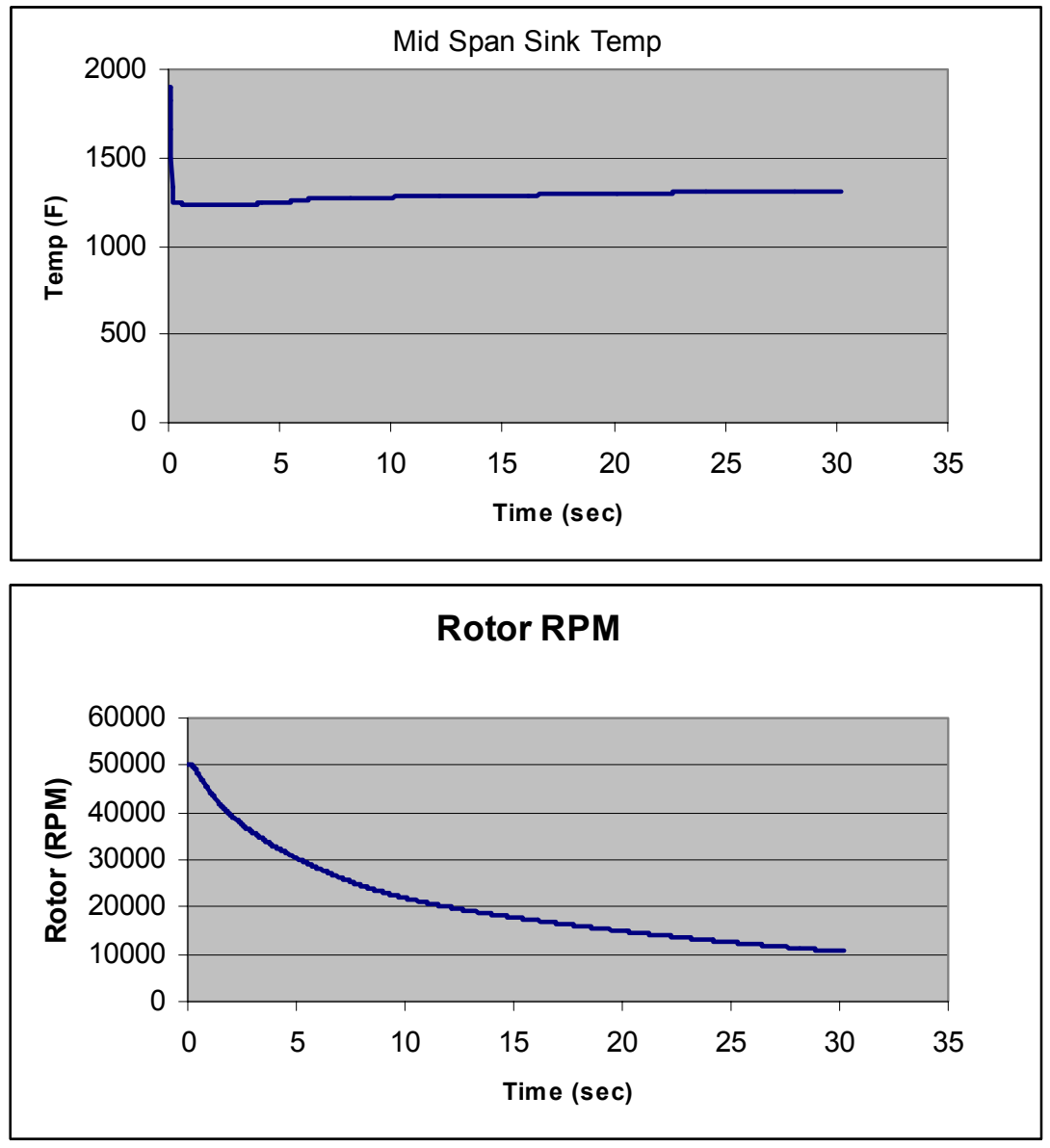

Figure 2.1.21 Emergency shut down blade mid span sink temperature and rotor speed as a function of time

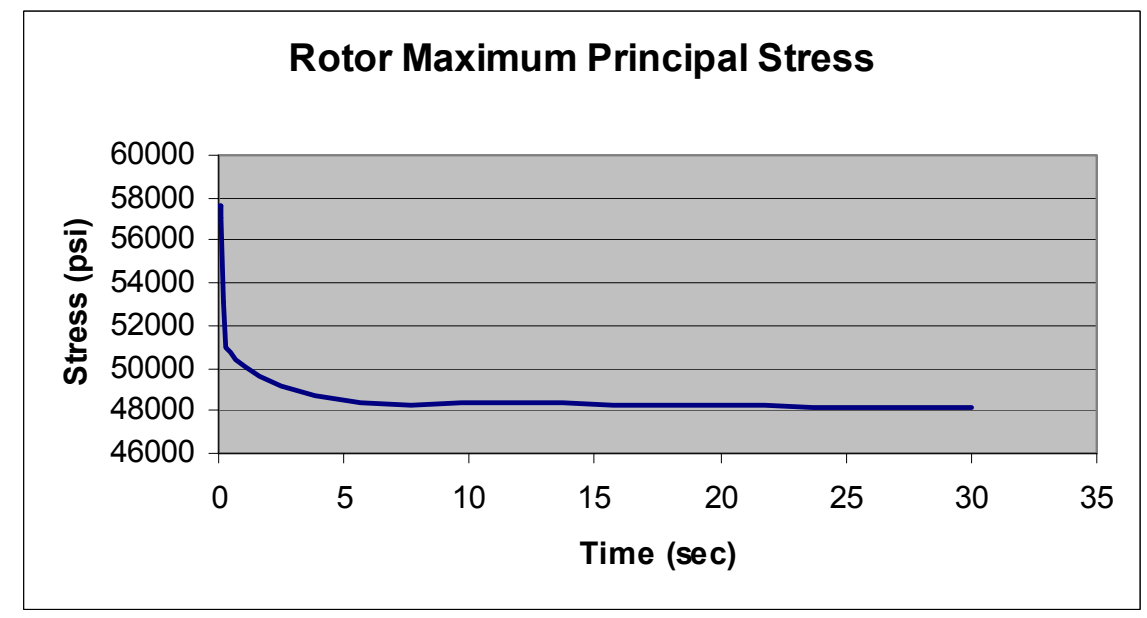

Figure 2.1.22 Emergency shut down maximum principal stress as a function of time 
The CARES code was used to predict the probability of failure for the rotor under various operating conditions. As processed material has a different strength and Weibull distribution that longitudinally or transversely ground material. Additionally the strength and Weibull modulus is a function of temperature. In order to more accurately predict the probability of failure, the FEA model was partitioned into three sets to treat each characteristic surface condition separately. Figure 2.1.23 shows the partitioning of the model into sections representing the blade and rim (as processed properties), the disk surface (transverse ground properties), and the interior of the disk (bulk and longitudinally ground properties).
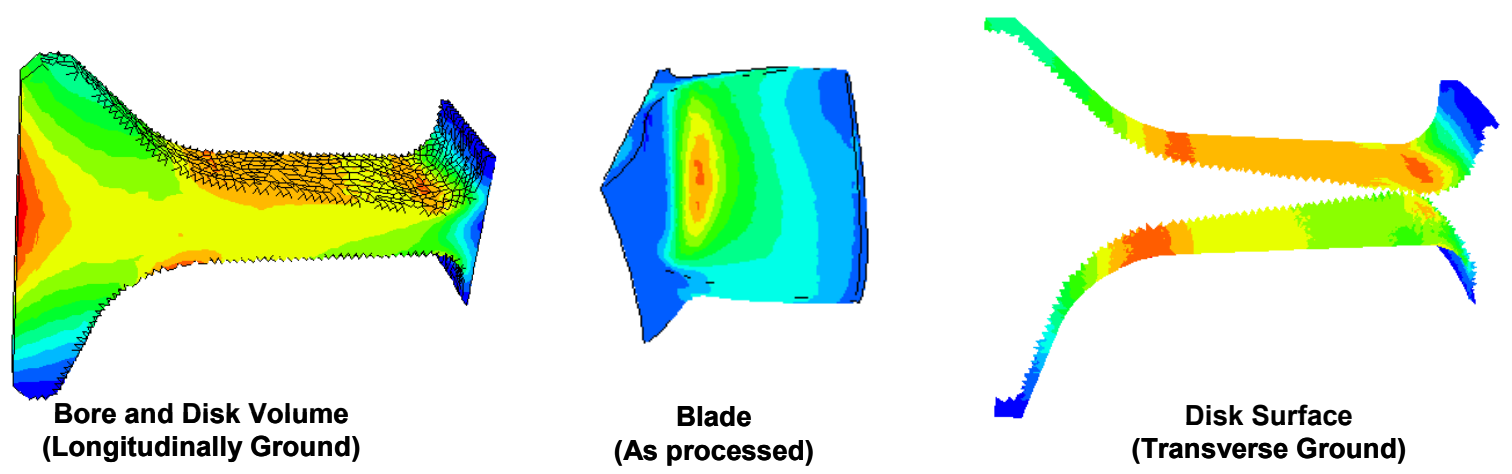

Figure 2.1.23 Partitioning of IBR FEA into representative data sets for CARES analysis

Table 2.1.3 contains a summary of the lifing results. It is apparent from examining the table that the cold spin case had the highest probability of failure. The cold spin conditions would only be encountered during spin burst test. The high probability of failure was due to the large hoop stress in the rim. This stress was greatly reduced as the rotor developed a thermal gradient. The probability of failure of the blade and rim would be reduced to approximately $0.1 \%$ if the blade surface was machined. The cost of doing this would be significant. In all cases the probability of failure was determined by the blade and rim. Further design modifications to decrease the failure probability were not completed prior to the conclusion of the design activity due to the redirection of the program. 


\section{Table 2.1.3 NT154 strength and weibull modulus}

CARES/LIFE Analysis of ST5+ Ceramic IBR

\begin{tabular}{|c|c|c|c|c|c|}
\hline \multirow{2}{*}{ IBR Location / Strength } & \multirow{2}{*}{$\begin{array}{l}\text { Charac. Strength ksi } \\
\text { (Weibull Modulus) }\end{array}$} & \multicolumn{4}{|c|}{ Probability of Failure } \\
\hline & & Cold Spin & Hot Spin & $\begin{array}{c}\text { Transient } \\
\text { Shut-down }\end{array}$ & $\begin{array}{c}\text { Transient } \\
\text { Start-up }\end{array}$ \\
\hline $\begin{array}{l}\text { Bore and Disk Volume / } \\
\text { Longitudinal ground }\end{array}$ & $90.79(14.73)$ & 4.32E-05 & $1.51 \mathrm{E}-04$ & $1.11 \mathrm{E}-04$ & 2.00E-08 \\
\hline $\begin{array}{c}\text { Disk Surface / } \\
\text { Transverse ground }\end{array}$ & $71.44(14.14)$ & $3.78 \mathrm{E}-04$ & $1.46 \mathrm{E}-03$ & 1.19E-03 & $3.10 \mathrm{E}-07$ \\
\hline $\begin{array}{c}\text { Blade I } \\
\text { As processed }\end{array}$ & $30.71(8.93)$ & $3.71 \mathrm{E}-01$ & 1.17E-01 & 1.10E-01 & $9.61 \mathrm{E}-04$ \\
\hline $\begin{array}{l}\text { Combined Probability of } \\
\text { Failure for IBR }\end{array}$ & - & 3.71E-01 & 1.18E-01 & $1.11 \mathrm{E}-01$ & $9.61 \mathrm{E}-04$ \\
\hline
\end{tabular}

Average values were used for NT154 strength and Weibull modulus

A very basic harmonic analysis of the IBR was performed. Eleven fundamental frequencies and mode shapes were found. Table 2.1.4 lists the frequencies and mode shapes. The disk rotates at $91.5 \mathrm{~Hz}$ and the vanes potentially produce a pressure pulse at a frequency of $1,373 \mathrm{~Hz}$. Since the harmonic frequencies of the rotor are significantly higher than the driving frequencies, no further analysis was preformed.

\section{Table 2.1.4 Rotor modal analysis}

\begin{tabular}{|c|c|c|}
\hline Mode & Frequency & Mode Shape \\
\hline 1 & $2,083 \mathrm{~Hz}$ & One nodal diameter \\
\hline 2 & $2,376 \mathrm{~Hz}$ & One nodal diameter \\
\hline 3 & $5,245 \mathrm{~Hz}$ & Zero nodal diameter \\
\hline 4 & $6,030 \mathrm{~Hz}$ & Zero nodal diameter \\
\hline 5 & $6,208 \mathrm{~Hz}$ & One nodal diameter \\
\hline 6 & $9,799 \mathrm{~Hz}$ & Two nodal diameter \\
\hline 7 & $14,376 \mathrm{~Hz}$ & Zero nodal diameter \\
\hline 8 & $16,018 \mathrm{~Hz}$ & Two nodal diameter \\
\hline 9 & $18,308 \mathrm{~Hz}$ & Disk and blade mode \\
\hline 10 & $20,400 \mathrm{~Hz}$ & Blade flap mode \\
\hline 11 & $21,367 \mathrm{~Hz}$ & Blade flap mode \\
\hline
\end{tabular}

\subsubsection{EBC Development for Ceramic Turbine Components}

Efforts in this task focused on assessing the need for an environmental barrier coating on ceramic vane and blade airfoils. As combustion products pass through the cT vane and through the blade throat passage, they sharply decrease in pressure and temperature, while going through significant changes in relative Mach number. An analysis of the cT 
vane and rotor was performed at the leading edge, mid span, and trailing edge of both the cT vane and cT blade to determine the amount of anticipated recession in 25,000 hours, with no EBC. For ease of understanding, the expected recession amounts are depicted in Figure 2.1.24. The calculations assumed that the blade temperature reached the hot gas temperature and that water vapor partial pressures were similar to those expected from combustion of natural gas.

Although the trailing edge would see 0.006 to 0.008 inches of recession on the pressure side surface, recession amounts in the range of 0.030 inches are expected elsewhere, indicating that an EBC is still needed on the leading edge and pressure surfaces of the blade.

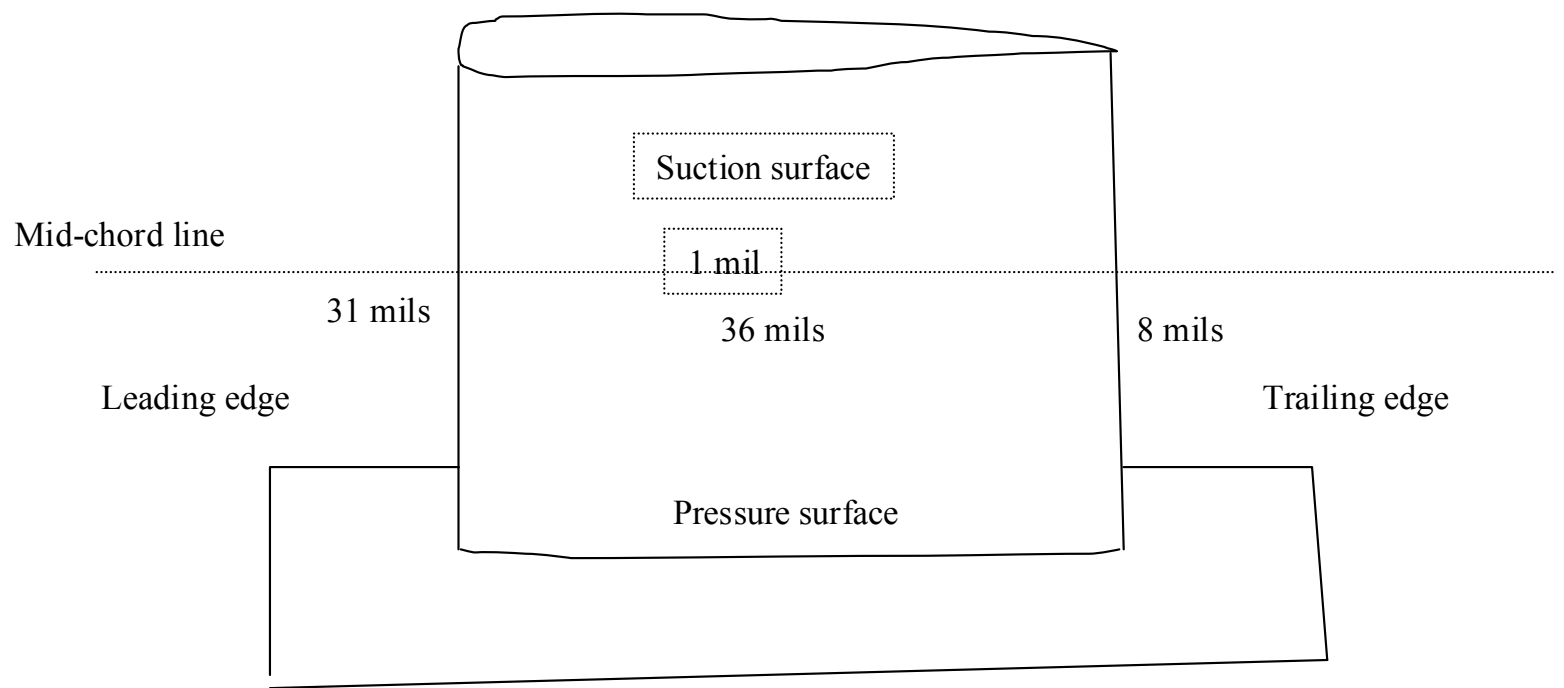

\begin{tabular}{|c|c|c|c|c|c|}
\hline & & & & & recession \\
\hline blade & & psi & $\mathrm{T}^{\circ} \mathrm{C}$ & Vel $(\mathrm{mps})$ & mils/25,000 hrs \\
\hline & le & 77.90 & 1014.06 & 105.39 & 31.16 \\
\hline & ss & 24.20 & 722.28 & 852.64 & 1.37 \\
\hline & ps & 72.50 & 997.78 & 216.42 & 35.58 \\
\hline & te & 41.10 & 845.56 & 635.34 & 7.79 \\
\hline
\end{tabular}

Figure 2.1.24 Predicted cT blade recession over 25,000 hours of microturbine operation

\subsubsection{Attachment Development for Silicon Nitride IBR}

The purpose of this task was to develop a ceramic to metal shaft attachment for attaching a silicon nitride IBR to both the radial compressor and the rearward air bearing system. Initial efforts focused on analysis of 2 designs, both derived from UTRC's successful attachment technique for low use temperature silicon nitride starter turbines. The first is 
a brazed attachment where a tapered stub shaft integral to the ceramic rotor is brazed to a threaded low expansion alloy intermediary piece. The second concept uses a rotor with a wedge shaped bore. Additional spring loaded retention disks press into the angled surface of the disk. The two concepts are shown in Figure 2.1.25.
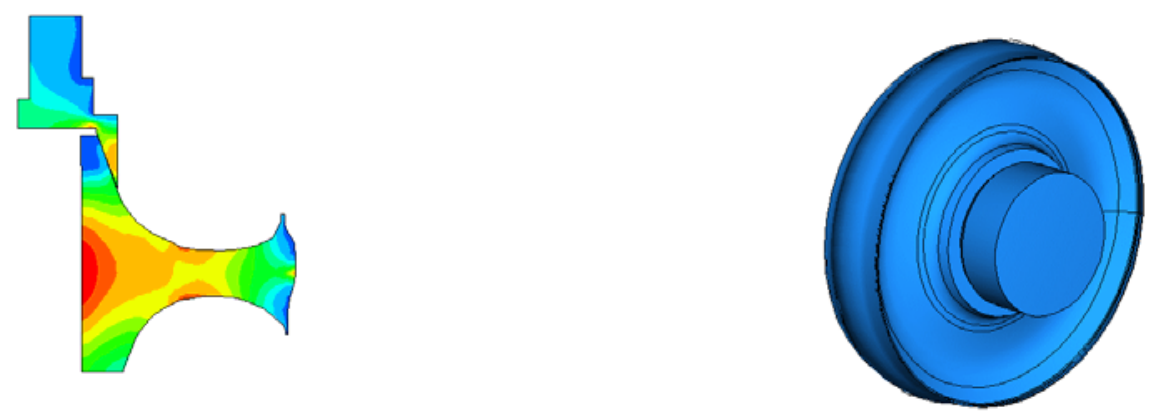

Figure 2.1.25 Brazed attachment (left) and wedge attachment (right)

These two attachment concepts were merged into one concept called the brazed wedge attachment, which is shown in Figure 2.1.26. The red lines depict the turbine rotor. The left side taper near the bore is brazed to a threaded low expansion alloy intermediary piece using an active metal braze. The right side of the rotor near the bore is forced in the axial, upstream direction by a preloaded bolt, into a rotating metal clamp. The torque is transmitted through friction with the clamp and the brazed joint. In the event of braze failure, the bolt/wedge assembly will ensure rotor retention. One or more belleville washers between the metal clamp and the bolt head will help maintain the clamping force when the bolt thermally expands.

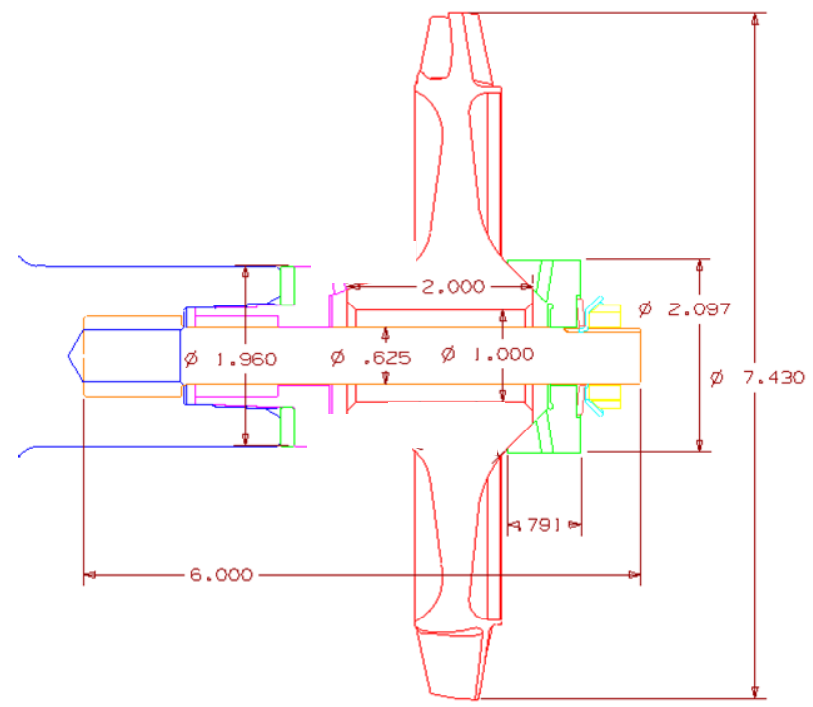

Figure 2.1.26 Brazed-Wedge attachment concept

An FEA analysis of the rotor stub, braze foil and transition piece was performed. The assembly was cooled from the braze temperature, after which a torque and centrifugal 
load were applied. Figure 2.1.27 shows the predicted stress levels in the three parts. The braze and transition pieces experience stress levels equivalent to their yield stress. A life prediction of the NT154 ceramic rotor stub was performed using the Weibull Modulus. Given a flexure strength of $131,500 \mathrm{psi}$ at $70^{\circ} \mathrm{F}$ and a Weibull Modulus of 15, the probability that the ceramic stub will fail is 1 in 10,000 .

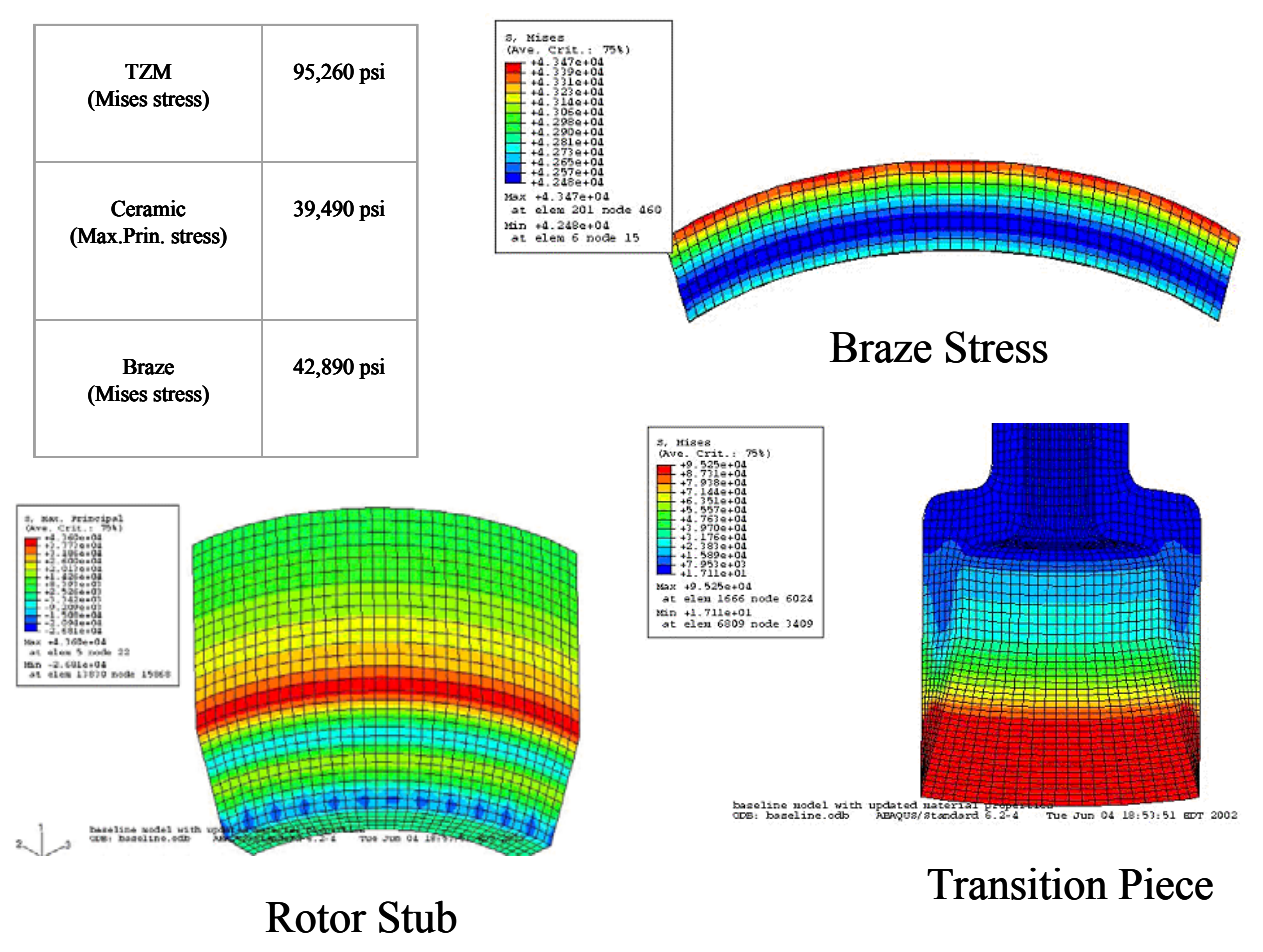

Figure 2.1.27 Brazed-Wedge attachment FEA results

Several brazing trials were run to optimize UTRC's high vacuum brazing furnace temperature cycle. Both TiCuSil ABA, and a proprietary gold based brazing material were used to make simple butt joints using silicon nitride rod stock. The actual attachment geometry is more complex than a simple butt joint - the purpose of the trials was to determine the exact temperature profiles needed for a successful braze. As seen in Figure 2.1.28, the TiCuSil ABA braze cycle has been optimized, while the gold based braze requires further refinement to avoid excessive melting. Testing of full scale rotor to metal hub attachments was not completed prior to the end of the design activity. 


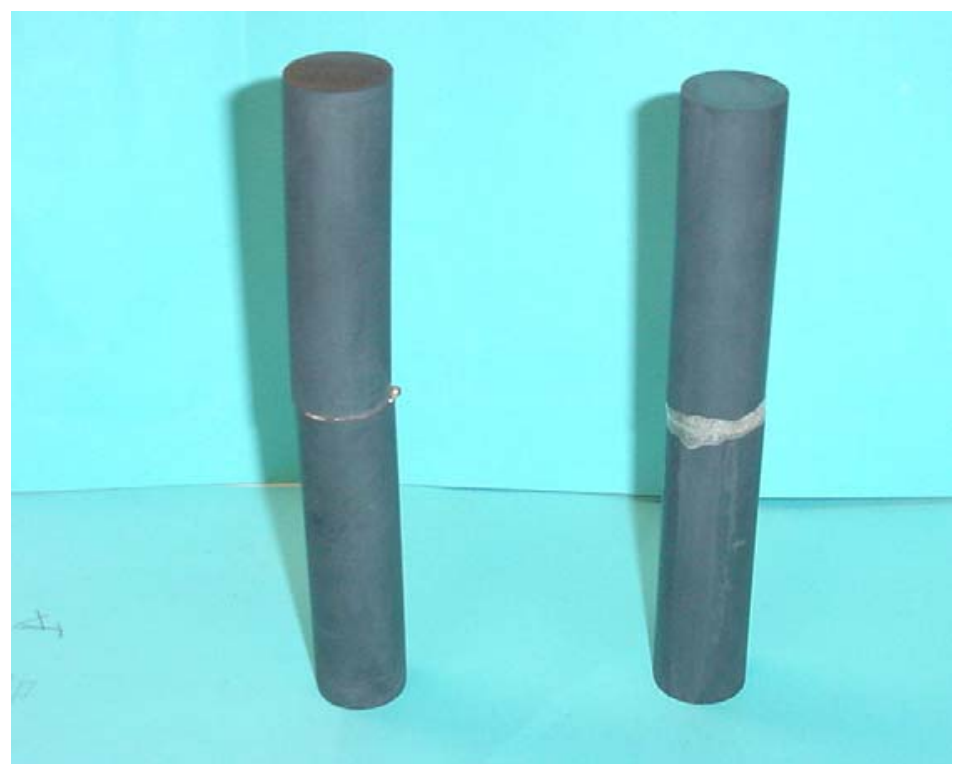

Figure 2.1.28 Brazing trial specimens. Gold based braze shown on left, TiCuSil ABA braze shown on right.

\subsubsection{Foreign Object Damage Assessment}

The purpose of this study was to analytically determine the magnitude of increase in foreign object damage resistance (FOD) through reduction in blade count and making rotor blades thicker. Honeywell AS800 was used as the material as there was considerable gas shot impact data in the literature. A state of the art analytical code was employed to determine damage thresholds, using an elastic model for the material. Both the baseline ST5 geometry and the ST5+ thick blade geometry were modeled using the AS800 data. The foreign object used was considered to be a 0.010 " diameter zirconia sphere, such as a spall from a thermal barrier coating within the combustor. Aerodynamic analysis was used to predict the speed and impact angle of the zirconia sphere.

The results indicated a 50\% reduction in damage at the impact site and a $40 \%$ reduction in post impact root stress when comparing the ST5 and ST5+ geometry. Figure 2.1.29 shows the foreign object rebounding from the ST5+ (thicker) blade. The same foreign object impact resulted in a hole in the ST5 blade, suggesting that the thicker ST5+ blade design was inherently more FOD resistant. 

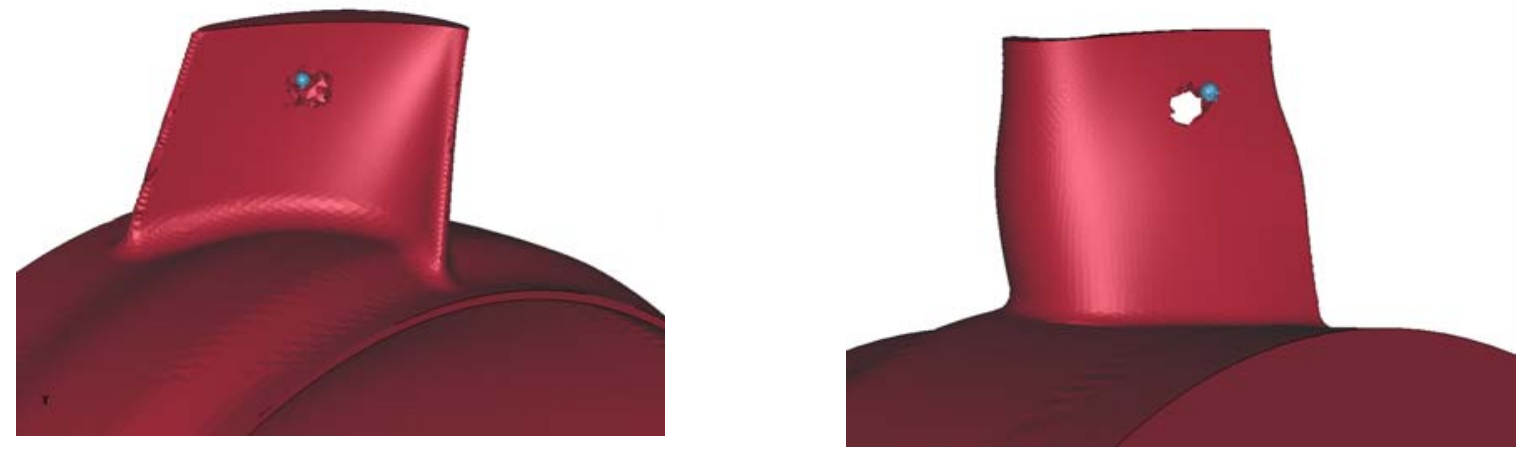

Figure 2.1.29 Effect of zirconia TBC spall impact on rotor blade at $100 \%$ rotor speed. ST5+ ceramic geometry is on left, and ST5 geometry is shown on right

Two additional cases were run to analytically predict the effect of FOD events at the blade tip. A foreign object particle (0.052" diameter) with no initial velocity was placed in the path of the blade tip and allowed to come into contact with the rotating blade tip for both ST5 and ST5+ blade geometries. Figure 2.1.30 shows the blades before and after impact. It was clear that the ST5+ blade tip sustained less damage at the tip during the simulated FOD event.

\section{ST5 Rotor Design}

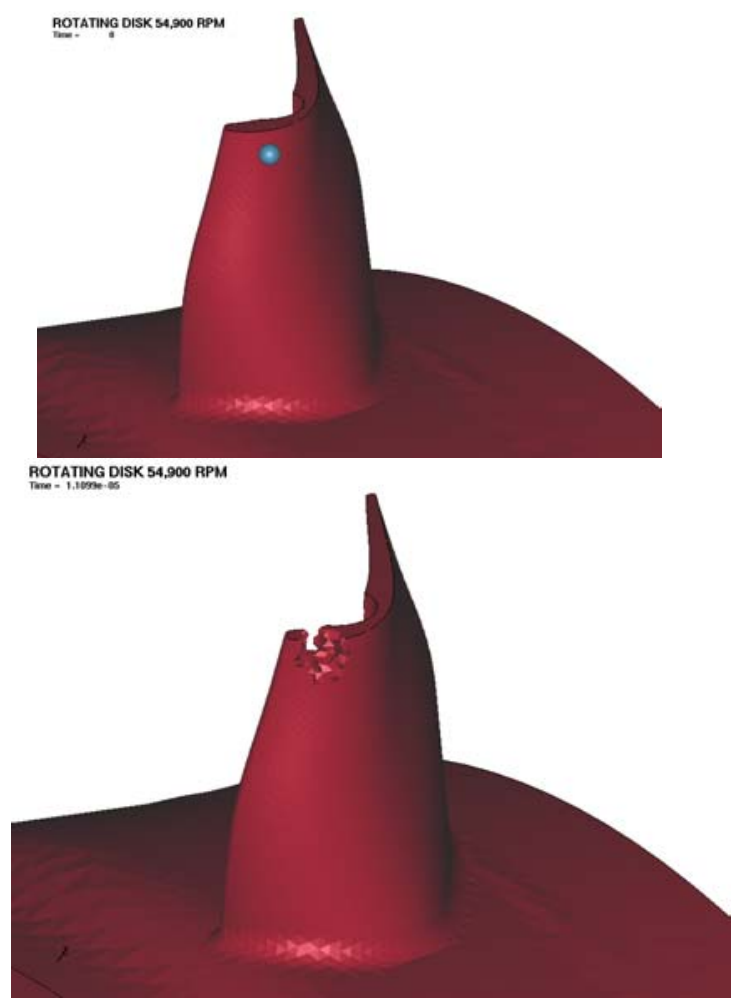

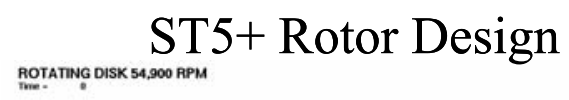

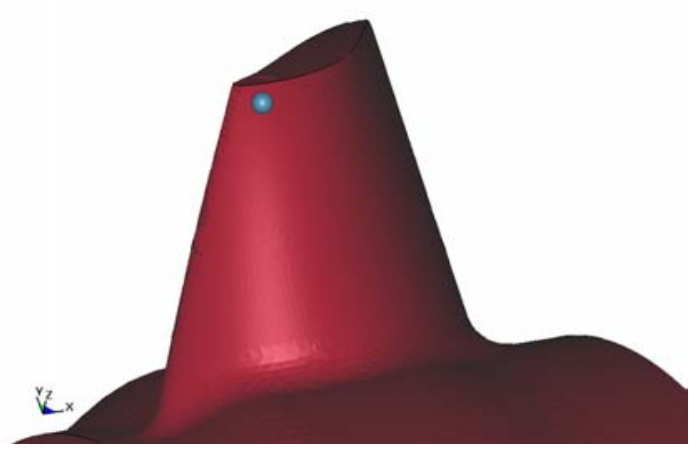

ROTATING DISK 54,900 RPM

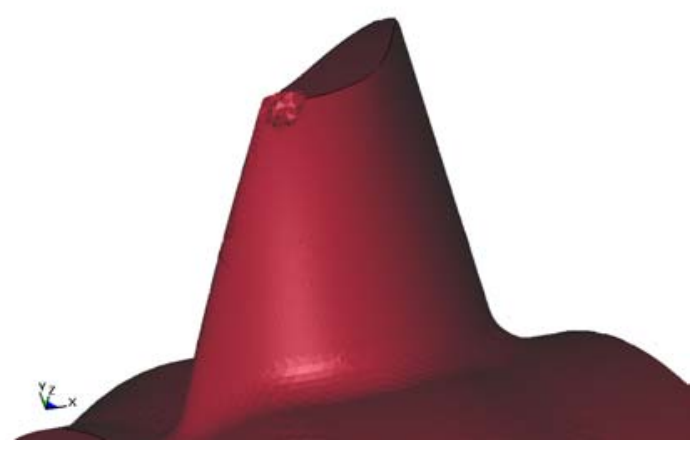

Figure 2.1.30 ST5 and ST5+ Leading edge FOD impact results 


\subsubsection{Manufacturing Development for Silicon Nitride cT Components}

The purpose of this task was to initiate manufacturing development activities for the cT integral vane ring, and cT integrally bladed rotor. Both parts are somewhat larger than any parts previously produced by U.S. based silicon nitride manufacturers, and the integral vane ring presented a significant difference in component geometry from all previous U.S. ceramic turbine development efforts. The vast majority of the effort was conducted by Kyocera Industrial Ceramics Corporation in Vancouver, WA. Efforts in manufacturing development at Kyocera, for integrally bladed rotors, included a bisque machining study where 8 different bisque machining conditions were studied, and over 50 test panels were fabricated. Different material feed rates, tool spindle speeds, and cutting depths were evaluated for the bisque shaping process. UTRC provided the panels to ORNL for mechanical property analysis. These data were subsequently provided to Kyocera to provide them with feedback on the best tool conditions for blade fabrication. In addition, integrally bladed rotors were fabricated both with and without hand polishing of the bisque machined blade surfaces.

The combined test data and manufacturing results from the integrally bladed rotors provided guidance to Kyocera for fabrication of integral vane rings. Vane ring blanks were pre-sintered and nitrided to prepare them for bisque machining. A CAM program was developed to enable machining of the complex vane ring geometry. The nitrided bisque-fired blanks were machined using a multi-axis ball end mill. Pictures of the vane ring after bisque machining of the airfoils are shown in Figure 2.1.31. 


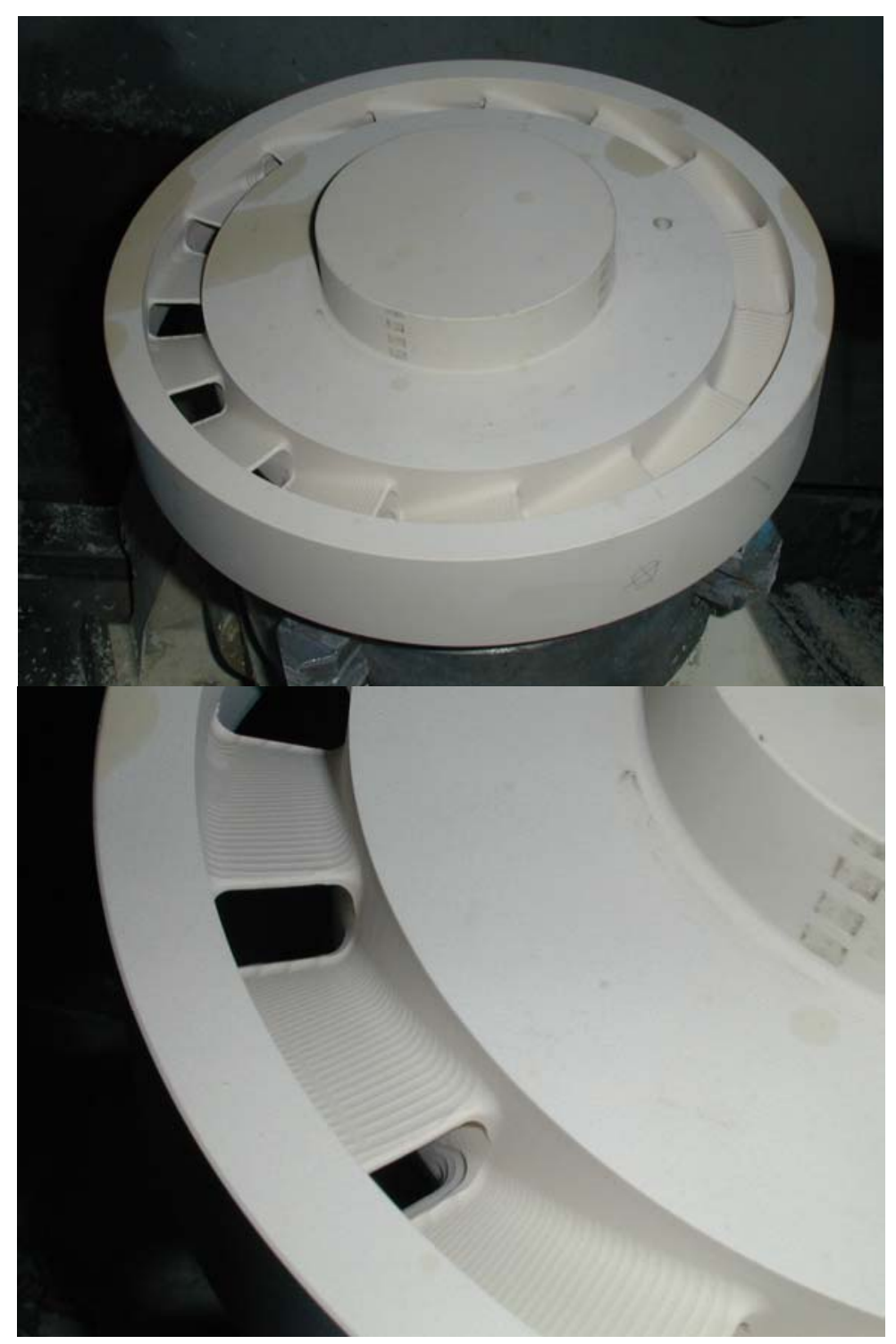

Figure 2.1.31 Multi-axis machined vane ring at Kyocera Industrial Ceramics (nominally 9 inches in diameter)

Kyocera completed sintering (densification) of three integral SN282 silicon nitride vane rings and delivered them to UTRC for preliminary evaluation. Of the three vane rings, two were candidates for eventual diamond grinding of attachment regions to facilitate testing in the ST5 combustor rig. Figures 2.1.32 depicts the bisque machined and sintered vane rings delivered to UTRC. The defects shown in Figure 2.1.33 reach into "machining stock" areas. As an initial prototyping/feasibility study, Kyocera's results were outstanding, and demonstrated that reduced part count, integral ceramic vane rings are viable for initial evaluation in microturbine engine applications. 

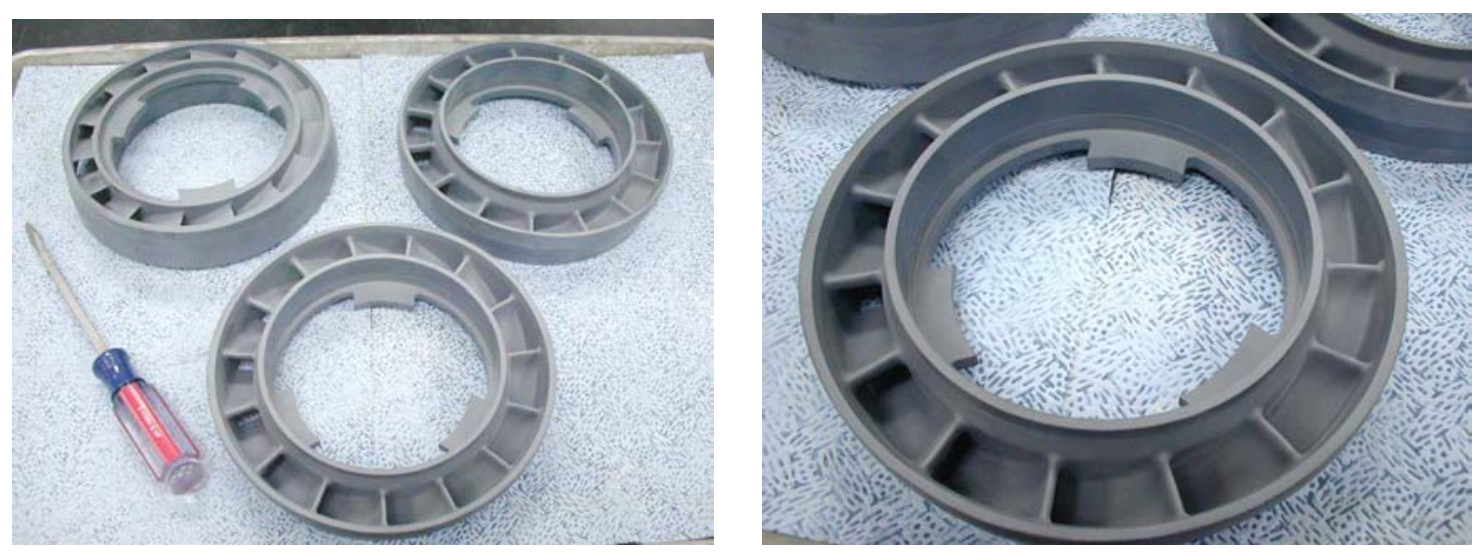

Figure 2.1.32 Multi-axis machined silicon nitride vane rings manufactured at Kyocera Industrial Ceramics (nominally 9 inches in diameter)

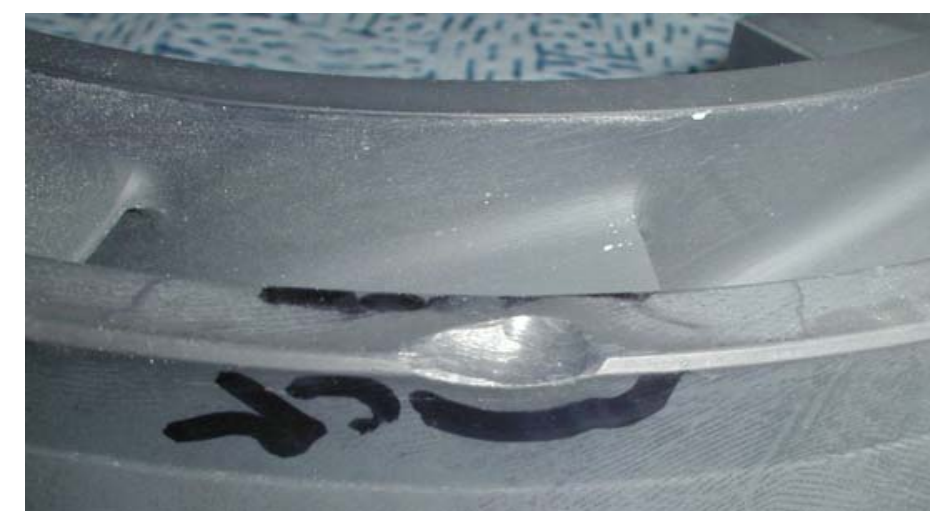

Figure 2.1.33 Typical defects seen in "reject" vane ring

\subsection{Low Emissions Combustor Technology Development}

A combustor design was required to affordably achieve $7 \mathrm{ppm}$ NOx and single-digit $\mathrm{CO}$ and UHC emissions using natural gas over a wide range of power turndown. Further the combustor had to be statically and dynamically stable. To achieve these goals, a ceramic combustor liner, including attachments, was designed, a fuel-air premixer was designed, and combustor performance was analyzed for emissions and dynamic stability. These analyses were based on the use of an off-board cylindrical combustor whose exit flow entered a annular transition duct to distribute the flow to the inlet of the turbine.

\subsubsection{Ceramic Combustor Liner Design}

A ceramic combustor liner was designed to reduce emissions, decrease the use of liner cooling air, and therefore increase the quantity of available cooling air to the downstream components, such as the combustor transition duct (CTD), to enhance its life. Compared to typical metal liners, ceramic liners can withstand higher temperature hence require less 
cooling. Thus, a higher quantity of lower temperature cooling air is available for cooling the CTD. Also the higher wall temperature can potentially enhance flame stability and therefore reduce $\mathrm{CO}$ and $\mathrm{UHC}$ emissions, especially at part power when flame temperature is lower. In addition, the ceramic liner may reduce design complexity by eliminating the impingement cooling shroud, decrease the risk of failure, and achieve lower cost. The main challenge for ceramic liner is its attachments to other parts, primarily due to different physical properties of ceramics. Rigid attachments do not allow the liner to withstand vibration or thermal expansion.

The design of a suitable liner and metal attachment posed numerous challenges. Ceramics are difficult to design because of the relatively poor mechanical properties of the ceramic material and the specific requirements for integration within the overall combustor assembly. A number of liner/attachment concepts were examined that were finally narrowed to two candidate designs, viz., a flat-flange design shown in Figure 2.2.1, and a tapered-flange design shown in Figure 2.2.2 that appeared to have a lower cost. The former figure also shows the maximum principal stress results for the flat flange liner using an AS800 (silicon nitride) material. The maximum computed stress was well below the max stress for 1 in 1,000,000 failure probability at 30,000 hours, and the peak liner temperatures are also well below the maximum recommended temperatures for continuous use.
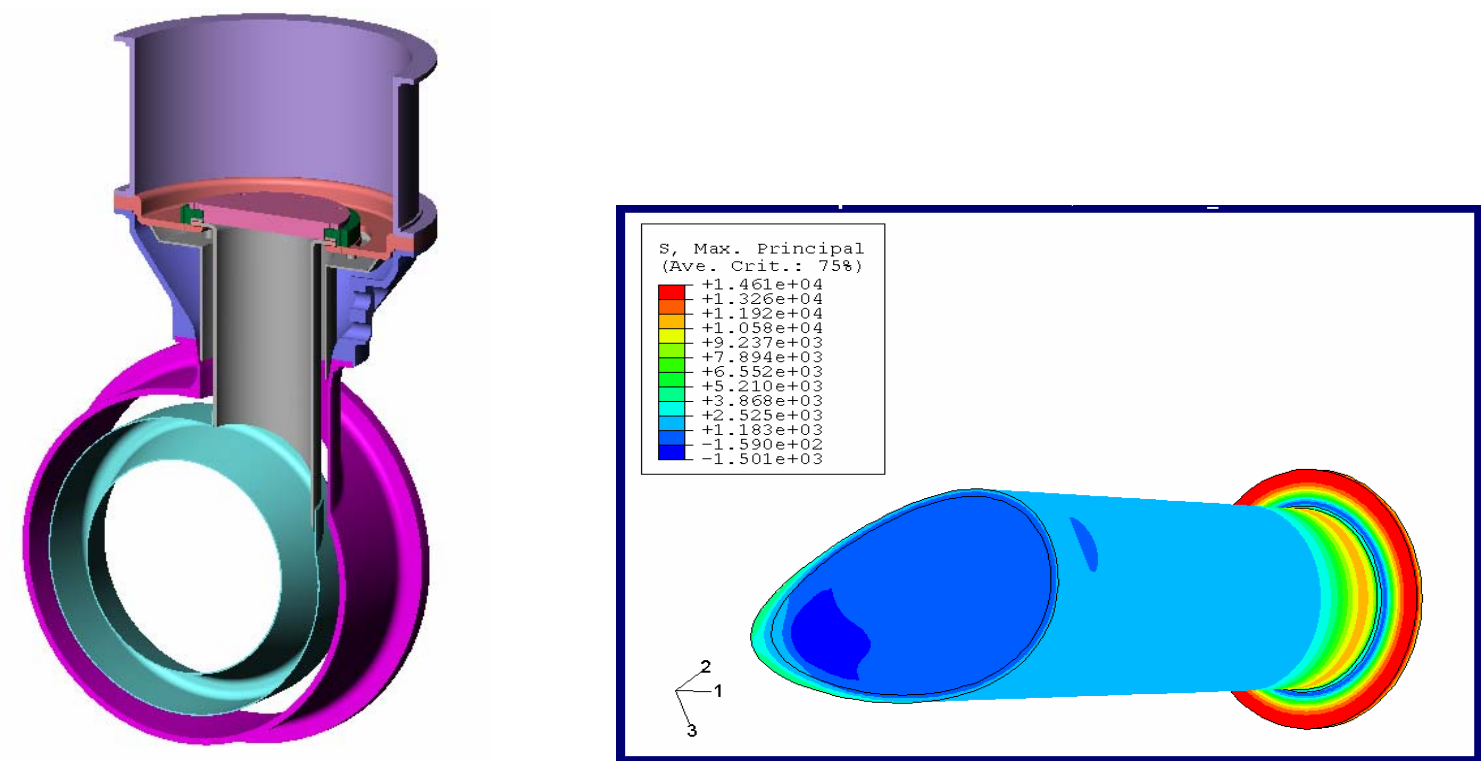

Figure 2.2.1 Isometric view of combustor assembly (left). Maximum principal stresses calculated for the flat-flanged ceramic liner using AS800 material (right). 


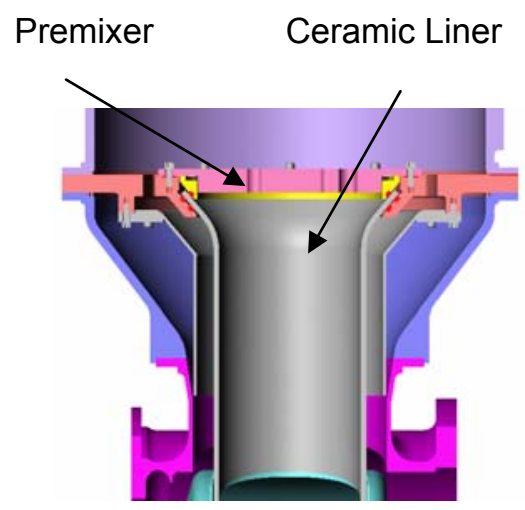

Figure 2.2.2 Cross-section of tapered ceramic combustor liner

Liner prototype and fabrication requests for quotes were issued to manufacturers. Based on responses received the Silicon Nitride AS800 material was ruled out as prohibitively expensive. Design modifications were effected to allow use of lower strength, more affordable ceramic materials. After verification of material properties at ORNL it was concluded that both the $\mathrm{SiC}$ material from St. Gobain and the $\mathrm{Si}-\mathrm{SiC}$ material from CoorsTek are suitable materials for the liner. A very low cost $\mathrm{Si}-\mathrm{SiC}$ material was determined to have both lower strength and poorer strength distribution, which resulted in unacceptable calculated probability of failure.

Silicon-based ceramics exhibit accelerated oxidation and material recession in the combustion environment due to the presence of water vapor. An environmental barrier coating $(\mathrm{EBC})$ is required for long term applications. EBC technology for silicon carbide base composite materials has been developed under the NASA/EPM program and scaled up and demonstrated on a Solar Turbines Centaur 50S engine for over 27,000 hours under the DOE-sponsored CSGT program. A slightly different coating process was used to apply EBC to the ID of the ST5+ combustor liner due to the small diameter of the part (5.8"). Preliminary coating tests showed that a modified EBC process could be applied successfully to the combustor liner. EBC deposited using the standard process is shown on the left of Figure 2.2.3 while a coating deposited using the modified process is shown on the right.
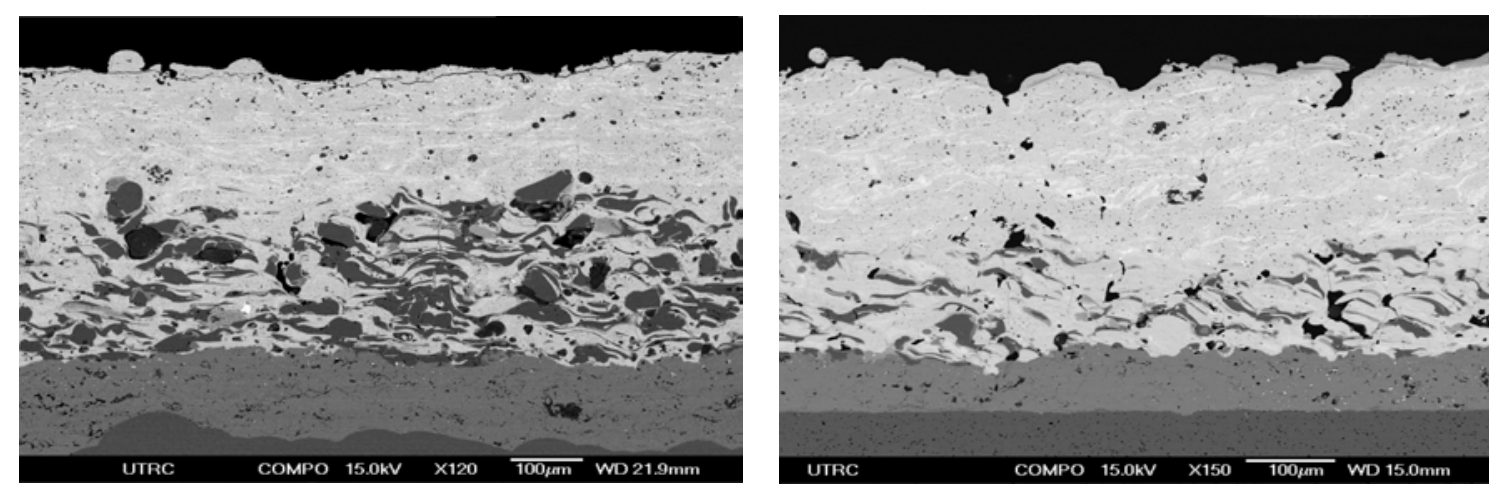

Figure 2.2.3 EBC coating - standard process (left) and modified process (right) 
Optimization of the plasma spray parameters for high quality EBC coating was completed. The coating fixtures and parameters that were established during coupon trials were refined. A dense coating with desired and uniform thickness was demonstrated on the inner surface of a SiC Hexoloy cylinder with the same ID and similar length as that of the advanced microturbine combustor liner. The coating applied was the standard BSAS-based EBC and a cross-section prepared from the coated cylinder is shown in Figure 2.2.4.

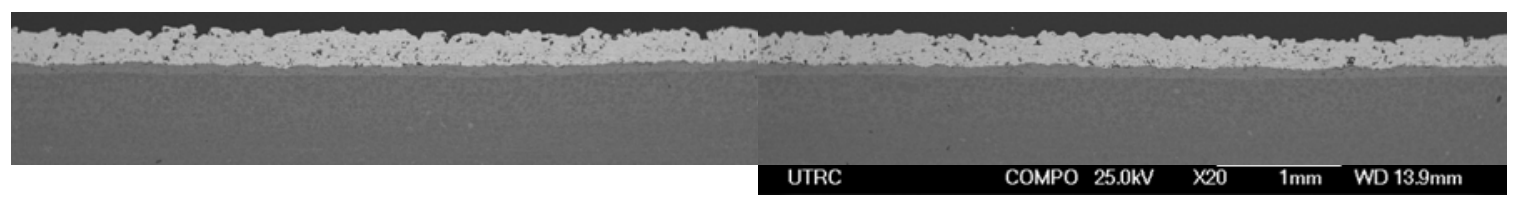

Figure 2.2.4 EBC on the ID surface of a 6 in. SiC Hexoloy cylinder

\subsubsection{Fuel/Air Premixer Design}

A key to achieving low emissions is proper execution of lean premixed combustion which relies heavily on the mixing performance of the fuel/air premixer. The approach was to design a staged premixer consisting of three annular arrays of premixing elements. A stage would be fueled to achieve stable operation for the desired power. Each premixer consisted of a fuel tube through the center of an eight-vane airflow swirler. Each stage is fed by an annular manifold in an arrangement as depicted in Figure 2.2.5. This figure shows both the multi-point premixer and the cylindrical ceramic liner and shroud, including the attachments.

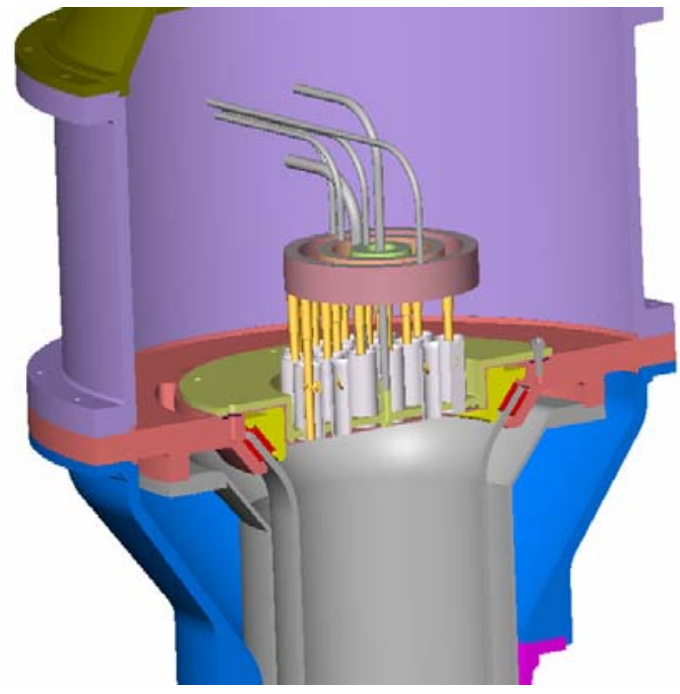

Figure 2.2.5 Multi-point premixer for low emission cylindrical combustor 
The mixing performance of the entire multi-point injection premixer depends on the mixing performance of individual premixers or swirlers as well as the consistency among all the premixers within each fuel circuit. Multiple steps were taken to ensure the performance of the multi-point injection premixer. First, each cast swirler was air flowed to determine its effective flow area or ACd. Based on the variation of the ACd measured, the swirlers were grouped for the three fuel zones. For each fuel zone, ACd values of the swirlers are within 2 percent of each other. Second, the fuel injection holes of each swirler were optimized for mixing. The mixing performance of the individual swirler was measured by PLIF tests. Finally, the optimized fuel holes were implemented consistently into each swirler.

Superior mixing performance of the entire nozzle was achieved. Figure 2.2.6 shows the mixing results at 2.5 percent air pressure drop and different fuel air ratio (F/A). The best ratio of the standard deviation to the mean fuel/air is 0.050 , which represented excellent mixing performance.
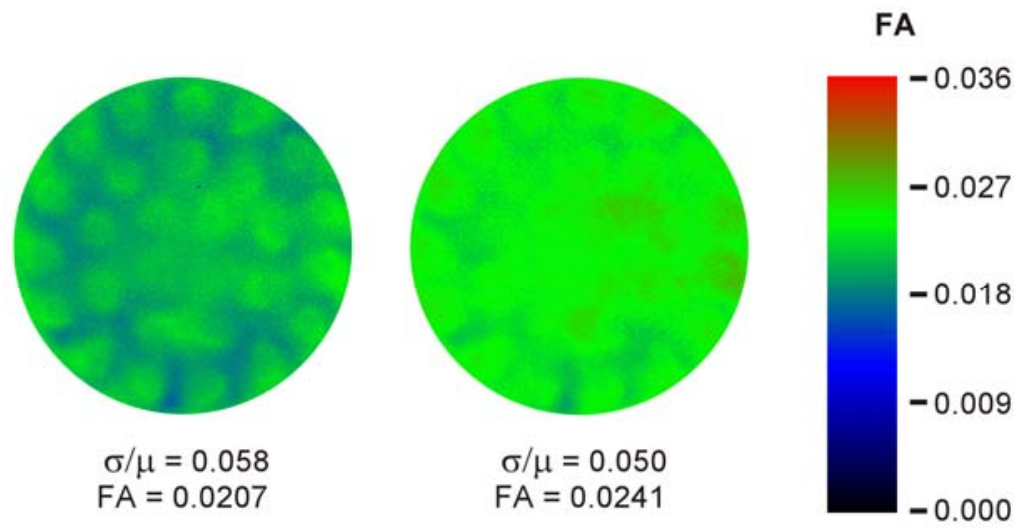

Figure 2.2.6 PLIF imaging for the axial swirler nozzle

\subsubsection{Combustor Performance Modeling}

All components in the microturbine combustor system (swirler, premixer, and liner) contributed to achieving stable, low-emissions operation. The flow through and near these components was analyzed to predict combustor performance using CFD, and chemical kinetics networks.

Typically, gas turbine carbon monoxide (CO) emission is satisfactory at 100-percent power level. The modeling effort, therefore, focused on part power $\mathrm{CO}$ emissions. Investigation of $\mathrm{CO}$ emissions at the combustor exit for the 70-percent power condition was completed. The Eddy Mixing and Reaction (EMR) model was used to simulate CO emissions for staged fuel injection in combustors for microturbines in which the fuel injector consists of multiple small injector elements mounted on a nozzle. These injector elements consist of eight-vane swirlers in which fuel and air mix prior to entering the combustor; fuel injection from both the nozzle centerbody (i.e., ID injection) and nozzle body (i.e., OD injection) were considered. A nozzle with this injector element 
arrangement had not been tested so that the accuracy of the model could not be readily determined. However, measured CO levels were available for an older nozzle with different arrangement that also featured eight-vane injector elements.

In the staged-injection concept used to reduce $\mathrm{CO}$ emissions at part-power operating conditions, the fuel was injected into three essentially concentric zones that were designated the inner, middle and outer zones. The swirler characteristics and nozzle ACD values varied from zone to zone. Generally, the equivalence ratio of the middle zone was reduced and that of the other zones was increased so as to maintain a constant overall equivalence ratio. The CFD cases were run for the 70-percent power condition. Detailed CFD results were obtained for a representative nozzle element for each stage; the results were then interpolated to a nozzle for use in the reacting-flow simulations. An example is shown in Figure 2.2.7, with the flow vectors at the nozzle colored by fuel-air ratio.

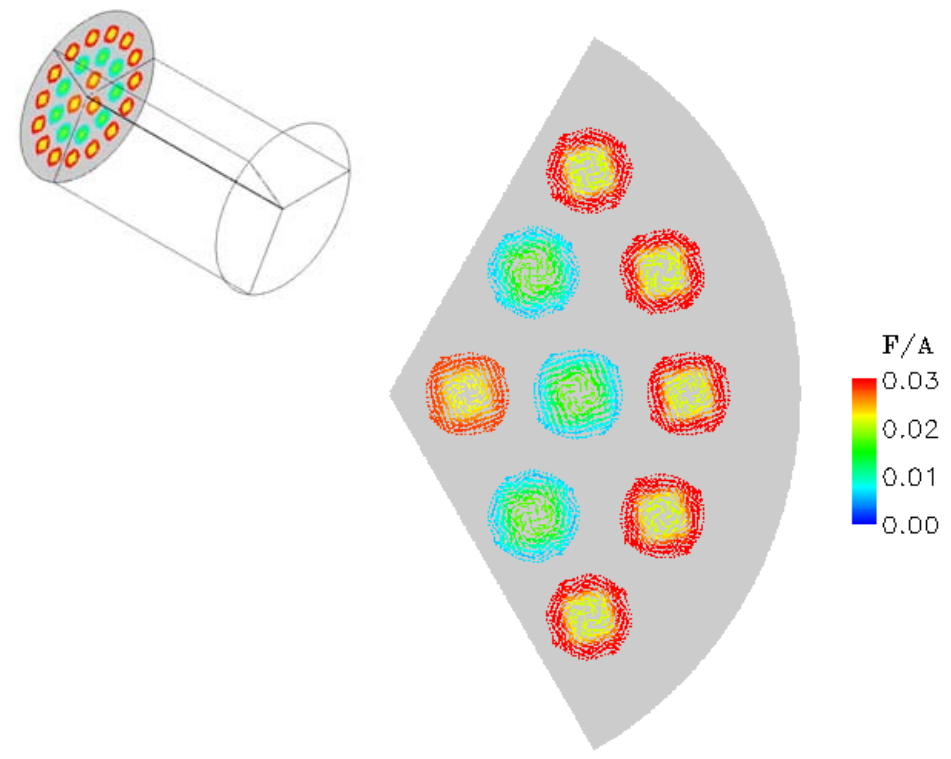

Figure 2.2.7 Representative nozzle boundary condition

Predicted CO results are shown in Figure 2.2.8 for the nozzle operated with both OD injection (Series 300) and ID injection (Series 500). In addition, results for the older nozzle for which data are available for the nominal fuel-air distribution (Series 400) are included; note that Series 400 results were obtained at a somewhat different operating condition corresponding to an actual test condition. The abscissa indicates the equivalence ratio of the middle zone relative to that at the nominal (design) condition. Values higher than 100 percent imply that the inner and outer zone equivalence ratios are reduced so that the overall fuel-flow rate is constant. The values shown in Figure 2.2.8 were computed at the exit of the combustor and did not include the effects of $\mathrm{CO}$ reduction due to further oxidation because of increased residence time in the transition duct and because of downstream air addition. 


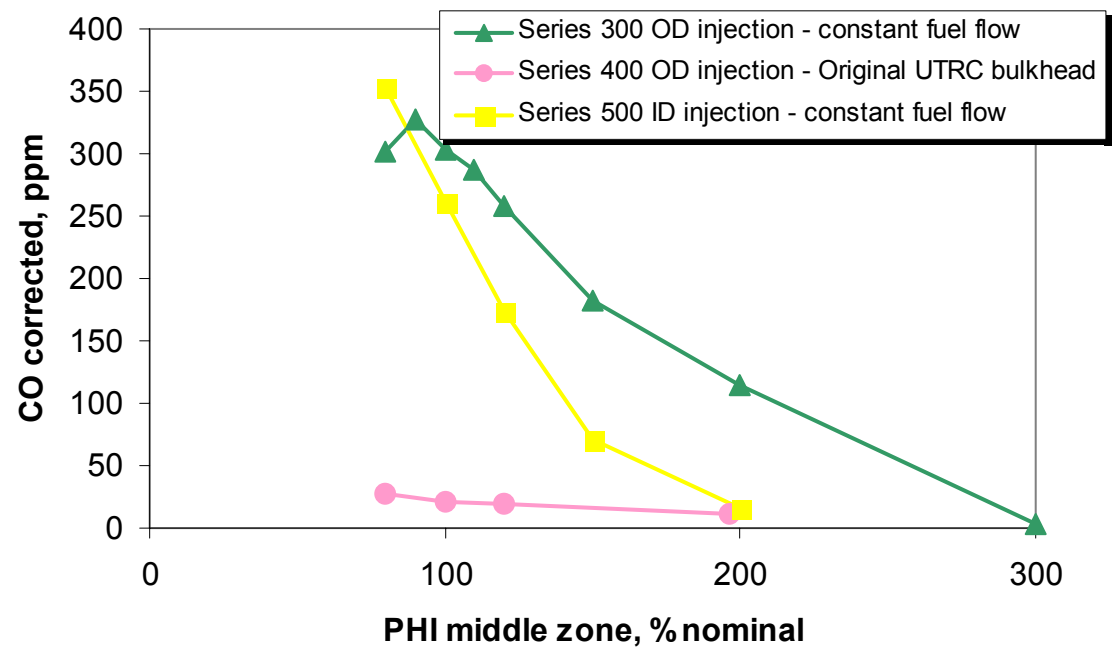

Figure 2.2.8 Predicted CO levels

For the current design using either ID or OD injection of the fuel, there was a rapid increase of $\mathrm{CO}$ as the middle-zone equivalence ratio was reduced. Comparing the results for ID and OD injection, it appeared that ID injection provided for reduced CO emission. $\mathrm{CO}$ levels were generally lowest for the older design operated at a somewhat different test condition.

For the older nozzle design, measured and computed $\mathrm{CO}$ values are compared in Table 2.2.1.

Table 2.2.1 Predicted vs. measured NOx and CO (previous nozzle)

\begin{tabular}{|l|l|l|l|l|l|}
\hline $\begin{array}{l}\text { Middle-zone } \\
\text { equiv, ratio, } \\
\% \\
\text { nominal of }\end{array}$ & $\begin{array}{l}\text { CO CFD, } \\
\text { ppm (comb. } \\
\text { exit) }\end{array}$ & $\begin{array}{l}\text { CO CFD } \\
\text { ppm, (trans. } \\
\text { exit) }\end{array}$ & $\begin{array}{l}\text { CO ppm, } \\
\text { measured } \\
\text { CFD }\end{array}$ & $\begin{array}{l}\text { NOx, ppm } \\
\text { NOx ppm, } \\
\text { measured }\end{array}$ \\
\hline 80 & 27 & 6 & & & \\
\hline 100 & 21 & 6 & 2.82 & 2.59 & 9 \\
\hline 197 & 19 & 8 & & & 6.86 \\
\hline
\end{tabular}

For this design, the combustor was five inches long and was followed by a transition duct that made the entire length approximately 12 inches. Due to the additional residence time in the transition duct, $\mathrm{CO}$ oxidation continued. The CFD values are about twice the measured values for the cases for which data were available. Measured and computed NOx levels are also shown and indicate that the NOx calculation under-predicted the levels measured. NOx levels were also computed for the new nozzles, Series 300 and 
500, and shown that NOx concentrations are less than $1.5 \mathrm{ppm}$. CFD results need to be further calibrated by test data.

\subsubsection{Dynamic Stability Analyses}

Thermoacoustic instabilities can severely impact the ability to achieve low emissions in lean premixed combustion systems. To perform acoustic modeling of the combustion system, accurate test data on impedance of the CTD or scroll were needed due to its complex geometry to model. The frequency dependent impedance of the scroll was successfully measured in a cold flow test. The purpose of the measurement was to use it as the boundary conditions to models in order to predict more accurate acoustic modes and damping upstream of the scroll. Acoustic impedance is defined as acoustic pressure divided by acoustic particle velocity. The 2-microphone technique was used to measure the impedance. This technique, under the assumption of 1-D planar waves, requires an acoustic pressure measurement at 2 closely spaced sensor locations as a function of frequency. Figure 2.2.9 shows the experimental setup. Upstream of the test section a venturi measured the flow rate, followed by a perforated plate acting as an upstream choked boundary condition. Downstream of the perforated plate was the inlet plenum of the test section. Airflow coming from left passed through a perforated plate simulating the fuel nozzle. After going through the long cylinder representing the combustor, it entered the scroll. At the exit of the scroll a perforated plate was inserted to simulate the choked exit boundary condition imposed by the first turbine blade row. From the exit the flow exhausted to atmosphere. Two speakers were mounted just down stream of the fuel nozzle to generate the acoustic excitation needed for the test.

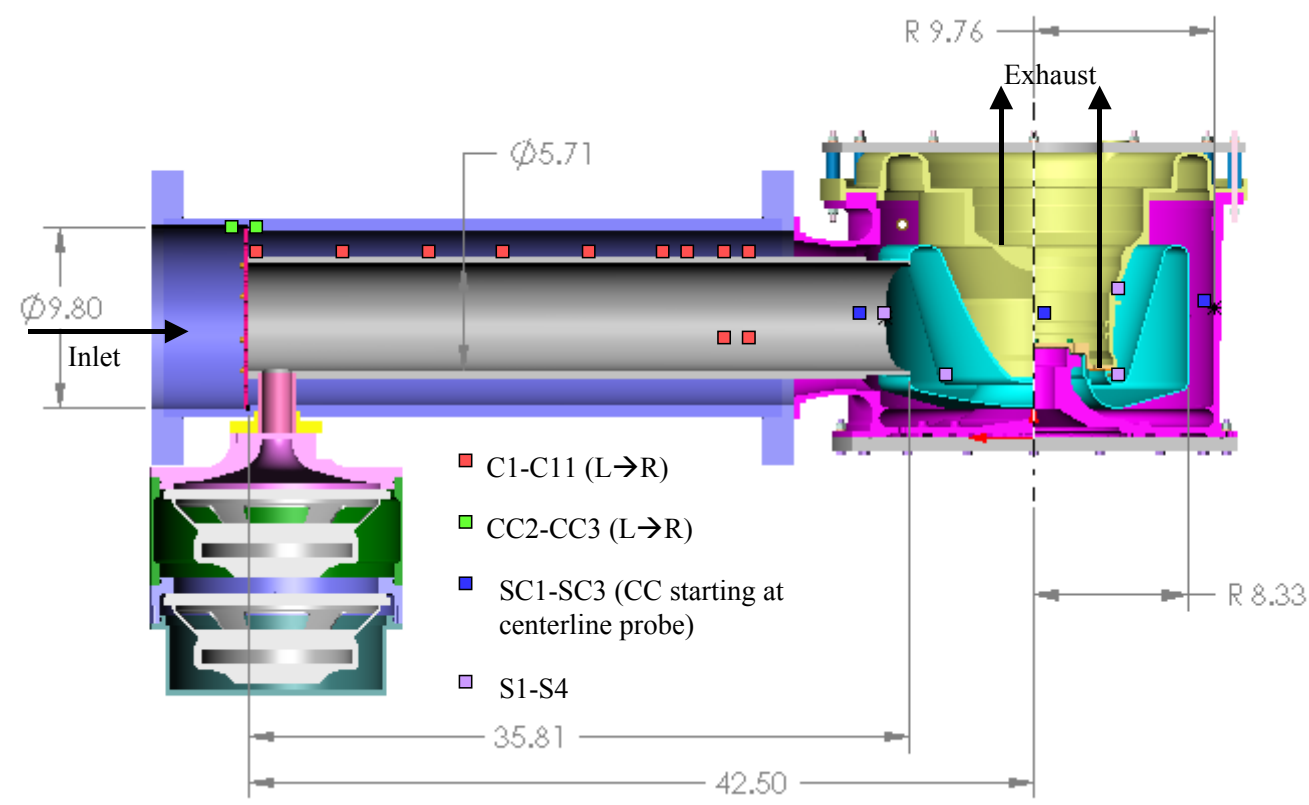

Figure 2.2.9 Scroll impedance measurement setup (C-combustor, CC-combustor casing, S-scroll, SC-scroll casing, Units: inch) 

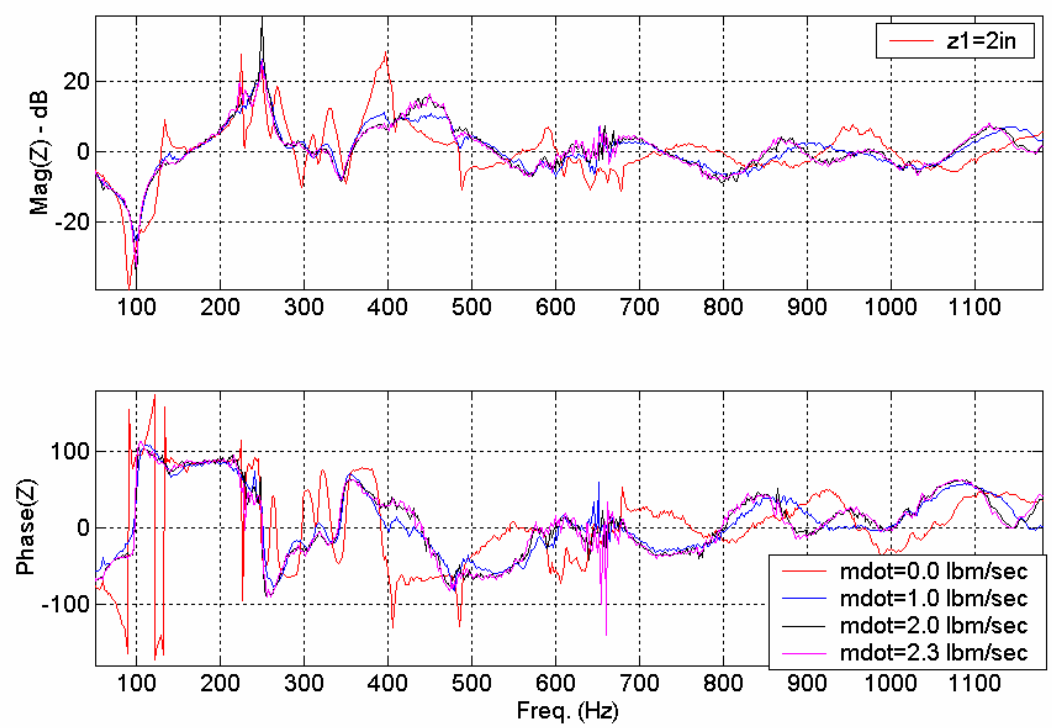

Figure 2.2.10 Impedance at various flow rates (normalized by characteristic impedance)

In order to simulate the actual engine operating temperature and pressure, the engine flow rates were scaled on the Mach number at combustor plenum. For the $70 \%$ power case the engine operating flow rate was $4.33 \mathrm{lb} / \mathrm{s}$ which scaled to $2.0 \mathrm{lb} / \mathrm{s}$ at experimental ambient pressure and temperature conditions. The $100 \%$ power case has a flow rate of $4.98 \mathrm{lb} / \mathrm{s}$ which scaled to $2.3 \mathrm{lb} / \mathrm{s}$. Figure 2.2.10 shows the impedance calculated for mass flow rates of 2.0 and $2.3 \mathrm{lb} / \mathrm{s}$. This plot represents normalized impedance in which $0 \mathrm{~dB}$ is equal to the characteristic impedance $(\rho \mathrm{c})$. Therefore, any value above $0 \mathrm{~dB}$ represented higher impedance in which more of the acoustic energy was reflected than transmitted (more closed) at the impedance boundary. Large impedance, representing an acoustically "closed" boundary, existed near $250 \mathrm{~Hz}, 450 \mathrm{~Hz}, 690 \mathrm{~Hz}$, and higher frequencies. The impedance data was then incorporated successfully into the models for acoustic stability analysis.

At 100-percent power and uniform fueling of each zone, a system instability would likely exist near $480 \mathrm{~Hz}$. To mitigate the risk, the fuel nozzle design was modified to allow the increase of the fuel convective length between the fuel injection point and the flame by 2 inches. As shown in Fig. 2.2.11, calculations showed that the instability was eliminated as indicated by the fact that the blue line goes below the green threshold line when convection length is increased to 4 inches. 


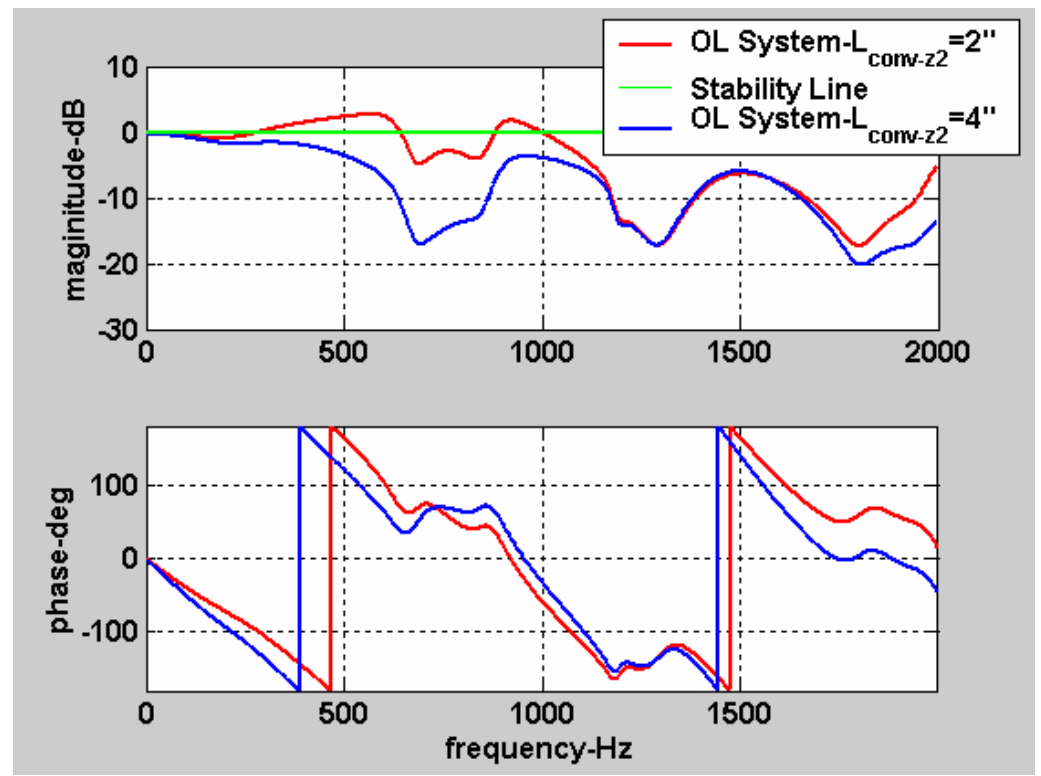

Figure 2.2.11 Thermo-acoustic instability model predictions

Fabricated combustor components were not tested prior to the redirection of the program.

\subsection{Organic Rankine Cycle (ORC) Technology Development}

Technology for the Organic Rankine Cycle (ORC) system was developed in two stages. The Generation 1 ORC subsystem was primarily a risk reduction activity that was evaluated using a simulated engine exhaust. Subsequently, many of the components were enhanced and integrated into a Generation 2 system that was operated off the exhaust of a 1.2 MW gas turbine.

\subsubsection{Generation 1 ORC}

The Generation 1 ORC utilized near-off-the-shelf components without modification. For example, the turbine was a Carrier (19XR225) centrifugal compressor running with reverse flow, and the condenser was a pair of Carrier (09DK094) air cooled condensers. The evaporator came from a Carrier supplier.

The 19XR225 is a Carrier centrifugal compressor employing conical diffuser. It is used for water chilling duty of about 225 tons with refrigerant R134a and is as such the smallest compressor in a family of compressors sized for duties up to 1500 tons. Figure 2.3.1 is a cross-section of this compressor. It consists of an induction motor driving the compressor through a gearbox. When the compressor is used as turbine, the high pressure vapor enters what used to be the discharge of the compressor, expands through the turbine, and discharges through what used to be the compressor inlet. The turbine drives the induction generator. 


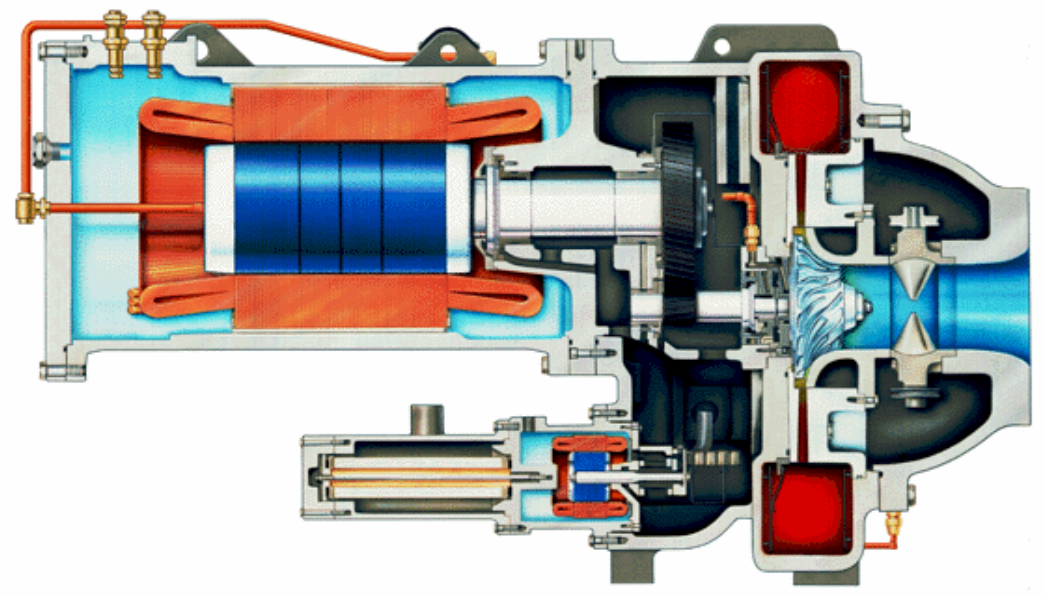

Figure 2.3.1 19XR225 compressor

The condenser used on this ORC was Carrier air cooled condenser shown in Figure 2.3.2. The refrigerant inlet and outlet were modified to match the ORC system. Such condensers are routinely used on many Carrier products and are manufactured in large quantities.

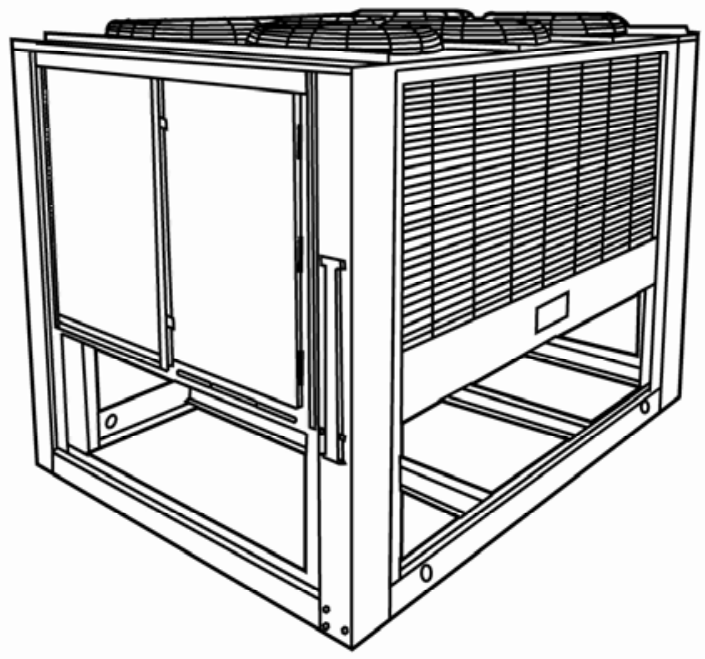

Figure 2.3.2 09DK094 Carrier air cooled condenser

The evaporator shown in Figure 2.3.3 was designed by Carrier and built by a Carrier supplier. It was constructed out carbon steel tubes and fins. The two sections of the evaporator were designed as a counter-flow type and co-flow type. The sub-cooled refrigerant got heated to boiling point in the counter flow section, and further got heated to the turbine inlet condition in the co-flow section. 


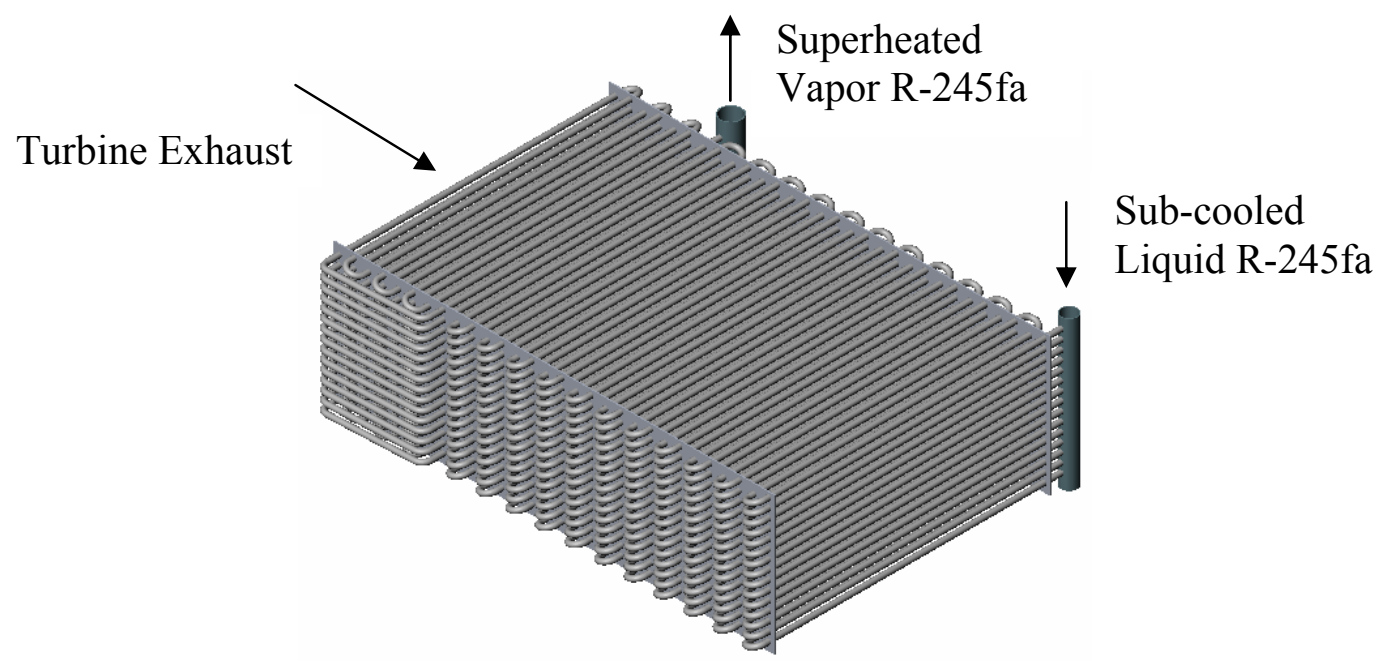

\section{Figure 2.3.3 Gen I ORC evaporator (air ducting not shown)}

The test facility shown in Figure 2.3.4 included provision for substantial pressure and temperature instrumentation to measure component overall performance, line losses, component health, and flow distribution for component model validation. The turbine had 30 internal pressure measurements in the shroud and impeller area and 3 exit wedge probes (to measure exit swirl angle) to diagnosis turbine performance. The evaporator and condenser were instrumented with a vast array of thermocouples for performance and heat transfer coefficient calibration. In addition, instrumentation was also in place to measure motor power consumption by the pumps and condenser fans, as well as electrical generator power output. The energy source was a controlled flowrate of electricallyheated air.

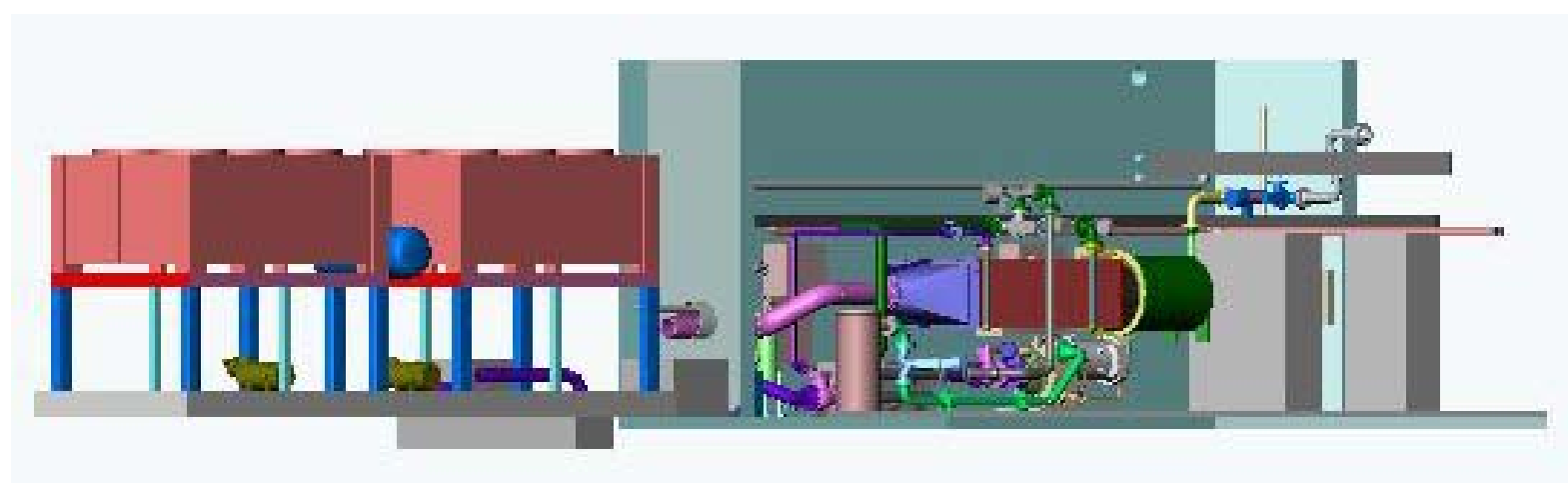

\section{Figure 2.3.4 Gen I ORC test system}

The turbine was tested for several hours. A peak electric power output of $64 \mathrm{~kW}$ was achieved during these tests, a result consistent with model predictions when using the production compressor impeller and nozzle arrangement. This achievement marked a major milestone on the path to demonstrating $80 \mathrm{~kW}$ net power target. Further power increase was expected after the installation of optimized impeller, shroud and nozzle 
designs. Behavior of the turbine oil reclaim and motor cooling subsystems was also studied during these tests. Several detail changes were made to these subsystems to properly balance the pressure in the three internal generator and gearbox cavities and thus maintain the appropriate oil and coolant flows. Reliable operation of the bearing/lubrication system was demonstrated except at the highest load conditions. This behavior, which was believed to result from the use of compressor bearings in reverse rotation, was addressed through modification of the original tilt-pad bearing.

Heat exchanger performance was verified. The vapor generator was to deliver $7 \mathrm{lb} / \mathrm{s}$ of R245fa with 20F superheat from a 700F, $5 \mathrm{lb} / \mathrm{s}$ inlet air stream with minimal allowable air-side pressure drop. The model accurately predicted the vapor generator capacity. The measured air-side temperature drop was predicted to within $<1 \%$. The R 245 fa side was also well predicted. Figure 2.3.5 shows a side view of the vapor generator, followed by the measured row-by-row temperature profile in the middle tube sheet and the model tube sheet average temperature prediction. (Note that the physical evaporator is counter-flow until row 24 and then co-flow to the exit at row 30 . For clarity, the plotted temperature profiles are shown as if the entire unit was counter-flow.) The model followed the measured profile closely, and predicted a final superheat between the measured middle tube sheet value and the mixed superheat measured in the outlet header. Some vertical mal-distribution of outlet superheat was noted, apparently caused by gravity effects. Pressure drop on both air and R245fa sides was under predicted by $10-20 \%$, but the astested values were acceptably low.
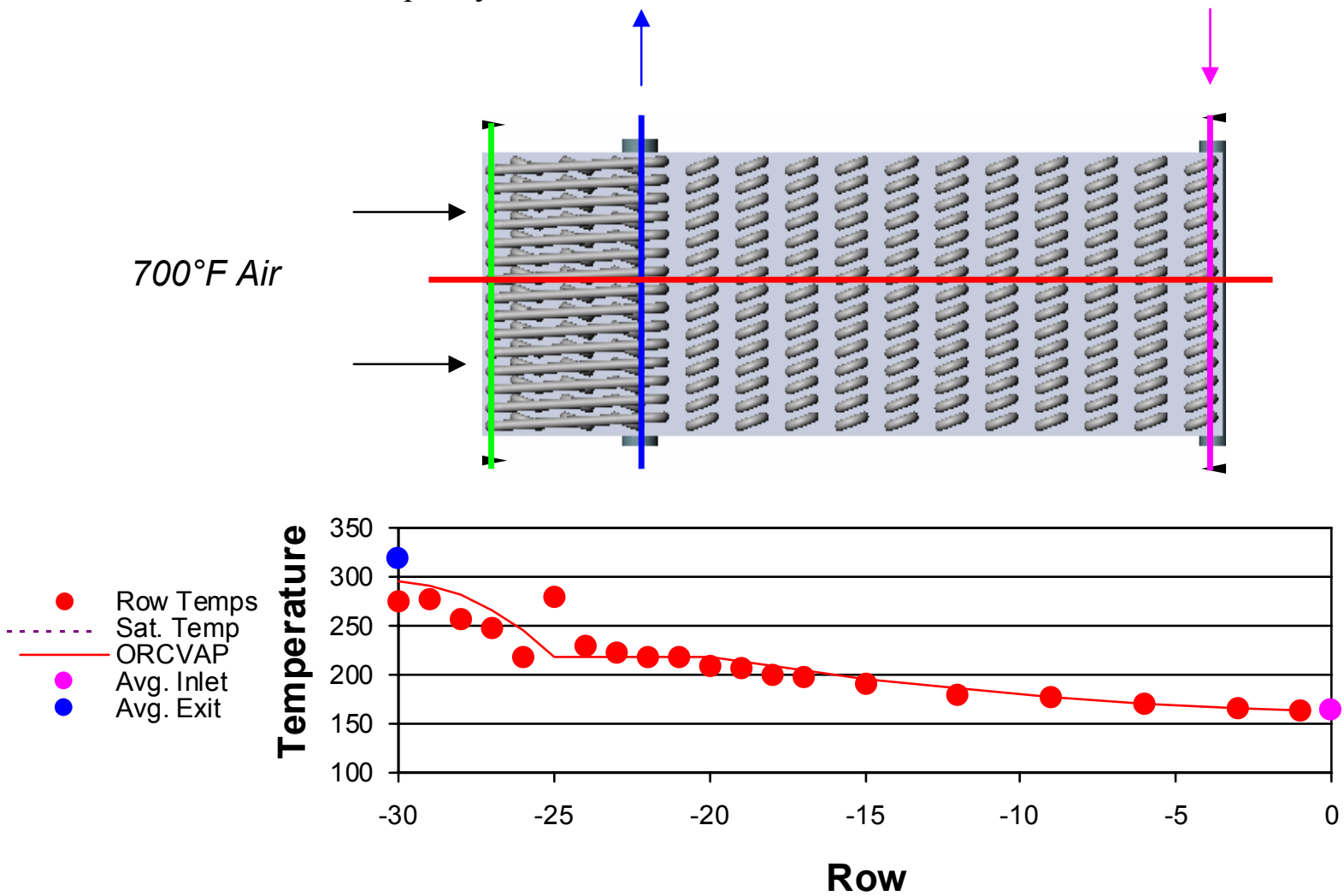

Figure 2.3.5 Gen I ORC evaporator performance 
The condenser had to reject $700 \mathrm{~kW}$ of energy with a saturation temperature no more than $36 \mathrm{~F}$ above the ambient to achieve the design turbine pressure ratio. Condenser capacity was measured to be $5-10 \%$ greater than model predictions. On the other hand, the saturation temperature limit was not achieved. Although the condenser coil pressure drop was well predicted, the overall condenser inlet pressure, and thus saturation temperature, was under-predicted due to excessive friction losses in the standard condenser inlet manifolds and buildup of non-condensable gases in the receiver tank. This indicated a need to implement a large size condenser inlet manifold to reduce the line loss and a purge mechanism to control the non-condensable. Finally, the $350 \mathrm{~kW}$ feed-heaters performed very well. Measured capacities on both sides were consistent to within $10 \%$ of design. Vapor-side pressure drop measurements exceeded the design value, but this was consistent with operation of the system at more than design superheat.

Pump performance was sufficient to support system testing, but improvements were clearly necessary to demonstrate technical readiness. The procured variable-speed pump showed a propensity to cavitate at half the nominal impeller speed when supplied with effectively saturated liquid at the specified net pump suction head (NPSH). Using two similar pumps in series allowed the first pump to be operated at low speed, and thus low pressure rise, without cavitation. Full speed operation of the downstream pump then delivered the required system pressure without cavitation because of the increased NPSH provided by the upstream pump. Control of the system flow currently required manual throttling, which dissipated a large amount of energy. The system was not efficient, but was fully functional. In subsequent tests however, the second pump was equipped with a variable speed drive to replace the throttle valve, improving efficiency and enabling tests of automatic superheat control algorithms.

\subsubsection{Component Modifications}

\subsubsection{Aerodynamic Enhancements}

A one-dimensional meanline model of the nozzle, gap, and impeller, as well as a threedimensional CFD model of the nozzle and gap, were developed to improve the design of these critical components. CFD model results comparing Mach number in the nozzles and gap for cases with eight and sixteen azimuthal nozzles are shown in Figure 2.3.6. The actual final design configuration was selected to achieve the target $80 \%$ efficiency. 

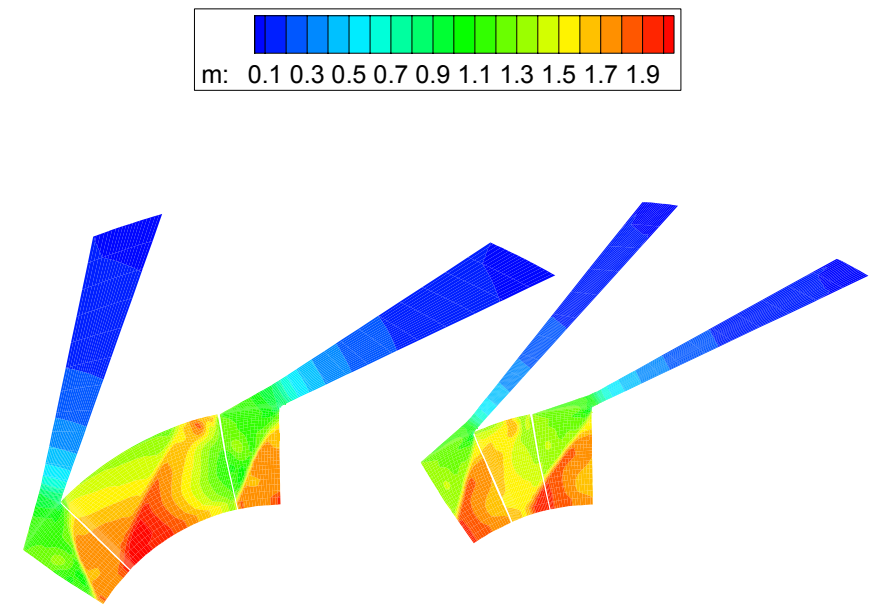

Figure 2.3.6 Mach number profiles for the turbine nozzles and gap.

\subsubsection{Generator Drive-System Enhancements}

Two issues involving the turbo-generator bearings and system oil management were identified that related to reversing the gas flow through the impeller. The thrust bearing for the impeller shaft, a tilt-pad unit designed for rotation in a compressor, could not support full design power over a long-term when rotating in the opposite direction. The bearing pads could be modified to tilt the opposite direction for improved power operation. However, analysis showed that the modified bearing would be marginal during a loss-of-power transient because the impeller coast is longer in turbine mode. For this reason, and to reduce turbo-generator mechanical losses by an estimated $6 \mathrm{~kW}$, rotating element bearings were designed and incorporated. The design drawing is shown in Figure 2.3.7.

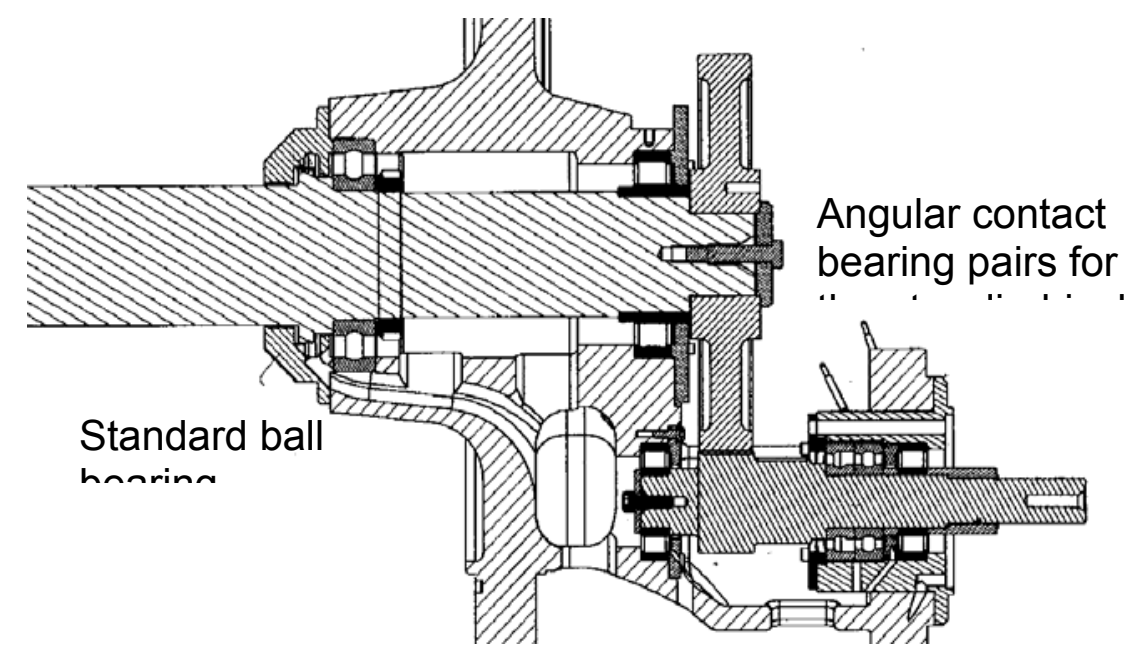

Figure 2.3.7 Turbine impeller and generator shafting with roller element bearings. 
Motor cooling and oil management in the motor/compressor unit required careful balancing of pressures in its three internal cavities. In addition, lubricant thermal stability testing was completed. Figure 3.2.4.8 shows oil samples maintained at $212 \mathrm{~F}$ for several weeks without metals and at $392 \mathrm{~F}$ with metals. Clearly, the oil stability is affected at the higher temperature in the presence of metals. Passivating the metal surfaces allows longterm operation at $347 \mathrm{~F}$ without loss of stability.

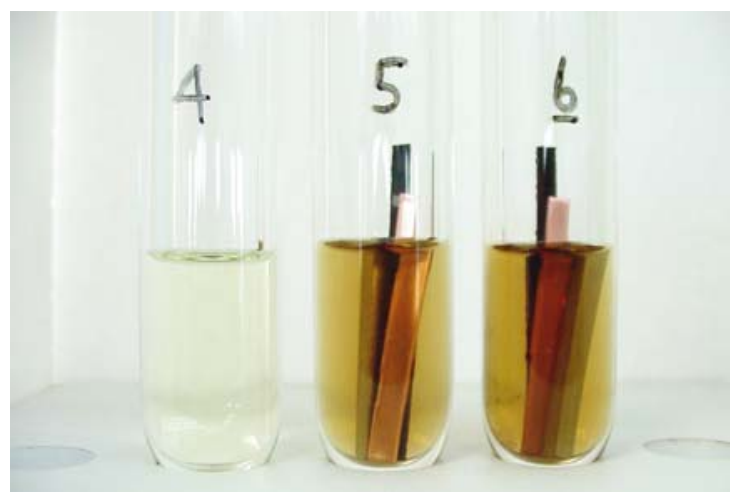

a.

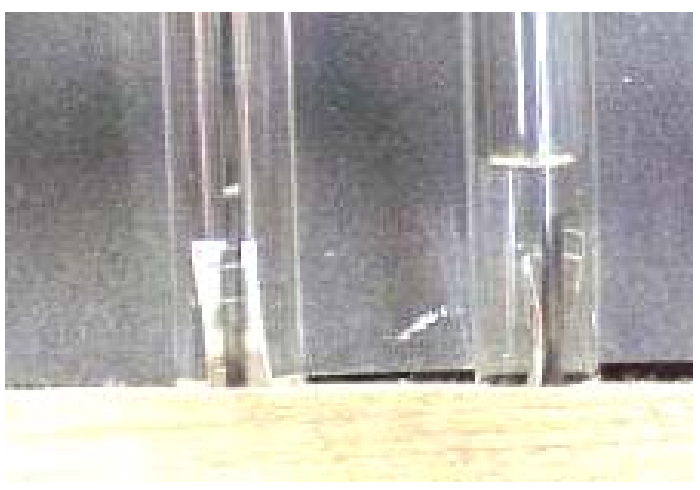

b.

Figure 2.3.8 Long-term lubricant stability test results

\subsubsection{Motor and oil cooling system modifications}

The interdependent oil management and motor cooling systems were completely redesigned. Earlier testing was often limited by significant losses of oil from the gearbox sump. These losses primarily occurred when initiating turbine operation from turbine bypass, and when the motor cooling system was manually actuated. Analysis of the system data showed that large pressure differences could occur between the motor cavity and the transmission cavity in these circumstances, causing ejection of bearing lubrication oil into the motor casing and subsequently into the system. Also, with a single coolant stream feeding the motor and oil cooler in series, we found it difficult to get the correct balance between cooling loads. To resolve these problems, the cooling system was revised to feed the motor and oil cooling loads in parallel. These cooling circuits are illustrated in Figure 2.3.9.

Management of oil inventory during transients was determined to be primarily an operational issue. To study this problem in more detail, a sophisticated UV spectrophotometer system was installed to measure oil concentration at the refrigerantpump outlet as a function of time. Oil losses can now be correlated with all other system data, allowing diagnosis and control of the phenomenon shown below in Figure 2.3.10. 


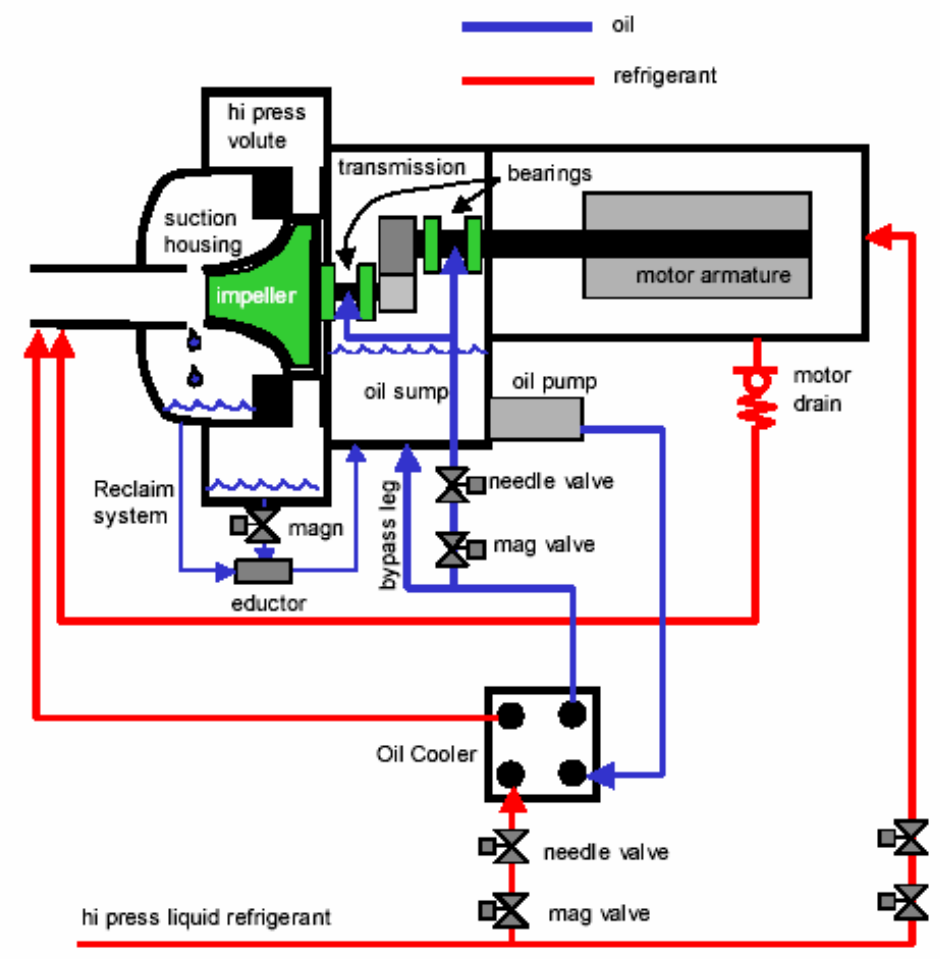

Figure 2.3.9 Motor \& oil cooling circuits and oil management system

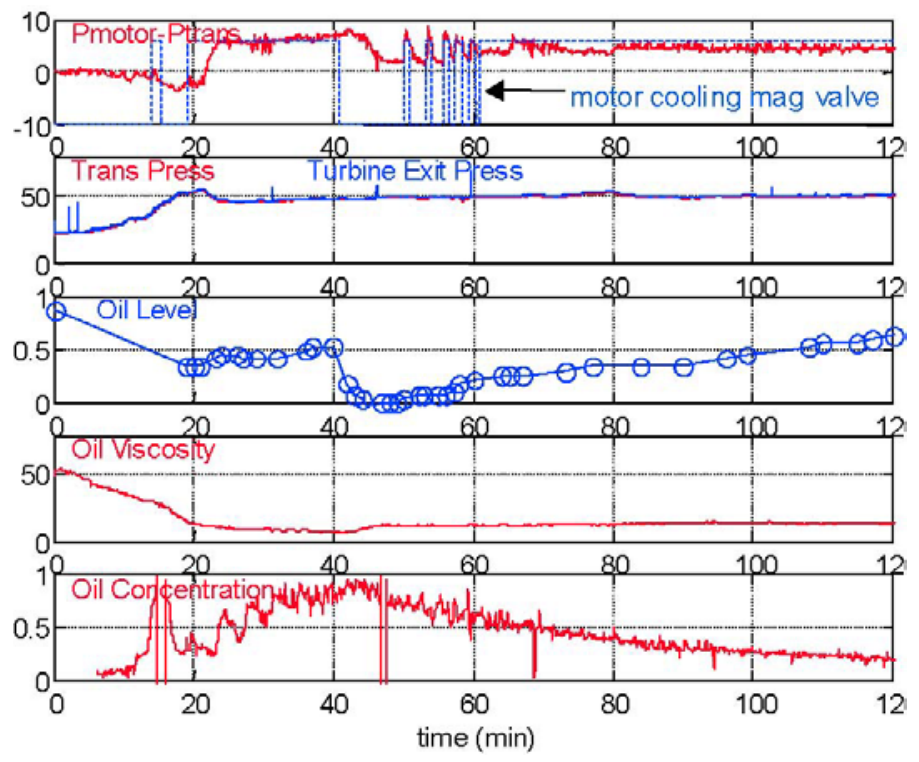

Figure 2.3.10 Motor and oil cooling circuit performance

Figure 2.3.10 shows representative test data that was recorded during the development phase of the oil/motor cooling system. In this series of plots, the system heat-up begins at approximately 5 minutes, reaching equilibrium at about 40 minutes. The circulating oil concentration rises during this time while the oil level drops and then stabilizes when 
motor cooling is initiated at 20 minutes, pressurizing the motor cavity and arresting the loss of oil from the transmission cavity. At 40 minutes, overcooling of the motor cavity required that motor cooling be discontinued, whereupon the motor cavity pressure and the oil level dropped dramatically. The oil eductor system was started approximately 42 minutes into the plot when the hot gas temperature was sufficiently high, and both oil concentration and level responded favorably within 2-3 minutes. Motor cooling was adjusted several times between 50 and 60 minutes until the correct flow rate was achieved. Once motor cooling was restored, oil was reclaimed steadily over the next hour while good motor temperature was maintained. Oil viscosity also rises and stabilizes over this time, demonstrating good control of oil temperature and refrigerant concentration in the oil sump.

Operation of the ORC with this revised oil management system, without the oil separator, showed that our current ORC startup sequence minimized the loss of oil from the turbogenerator sump. Also, the eductor system was able to restore the circulating oil concentration to an acceptable level over about an hour of operation.

\subsubsection{Condenser modifications}

Condenser coil capacity was well predicted by models, but the condensing temperature was higher than anticipated. This higher condensing temperature reduced the pressure ratio across the turbine and consequently the work that could be extracted from it. Analysis of the data, summarized in Fig. 3.2.4.12, shows that a larger than expected pressure drop in the condenser inlet manifold, combined with collection of noncondensable gases in the system, accounted for the high condensing temperature. The manifold design was revised to reduce vapor velocities and to trap any liquid R245fa condensed on the vapor line walls. Also, commercial refrigerant purge units were evaluated for their applicability to R245fa and got incorporated in the system.

Capacity Comparison

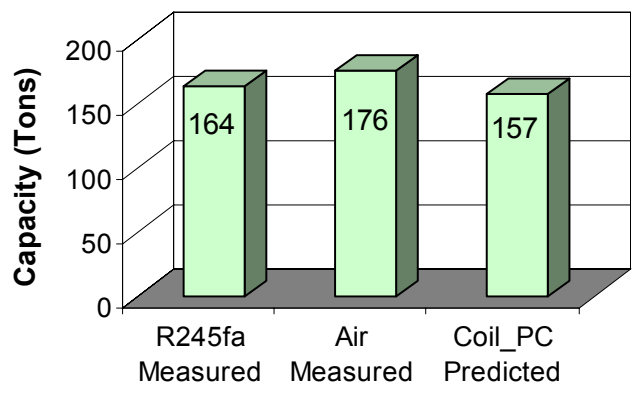

Turbine Exit Pressure

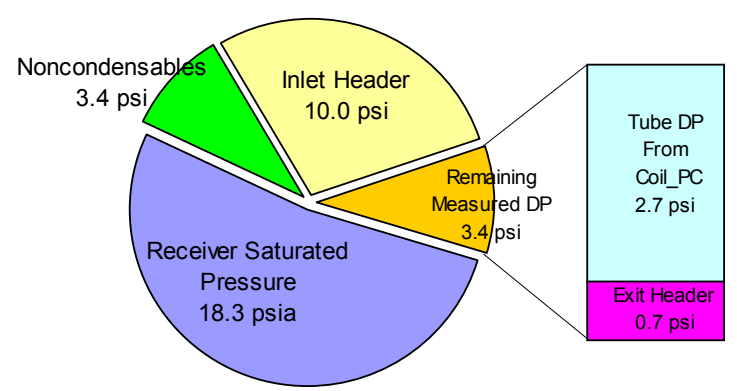

Figure 2.3.11 Validation of condenser capacity and pressure drop 


\subsubsection{Pump Enhancements}

A major contributor to pump cavitation was entrainment of vapor bubbles from the receiver at low fluid level operations. The condenser return lines were initially routed into the vapor space of the tank, causing considerable frothing. These lines were later extended to the bottom of the tank to prevent condensation in the vapor space and to minimize frothing. This was effective until the receiver level dropped below a certain level, when the returns would uncover and entrain vapor into the remaining liquid. Any bubbles sucked into the pump inlet would not have time to condense in the nearsaturation liquid, and cavitation would occur. A sparger was developed to slow the flow velocity and thus greatly minimize this entrainment.

Regardless of the receiver design, the provided NPSH could not support full flow without the use of a boost pump. Because non-condensable gases are continuously purged from the system, it appeared likely that the pump inlet fluid was simply too close to saturation. Increasing the physical pump suction head was not feasible, but it was possible to add a small water-cooled heat exchanger to give a few degrees more sub-cooling to the nearly saturated fluid entering the pump. Testing showed that the combination of spargers and sub-cooling allowed operation of the system at full capacity without the boost pump. Also, sensitivity of the pump to rapid condenser fan variations appeared decreased.

However, effect of low available NPSH was persistent and the pump cavitated readily. Secondly, since the characteristic curve of the pump was practically horizontal, little change in pressure difference across the pump resulted in large swings in flow rate making control of the system exceedingly difficult. The problem was eradicated only after the introduction of a regenerative pump with a steep characteristic curve albeit with poorer efficiency.

\subsubsection{Electrical Interconnection}

In the Generation $1 \mathrm{ORC}$, the induction generator was connected to the grid through an inverter. In the Generation 2 design, the generator should be connected directly through contactors. In the event that the generator is disconnected from the grid due to a fault trip, the turbine will over-speed to approximately 1.6 times its nominal design speed. The Generation 1 design experienced this phenomenon several times without any apparent damage; however, to avoid potential reliability issues a scheme has been developed to prevent the over-speed condition.

An electrical break was designed to hold the induction motor at close to its nominal operational speed for more than 5 seconds to give the controller time to close the turbine inlet valve and open the bypass valve. The electrical break is shown in Figure 2.3.12. 


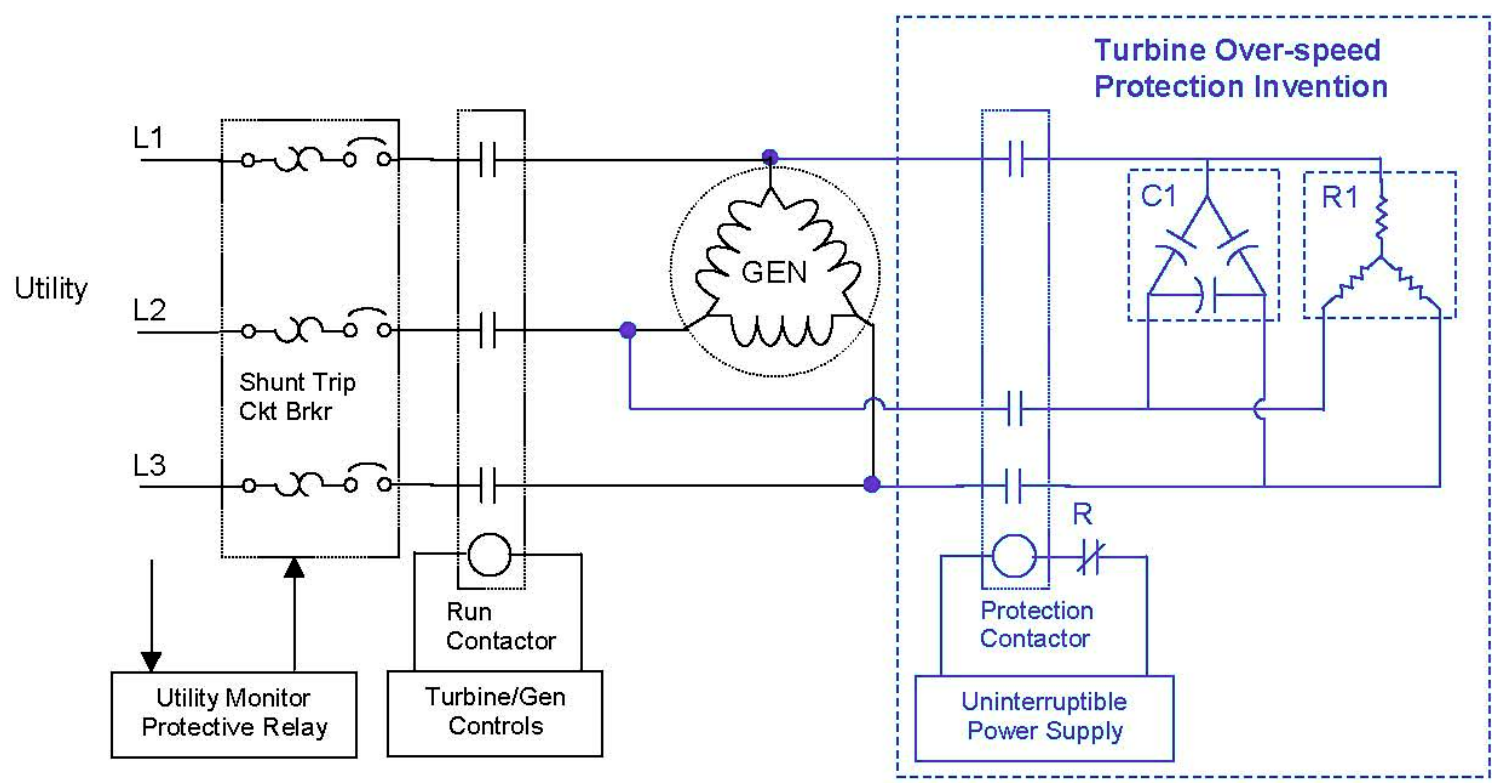

Figure 2.3.12 Over-speed protection scheme

\subsubsection{Generation 2 ORC}

A $100 \mathrm{~kW}$ Generation 2 ORC was assembled and installed at the UTRC Jet Burner Test Stand (JBTS). This site was selected because the JBTS has a 1.2 MW gas turbine engine that could provide the waste heat energy for the ORC. Figure 2.3.13 shows the placement of the ORC at the JBTS. The evaporator was located on the roof of the JBTS where the engine exhaust was available, with insulated pipes for the liquid and vaporized refrigerant. The figure also shows a photograph of the assembled ORC. All of the ORC enhancements described above were implemented in the Generation 2 system. Overall, the unit met all of its requirements. It achieved the design net power of $100 \mathrm{~kW}$, and the turbine met the expected $80 \%$ isentropic efficiency. The evaporator, condenser and receiver also performed according to design requirements. 

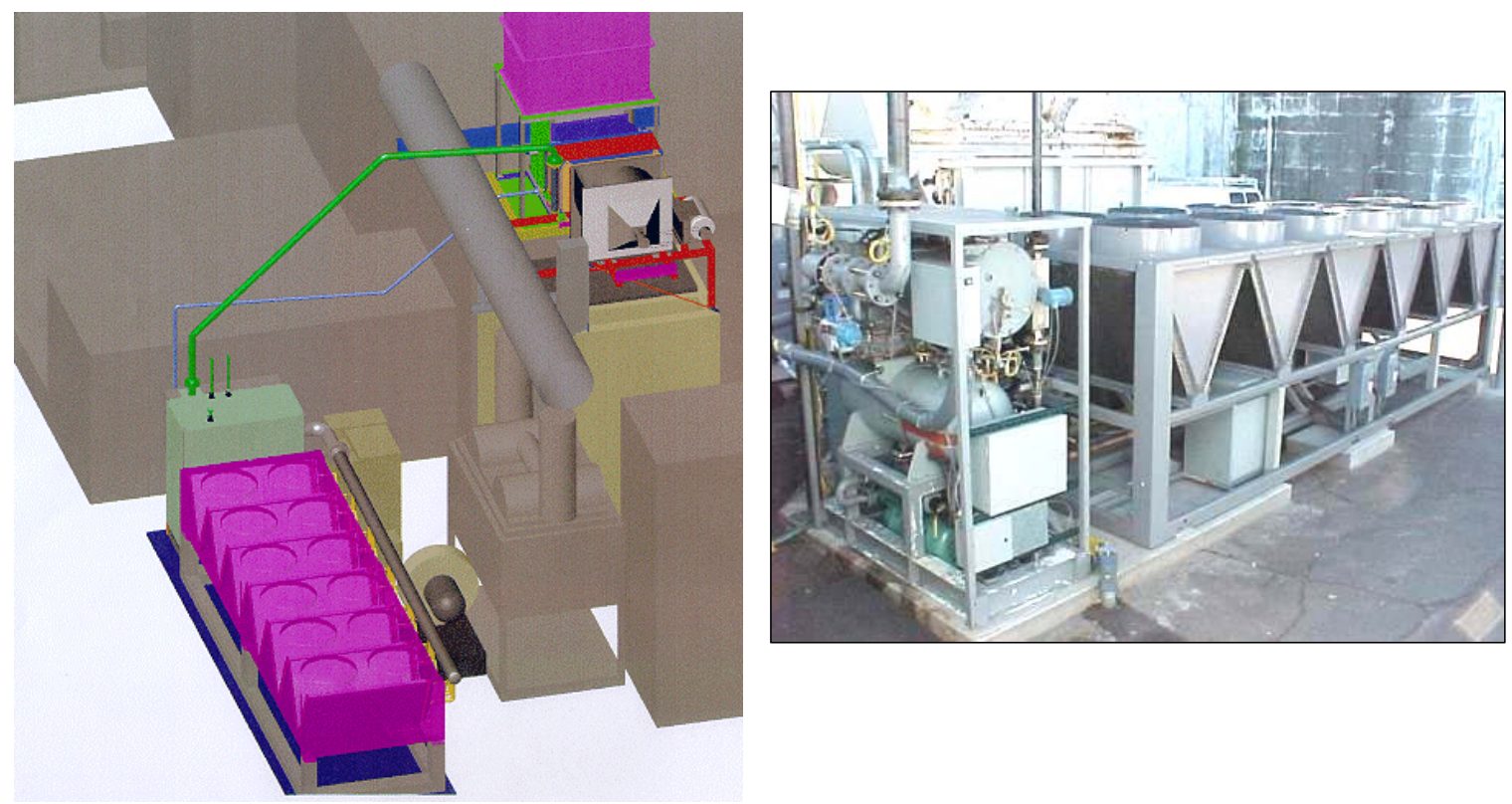

Figure 2.3.13 Generation 2 ORC

The ORC closed-loop control system was further developed during the Generation 2 testing. Throughout the system-operating envelope the following criteria were the guide to develop the control system:

1. The maximum pressure limit must not be exceeded,

2. The maximum temperature limit must not be exceeded, and

3. The superheat must not approach zero

4. It must allow for a smooth system startup and

5. It must allow for safe shutdown if loss of generator power or heat source is sensed.

The evaporator exit condition (turbine inlet) must be maintained in the zone shown in Figure 2.3.14 for reliable operation.

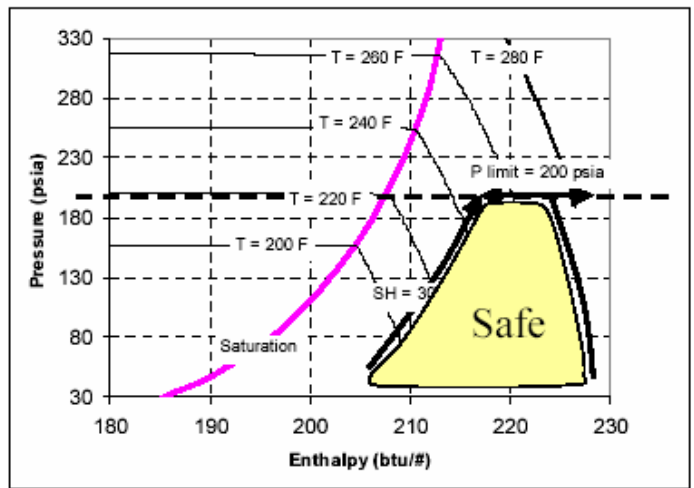

Figure 2.3.14 Safe Turbine Operating Zone 
The maximum pressure limit defining the zone is dictated by mechanical strength of the hardware. The maximum temperature limit is dictated by allowable oil temperature. The minimum superheat requirement is imposed to protect the turbine from ingesting liquid for fear of erosion. In addition to the above criteria, the controls must drive the operation state to the high-pressure limit in order to maximize the power efficiency of the system. To achieve these goals a modified-cascade closed loop control scheme was implanted as shown in Figure 2.3.15.

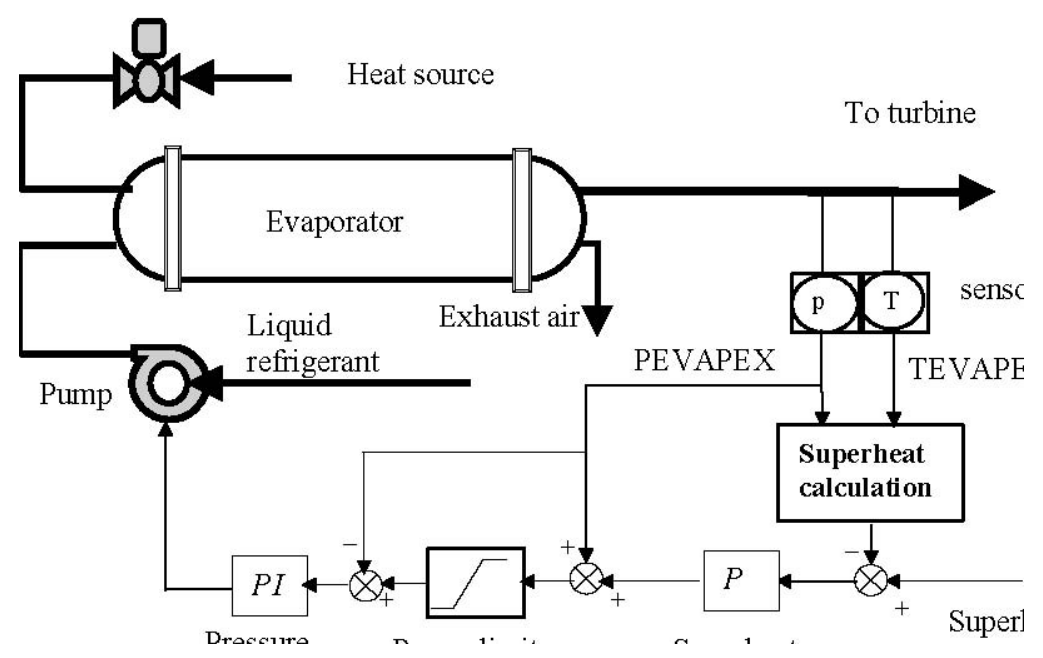

Figure 2.3.15 Modified-cascade closed loop controller.

Using this control scheme there are three modes of operation possible:

- Closed loop PID on superheat,

- Closed loop PID on pressure, and

- Open loop on pump speed.

When in closed loop the pressure/superheat transition occurs seamlessly. When in openloop the algorithm is not called, and the pump speed is held constant or set by other logic.

The refrigerant pump, which is the primary superheat-control actuator, is designed by the manufacture to be used as a nearly constant-pressure source, in that for a given speed it provides a large range of flow at nearly constant pressure. Using the cascade control scheme, the pressure limits may be varied dynamically to move the system operation from one region to another. The startup scheme transitions from open loop to closed loop, and then varies the pressure limits to slowly increase the operation pressure. The time constant of the pressure loop is fast, which prevents pressure over-shoot. The startup sequence is:

- Apply hot air to evaporator (approximately half the design enthalpy flux)

- Turn on pump to minimum speed $(20 \mathrm{~Hz})$.

- Set high pressure limit to a value of pressure that can be achieved at steady-state at the initial low pump speed. (70 psia)

- Wait until operating condition is on the pressure plateau of the pump curve, as determined by a model. 
- Ramp up the pressure limit to its normal value (currently 280 psia). At some level the mode will switch from pressure control to superheat control.

- Increase (and control) hot air enthalpy flux to bring the system to full load (maximum pressure and temperature at the evaporator exit).

In the process of testing for reliability, however, four new major problems emerged.

- First, the lack of sufficient NPSH caused the centrifugal pump to cavitate frequently. Sudden change in ambient temperature or sudden increase in the condenser fan speed starved the receiver of refrigerant and subsequently also cavitated the pump. To make things worse, the horizontal shape of the pump's characteristic curve gave the controller a challenge to keep the unit running.

- Second, small pieces of hardened metals such as weld slag, copper and aluminum shavings, bombarded the rotor and nozzle during operation and caused it to fail mechanically. Once the debris reached the area between the rotor and the nozzle, it had no means to exit and therefore, repeatedly damaged both the nozzle and the rotor.

- Third, the match between the natural frequencies of the rotor blades and the second harmonics of the pressure field created by the number of stators, rotor blade number, and the angular velocity of the rotor combinations, caused the rotor to break up.

Each one of these problems were thoroughly analyzed, their root cause were well identified and finally solved and retested on the Generation 2 ORC.

- The solution for the pump problem was to use a regenerative pump instead of a centrifugal pump. Although the efficiency of this pump is slightly inferior, its robust operation under cavitating condition and its low NPSH requirement made it an ideal solution to the problem at hand. Even more attractive is the shape of the characteristic curve of the regenerative pump. The monotonically negative slope made system operation very stable.

- The FOD problem was challenging. . At first it was believed that debris could be filtered out during the commissioning process. However, it was determined that the debris could be introduced during field service operation. Therefore a commissioning filter became permanent.

- A more thorough calculation identified the high cycle fatigue failure problem at the high end of the frequency range. Prior Carrier experience for the turbomachinery used as a compressor did not require this process. The problem was solved by detuning the impeller's natural frequency in a redesign process.

These solutions were all implemented on the Generation 2 ORC which was successfully tested for over 1000 hours. 


\section{Section 3.0 Integration and Test of Advanced Microturbine System}

The object was to achieve 40\% electrical efficiency (LHV at ISO day) from an AMS that consisted of two Capstone C200 microturbines integrated with a water-cooled condenser ORC bottoming system. Two C200 Beta units (identified as unit \#3 or \#4) were received in late 2004 while UTRC provided the ORC.

\subsection{System Integration, Installation, and Instrumentation}

A test site at the UTRC CHP Laboratory was prepared for the integrated AMS system. Two C200 engines were mounted on an external concrete pad, with the manifolded exhaust ducted to the evaporator mounted on the CHP Laboratory roof. The top, left image of Figure 3.1.1 depicts the pad and the junction box for the C200 electrical power. The bottom, left image shows the evaporator. The right side of the figure shows the turbine, ORC recuperator, refrigerant pump and pump inverter mounted on the condenser inside the CHP Laboratory. The system was instrumented according to the PID of Figure 3.1.2. The ORC was instrumented exhaustively to calculate the turbine aerodynamic efficiency, condenser performance, evaporator performance, pump performance and recuperator performance. This figure shows that the ORC evaporator exhaust was coupled to a blower on the down-stream side. The blower was turned on or off or its speed was adjusted to set various levels of system backpressure. The entire exhaust assembly, including the evaporator, was insulated to minimize heat loss.

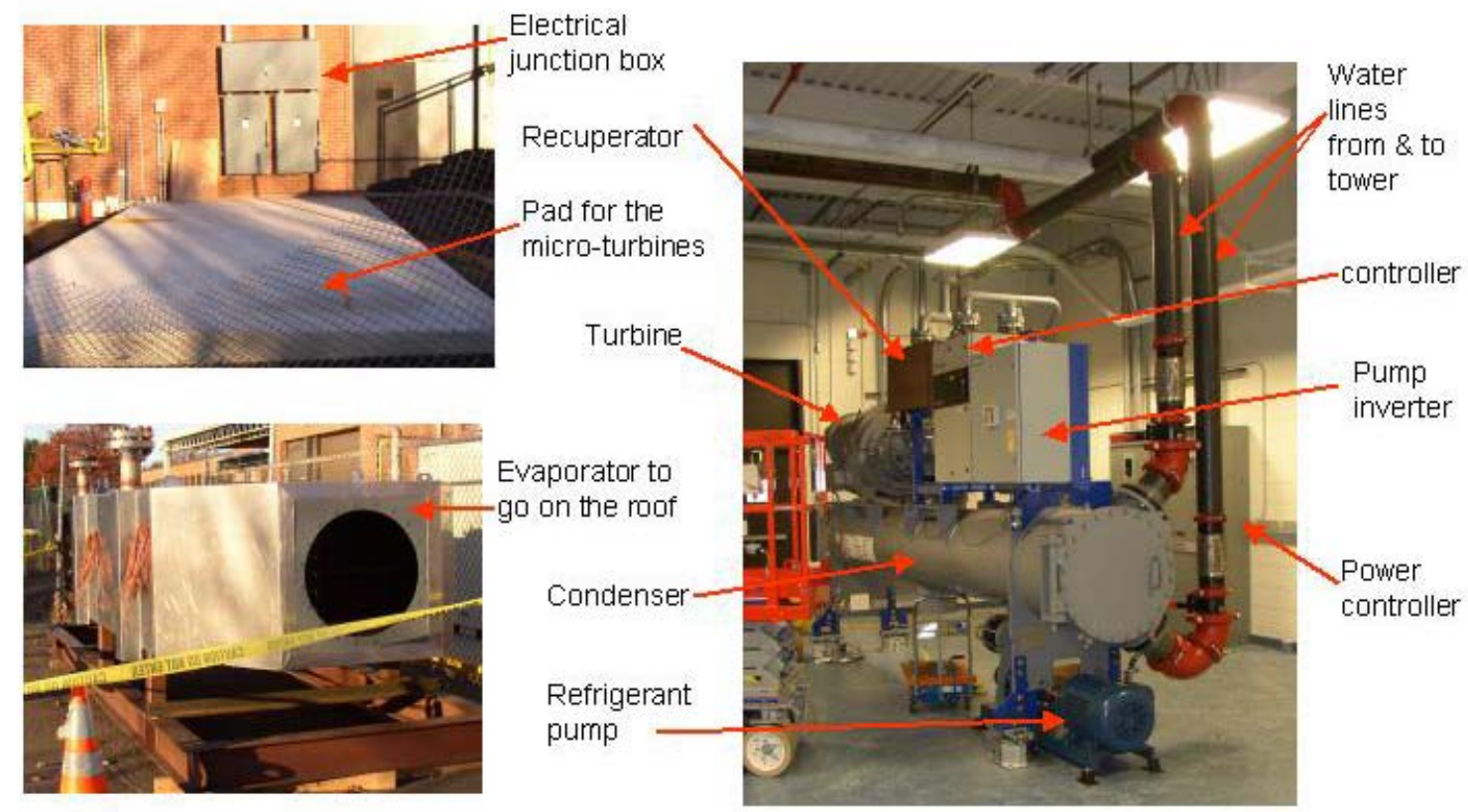

Figure 3.1.1 Installation and integration of C200/ORC AMS 


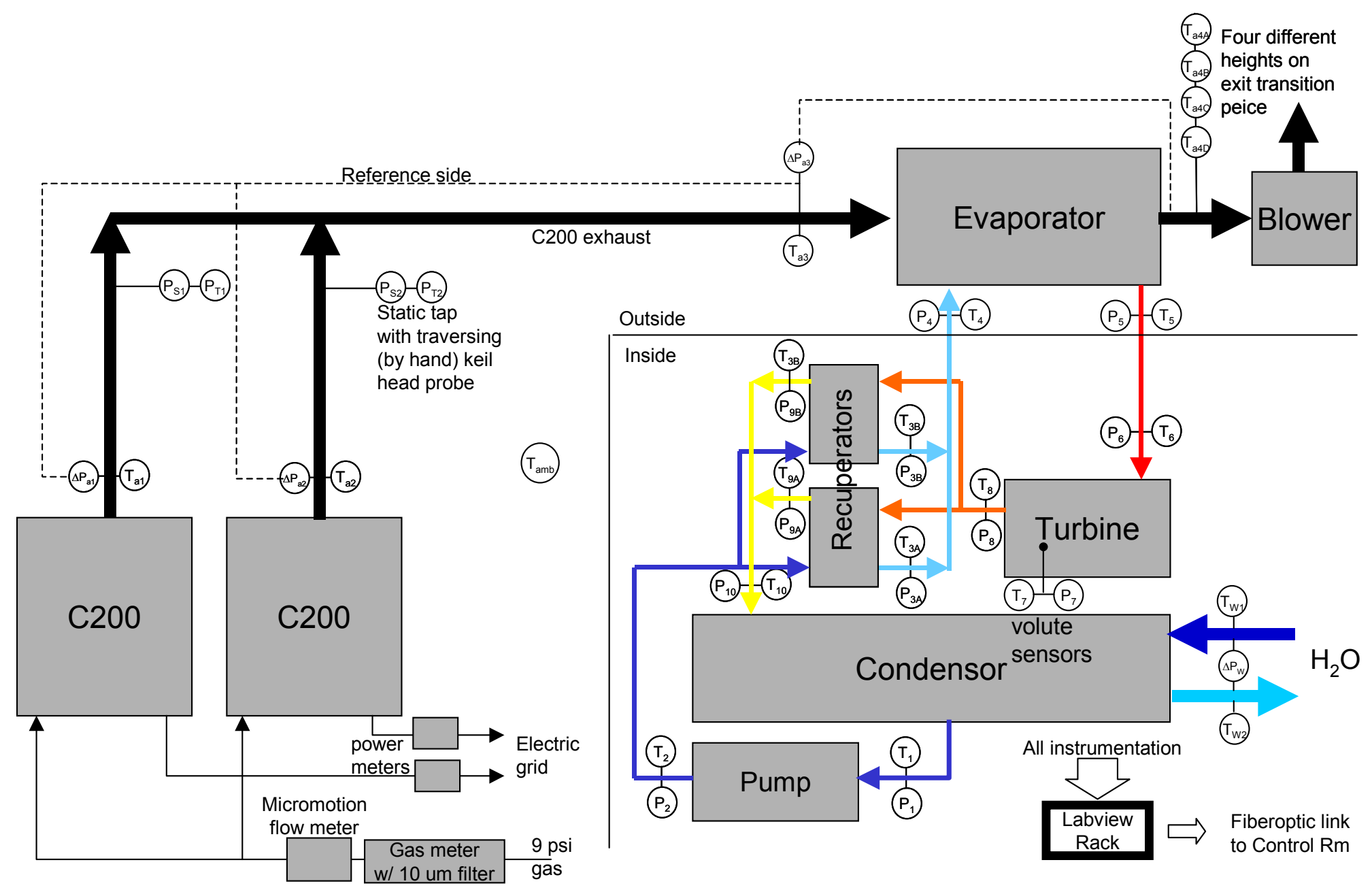

Figure 3.1.2 Instrumentation for integrated C200/ORC AMS 
Data were acquired to characterrize each microturbine and the ORC components. It became apparent that characterizing the C200 electrical power, exhaust energy, and energy losses from the C200 cabinet was important. Individual electrical power meters were used for each microturbine, and the exhaust energy was determined from individual measurements of temperature and flow at the locations shown in Figure 3.1.3. Also indicated are the two roof vents on each microturbine enclosure. Internal blowers draw outside air through the electronic or engine compartments and discharge it through the respective vent. Energy loss through the vents was calculated from integrating temperature and velocity measurements made over the vent exit area.

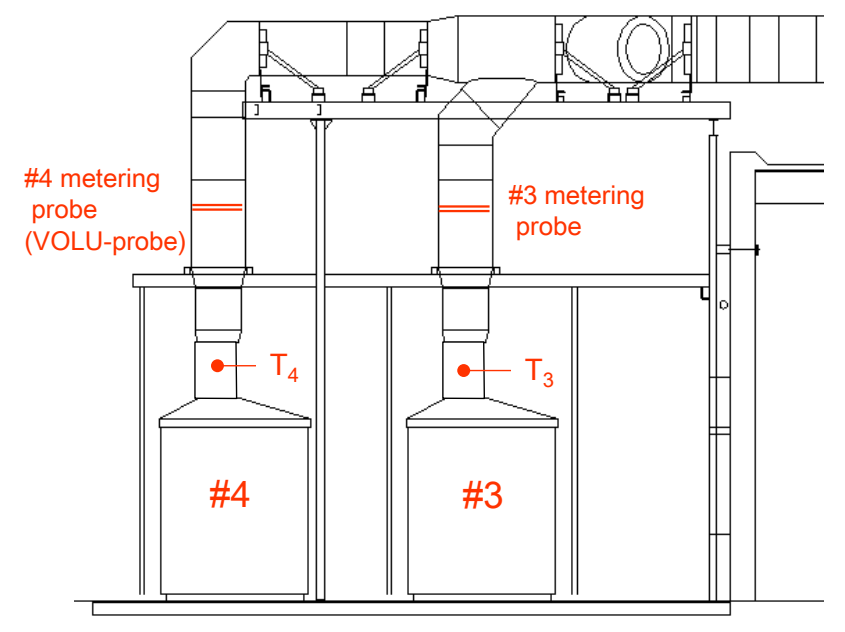

\section{Auxilary cooling vents}

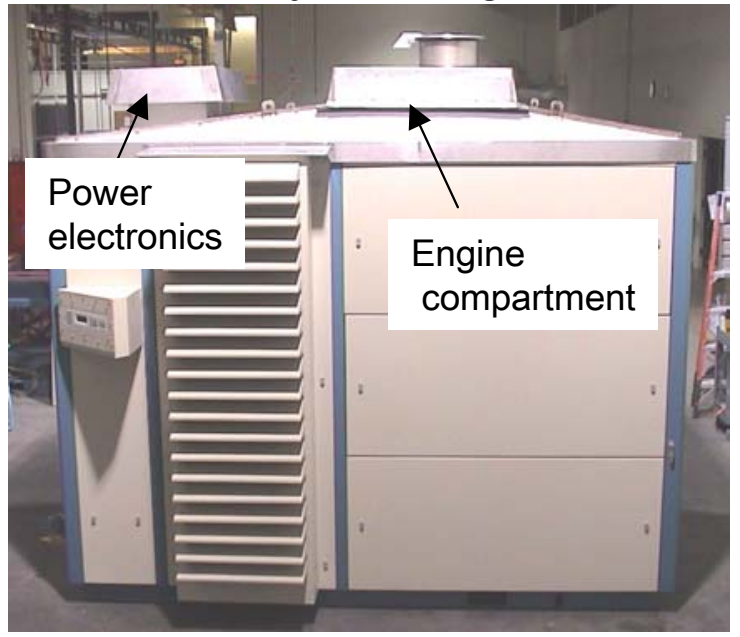

Figure 3.1.3 Microturbine measurements for exhaust and lost energy

\subsection{C200 Performance}

Figure 3.2.1 plots C200 electrical efficiency data for a modest range of ambient temperature and backpressure. Both plots include the predictions of the same according to Capstone's Design Review document. In the first plot, the data show that the turbine efficiency is $33 \%$ at about $37 \mathrm{~F}$ ambient temperature without backpressure. This is very consistent with prediction. Efficiency levels with backpressure were reduced by $1 / 2 \%$.

The second plot recasts the same data according to backpressure. The 4 to 5 in $\mathrm{H} 2 \mathrm{O}$ positive backpressure variation was achieved by varying the blower speed. The prediction for loss of efficiency with backpressure is extremely accurate. 

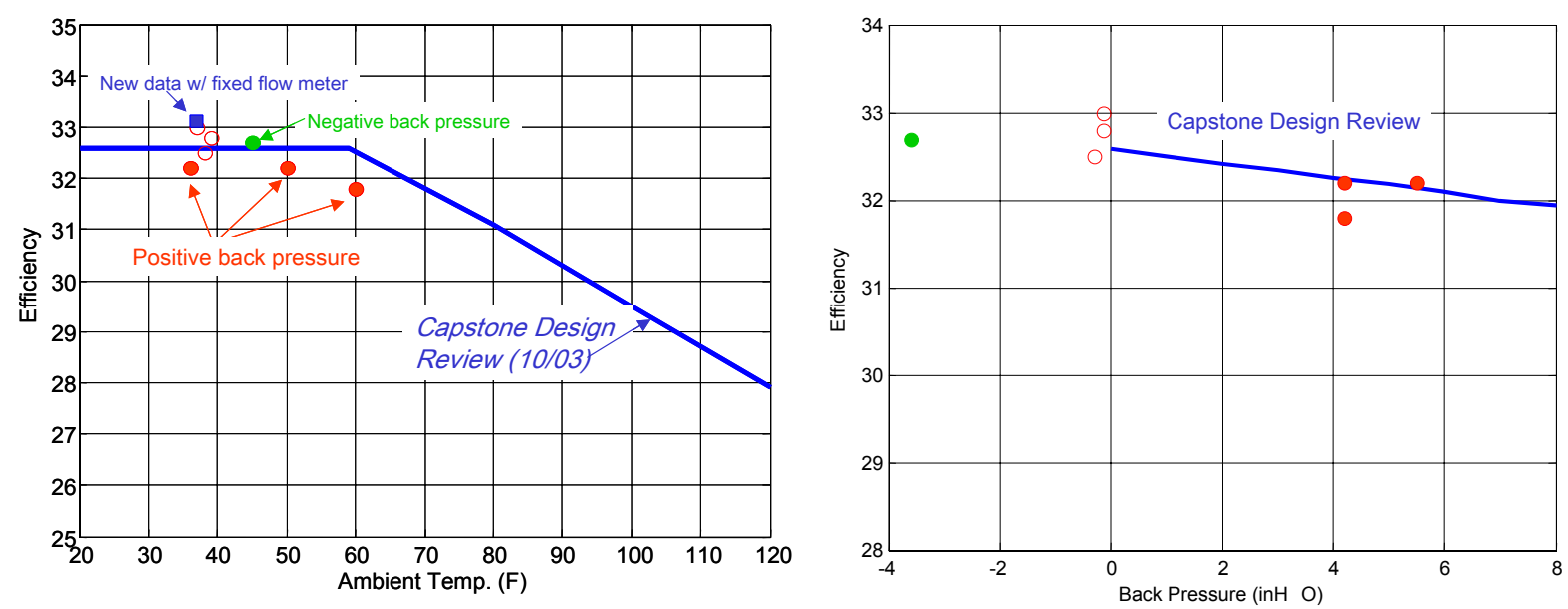

Figure 3.2.1 C200 electrical efficiency

Although the efficiency of the C200 was accurately predicted, the parasitic losses were grossly underestimated, resulting in an over-prediction of the available exhaust energy. As stated above, the turbine enclosure has two major chambers that require adequate ventilation - the engine and the electronics. External air is sucked through the louvers and circulated through these chambers and blown out through the cooling vents. Measurements were conducted on two different days to survey the amount of heat rejected through these vents. A systematic grid was laid out defining a control surface. At each grid point, the temperature and the air velocity was measured and the heat flux through the control surface was then calculated. These surveys indicated that $52 \mathrm{~kW}$ of energy was lost from microturbine \# 4 and $57 \mathrm{~kW}$ was lost from microturbine \#3 for a total loss of $109 \mathrm{~kW}$. Table 3.2.1 and Table 3.2.2 below show sample data and the corresponding calculation used to determine the heat loss through the cooling vents. In addition thermal energy was lost through natural convection from the enclosure surfaces. The surface temperature was measured to estimate the lost heat by natural convection. It was determined that each unit lost $17 \mathrm{~kW}$ by this process. Therefore the total heat loss from both mechanisms was $143 \mathrm{~kW}$. 
Table 3.2.1 Energy losses from C200 \#4

$2 / 17 / 05$, Heat Leaving Auxilary Cooling Duct of C200 \#4 is $32 \mathrm{~kW}$

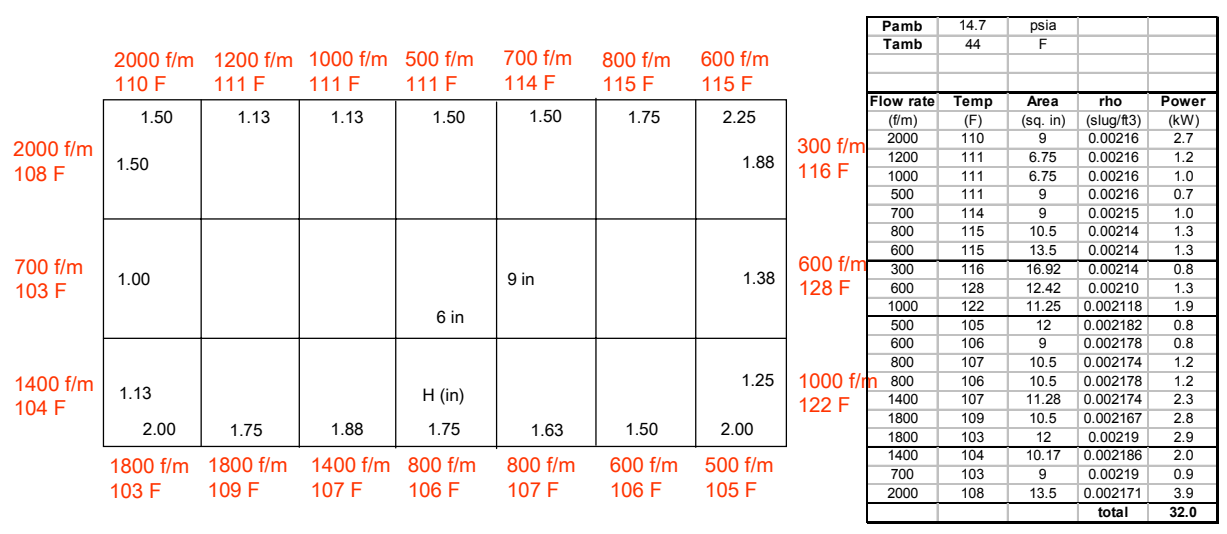

2/04/05: Electronics cooling duct of C200 \# is $20 \mathrm{~kW}$

Table 3.2.2 Energy losses from $\mathrm{C200} \# 3$

2/17/05: Heat Leaving Auxilary Cooling Duct C200 \#3 is $31 \mathrm{~kW}$

\begin{tabular}{|c|c|c|c|c|c|c|c|c|}
\hline & $\begin{array}{l}800 \mathrm{f} / \mathrm{m} \\
113 \mathrm{~F}\end{array}$ & $\begin{array}{l}700 \mathrm{f} / \mathrm{m} \\
94 \mathrm{~F}\end{array}$ & $\begin{array}{l}700 \mathrm{f} / \mathrm{m} \\
100 \mathrm{~F}\end{array}$ & $\begin{array}{l}500 \mathrm{f} / \mathrm{m} \\
116 \mathrm{~F} \\
\end{array}$ & $\begin{array}{l}600 \mathrm{f} / \mathrm{m} \\
118 \mathrm{~F} \\
\end{array}$ & $\begin{array}{l}700 \mathrm{f} / \mathrm{m} \\
119 \mathrm{~F}\end{array}$ & $\begin{array}{l}700 \mathrm{f} / \mathrm{m} \\
118 \mathrm{~F}\end{array}$ & \\
\hline $\begin{array}{l}800 \mathrm{f} / \mathrm{m} \\
121 \mathrm{~F}\end{array}$ & $\begin{array}{r}2.00 \\
1.50\end{array}$ & 1.88 & 1.75 & 1.63 & 1.38 & 1.38 & $\begin{array}{l}1.50 \\
1.50\end{array}$ & $\begin{array}{l}1000 \mathrm{f} / \mathrm{m} \\
137 \mathrm{~F}\end{array}$ \\
\hline $\begin{array}{l}200 \mathrm{f} / \mathrm{m} \\
105 \mathrm{~F}\end{array}$ & 1.00 & & & 6 in & 9 in & & 1.63 & $\begin{array}{l}400 \mathrm{f} / \mathrm{m} \\
147 \mathrm{~F}\end{array}$ \\
\hline $\begin{array}{l}300 \mathrm{f} / \mathrm{m} \\
115 \mathrm{~F}\end{array}$ & $\begin{array}{l}1.13 \\
2.00\end{array}$ & 1.63 & 1.63 & $\begin{array}{c}H \text { (in) } \\
1.75\end{array}$ & 2.25 & 2.25 & $\begin{array}{r}1.75 \\
2.25\end{array}$ & $\begin{array}{l}300 \mathrm{f} / \mathrm{m} \\
136 \mathrm{~F}\end{array}$ \\
\hline & $\begin{array}{l}1700 \mathrm{f} / \mathrm{m} \\
122 \mathrm{~F}\end{array}$ & $\begin{array}{l}1700 \mathrm{f} / \mathrm{m} \\
126 \mathrm{~F}\end{array}$ & $\begin{array}{l}1500 \mathrm{f} / \mathrm{n} \\
127 \mathrm{~F}\end{array}$ & $\begin{array}{l}1600 \mathrm{f} / \mathrm{n} \\
125 \mathrm{~F}\end{array}$ & $\begin{array}{l}700 \mathrm{f} / \mathrm{m} \\
126 \mathrm{~F}\end{array}$ & $\begin{array}{l}600 \mathrm{f} / \mathrm{m} \\
128 \mathrm{~F}\end{array}$ & $\begin{array}{l}500 \mathrm{f} / \mathrm{m} \\
128 \mathrm{~F}\end{array}$ & \\
\hline
\end{tabular}

\begin{tabular}{|c|c|c|c|c|}
\hline Pamb & 14.7 & psia & & \\
\hline Tamb & 37 & F & & \\
\hline & & & & \\
\hline Flow rate & Temp & Area & rho & Power \\
\hline (f/m) & (F) & (sq. in) & $\begin{array}{c}\text { (slug/ft3) } \\
\text { (kW) }\end{array}$ \\
\hline 800 & 113 & 12.0 & 0.00215 & 1.5 \\
\hline 700 & 94 & 11.3 & 0.00223 & 0.9 \\
\hline 700 & 100 & 10.5 & 0.00220 & 1.0 \\
\hline 500 & 116 & 9.8 & 0.00214 & 0.8 \\
\hline 600 & 118 & 9.8 & 0.00213 & 1.0 \\
\hline 700 & 119 & 8.3 & 0.00213 & 1.0 \\
\hline 700 & 118 & 9.0 & 0.00213 & 1.0 \\
\hline 1000 & 137 & 13.5 & 0.00207 & 2.6 \\
\hline 400 & 147 & 14.7 & 0.00203 & 1.2 \\
\hline 300 & 130 & 15.8 & 0.00209 & 0.9 \\
\hline 1700 & 122 & 12.0 & 0.00212 & 3.5 \\
\hline 1700 & 126 & 9.8 & 0.00210 & 2.9 \\
\hline 1500 & 127 & 9.8 & 0.00210 & 2.6 \\
\hline 1600 & 125 & 10.5 & 0.00211 & 2.9 \\
\hline 700 & 126 & 13.5 & 0.00210 & 1.7 \\
\hline 600 & 128 & 13.5 & 0.00210 & 1.5 \\
\hline 500 & 128 & 13.5 & 0.00210 & 1.2 \\
\hline 300 & 115 & 10.2 & 0.00214 & 0.5 \\
\hline 200 & 105 & 9.0 & 0.00218 & 0.3 \\
\hline 800 & 121 & 13.5 & 0.00212 & 1.8 \\
\hline & & & total & 30.7 \\
\hline & & & & \\
\hline
\end{tabular}

2/04/05: Electronics cooling duct C200 \#3 is $26 \mathrm{~kW}$ 
Figure 3.2.2 shows the measured temperature and flowrate of the C200 exhaust energy. The measured C200 exhaust temperature was at least 35F below expectation from the Capstone Design Review predictions. The exhaust flow rate was also lower than predicted by $6 \%$.
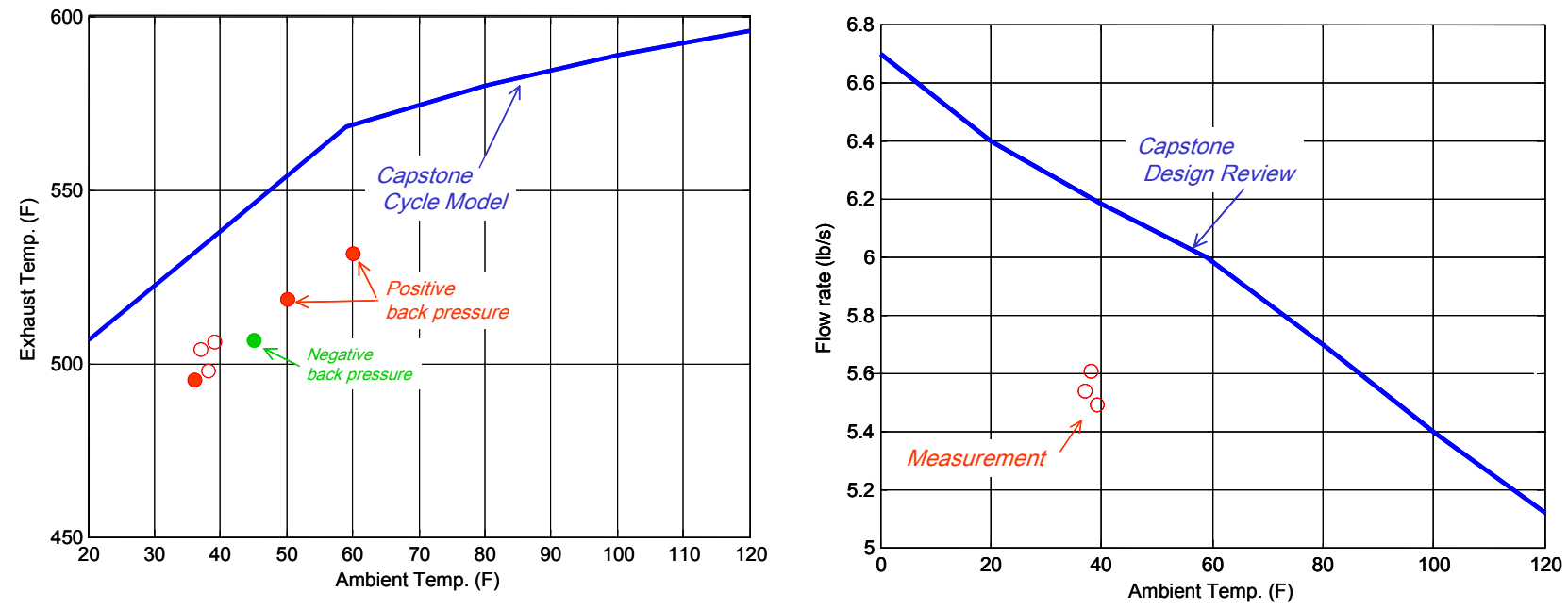

Figure 3.2.2 Measured C200 exhaust characteristics

As a result of all of these deficiencies, the total heat delivered to the ORC evaporator was approximately $150 \mathrm{~kW}$ lower than expected based on predictions of exhaust properties. This deficient was consistent with the energy losses described above, providing a very reasonable energy balance of the input fuel energy.

\subsection{ORC System Performance}

Figure 3.3.1 is a design point calculation summary of the ORC system. In this case, it was assumed that the exhaust temperature of the Capstone 200, or the input temperature of the hot gas to the evaporator of the $\mathrm{ORC}$, would be $568 \mathrm{~F}$ and that the gas flow of the same stream would be $6 \mathrm{lbm} / \mathrm{s}$, values consistent with the C200 predictions. 


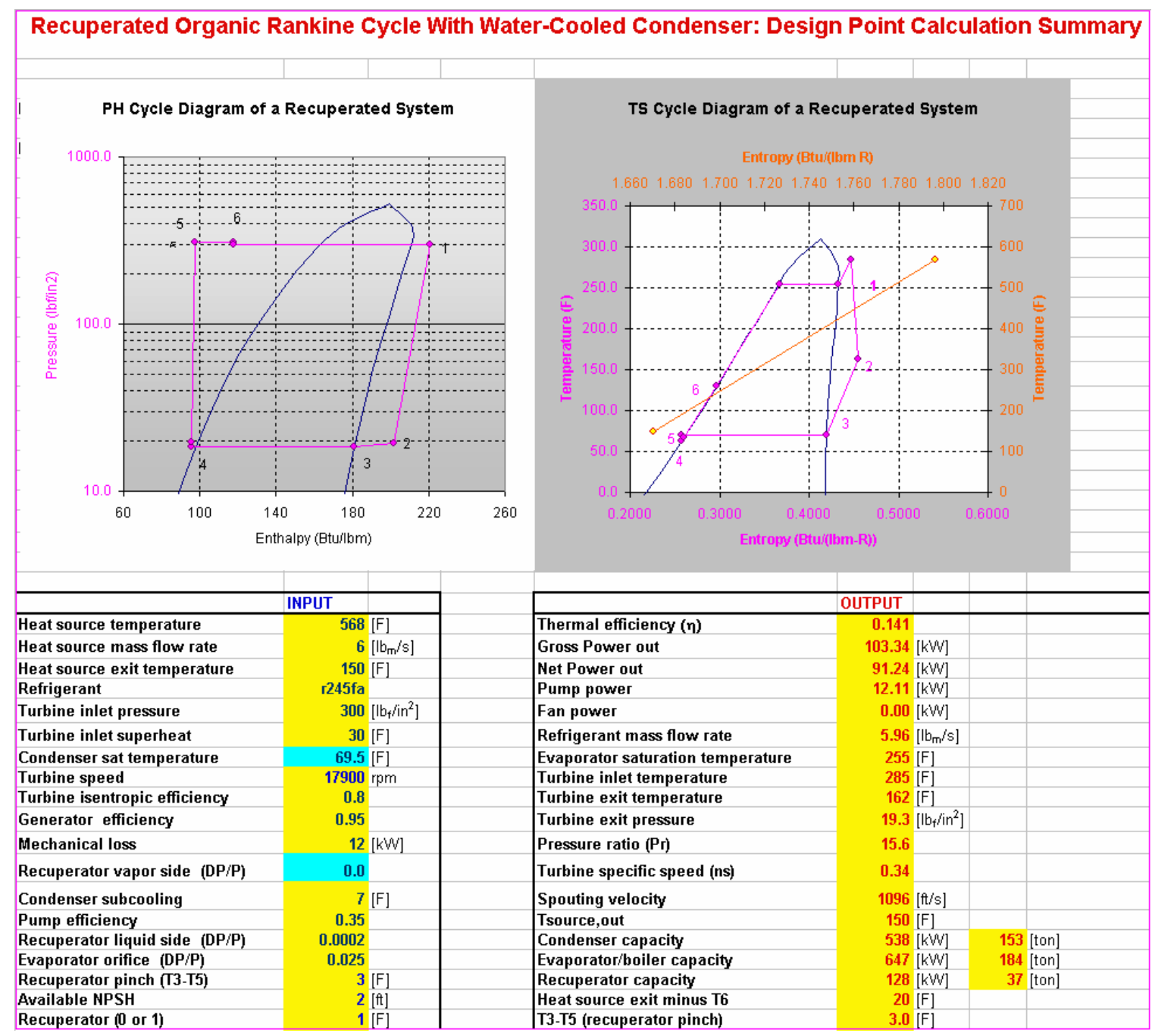

\section{Figure 3.3.1 Predicted ORC design point performance}

The output section of the model shows all the predictions. The net power calculated here had allowances for additional mechanical losses in the drive system when we increase the speed for the high pressure-ratio application. It was estimated that the turbine inlet pressure would be $300 \mathrm{lbf} / \mathrm{in} 2$ and the condensing temperature would be $69.5 \mathrm{~F}$, consuming $647 \mathrm{~kW}$ (184 ton) of the heat in the exhaust flue and reject $538 \mathrm{~kW}$ (153 ton) of the heat to the condenser. The gross generated power is $103 \mathrm{~kW}$.

Figure 3.3.2 below shows ORC system data when driven by the C200 exhaust. The gross electrical output was $72 \mathrm{~kW}$ that is debited by the refrigerant pump power of $8.5 \mathrm{~kW}$, yielding a net power of $63.5 \mathrm{~kW}$. This power was generated with turbine inlet pressure of $212 \mathrm{lbf} / \mathrm{in} 2$, much lower than the $300 \mathrm{lbf} / \mathrm{in} 2$ predicted by the above model because of the reduced C200 available exhaust energy. 


\section{Ambient_T, Condensing_T, Pump Power \& Gross \\ Power}

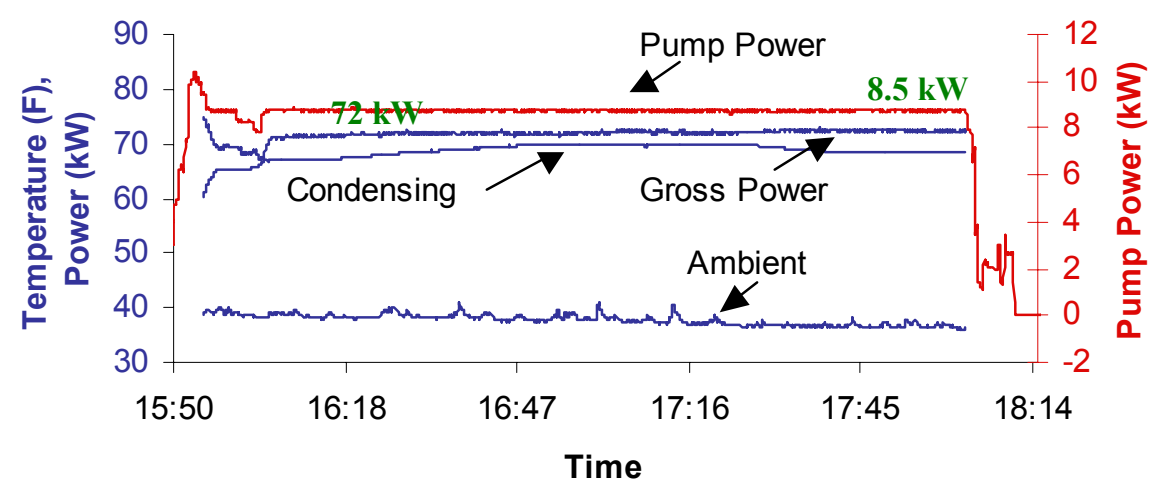

\section{Ambient_T, Condensing_T, Turbine Pressure \& Gross Power}

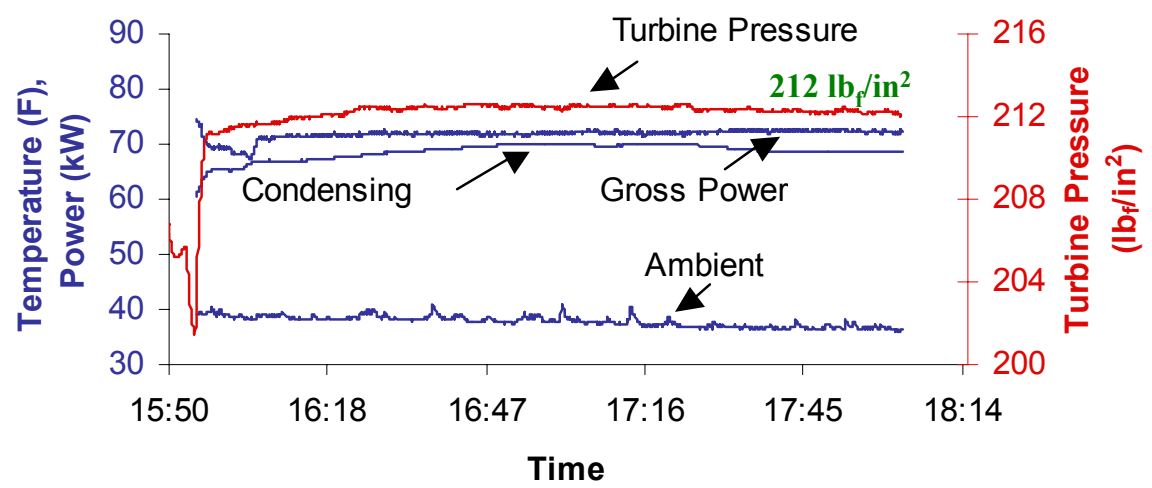

\section{Figure 3.3.2 Measured ORC system performance with C200 exhaust}

\subsubsection{ORC Component Performance}

Analyses were performed to determine whether each ORC component performed as predicted. Figure 3.3.3 and the following figures are aimed at answering just that question. The first curve of Figure 3.3.3 was a measure of ORC aerodynamic efficiency when the turbine was run in steady state. It shows an efficiency of $80 \%$ at pressure ratio of 15.6 matching the prediction very well.

It was also desired to determine whether full predicted power would have been generated if the design point exhaust energy was delivered to the evaporator. In order to answer 
this question, the ORC system was operated in a quasi-transient manner. The process involved deliberately starving the evaporator refrigerant in order to get the evaporator metal hotter. The refrigerant pump speed was initially reduced and then suddenly increased to full speed. By this method, the design point of a $300 \mathrm{lbf} / \mathrm{in} 2$ turbine inlet pressure was achieved for a quasi-steady period.

Steady-state Power \& Efficiency

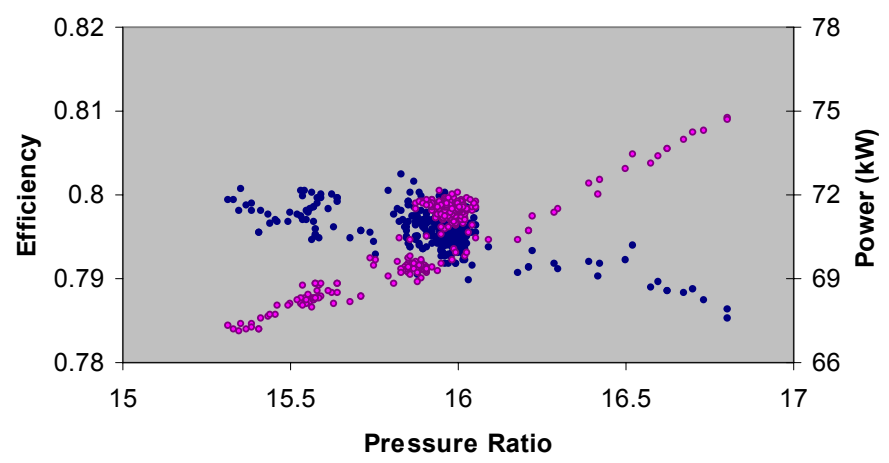

Inlet Pressure and Turbine Power

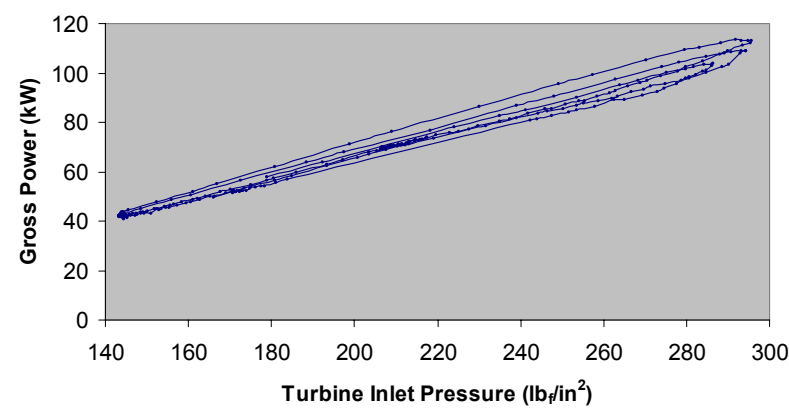

Figure 3.3.3 ORC performance characteristics (a) Steady (b) Quasi-steady

Figure $3.3 .3 \mathrm{~b}$ is the result of such measurement. The multiple curves show repeated quasi-steady periods of operation. Importantly, the ORC gross generated power was repeatedly measured as $110 \mathrm{~kW}$ for the $300 \mathrm{lbf} / \mathrm{in} 2$ inlet pressure condition. This value validated that the turbine design point performance was achieved.

Figure 3.3.4 is a plot of condenser heat rejection and the temperature difference between the leaving water temperature and the condenser saturation temperature. A small difference is a measure of good condenser performance and absence of non-condensibles in the condenser. Although the load 122 ton is $80 \%$ of the 153 ton design, the $2.2 \mathrm{~F}$ difference is in line with the predicted $3 \mathrm{~F}$ at the full load of $153 \mathrm{~F}$.

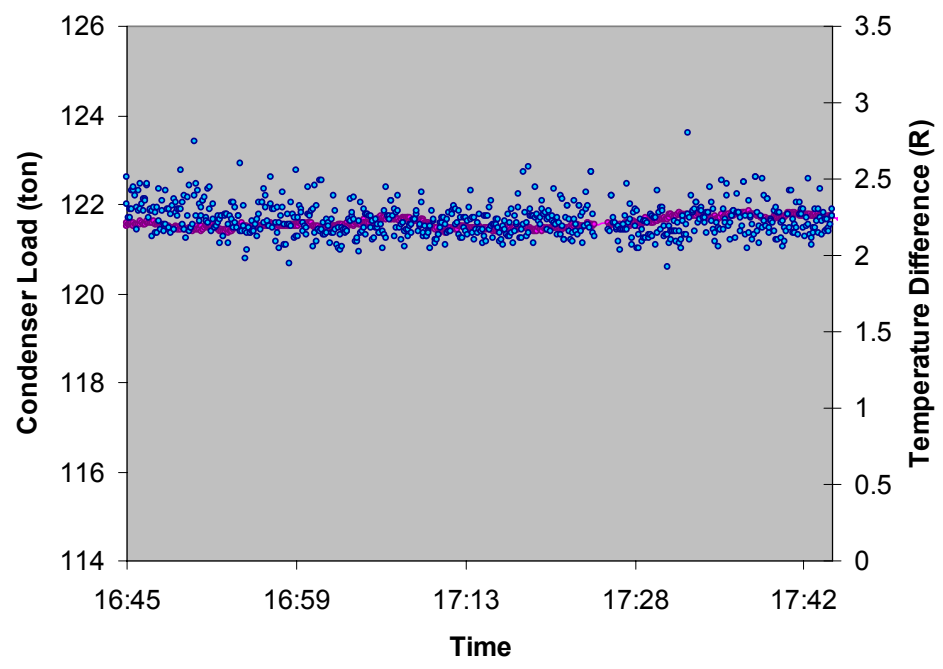




\section{Figure 3.2.4 ORC condenser performance}

The refrigerant pump performed according to the performance map, which was supplied by the manufacturer. The criterion for selecting the recuperator was to minimize gas side pressure drop. It was therefore over sized in terms of heat transfer by a factor of 2 . Figure 3.2.5 shows that this minimal pressure drop was achieved.

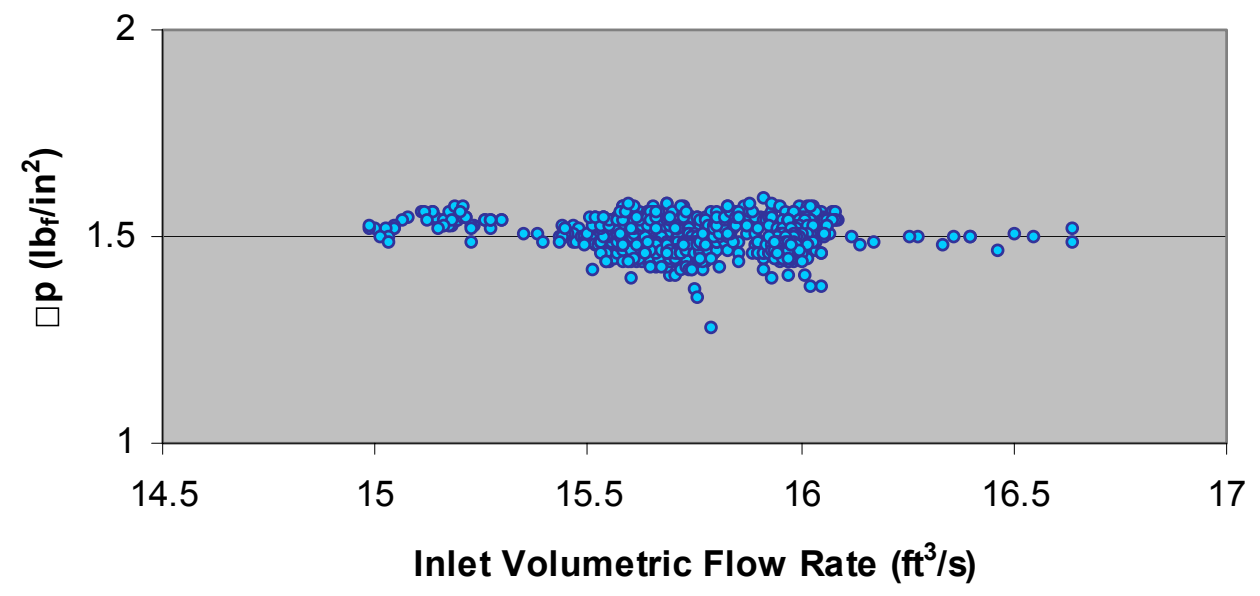

Figure 3.2.5 ORC recuperator pressure drop

Calculations were also was made using our model to predict the performance of the evaporator for the inlet condition of actual measured C200 exhaust temperature and gas flow rate. The evaporator exit temperature and total heat transfer predictions track with the actual measured values as shown in Figure 3.2.6.

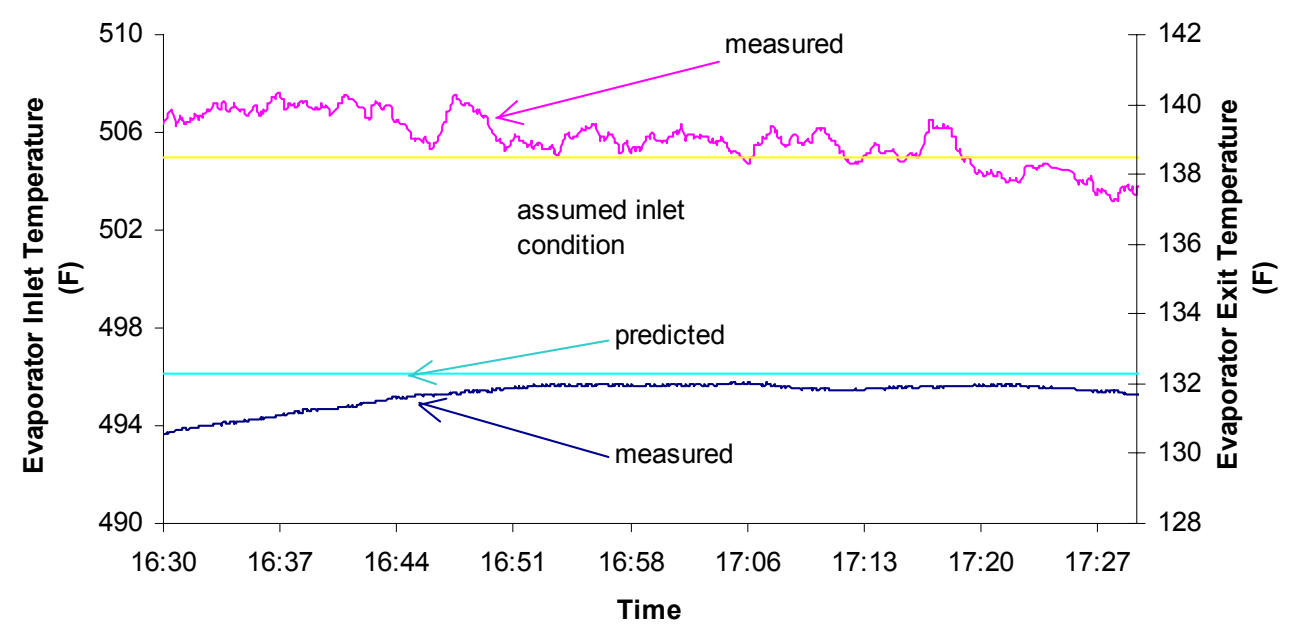

Figure 3.2.6 ORC evaporator performance 


\subsection{Integrated Advanced Microturbine System Performance}

The results of analyses of data from the C200/ORC integrated system tests are shown in Table 3.3.1.

Table 3.3.1 Performance of C200/ORC Advanced Microturbine System

\begin{tabular}{|l|c|r|r|}
\hline \multirow{2}{*}{ Parameter } & \multicolumn{2}{c|}{ Integrated System } \\
\cline { 3 - 4 } \multicolumn{2}{|c|}{} & \multicolumn{1}{c|}{ Spec } & \multicolumn{1}{c|}{ Meas } \\
\hline Ambient Temperature & $\mathrm{F}$ & 34 & 34 \\
\hline C200 Beta Backpressure & ${\mathrm{in} \mathrm{H}_{2} \mathrm{O}}^{2}$ & 4 & 4 \\
\hline C200 Beta Power & $\mathrm{kW}$ & 400 & 400 \\
\hline C200 Beta Electrical & $\%$ & 32.3 & 32.8 \\
\hline ORC Power & $\mathrm{kW}$ & 82.0 & 64.6 \\
\hline System Efficiency & $\%$ & 38.9 & 38.0 \\
\hline
\end{tabular}

The measured C200, ORC, and system data indicated that:

- With no backpressure, each C200 unit achieved an electrical efficiency of $33 \%$. With the slight backpressure of the integrated system, the C200 electrical efficiency was reduced only to $32.8 \%$.

- The ORC system and component performance matched or slightly exceed pre-test predictions enabling it to achieve a system electrical efficiency of $13 \%$.

- The integrated system produced $400 \mathrm{~kW}$ from the two C200 units and an additional $64.6 \mathrm{~kW}$ from the ORC to achieve a system efficiency of $38.0 \%$ at a $34 \mathrm{~F}$ ambient day.

- The integrated system produced less than the pre-test predicted efficiency of $38.9 \%$ because unplanned C200 cabinet cooling reduced the exhaust energy available to the ORC by $\sim 12 \%$ of the fuel energy. 


\section{Section 4.0 Ceramic Turbine Technology Development}

Task 6 - Ceramic Turbine Technology

The benefits of ceramic turbines have been discussed in sections 1 and 2. Critical risk reduction on ceramic turbine technologies was added as Task 6 to the AMS contract in 2005. The aim was to enable the implementation of uncooled EBC-coated ceramic turbine components capable of $2100 \mathrm{~F}$ T4 operation within integrated CHP systems in order to maximize fuel utilization and energy cost savings, improving electrical efficiency by 5 points, increasing power by $50 \%$, and reducing the effective cost of electricity $(\$ / \mathrm{kW})$ by $15 \%$. The critical risk reduction for ceramic component design in preparation for feasibility demonstration of ceramic turbine components in a C60 was planned but could not be completed because of strategic differences with Capstone. UTRC focused its activities on EBC design, composition and process development and scale-up.

\subsection{Ceramic Component Design.}

Current design practice for silicon nitride ceramic components involves manual transfer between various codes and only allows for the uncertainty in the strength of the silicon nitride material. An effort was initiated to enhance the current design methodology, focusing on the integration of the FEA code (ANSYS) and the ceramic reliability code (CARES) with an advanced probabilistic code (UNIPASS) to provide for the ability to incorporate additional uncertainties in the design process and to more fully automate the entire process and remove sources of error associated with manual transfer of results between the ANSYS and CARES codes. Integration with UNIPASS allows for the effects of additional uncertainties such as dimensional variation and heat transfer coefficients to be factored into the overall component reliability. The capability of this enhanced approach was demonstrated using a simple component geometry representative of a turbine shroud. It was demonstrated that the enhanced capability reduced the time required to reach an optimized survival probability and also showed the sensitivity of the design reliability to uncertainties other than material strength (e.g. dimensional variation stemming from manufacturing tolerances, heat transfer coefficient used in thermal analysis). Future work will consider integration with the CAD model to allow for automated design revisions for optimized reliability as well as demonstrations on more complex turbine component geometries. This enhanced design methodology should reduce the time required for design of ceramic components while at the same time providing a more accurate prediction of reliability. A paper that has been accepted for publication at the IGTI-ASME Turboexpo 2007 is included in the appendix (GT200727935). This paper describes the methodology developed in much greater detail.

\subsection{Development of Environmental Barrier Coatings for Silicon Nitride}

The poor steam stability of Si-based ceramics has been well documented in recent literature and the development of environmental barrier coatings are key to ensuring the 
utility of ceramic components for long term microturbine applications (discussed in section 2). The three layer BSAS-based EBC, developed in earlier NASA and CSGT programs, was found to be unsuitable for application to monolithic silicon nitride because it reduced the strength of the substrate by $50 \%$. The reduction in the strength of the ceramic substrate caused by the CTE mismatch between the coating and substrate was not acceptable and it was clear that a new coating system was needed for $\mathrm{Si}_{3} \mathrm{~N}_{4}$ components. This was reported in an earlier DOE/ONR EBC for Silicon Nitride contract report. Coatings tailored specifically for $\mathrm{Si}_{3} \mathrm{~N}_{4}$ that would preserve the baseline strength of the underlying substrate were initiated under the DOE/ONR funded Enabling Technologies Program and continued under the DOE AMS program. Two papers that describe the details of the substrate strength reduction and coating development that helps overcome the problem are included in the appendix (GT $2004-54092$ and GT 200727685). The manuscripts were prepared and presented at IGTI meetings during the course of the AMS contract.

\subsubsection{Emphasis on non-line-of-sight coatings}

In the initial phase of the coating development, the complexity and small size of the monolithic silicon nitride components that needed to be coated were considered. The integral vane rings and IBRs for the ST5+ are described in Section 2. Most of the prior experience in EBC development consisted of plasma sprayed coatings and it appeared that existing thermal spray technologies might not be suitable to coat the components of interest. A feasibility study was performed to determine if an air plasma spray technique can be used to coat complex shaped engine components such as an integral vane ring. The study was based on a simple analytical approach that considered the ability of a plasma gun to coat "hidden" areas (vanes and platforms) by calculating the angle at which the spray gun approached the component using the ST5+ vane ring design developed under this contract. The quality of the coating as a function of gun angle was independently assessed by thermal spraying a cylinder. The other factors that weighed in on the final feasibility assessment included fixtures, cost, coating uniformity and existing mini-gun technologies. It was established that air plasma spray could not be used to apply environmental barrier coatings (EBCs) of acceptable quality to an integral vane ring assembly. Figure 4.2.1 is a pictorial representation of the approach used to assess the relative "accessibility" of the plasma plume to the component. Subsequent coating development for silicon nitride focused on non-line of sight coating methods, such as electrophoretic deposition, chemical vapor deposition (CVD), sol-gel, slurry coating, and pack cementation. The processing routes found most promising were slurry coatings and CVD.

EBC development for silicon nitride consisted of work in four primary areas: (i) Bond coat composition and process development, (ii) Top coat composition and process development, (iii) Scale up, and (iv) Testing. Each of these areas is covered in more detail in the subsequent sections. 


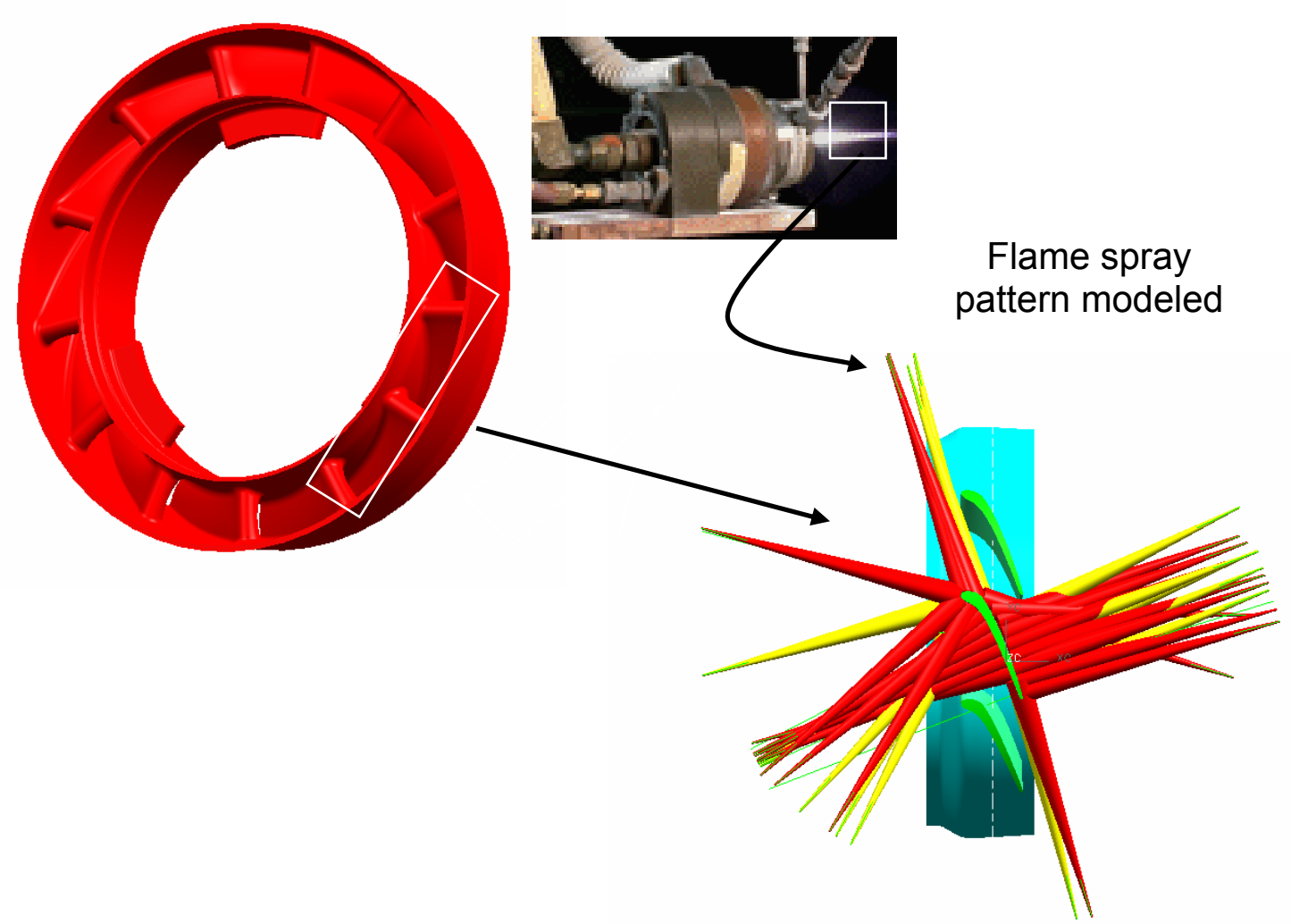

Figure 4.2.1 Study of the feasibility of thermal spraying an integral vane ring.

\subsubsection{Bond coat composition and process development}

Numerical modeling was used to understand the mechanism that causes the reduction in substrate strength when a silicon bond coat is used on monolithic silicon nitride. When a thin layer of silicon is deposited on a silicon nitride substrate and the system is cooled from a stress-free temperature of $1000^{\circ} \mathrm{C}\left(1832^{\circ} \mathrm{F}\right)$, the in-plane tensile residual stress in silicon is given by the following equation:

$$
\sigma=\mathrm{E} \Delta \alpha \Delta \mathrm{T} /(1-\mathrm{v})
$$

where $\mathrm{E}$ is the modulus of silicon, $\Delta \alpha$ is the difference in coefficient of thermal expansion (CTE) of silicon and silicon nitride, $\Delta \mathrm{T}$ is the temperature difference and $v$ is the Poisson's ratio. Equation 4.1 predicts that the in-plane residual stress is of the order of $26 \mathrm{ksi}(=179 \mathrm{MPa})$ which far exceeds the published values of tensile strength of silicon. The magnitude of tensile stress in silicon is fairly independent of thickness of silicon layer, and thickness and moduli of intermediate and top layers, as long as the thickness of coating layers is at least an order of magnitude lower than the substrate thickness (which is typically the case in most applications), as shown in Figure 4.2.2.

A variety of coating architectures were considered with an objective to drive down the residual stress in the silicon layer. Some of the architectures are shown in Figure 4.2.3. The thermophysical properties of the layers were varied and it was found that if the CTE 
of the materials was varied within $4 \mathrm{ppm} / \mathrm{C}$ of $\mathrm{Si}_{3} \mathrm{~N}_{4}$, the residual stress in the silicon layer did not decrease to levels much lower than 23-25 ksi $(158-172 \mathrm{MPa})$.

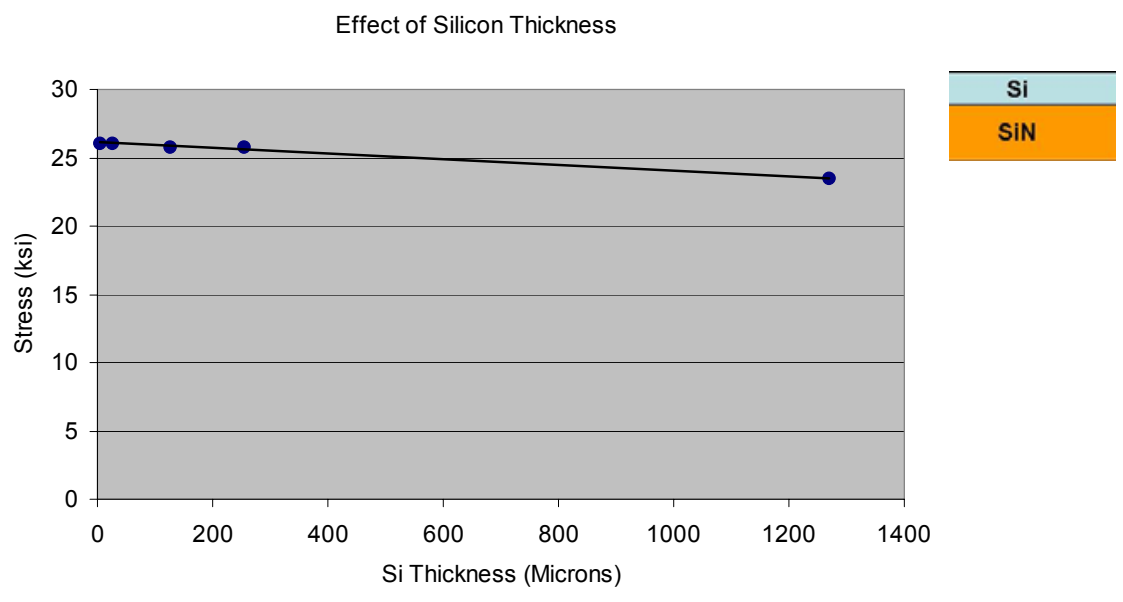

Figure 4.2.2: Calculation of residual stress in $\mathrm{Si}$ layer on monolithic $\mathrm{Si}_{3} \mathrm{~N}_{4}$. The stress in the coating is fairly independent of the coating thickness.
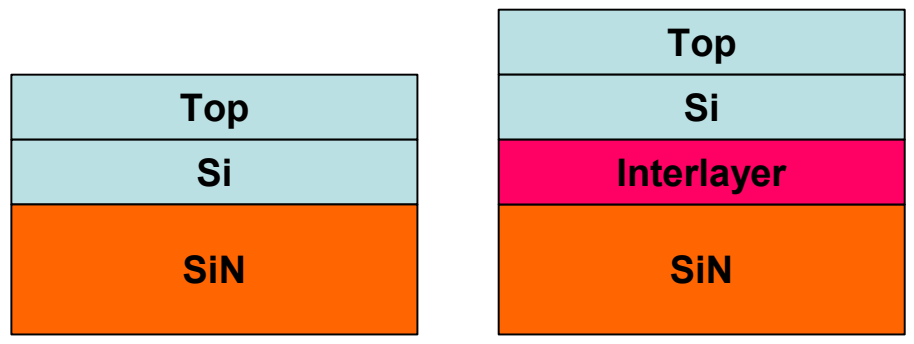

Figure 4.2.3: Various architectures considered to drive down residual stress in the Si-layer of the coating.

In addition to the stress analyses, micromechanical fracture modeling was also conducted to explain the effects of residual stress in the Si layer on flaw creation, propagation and interaction with pre-existing flaws in silicon nitride. An object oriented finite element analysis code developed at NIST, known as OOF, was used to investigate the response of the coated substrate to thermal loads. The program performs thermoelastic calculations in two dimensions (plane strain or plane stress) using 3-node triangular elements. Several "smart" meshing schemes based on energy minimization are available to mesh curved features, such as grain boundaries. A digital image of a microstructure, either from an optical/electron microscope or a result of a computer simulation, can be used for analysis. Based on this data, a finite element grid with associated material properties is generated on which mechanical and/or thermal loading can be applied. A solution is then obtained for the specified boundary conditions, distortion, and temperature change. The calculations were done assuming plane stress $\left(\sigma_{33}=0\right)$ and free boundary conditions to mimic unconstrained cooling of a thin plate from its sintering temperature. 
A typical coating microstructure (Figure 4.2.4) was imported into the OOF code, digitized for thermal analysis and then subjected to a temperature change of $1000^{\circ} \mathrm{C}$ $\left(1832^{\circ} \mathrm{F}\right)$. The calculated global stresses were similar to that obtained from equation 1 [Figure 4.2.2].

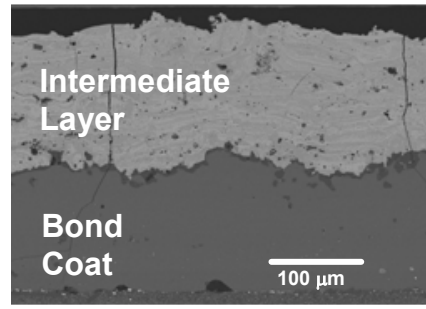

Typical EBC

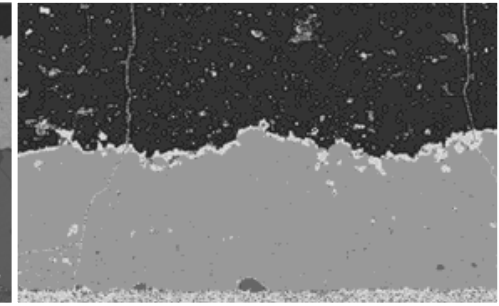

Digitized Microstructure

\section{Figure 4.2.4: $\mathrm{EBC}$ coating microstructure and digitized image for OOF analysis}

In addition to the calculation of the residual stresses, the elements in the OOF code are designed to fail under a Griffith-like strain energy based criterion. The elements crack when the required surface energy can be supplied by the stored strain energy per crack extension $(\Delta \mathrm{L})$, i.e.,

$$
\frac{1}{2} \sigma_{i j}^{\text {elem }} \varepsilon_{i j}^{\text {elem }} A_{\text {elem }} / \Delta L \geq 2 \gamma
$$

where $\gamma$ is the surface energy of the cracked interface.

The analysis involves the following steps:

a. Thermal and mechanical loads are applied and the microstructure is equilibrated to determine stress/strain distribution.

b. The energy balance is computed and if an element satisfies the energy criterion for cracking, the stiffness of the element is set to zero.

c. The microstructure is re-equilibrated and the stress distribution is re-calculated.

d. The procedure is repeated until no more elements mutate or one or more cracks become unstable, causing fracture into two or more fragments.

A parametric study was undertaken to develop an understanding of the effects of material properties on residual stresses and crack initiation and propagation using simple geometries. The simulation results indicated that crack propagation and arrest were strongly dependent on relative surface energies and residual stresses. Further, it was found that incorporating a low modulus interlayer between $\mathrm{Si}_{3} \mathrm{~N}_{4}$ and silicon could help in isolating the flaws in the coating from the pre-existing flaws in $\mathrm{Si}_{3} \mathrm{~N}_{4}$.

As predicted by the OOF approach, it was observed that a low modulus oxide inter-layer between $\mathrm{Si}_{3} \mathrm{~N}_{4}$ and $\mathrm{Si}$ successfully solved the problem of substrate strength retention. The interlayer was applied using a dip coating process and the Si layer was applied by CVD. The interlayer coating was found to help retain the strength of $\mathrm{Si}_{3} \mathrm{~N}_{4}$ as is shown in 
Figure 4.2.5. The two bars in Figure 4.2.5(a) represent $35 \mu \mathrm{m}$ and $70 \mu \mathrm{m}$ thick silicon layers. The inter-layer approach has been used for Si thicknesses up to $100 \mu \mathrm{m}$ with successful retention of baseline strength. Figure $4.2 .5 \mathrm{~b}$ shows a typical microstructure of the bond coat system. A well adhered gas tight top layer is expected to provide the steam protection required in the gas turbine environment.

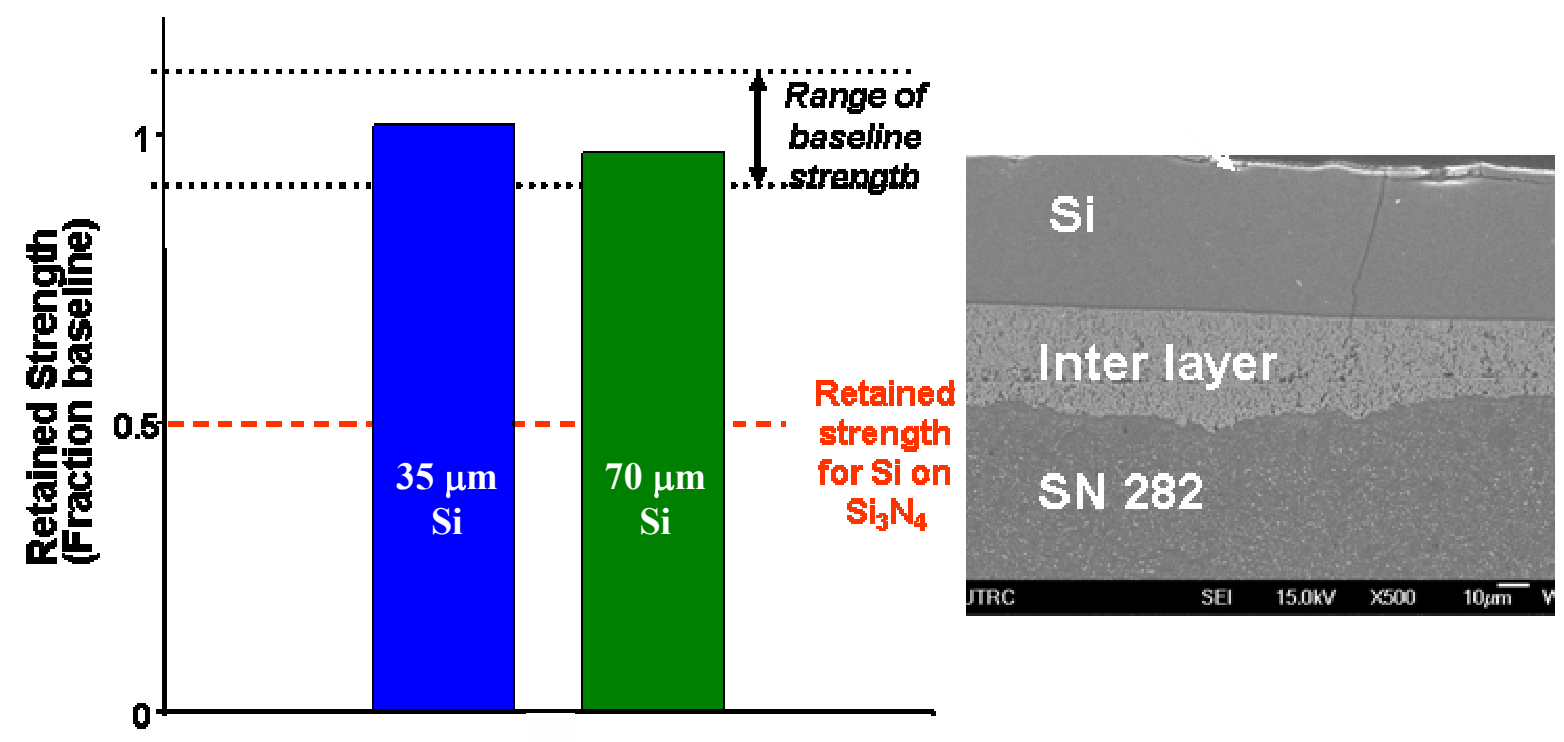

(a)

(b)

Figure 4.2.5: (a) Retained strength of silicon nitride using an oxide interlayer between silicon nitride and $\mathrm{Si}$ bond coat. (b) Microstructure of the bond coat system that retains baseline substrate strength.

Weibull analysis and fractographic investigation were performed to understand the nature and distribution of strength controlling defects, and verify the effectiveness of the interlayer. The Weibull plot of the cumulative probability of failure for as received silicon nitride and silicon nitride samples coated with the new bond layer system ( $\mathrm{Si}$ and interlayer) is shown in Figure 4.2.6. The Weibull distribution is given as

$$
P_{f}=1-\exp \left[-\left(\frac{\sigma}{\sigma_{c}}\right)^{m}\right]
$$

where $\mathrm{P}_{\mathrm{f}}$ is cumulative probability of failure, $\sigma$ is the order parameter or strength at which probability of failure is to be determined, $\sigma_{c}$ is the scaling parameter of the distribution and also known as characteristic strength, $m$ is the shape parameter of the distribution and is also known as the Weibull Modulus. The Weibull distribution parameters $\left(\sigma_{\mathrm{c}}\right.$ and $\left.\mathrm{m}\right)$ were determined from linear regression fit. 


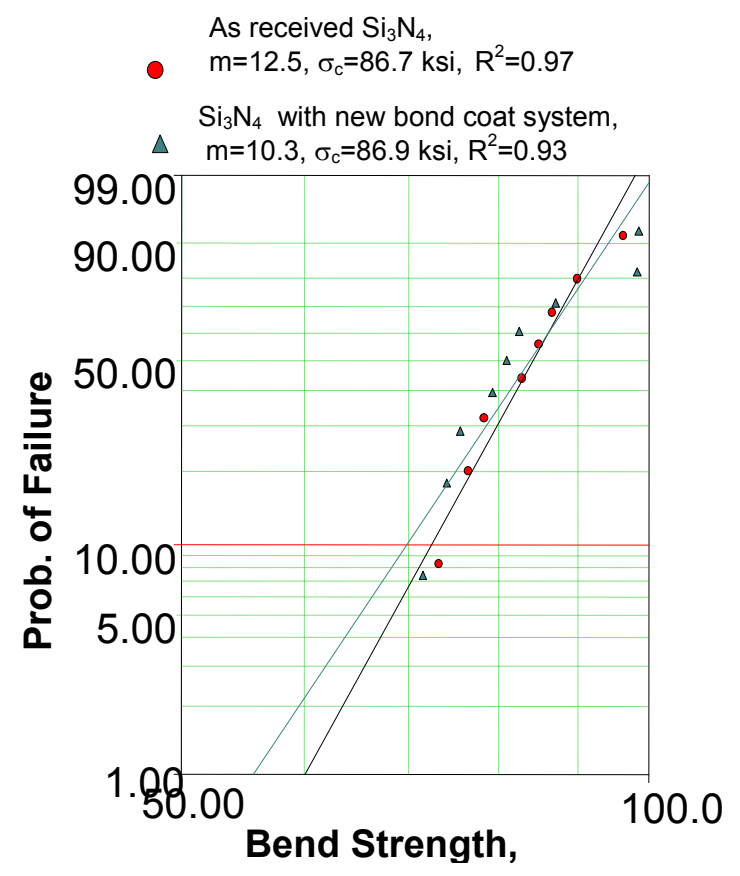

Figure 4.2.6: Strength of samples fractured in four point bending shown as Weibull distribution

The Weibull modulus and characteristic strength for the as received silicon nitride samples are 12.5 and $86.7 \mathrm{ksi}$, respectively. The Weibull modulus and characteristic strength for silicon nitride with bond coat system are 10.3 and $86.9 \mathrm{ksi}$, respectively. The distributions of the two sets of data are similar both in magnitude and in scatter. The regression analysis shows similar degree of fit for both sets of samples as judged from the $\mathrm{R}^{2}$ value. The Weibull analysis suggests that both sets of samples contain strengthcontrolling flaws of nearly the same size and distribution.

Fractographic analysis indicates that the nature of strength-limiting flaws in the uncoated substrate and the substrate with the bond coat system remains unchanged. Figures 4.2.7(a) and (b) show fracture surfaces of coated and uncoated SN282 as observed under a low magnification stereo microscope. The failure strength of as received silicon nitride is $86.6 \mathrm{ksi}$, while the failure strength of the coated silicon nitride is $81.4 \mathrm{ksi}$. The fracture origin for both samples, as marked in the Figure 4.2.7, is from the silicon nitride surface as judged by the fracture mirror and crack branching pattern. The magnitude of fracture mirror radius is also approximately the same for both the samples $(\sim 300 \mu \mathrm{m})$. 


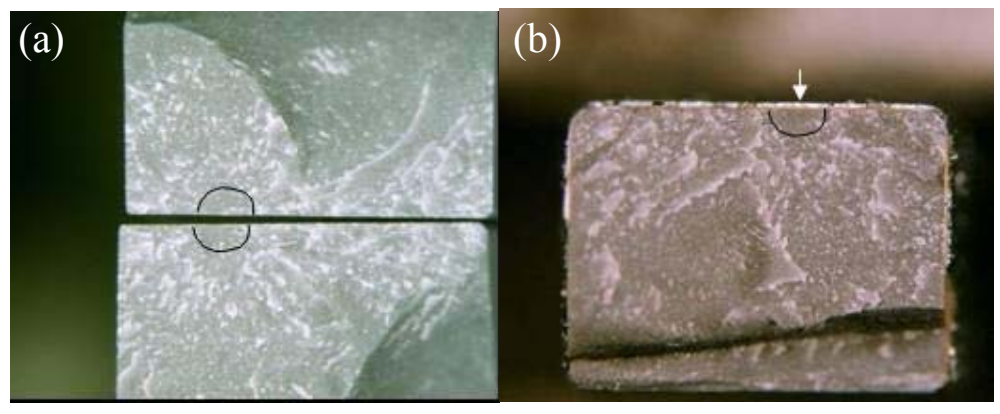

Figure 4.2.7: (a) Fracture surface of as received silicon nitride that failed at $86.6 \mathrm{ksi}$ in bend test. (b) Fracture surface of as silicon nitride coated with the compliant later and Si that failed at $81.4 \mathrm{ksi}$ in bend test

The fracture mirror radius is directly proportional to crack size from which the fracture initiated. The local stress at failure is hence inversely proportional to square root of fracture mirror radius. Since the failure strength determined from testing and the fracture mirror sizes are nearly the same for both samples shown in Figure 4.2.7, the local stresses at failure are also the same. This implies that the bond coat system on silicon nitride does not contribute to any additional local stresses and isolates the interaction of residual stress in the silicon layer from pre-existing flaws in silicon nitride. It is thus demonstrated that the bond coat system neither creates a different critical flaw population nor does it affect the stress intensity factor associated with the original flaw population present in the as received material.

Collaborative work with Oak Ridge National Lab (ORNL) was initiated during the course of the contract for the purpose of developing optimum slurry conditions for dip coating of yttrium silicate layers for use in an EBC system. ORNL had demonstrated during 2004 the ability to produce uniformly thick, dense layers of BSAS and mullite on silicon carbide substrates using dip coating technology. Under this collaborative effort, ORNL used their expertise in colloid chemistry and the knowledge gained in 2004 to develop slurry compositions tailored specifically to UTRC's coating chemistries and EBC architectures. The initial work focused on yttrium silicate slurry characteristics, since this is the prime candidate as the interlayer composition described in the earlier section. Working collaboratively with UTRC, ORNL did work to define the zeta potential and characterize the rheological behavior of the slurry as functions of slurry $\mathrm{pH}$ and percent solids loading. This basic information was then used to select the optimum slurry composition for initial dipping studies. Crack-free, uniformly thick layers of yttrium silicate were produced on substrates of SN282 silicon nitride using single and multiple dips to build up the desired coating thickness.

CVD Si coatings were processed at UTRC using dichlorosilane as the precursor. Control of this process within a fairly narrow process window was found to be critically important to produce stable Si coatings and avoid chemical interactions with the other materials in the system. 
Four-point flexure samples coated with the bond coat system were prepared and the coatings were aged in dry air to assess the stability of the coatings. It was found that the samples retained their strength after aging up to $2400 \mathrm{~F}$ (1315C) for 500 hours. The coating microstructures were also found to be relatively unchanged indicating that the material system did not have intrinsic problems with high temperature stability. It also indicated that the slurry additives used to prepare the dip coated interlayer and the CVD process did not cause the microstructural destabilization of the coating.

\subsubsection{Top-coat development}

The purpose of the top layer applied on to the bond coat system is to provide improved environmental protection against high velocity, high pressure steam at elevated temperatures. UTRC was able to draw from the synergy between the EBC development activity for monolithic silicon nitride and EBCs for SiC/SiC CMCs. The steam stability of the candidate top layer materials was evaluated on dense cold-pressed samples at temperatures between $2400-2700 \mathrm{~F}$ (1315-1482C). The relative recession resistance of the candidate materials is shown in Figure 4.2 .8 below, in comparison with barium strontium aluminosilicate (BSAS) and strontium aluminosilicate (SAS) at 2200F (1204C). The candidate top layer materials $\left(\mathrm{HfO}_{2}\right.$ and yttrium silicate) exhibited superior recession resistance in this specific comparative test.

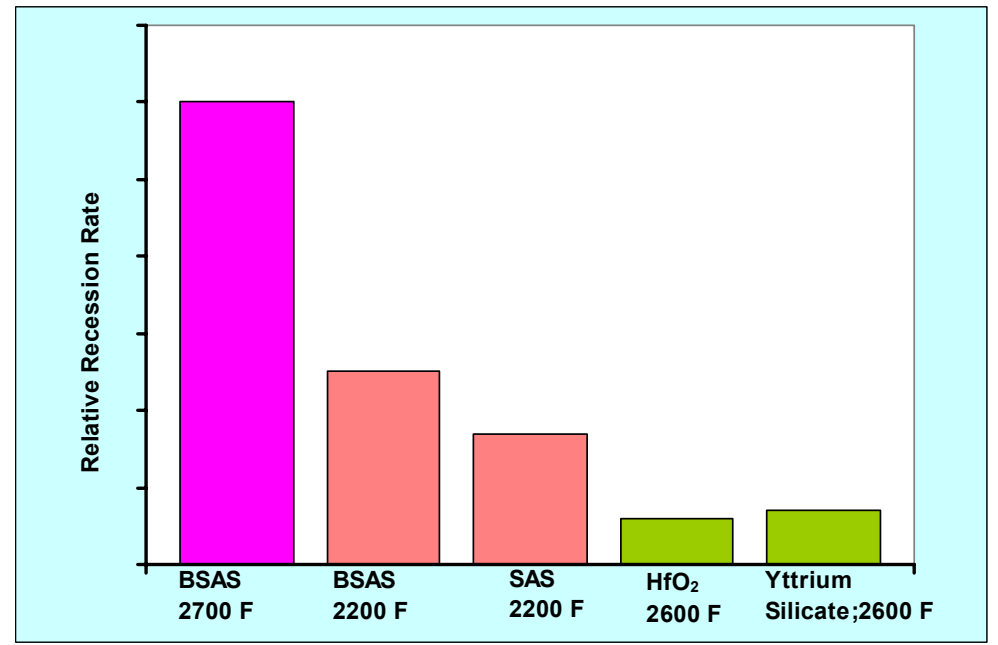

Figure 4.2.8: Relative high temperature steam resistance of candidate EBC top layer materials

It is also recognized that the ability of a coating to provide steam resistance is highly dependent on its microstructure which in turn depends on the processing technique. As discussed earlier, the ability to process non-line-of-sight coatings was found to be a critical coating requirement and hafnium dioxide $\left(\mathrm{HfO}_{2}\right)$ was down selected as the best gas-tight top layer candidate. $\mathrm{HfO}_{2}$ is a simple oxide and is relatively simple to apply by both CVD and dip coating. Further, $\mathrm{CVD} \mathrm{HfO}_{2}$ was expected to be a relatively well understood process compared to other complex oxides and silicates since it is considered to be a particularly useful dielectric material for electronic/semiconductor applications. 
Deposition of $\mathrm{HfO}_{2}$ was undertaken by dip coating and CVD. Dip coated $\mathrm{HfO}_{2}$ was considered to be a relatively higher risk, but potentially lower cost approach for the coating system. The $\mathrm{HfO}_{2}$ dip coating process was pursued in collaboration with ORNL, who used their expertise to design the slurry system so as to obtain dense, crack-free coatings of $\mathrm{HfO}_{2}$. Figure 4.2.9 shows the cross-section obtained from slurry formulations using pure $\mathrm{HfO}_{2}$ powders. After heat treatment to densify the layer, the coatings were substantively free of cracks and porosity. Although the $\mathrm{HfO}_{2}$ coatings appeared to be well adhered to the underlying silicon layer, there were significant issues associated with maintaining coating adhesion after thermal cycling. Also, the coating was not gas tight and subsequent efforts for top layer coatings were focused on $\mathrm{CVD} \mathrm{HfO}_{2}$.
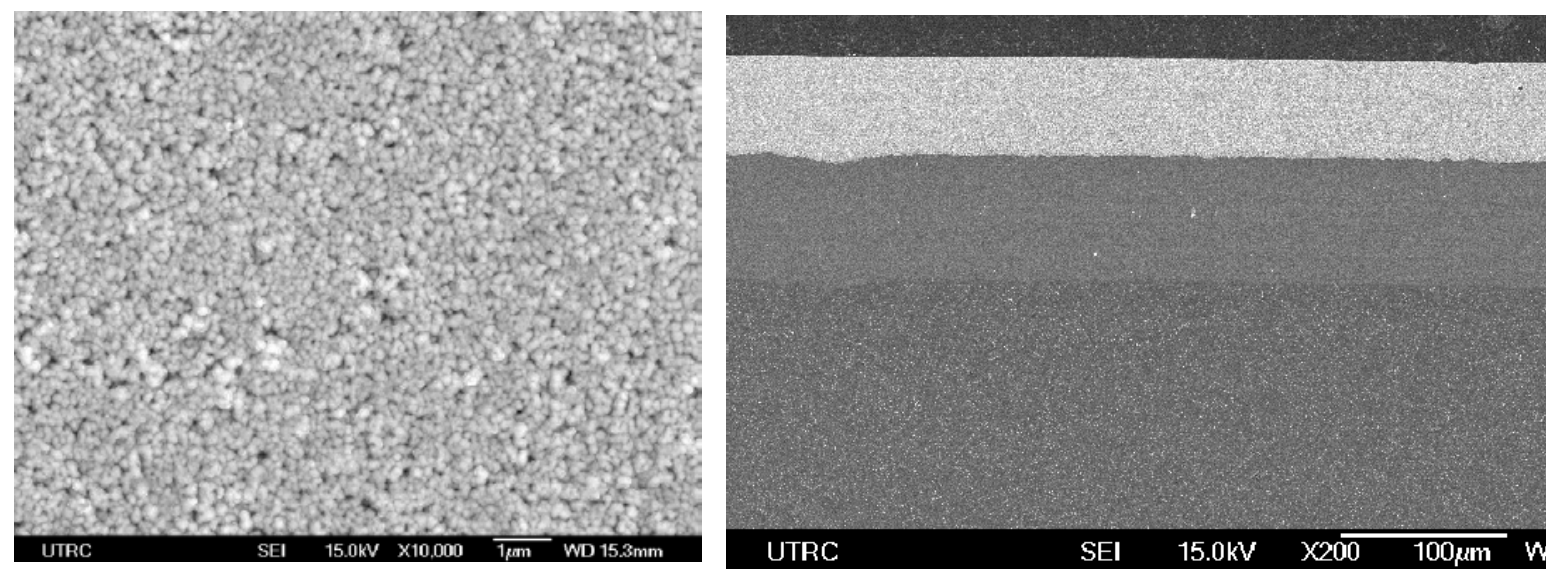

Figure 4.2.9: Dip coated $\mathrm{HfO}_{2}$ on CVD Si. (a) Top view and (b) Cross section

UTRC worked in collaboration with Ultramet to develop and optimize a novel CVD process that would produce dense hafnium dioxide coatings of the appropriate microstructure, phase, and thickness. Early trials showed the coatings to be very thin (due to slow growth) or to have excessive thickness as shown in Figure 4.2.10. Optimized deposition parameters were developed and these $\mathrm{CVD} \mathrm{HfO}_{2}$ coatings survived over 100 furnace thermal cycles to $2400 \mathrm{~F}$ (1315C). Early attempts at steam testing the $\mathrm{CVD} \mathrm{HfO}_{2}$ coatings showed further work needed to be done to provide steam resistance required of the full coating system.
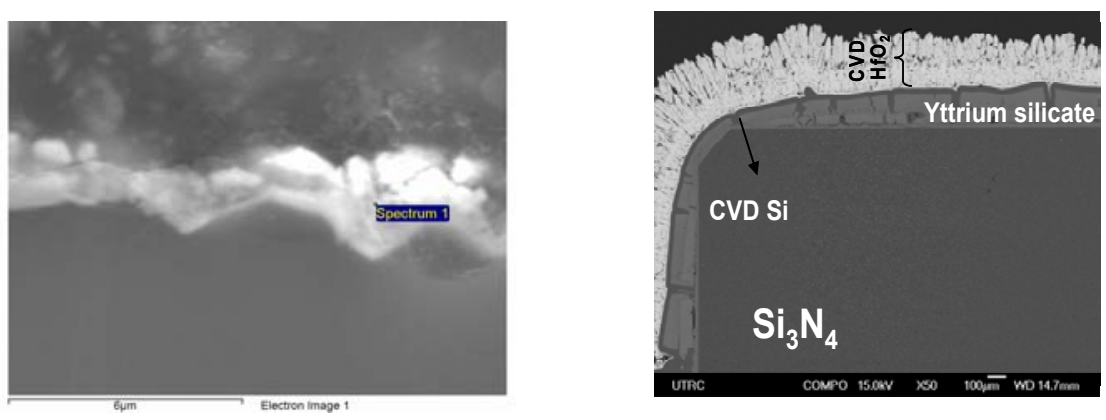

Figure 4.2.10: Coating trials aimed at producing a "full EBC" system. 


\subsubsection{Slurry Coating Process Scale-up}

Preliminary scale-up of the coating process to more complex turbine geometries was initiated using turbine airfoils of NT154 silicon nitride. These single airfoils were used to develop the coating process for eventual coating of more complex turbine components such as rotor and vane ring components. Initial dip coating trials were performed to deposit the yttrium silicate interlayer coating on an NT154 silicon nitride airfoil. Characterization of the coating showed uniform coverage of the YS2 layer over the majority of the airfoil cross section including the leading edge (Figure 4.2.11). The main trouble spot in terms of coating coverage was on the trailing edge of the airfoil and this was addressed in subsequent scale-up activity.
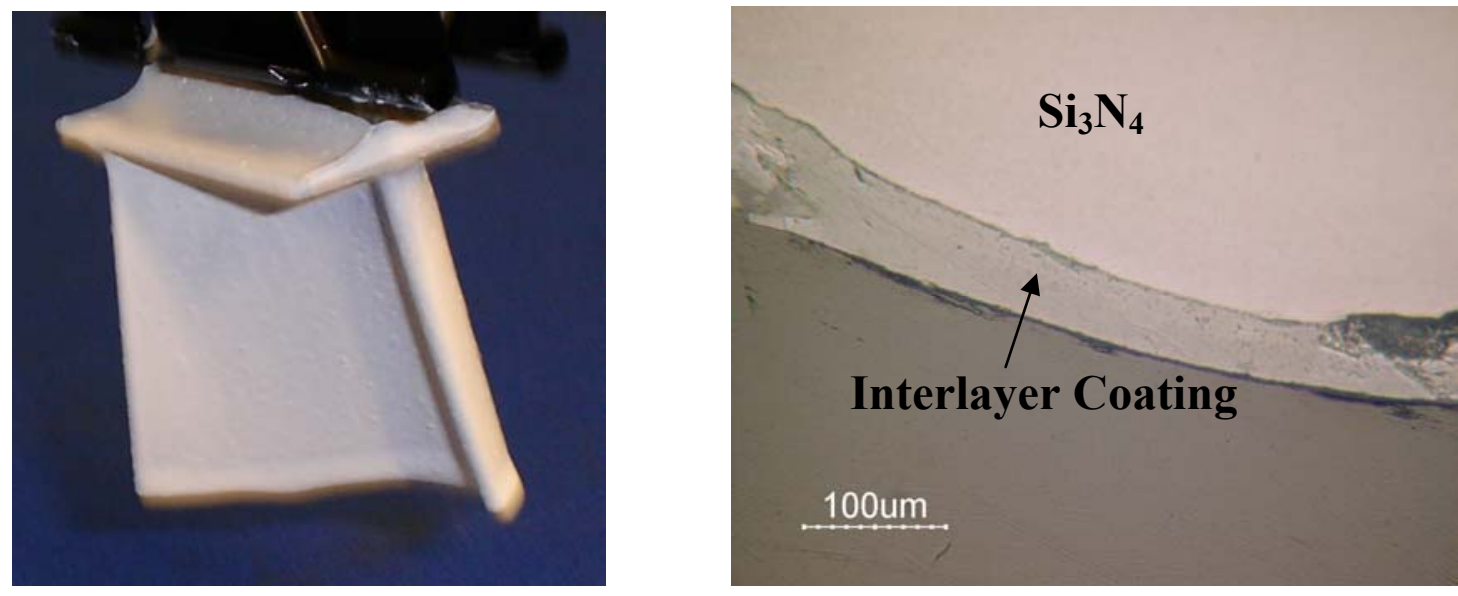

Figure 4.2.11 .A yttrium silicate coating was applied to a NT154 silicon nitride airfoil via dip coating. The optical micrograph on the right shows a section of the leading edge with a uniform layer of the coating.

Further developments reiterated that coating coverage and uniformity at the coupon level could not be used to guide slurry optimization as component geometries played an important role in determining coating quality. It was also clear from this first scale-up trial that a non-destructive tool to evaluate coating uniformity needed to be used to guide scale up because it was not realistic to cut-up prototype components after each coating trial. In recognition of this need, a white light fringe projection technique was identified to characterize coating thickness as a function of position and geometry through the series of steps as the coating builds up. The blade (or other prototype component) is first scanned without the coating to obtain a baseline contour measurement. The blade is again scanned after the coating is applied. The difference between the coated and uncoated contours results in the contour of the coating on the blade. The white light fringe projection method was found to be a very powerful tool to understand coating uniformity and how uniformity is governed by slurry characteristics, component characteristics, and firing cycles.

Efforts at scale-up were focused on two classes of components: (1) single SN282 blades for burner rig tests, and; (2) integral turbine components (integrally bladed rotors and 
integral vane rings) in order to closely understand the challenges of coating complex geometries. Dip coating the single silicon nitride blades helped in optimization of slurries and designing fixtures to hold and manipulate the components during the dip coating process. Figure 4.2.12(a) is a picture of an EBC coated blade before burner rig testing. The blade was burner rig tested in the UTRC burner rig facility to qualitatively assess the adherence of the coating via thermal cycling. The flame from the burner impinged on the blade and the material temperature on the leading edge was in excess of $2400 \mathrm{~F}$ (1315C). The approximate hot time was 2 minutes and the blade was subsequently cooled for 1 minute. As is seen from Figure 4.2.12(b), there was no observable damage after 50 thermal cycles. Similar burner rig testing will be used to qualify the coating as the final coating architecture and process is down selected.

(a)
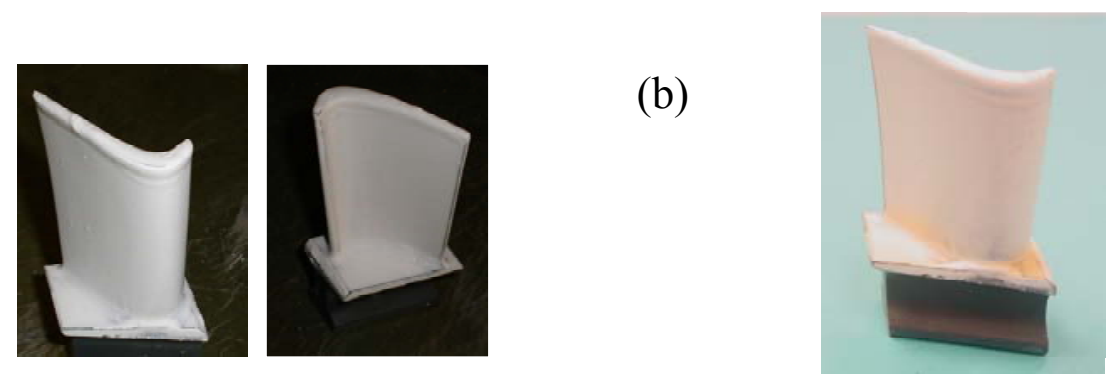

Figure 4.2.12: Slurry coated SN282 blade. (a) Before and (b) After burner rig testing to $2400 \mathrm{~F}$ ( 50 cycles)

When integral vane rings or rotors were dipped, the drip issues were found to be much less severe than in the single blade. Because of this observation, it was decided to focus scale-up on the integral components since they are more relevant to the program. A dip coated integral vane ring prototype similar to one described in Figure 4.2.1 is shown in Figure 4.2.13. Note that the holes in the airfoils are from an earlier set of experiments performed on the vane ring to determine material strength in full-sized components. The focus of the current dipping studies has been vanes A and B (see markings in Figure 4.2.13). It can be seen from the figure that the airfoils and platforms have fairly uniform coverage by the coating. In order to understand the variability of coating thickness on the component and "quantify" coating quality, the white light fringe projection technique (described previously) was used extensively to map the contours of the component before and after coating application. Figure 4.2.13(e) shows sections across blade A (A1, A2 A3) and across the various points along the blade where measurements were recorded. Table 4.2.1 tabulates the coating thickness at the locations 1 through 6 on sections A1, $\mathrm{A} 2$ and A3. The high thickness on the leading edge (position 4) is due to a drip that collected on the leading edge. Of concern is the low amount of coating in the fillet areas (position 3) - it was repeatedly found through more analysis that the coating is lean in the areas adjacent to the attachment portions between the vane and the substrate. Further work needs to be done to understand the reason for the lack of coating in these areas and methods to mitigate it. In most areas with coverage the coating thickness varied between $\sim 10-50 \mu \mathrm{m}$. 

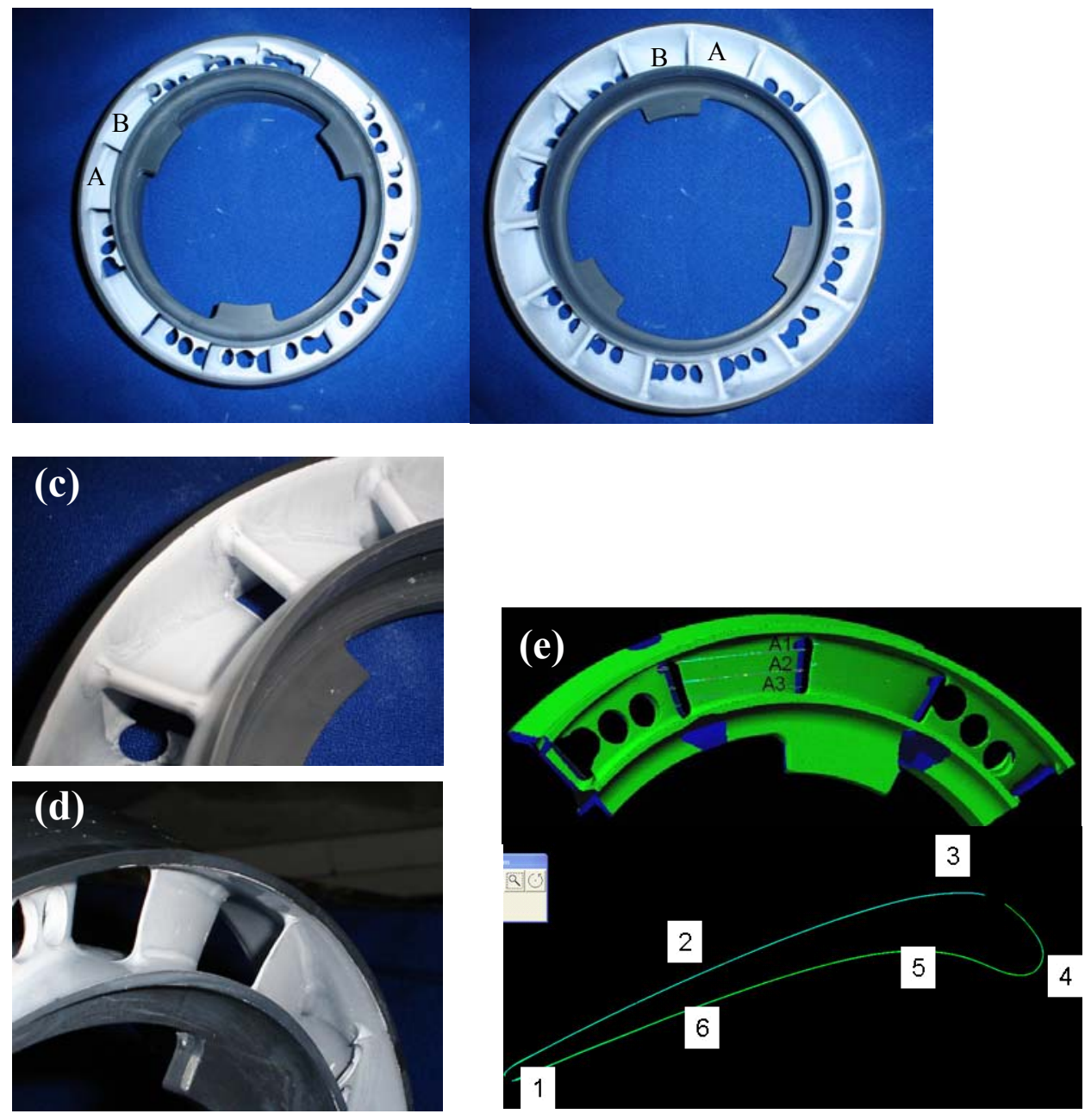

Figure 4.2.13: Coating of integral vane ring to demonstrate scalability of the process

Table 4.2.1: Coating thickness as a function of position and section on blade $A$

\begin{tabular}{|c|c|c|c|}
\hline \multirow{2}{*}{ Position } & \multicolumn{3}{|c|}{ Coating Thickness $(\mu \mathrm{m})$} \\
\cline { 2 - 4 } & Section A1 & Section A2 & Section A3 \\
\hline 1 & 16 & 23 & 15 \\
\hline 2 & 9 & 10 & 9 \\
\hline 3 & 0 & 7 & 0 \\
\hline 4 & 54 & 135 & 58 \\
\hline 5 & 30 & 28 & 33 \\
\hline 6 & 35 & 30 & 25 \\
\hline
\end{tabular}




\subsection{Spin Testing}

As part of ceramic prototype manufacturing effort, UTRC contracted Saint-Gobain Ceramics \& Plastics to manufacture microturbine rotors. Saint-Gobain delivered six rotors on the contract. The report of their activity is included in the appendix. Three of the NT154 microturbine rotors manufactured by Saint-Gobain were spin tested to $120,000 \mathrm{rpm}$, which was approximately $1.33 \mathrm{X}$ the design speed, and produced 1.51X the maximum design stress. The maximum stress in cold spin was approximately $\sim 340 \mathrm{MPa}$ $(\sim 49 \mathrm{ksi})$. All three rotors survived the spin test.

The spin tested rotors were subsequently coated with the yttrium silicate interlayer and one of the coated rotors was spin tested under identical conditions. The coated rotor survived the spin test and the coating remained mostly adhered to the substrate. Figure 4.3.1 documents one of the rotors after the initial spin test, after coating and after spin test with the interlayer coating.

As the coating is optimized and the processes are scaled up, it is recommended that the coated rotors are spin tested with the entire coating system including the top coat.

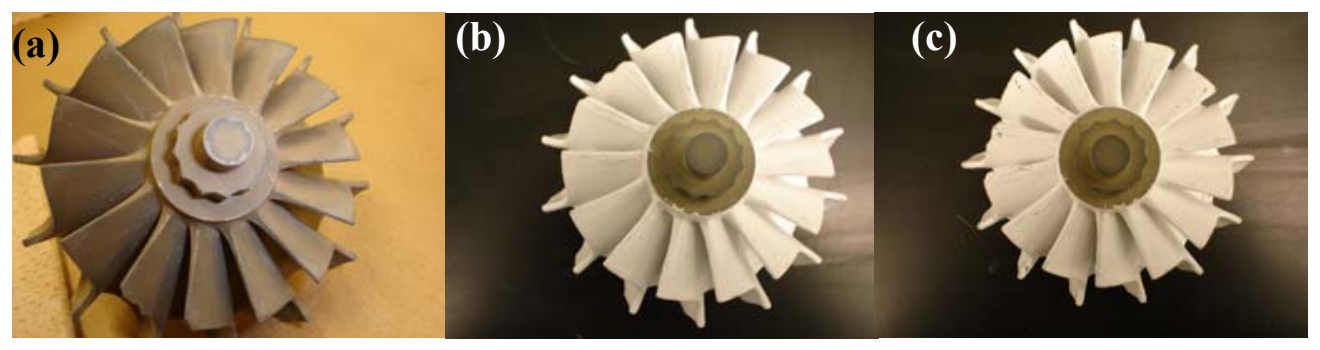

Figure 4.3.1: Spin tested microturbine rotor. (a) Uncoated rotor, (b) Coated rotor before spin test and (c) Coated rotor after spin test 


\section{Section 5.0 Conclusions, Program Leverage, and Recommendations}

\subsection{Conclusions}

A viable approach to achieve an Advanced Microturbine System with a $40 \%$ electrical efficiency and very low emissions is to integrate a high performing microturbine and an Organic Rankine Cycle (ORC) system.

- The microturbine should have an electrical efficiency greater than $32 \%$ and produce single-digit emissions of NOx and CO @ 15\% O2.

- The ORC should convert the microturbine exhaust energy into electrical power at an efficiency greater than $12 \%$. Since the ORC produces power without any additional fuel consumption or combustion process, the ORC power is produced with zero NOx and $\mathrm{CO}$ emissions.

- The components and the integration hardware should not reject more than $6 \%$ of the fuel energy as parasitic loss.

Ceramic materials can be designed to meet realistic microturbine performance and life targets.

- A long life microturbine ceramic turbine can be designed by proper consideration and analyses of ceramic failure modes without compromising turbine performance.

- Complex ceramic components can be manufactured and EBC coated.

- Ceramic SiC Hexoloy can be used for combustor liners to reduce the need for cooling airflow. The avoided airflow can be used in the combustor to alter its stoichiometry or to cool other engine components. The former may yield combustor conditions favorable to lower pollutant production; any reduction of liner cooling air will reduce $\mathrm{CO}$ production because of wall quenching.

A statically and dynamically stable natural-gas-fired microturbine combustor can be designed to achieve ultra-low emissions over a wide turndown range.

- Experimental techniques and analytical tools are available to evaluate the premixer performance, the consequence of this performance on $\mathrm{CO}$ emissions, and the likelihood of encountering acoustic instabilities.

A high performing, affordable Organic Rankine Cycle (ORC) system can be achieved through the use of components produced by HVAC suppliers.

- ORC systems are similar to those used for air conditioning. The use of HVAC components in the ORC leverages their low cost arising from the high volume manufacturing.

- ORC performance can be tailored to an application by the selection of: the means to accept energy (i.e. hot air or liquid), means to reject energy (i.e. air-cooled or water-cooled condensing), or the match of the working fluid to the temperature environment (i.e. selection of alternative refrigerants in an ORC). These options are consistent with alternative HVAC components and fluids. 


\subsection{Program Leverage}

The ORC system technology was commercialized by UTC Power as the PureCycle $^{\mathrm{TM}}$ product to recycle energy from any waste heat stream into electrical power without any fuel consumption or pollutant production.

- The PureCycle ${ }^{\mathrm{TM}}$ system appears well aligned with converting renewable geothermal energy into electricity.

Other US Government sponsored efforts to use ceramic turbine components are benefiting from the AMS accomplishments.

- The US Army Aviation Applied Technology Directorate (AATD) awarded Pratt \& Whitney a \$2.3M Advanced Small Turbine (AST) Technology Demonstration contract to design, fabricate, and demonstrate ceramic turbine components for an advanced small turbine that will be required for future small unmanned aerial vehicles. UTRC is a major participant in the program and utilized the experience gained in the microturbine design activity as a starting point for the AATDfunded program.

- Developed methods for ceramic component designs that achieve life while preserving performance, and for production of complex prototype parts, are being applied in this US Army program.

\subsection{Recommendations}

Efforts are required to increase the value of the microturbine system and thereby benefit end-users and society. There are several areas worthy of development:

- Microturbine engine performance and value can be enhanced by the proper insertion of ceramic technologies. While the UTRC AMS program made progress toward this goal, further efforts are required to validate the benefit and reduce the risk of ceramic turbine components. This includes the design and manufacturing of them, and for the associated technologies as may be required such as EBC coatings, attachments and life prediction of coated ceramic components.

- Recognizing that the microturbine exhaust contains energy that can provide value for the end-user, integrated systems should be developed beyond the one validated in this AMS program. In addition to using an ORC to produce additional power, such systems could include a microturbine to produce electrical power and a thermally-activated technology (TAT) device that recycle the exhaust into a thermal energy stream such as chilling, heating, de-humidification, or refrigeration.

- The value of microturbine/TAT systems can be enhanced through efforts to optimize the package integration for lowest first cost, simpler installation, and greater reliability. 


\section{APPENDIX}

\section{List of Invention Disclosures Developed Under the Contract That Resulted in Patent Submissions}

\begin{tabular}{|c|c|c|c|}
\hline $\begin{array}{c}\text { Title } \\
\end{array}$ & Matter Type & Country & Status \\
\hline $\begin{array}{l}\text { Mechanical Support of a Ceramic Gas } \\
\text { Turbine Vane Ring }\end{array}$ & Invention Disclosure & United States of America & Final Disposition: Patent \\
\hline $\begin{array}{l}\text { MULTIPLE DISTRIBUTED GENERATORS } \\
\text { SHARING THE SAME POWER- } \\
\text { CONDITIONING MODULE }\end{array}$ & Invention Disclosure & United States of America & Final Disposition: Patent \\
\hline $\begin{array}{l}\text { LOW THERMAL STRESS GAS TURBINE } \\
\text { VANE }\end{array}$ & Invention Disclosure & United States of America & Final Disposition: Patent \\
\hline $\begin{array}{l}\text { STARTUP METHODS FOR AN ORC } \\
\text { BOTTOMING PLANT }\end{array}$ & Invention Disclosure & United States of America & Final Disposition: Patent \\
\hline $\begin{array}{l}\text { TRIPLE CASCADE FOR POWER } \\
\text { GENERATION FROM A HIGH PRESSURE } \\
\text { STEAM / WATER SOURCE }\end{array}$ & Invention Disclosure & United States of America & Final Disposition: Patent \\
\hline $\begin{array}{l}\text { NESTING ORGANIC RANKINE CYCLES } \\
\text { FOR WASTE HEAT UTILIZATION }\end{array}$ & Invention Disclosure & United States of America & Final Disposition: Patent \\
\hline $\begin{array}{l}\text { HEAT EXCHANGER BYPASS SYTEM TO } \\
\text { OPTIMIZE HEAT WASTE TRANSFER } \\
\text { FROM A RECPROCATING ENGINE TO AN } \\
\text { ORGANIC RANKINE BOTTOMING CYCLE }\end{array}$ & Invention Disclosure & United States of America & Final Disposition: Patent \\
\hline $\begin{array}{l}\text { ORGANIC RANE CYCLE DRIVEN FROM } \\
\text { INDUSTRIAL COMPRESSOR INTER / } \\
\text { AFTER COOLERS }\end{array}$ & Invention Disclosure & United States of America & Final Disposition: Patent \\
\hline $\begin{array}{l}\text { USE OF AN ORGANIC RANKINE CYCLE } \\
\text { ON A RECIPROCATING COMBUSTION } \\
\text { CYCLE }\end{array}$ & Invention Disclosure & United States of America & Final Disposition: Patent \\
\hline $\begin{array}{l}\text { A RANKINE CYCLE WORKING FLUID } \\
\text { COMPRISING AN HFC REFRIGERANT } \\
\text { AND A POLYOL ESTER LUBRICANT }\end{array}$ & Invention Disclosure & United States of America & Final Disposition: Patent \\
\hline $\begin{array}{l}\text { A Ceramic Turbine Rotor Attachment } \\
\text { Method }\end{array}$ & Invention Disclosure & United States of America & Final Disposition: Patent \\
\hline $\begin{array}{l}\text { COMBINED RANKINE AND VAPOR } \\
\text { COMPESSION CYCLES }\end{array}$ & Invention Disclosure & United States of America & Final Disposition: Patent \\
\hline $\begin{array}{l}\text { ORGANIC RANKINE CYCLE SYSTEM } \\
\text { WITH SHARED HEAT EXCHANGER FOR } \\
\text { USE WITH A RECIPROCATING ENGINE } \\
\end{array}$ & Invention Disclosure & United States of America & Final Disposition: Patent \\
\hline $\begin{array}{l}\text { ORGANIC RANKINE CYCLE SYSTEM FOR } \\
\text { USE WITH A RECIPROCATING ENGINE }\end{array}$ & Invention Disclosure & United States of America & Final Disposition: Patent \\
\hline $\begin{array}{l}\text { CONTROL OF FLOW THROUGH A VAPOR } \\
\text { GENERATOR }\end{array}$ & Invention Disclosure & United States of America & Final Disposition: Patent \\
\hline ORGANIC RANKINE CYCLE FLUID & Invention Disclosure & United States of America & Final Disposition: Patent \\
\hline $\begin{array}{l}\text { MULTI-POINT STAGING STRATEGY FOR } \\
\text { LOW EMISSION AND STABLE } \\
\text { COMBUSTOR }\end{array}$ & Invention Disclosure & United States of America & Final Disposition: Patent \\
\hline $\begin{array}{l}\text { IMPROVED METHOD OF ADHESION IN } \\
\text { ENVIRONMENTAL BARRIER COATINGS } \\
\text { (US Gov) }\end{array}$ & & United States of & Final Disposition: Patent \\
\hline
\end{tabular}




\title{
APPENDIX
}

\author{
Proceedings of: \\ ASME TURBOEXPO 2002 \\ June 3-6, 2002, Amsterdam, The Netherlands
}

2002-GT-30547

\section{Preliminary Design of Ceramic Components for the ST5+ Advanced Microturbine Engine}

\author{
Jun Shi, Venkata R. Vedula, John Holowczak, Connie E. Bird, S. Scott Ochs, \\ Luca Bertuccioli and David J. Bombara \\ United Technologies Research Center, East Hartford, CT
}

\begin{abstract}
Progress in the preliminary design of an axial vane ring and axial turbine rotor composed of silicon nitride structural ceramics is presented. The silicon nitride components allow for significantly increased turbine inlet temperature in the ST5+, an advanced version of the Pratt \& Whitney Canada's ST5, which powers the DTE Technologies ENT400 Distributed Energy Generator. Preliminary aerodynamic and mechanical design, steady state thermal and stress analysis, and life prediction results will be reviewed. Foreign object damage resistance will be compared between ceramic versions of the baseline rotor blade geometry and that developed for the ST5+ engine.
\end{abstract}

\section{INTRODUCTION}

The demands for fast installation of power generators and easy upgrade of power output have spurred the development of microturbines in the last few years. The California power crisis heightened such demand when power shortages and blackouts disrupted normal business operations and everyday life. The power crisis shook public confidence in electric utilities and forced consumers to rethink alternative, reliable sources of power, such as microturbines.

In response to market demand, Pratt \& Whitney Canada (P\&WC) has teamed up with DTE Energy Technologies to develop and produce a $400 \mathrm{~kW}$ microturbine system, the ENT400. The ST5 microturbine is based on P\&WC's PW207 helicopter engine with modifications to suit the needs of industrial power generation.

With funding from the US Department of Energy, United Technologies Research Center (UTRC) has been working closely with P\&WC to improve major ENT400 performance parameters: electrical efficiency from $30 \%$ to $40 \%$ or higher and $\mathrm{NO}_{\mathrm{x}}$ emission from 9ppm to $7 \mathrm{ppm}$ or less on natural gas. The efficiency gain comes from a bottoming Organic Rankine Cycle (ORC) and from the use of ceramic components in the engine hot gas path. The ORC makes use of the exhaust gas to heat a low boiling point liquid that drives a second generator and thus recovers some of the energy that is otherwise lost through the stack. By using high-temperature resistant ceramic components, the engine cycle can run hotter with reduced cooling requirements, both contributing to increased cycle efficiency.

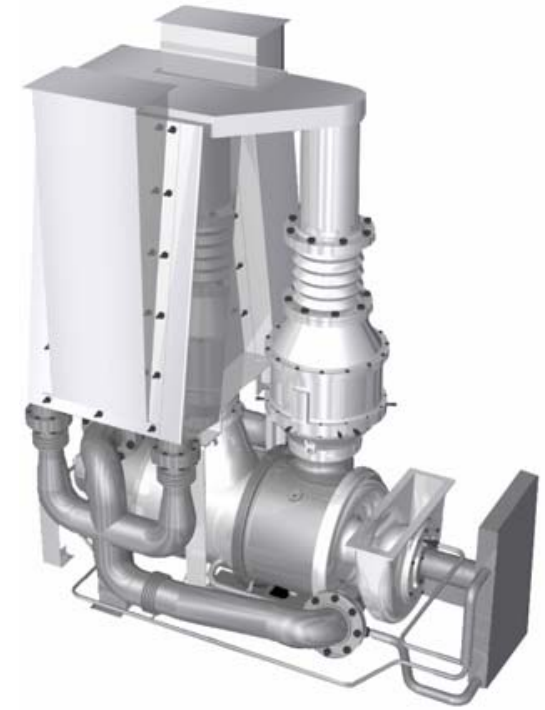

Figure 1 Baseline ST5 microturbine engine

The ST5 (see Figure 1) is a twin shaft engine with separate compressor and power turbine stages. ST5's single stage radial compressor has a nominal compression ratio of $8: 1$ and the single stage axial compressor rotor speed is nominally 51,000 $\mathrm{rpm}$. The compressor turbine vane ring and compressor turbine rotor blades are made of single crystal materials to withstand the high temperature gas exiting from the combustor transition duct. The high-temperature combustion gas requires the vane ring to be cooled by compressor discharge air. Although the compressor turbine blades are uncooled, they operate close to their temperature limit. Therefore, an uncooled ceramic vane ring and ceramic turbine rotor could offer substantial cycle benefits. The ST5+ turbine inlet temperature is approximately $1150^{\circ} \mathrm{C}$, a substantial increase over that of the baseline ST5 engine. Cycle studies show that an approximate 3\% gain in electrical efficiency can be obtained by using ceramic materials [1]. 
This paper summarizes UTRC's first-year effort in designing vane ring and integrally bladed rotor made from monolithic ceramics.

\section{AERODYNAMIC DESIGN}

A meanline optimization was performed that resulted in a first-stage design consisting of 15 vanes and 27 blades. The blade count was reduced from that of the baseline design to improve ceramic manufacturability and to allow for increased blade thickness (See Figure 2). Blade trailing edge thickness was increased for improved FOD (foreign object damage) resistance (to be discussed later). The flow path was unchanged from the baseline to reduce the number of dissimilar parts between the two designs. Axial chords were held to those of the baseline to limit airfoil aspect ratios and the associated profile losses, while reaction was limited to $45 \%$ to limit blade exit flow angle and Mach number and the associated transition duct losses. This reaction is a substantial increase over that of the baseline, which was held to $25 \%$ to reduce the effects of combustion gas temperature on the uncooled single crystal superalloy vanes. To match the compressor performance map, turbine power was varied until the turbine exit flow parameter matched that predicted by the cycle analysis. The meanline optimization resulted in a design with an increase in aerodynamic stage efficiency of between 1 and $2 \%$ over that of the baseline.

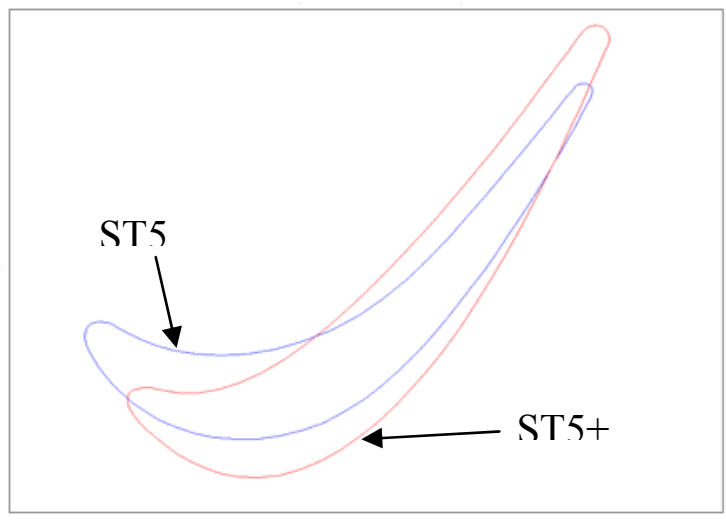

Figure 2. Airfoil has been thickened to improve FOD resistance

The meanline and flow path data were converted to an initial three-dimensional design, which was optimized for pressure distribution using a steady, inviscid flow solver. Correlations between pressure distribution characteristics and losses in viscous flows have been derived from experience. The relative Mach number distribution at mid-span of this design can be seen in Figure 3. The optimized aerodynamic design was then converted to $\mathrm{CAD}$ format and integrated with the vane ring and integrally bladed rotor (IBR) disk designs to be analyzed for structural integrity and ceramic manufacturability.

Another objective of the aerodynamic analysis was to provide thermal boundary conditions for the structural analysis of the ceramic vane ring and IBR. To obtain these boundary conditions, two Navier-Stokes computations on dense meshes were performed. The first case was run with adiabatic wall thermal boundary conditions, while the second was run with a constant wall temperature. The wall temperature was set to be $56^{\circ} \mathrm{C}$ less than the minimum gas temperature at the airfoil surface found in the adiabatic case. This ensures that the heat transfer will be from the fluid to the airfoil. In both cases, the $\mathrm{y}^{+}$ value of the first grid point off the wall was less than 1 . These computations provide convective heat transfer coefficients (Figure 4) and driving temperatures for the airfoil, and inner and outer platforms. The approach used to determine the convective heat transfer coefficients has been extensively validated against experimental data at $\mathrm{P} \& \mathrm{~W}-\mathrm{C}$. Thermal boundary conditions were calculated for both average-inlet and hot-streak conditions. The hot-streak inlet profile was obtained from a threedimensional Navier-Stokes simulation of the combustor and scroll [2].

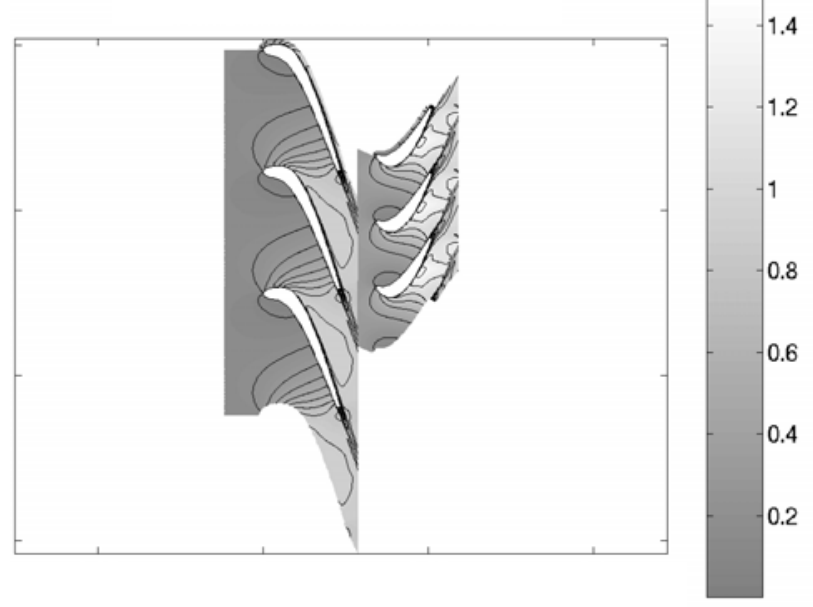

Figure 3. Relative Mach number distribution for the first stage

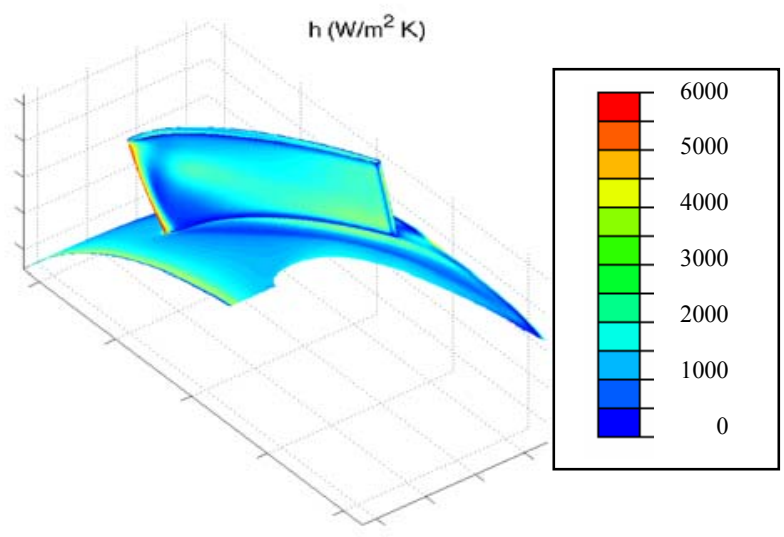

Figure 4. Heat transfer coefficient determined by CFD

\section{CERAMIC VANE DESIGN AND ANALYSIS}

The primary source of stress in a turbine nozzle vane is thermal in nature. To minimize these stresses, ceramic vanes 
have been mostly made as singlets [3-7]. In such a design, the platforms of one vane are not connected to those next to it and the thermal deformation of two neighboring vanes are decoupled, which leads to less constraint and lower thermal stress. However, there are also disadvantages associated with such a vane concept. Cost per vane tends to be higher for singlet vanes in comparison to a full vane ring, as more mating surfaces require extra post-processing machining. Other issues include sealing and attachment. As cost competitiveness is one key parameter for small gas turbine engines, a full ceramic vane ring was chosen as the first design concept.

The vane ring is attached to the engine by a tab-and-slot arrangement. This allows the ceramic vane ring to grow radially relative to a metallic retaining plate without introducing thermal stresses. The tabs and slots need to be machined to a high dimensional tolerance so that an accurate position of the vane ring relative to turbine rotor can be maintained.

The outer platform of the vane ring has been modified to reduce thermal stress (see Figure 5). The thickness of the platform has been reduced and the front and rear fins on the platform have been removed to decrease the thermal mass, which is beneficial in controlling transient thermal stresses. Compressive pressure loading is introduced by a metallic spring ring positioned between the turbine support casing and the outer platform. Insulating material is added between the ceramic vane ring and the surrounding metallic stru.sture to thermally shield the metal parts and to lower the temperatire gradient and stress in the vane.

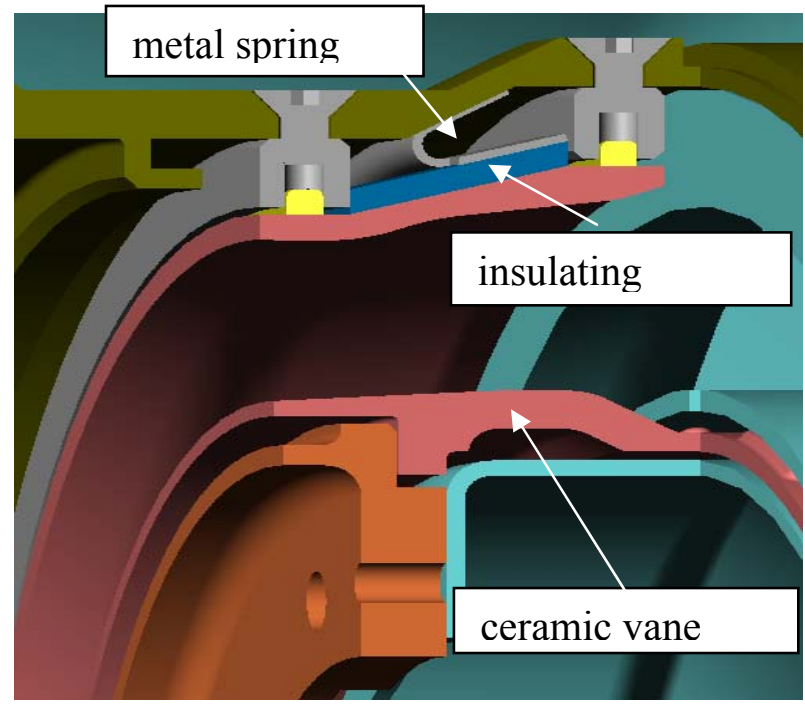

Figure 5. Ceramic vane ring attachment

The candidate ceramic material for the vane ring is silicon nitride (SN282) from Kyocera Industrial Ceramics Corp. (KICC). Vendor supplied temperature dependent physical and mechanical properties (strength and strength distribution) were used for finite element analysis and life predictions. The slow crack growth (SCG) susceptibility of this material was determined by dynamic fatigue testing at the Oak Ridge National Laboratory, TN (ORNL). The SCG parameter (n) at $1260^{\circ} \mathrm{C}$ was calculated as 232, indicating that time dependent strength degradation is not an issue at high temperatures. Tanaka et al. had reported much higher $\mathrm{n}$ values $(>10,000)$ from stress rupture tests at 1200 and $1400^{\circ} \mathrm{C}$ [8]. The material also has excellent creep resistance up to and well beyond the maximum vane temperature of $\sim 1200^{\circ} \mathrm{C}$. Silicon nitride under high temperature steam environment is subject to grain boundary degradation and recession [9]. An environmental barrier coating will be used to protect the ceramic vanes from accelerated oxidation.

The thermal gradients and the resulting thermoelastic stresses in the vane cascade were estimated using the finite element code ABAQUS. The analysis was performed on the existing ST5 metal design, as if manufactured as a single siliconnitride (SN282) part. Sequential thermal and stress analysis was performed for average-inlet conditions for the complete vane ring. The steady-state maximum and minimum temperatures in the vane were predicted as 1103 and $894^{\circ} \mathrm{C}$ and the resulting maximum principal stress was $178 \mathrm{MPa}$. The maximum stress occurred at the inner platform due to lower temperatures in that region. The stresses at the trailing edge were approximately 103 $\mathrm{MPa}$. The mechanical constraints and attachment schemes were not included in the analysis.

Detailed stress and life analyses were also performed on the new ST5+ design. Due to a non-uniform combustor exit temperature profile (pattern factor), the vane gas temperature field will be more severe than average-inlet conditions. The FEA was performed for both average-inlet and hot-streak conditions. Figures 6 and 7 show the temperature gradients and thermal stress distribution in the vane cascade for hot-streak conditions, respectively. As expected, the temperature gradients were more severe and the stresses $(179 \mathrm{MPa})$ were higher in the hot-streak case as compared to the average-inlet case (107 MPa). The stresses in both cases, however, were lower in the ST5+ design than in the ST5 design due to less severe thermal gradients. Transient analyses for engine start-up and emergency shutdown condition are currently underway.

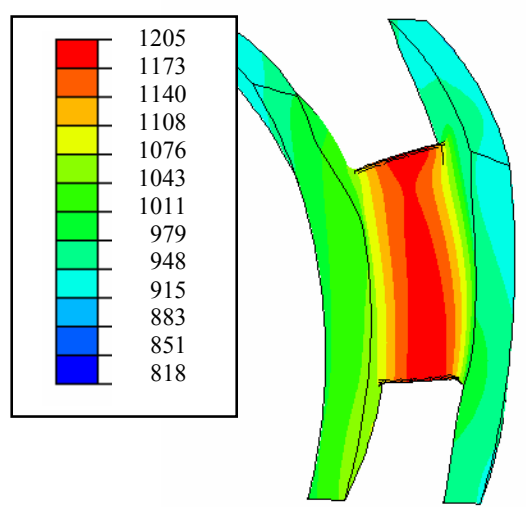

Figure 6. Steady state temperature $\left({ }^{\circ} \mathrm{C}\right)$ in the ST5+ vane for hot-streak conditions 
The fast fracture mechanical strength data at $1200^{\circ} \mathrm{C}$ (Average as-processed 4-point bend strength $\sigma_{\text {avg }}=524 \mathrm{MPa}$, Weibull modulus $m=19$ ) was used to predict the life and reliability of the ceramic vane using the CARES/LIFE code [10]. The probability of failure $\left(\mathrm{P}_{\mathrm{f}}\right)$ was calculated using stresses predicted by FEA. The calculations assumed volume flaws and Shetty's mixed-mode micro-cracking criterion. The $\mathrm{P}_{\mathrm{f}}$ of ST5+ vane for average-inlet and hot-streak condition was $7.5 \times 10^{-14}$ and $2.6 \times 10^{-10}$, respectively. The stress and life predictions indicate that the stresses are lower and the reliability is higher for the new aero-optimized design.

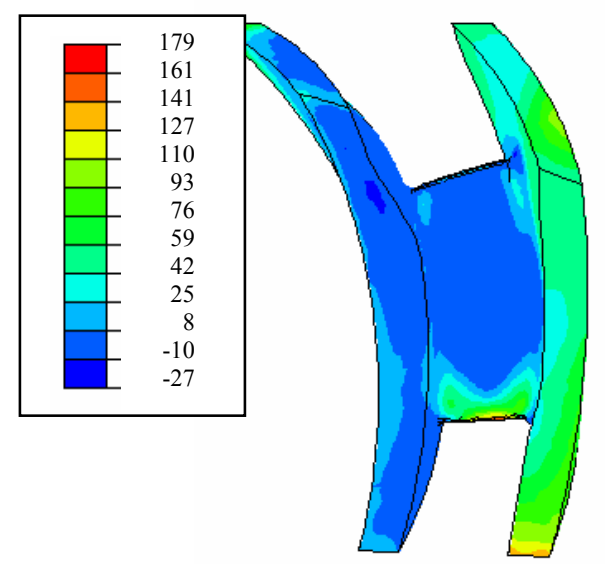

Figure 7. Steady state thermal stress $(\mathrm{MPa})$ in ST5+ vane for hot-streak conditions

\section{CERAMIC INTEGRALLY BLADED ROTOR}

Due to high centrifugal loading, the ceramic rotor design is much more challenging than designing ceramic vanes. The high thermal loading in the hot gas path demands heat resistant blades, while high rotating speed requires more mechanical strength at the disk bore. To ensure component reliability, a hybrid ceramic rotor design, using ceramic blades and a metallic disc, has been pursued in the past $[11,12]$. It offers a good solution for both the challenging design requirement of hot gas path and metallic disk in a thermally less aggressive but mechanically more demanding environment. This is particularly important for medium to large size turbine rotors, as ceramic component reliability is dependent on the stressed volume.

Despite the attractiveness of low stressed volume, hybrid ceramic rotors suffer from several major drawbacks. The first is related to the high contact stress at the ceramic blade root where the ceramic blade is attached to the metallic disc. Although a compliant layer material has been developed to act as a buffer between the blade and the disk and hence reduce contact stress, the durability of this compliant layer material has not been demonstrated for the required engine life. The second drawback is the cost associated with the machining of blade roots so that good contact can be achieved between the blade and the disc. A third drawback is the difficulty in controlling the blade tip clearance, which is important for small gas turbine engines, where even a small absolute tip clearance can result in high tip loss due to the relatively small rotor dimension.

As mentioned before, one determining factor of whether the microturbine can be successful in the gas turbine market is its cost competitiveness. This important consideration combined with the relative small engine size directed the initial ST5+ compressor turbine design to a ceramic IBR. Such a concept has been pursued in the past $[13,14]$. During the first phase of rotor design, most of the design efforts have been focused on two areas: disk geometry optimization and blade FOD resistance assessment. Preliminary results of these two efforts are presented next.

The blade and outer rim shape were determined by the aerodynamic optimization. The profile of the disk is designed to minimize stress and accommodate an attachment method between the ceramic disk and a metallic shaft. Although for stress considerations, it is desirable to have a solid ceramic IBR, there are other design considerations that require a bored IBR. For example, there is a need for cooling air passage between the front and rear disk surfaces to keep both surfaces at equal temperatures and to create a pressurized cavity so that the disk rear cavity can be air-sealed. This is most conveniently realized by the disk centre bore.

To save computing time, a two-dimensional, axisymmetric model was employed to optimize disk geometry. The ST5 disk and thermal boundary conditions were used as a baseline condition and rotor blades were represented by pressure loading at the rim, as aerodynamic design of the blade was done in parallel. The four main control parameters are bore diameter, hub width, web width and the bend radii between the web and the hub. There are two locations of high stress: one at the bore and another at the web. The stress at the bore is primarily circumferential, while the stress at the web is mainly radial. It was found that the maximum stress at the bore is not sensitive to the bore diameter for the range of practical importance. The maximum principal stress during steady state shown in Figure 8 is still high and further optimization is needed.
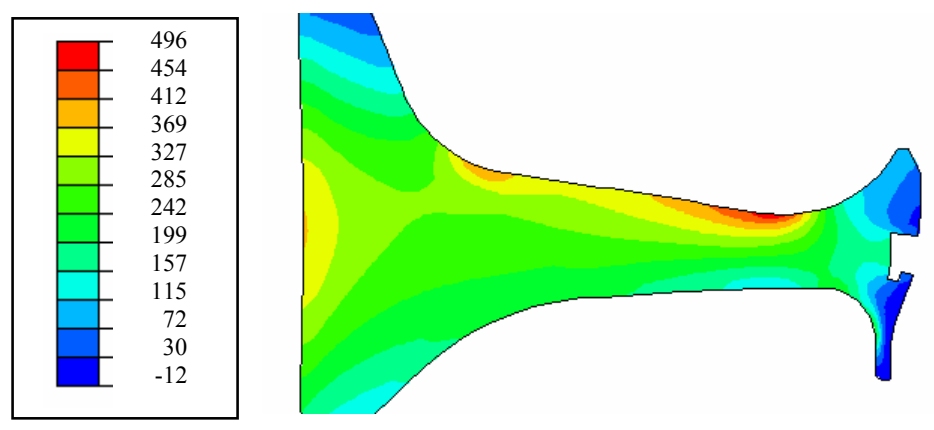

Figure 8. Maximum principal stress $(\mathrm{MPa})$ in turbine disc

A 3D finite element (FE) model was created using the current 2D geometry to account for the bending stress induced by the blade. Since the rotor has 27 blades, a $1 / 27^{\text {th }}$ model 
shown in Figures 9 and 10 was developed, taking advantage of cyclic symmetry. ABAQUS FEA software was used to determine the centrifugal and thermal stresses. Convective heat transfer coefficients and sink temperatures were obtained from the aero-analysis to reflect ST5+ flow conditions. However, thermal boundary conditions for the disk front and rear surfaces and bore were based on the ST5, as flow conditions were not finalized yet. The stress distribution (Figure 10) is in good agreement with the $2 \mathrm{D}$ prediction. The maximum stress however is high in both cases. This is mainly caused by the introduction of the bore and to a lesser extent caused by a larger temperature gradient due to the hot blade. The rotor shape optimization to minimize maximum principal stress is in progress and the CARES/LIFE code will be used to predict the probability of failure.
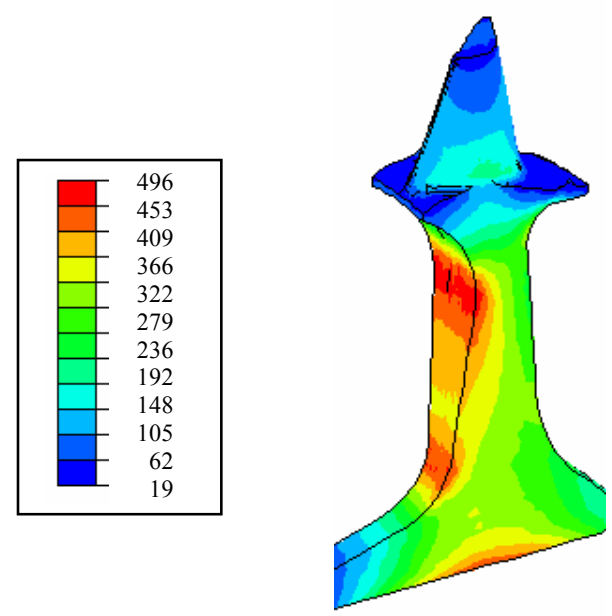

Figure 9. Temperature distribution $\left({ }^{\circ} \mathrm{C}\right)$ from the $3 \mathrm{D}$ analysis
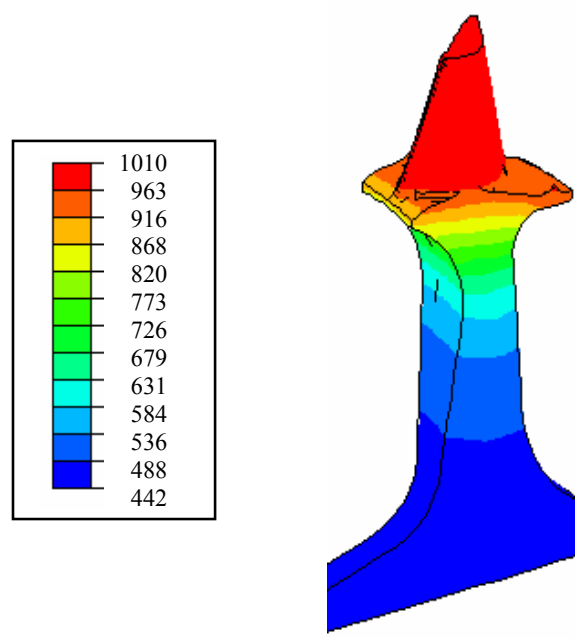

Figure 10. Maximum principal stress $(\mathrm{MPa})$ in a 3D analysis

\section{Foreign Object Damage Assessment}

A foreign object damage (FOD) assessment was preformed on the ST5+ rotor. The same analysis was also performed on the ST5 rotor to compare the FOD susceptibility of the two designs. For this analysis, the rotors were assumed to be made of AS800 silicon nitride from Honeywell Ceramic Components. The ST5+ rotor was designed with fewer, thicker blades, which have relatively large leading and trailing edge radii. The root fillet was also made as large as practically possible.

The analysis was performed using DYNA3D software. A one-quarter disk with a single blade was modeled as shown in Figures 11 and 12 . While the disk is rotating at speed, a 1.33 $\mathrm{mm}$ diameter zirconia particle weighing $0.007 \mathrm{gms}$ entrained in the gas stream impacts the blade. This represents an event of TBC spallation from the combustor liner. The direction and speed of the particle were determined from the aero-analysis.

An elastic material model with damage based on principal stress was used in the analysis. Elements were removed from the model when specified fracture strength was exceeded on two perpendicular planes. Gas shot test data was available and the damage model was calibrated to produce gas shot simulations that showed good agreement with the reported test results [15].

Figures 11 and 12 compare the damage incurred by the ST5 and ST5+ rotors subjected to an impact with the same size foreign object traveling at identical speeds. The foreign object penetrated all the way through the ST5 blade and rebounded from the ST5+ blade. It needs to be emphasized that this is a qualitative comparison of the extent of impact induced damage. The currently available damage models at UTRC do not include detailed fracture mechanics. It is likely that the damage shown in figure 11 would result in the loss of the trailing edge tip of the blade.

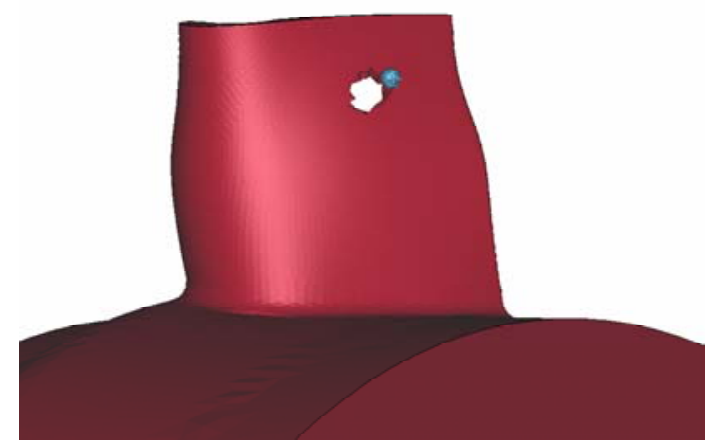

Figure 11. ST5 ceramic blade after particle impact 


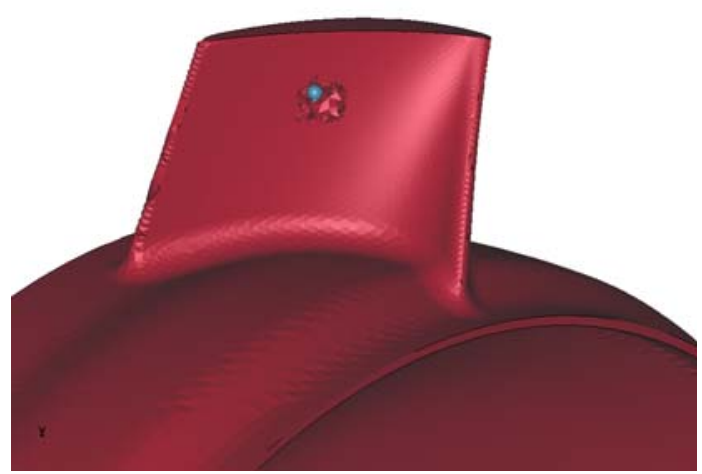

Figure 12. ST5 + ceramic blade after particle impact

Another important measure of FOD susceptibility is blade root stress. After the impact a pressure wave is propagated to the root. Damage is often seen in the root due to the bending stress. Figure 13 shows the root stresses in the ST5+. The stresses represent an approximate $40 \%$ decrease compared to the root stresses in the ST5 geometry.

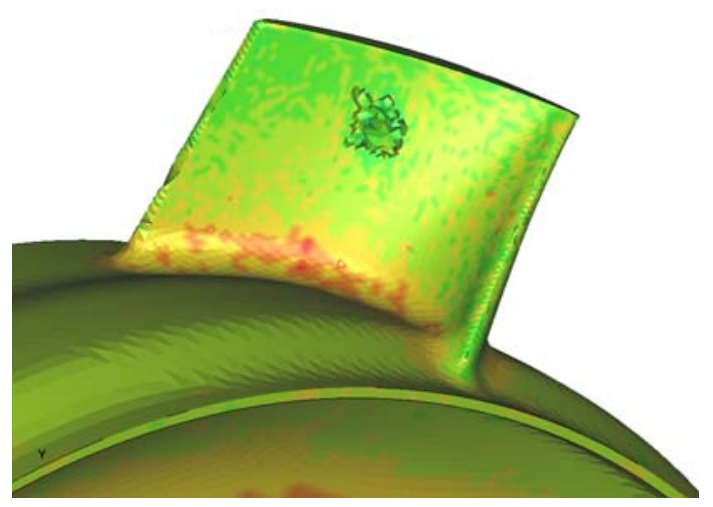

Figure 13. Root stresses (MPa) in ST5+ ceramic blade after particle impact

\section{SUMMARY AND CONCLUSIONS}

Preliminary aerodynamic and mechanical design of a ceramic vane ring and a ceramic IBR has been conducted for the ST5+ microturbine. Vane and IBR airfoils of the baseline engine ST5 have been thickened and blade counts were reduced to achieve a better FOD resistance. Detailed thermal and stress analyses were performed to establish structural integrity. It was found that ST5+ ceramic vane has a low probability of failure under steady state average-inlet and hot-streak conditions. The stress in the IBR, however, is higher than desired. Further efforts are focused upon reducing the stresses in IBR and transient thermal stress analysis.

\section{ACKNOWLEDGEMENTS}

The authors would like to thank DOE for its financial support and Debbie Haught of the DOE Office of Power Technologies and Stephen Waslo of the DOE Chicago Operations Office for their programmatic support. They also wish to acknowledge the technical support from Zarir Irani of Pratt \& Whitney Canada.

\section{REFERENCES}

[1] Rosfjord,T., Advanced Microturbine Systems, Progress Report for Period October 6, 2000 to December 31, 2000, for US Department of Energy.

[2] Chiappeta, L., 2001, ST5: Scroll Flow Field Features and Profile Factor, UTRC Internal Memo.

[3] Day, W.H., Kouris, K., Holowczak, J.E., Blair, M.F., Hale, S.E. and Bornemisza, T.G., 2000, "Development of Cooled, Ceramic First Stage Vanes for the FT8 Aeroderivative Gas Turbine", ASME Paper 00-GT-133.

[4] Easley, M.L. and Smyth, J.R., 1996, "Ceramic Gas Turbine Technology Development", ASME Paper 96-GT-367.

[5] Faulder, L., McClain, J., Edwards, B. and Parthasarathy, V., 1998, "Ceramic Stationary Gas Turbine Development ProgramDesign and Test of a First Stage Ceramic Nozzle", ASME Paper 98-GT-528, International Gas Turbine and Aeroengine Congress and Exhibition, Stockholm, Sweden, 1998.

[6] Tsuchiya, Y., Yoshino, S., Chikami, R., Tsukuda, Y. and Mori, M., 1996, "Development of Air-cooled Ceramic Nozzles for a Power-Generating Gas Turbine", p717, vol118, 1996, J. of Eng. for Gas Turbines and Power, Tran. of ASME.

[7] Wenglarz, R.A., Calcuttawala, S.M. and Pope, J.E., "Ceramic Vane Demonstration in an Industrial Turbine", ASME Paper 97GT-155, International Gas Turbine and Aeroengine Congress and Exhibition, Orlando, Florida, 1997.

[8] Tanaka, K., Tsuruzono, S., and Terazono, H., "Characteristics and Applications of the New Silicon Nitride Materials, SN281 and SN282, for Ceramic Gas Turbine Components", $6^{\text {th }}$ International Symposium on Ceramic Materials and Components for Engines, 1997, pp. 248-252.

[9] Smialek, J.L., Robinson, R.C., Opila, E.J., Fox, D.S., and Jacobson, N.S., "SiC and $\mathrm{Si}_{3} \mathrm{~N}_{4}$ Recession Due to $\mathrm{SiO}_{2}$ Volatility Under Combustor Conditions", Adv. Composite Mater., Vol. 8, No. 1, 1999, pp. 33-45.

[10] Nemeth, N.N., Janosik, L.A, Gyekenyesi, J.P., "Ceramics Analysis and Reliability Evaluation of Structures/Life Prediction Program, Users and Programmers Manual", NASA Glenn Research Center, 1993.

[11] Jimenez, O., McClain, J., Edwards, B., Parthasasathy, V., Bagheri, H. and Bolander, G., "Ceramic Stationery Gas Turbine Development Program-design and Test of a Ceramic Turbine Blade", ASME 98-GT-529, International Gas Turbine and Aeroengine Congress and Exhibition, Stockholm, Sweden, 1998. 
[12] Norton, F.P., Frey, G. A., Bagheri, H., Flerstein, A., Twardochieb, C., Oscar, J. and Saith, A., Ceramic Stationary Gas Turbine Development Program-Design and Life Assessment of Ceramic Components, ASME Paper 95-GT-383, International Gas Turbine and Aeroengine Congress and Exhibition, Houston, Texas, 1995.

[13] Sinnet, G.T., French, J.M. and Groseciose, L.E., "Progress on the Hybrid Vehicle Turbine Engine Technology Support (HVTE-TS) Program", ASME Paper 97-GT-88, International
Gas Turbine and Aeroengine Congress and Exhibition, Orlando, Florida, 1997.

[14] Robinson, D.J. and Meacham, W.L., United States Patent 6,250,883, Jun. 26, 2001.

[15] van Roode, M., Jimenez, O., McClain, J., Price, J., Parthasarathy, V., Poormon, K.L., Ferber, M.K., and Lin, H-T., "Ceramic Stationary Gas Turbine Development Program Impact Study", ASME TURBOEXPO 2002, Land, Sea and Air, Amsterdam, The Netherlands. 
Proceedings of:

ASME TURBOEXPO 2004

June 14-17, 2004, Vienna, Austria

GT-2004-54205

\title{
Design of Ceramic Components for an Advanced Micro-turbine Engine
}

\author{
Bill Tredway, Jun Shi, John Holowczak, Venkata Vedula, Connie E. Bird, S. Scott Ochs, Luca Bertuccioli, \\ David J. Bombara and Kevin E. Green \\ United Technologies Research Center, East Hartford, CT
}

\begin{abstract}
Ceramic components, due to their high temperature capability, allow significantly higher turbine inlet temperatures with minimal cooling. Hot-section engine components, including combustor, integral vane ring, integrally bladed turbine rotor, and turbine tip shroud were designed for an advanced micro-turbine engine, with special attention to attachment methods that minimize thermal stresses due to large differences between coefficients of thermal expansion between metallic and ceramic materials. Detailed aerodynamic, thermal and stress analyses were performed. Both steady state and transient conditions were evaluated to guide design decisions that lead to optimal component reliability and manufacturability. This paper describes the component design, analysis, and fabrication experiences with silicon based monolithic ceramic materials.
\end{abstract}

\section{INTRODUCTION}

The recent massive blackout in North America highlighted the vulnerability of the current electric grid system for reliable distribution of electric power [1]. The blackout on August 14, 2003, affected 50 million people in eight U.S. states and eastern Canada. Billed as the worst blackout in America's history, it cost at least $\$ 6$ billion in economic and other losses.

The U.S. Department of Energy (DOE) had foreseen the potential problems with antiquated power distribution systems and initiated an Advanced Micro-turbine Systems program [2]. Under this program, electric generators driven by high efficiency micro-turbine engines are developed to provide electric power local to power demands, thereby relieving the reliance on electricity grids that are already congested and are costly to maintain and upgrade.

United Technologies Research Center and Pratt and Whitney recognized the market potential for micro-turbine engines for distributed power generation and were awarded a DOE contract to develop a high thermal efficiency $(>40 \%)$ and low installed cost $(<\$ 500 / \mathrm{kW}) \mathrm{ST} 5+$ micro-turbine with a power output of $400 \mathrm{kw}$ [3].

A key improvement to the advanced micro-turbine is application of structural ceramics to hot gas path components: combustor, first stage turbine vanes, integrally bladed rotor (IBR), and turbine tip shroud. Together, these ceramic components account for 3\% increase in engine thermal efficiency relative to the baseline ST5 engine.

A picture of the ST5+ micro-turbine with its major components are shown in Figure 1. Engine specifications and early work on the design, analysis and fabrication of these components were reported in a previous paper [4]. This paper describes more recent development efforts.

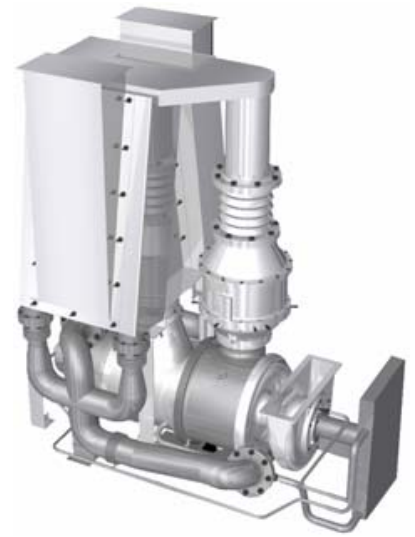

Figure 1: Baseline ST5 micro-turbine engine

\section{CERAMIC COMBUSTOR}

Metal combustor cans are either film cooled (earlier gas turbine engines) or impingement cooled (more recent engines) to maintain structural integrity under severe thermal loading. In both cases, the cooled combustor wall leads to local quenching of $\mathrm{CO}$ burnout, thereby resulting in high (toxic) $\mathrm{CO}$ emissions. In addition, active film cooling of the combustor wall also introduces flow losses that are detrimental to engine performance.

By using high temperature ceramic materials, film or impingement cooling, $\mathrm{CO}$ quenching as well as the associated flow losses can be eliminated [5]. Elimination of the impingement cooling sleeve also represents a substantial cost saving, as the sleeve is fabricated with a large number of 
precision drilled cooling holes. Since a ceramic combustor wall operates at a higher temperature than a metal combustor wall, it helps to stabilize combustion process, especially at part-load conditions for lean premixed combustion, which is prone to combustion instability and flameout.

Six ceramic materials were considered for the micro-turbine combustor, four monolithic ceramics; silicon carbide (SiC), silicon nitride $\left(\mathrm{Si}_{3} \mathrm{~N}_{4}\right)$, siliconized silicon carbide ( $\left.\mathrm{SiSiC}\right)$, alumina $\left(\mathrm{Al}_{2} \mathrm{O}_{3}\right)$, and two ceramic matrix composites (CMCs)Oxide/Oxide and $\mathrm{SiC} / \mathrm{SiC}$. Although $\mathrm{CMC}$ combustors have been successfully demonstrated on industrial gas turbine engines $[5,6,7,8]$, their cost was found to be prohibitive for the cost sensitive micro-turbine. In addition, the small size and low stress expected in the micro-turbine combustor warranted monolithic ceramics as past engine experience has illustrated $[9,10,11]$. As a result, CMCs were not pursued for the ST5+ micro-tubine combustor.

The four monolithic ceramics, they were ranked according to their strength, resistance to thermal shock, and cost of manufacturing. $\mathrm{Al}_{2} \mathrm{O}_{3}$ and $\mathrm{Si}-\mathrm{SiC}$ were eliminated because of low thermal shock resistance and low strength respectively. SiSiC was also found to be prone to creep at stress and temperature regime expected for the ceramic combustor can. Insitu toughened $\mathrm{Si}_{3} \mathrm{~N}_{4}$ offers the highest strength and toughness, but it is more costly than $\mathrm{SiC}$. Therefore $\mathrm{SiC}$ was selected as the primary candidate material for combustor can.

The ST5+ has a single silo type combustor (see Figure 1) and the current metal combustor in the baseline configuration is impingement cooled. The metal can is supported at the fuel nozzle and is free to slide at its exit in and out of the combustion transition duct. The ceramic combustor adopted the same arrangement at exit, but special attention was paid to the attachment method at the fuel nozzle end in order to minimize thermal stress resulting from the thermal expansion difference between the metal support and the ceramic combustor.
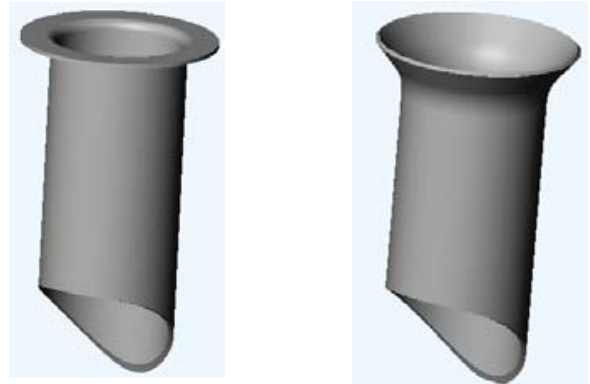

Figure 2: Two Ceramic Combustor Attachment Methods

Two ceramic combustor cans were designed; both with a flange at the fuel nozzle end for attachment (see Figure 2). One design has a right angle flange, while the other design has a 45degree flange. The ceramic cans are clamped down to a metal support through a spring that purports to absorb the thermal expansion mismatch between the can and the metallic support.

Extensive thermal and stress analyses were performed to ascertain the temperature, thermal stress and probability of failure. The temperature and maximum principal stress distributions are shown in Figure 3. The temperature is lower at the flange area, necessary for attachment, but higher at the main combustor can body. The temperature difference between metal and ceramic at attachment generates substantial thermal stress and insulation material was added to minimize heat flow from the ceramic can to the metal support, thereby raising temperature at the ceramic can attachment area while still maintaining a low temperature for the metal support.

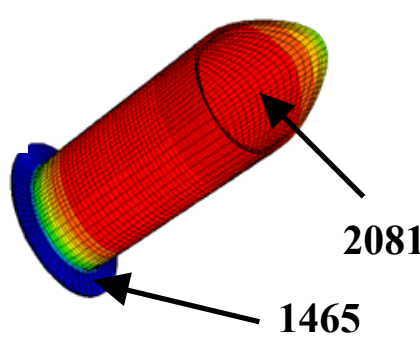

(a)

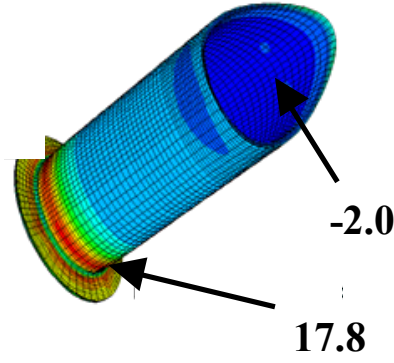

(b)
Figure 3: (a) Temperature distribution ( $F$ ) and (b) maximum principal stress (ksi) in Ceramic Combustor Can

The final results for the two designs are summarized in Table 1, where three materials other than $\mathrm{SiC}$ are also included for comparison purpose. The ceramic can design with a 45 degree flange has a lower thermal stress and corresponding failure probability than the 90 degree flange design because of its lower constraint on the thermal expansion of the hotter main ceramic can body.

Table 1: Maximum Temperature and Stress in Two Ceramic Combustor Designs

\begin{tabular}{|c|cc|cc|}
\hline \multirow{4}{*}{ Material } & \multicolumn{4}{|c|}{ Design } \\
\cline { 2 - 5 } & \multicolumn{2}{|c|}{90 Degree Flange } & 45 Degree Flange \\
\cline { 2 - 5 } & Max./Min. & Max. Stress & Max./Min. & Max. Stress \\
& Temp $\left({ }^{\circ} \mathrm{F}\right)$ & (ksi) & Temp $\left({ }^{\circ}\right.$ F) & (ksi) \\
\hline Honeywell AS800 & $2103 / 1330$ & 14.6 & $2103 / 1320$ & 7.9 \\
Hexoloy SA SiC & $2081 / 1465$ & 17.8 & $2080 / 1457$ & 7.8 \\
CoorsTek SCRB-210 & $2090 / 1391$ & 16.6 & $2090 / 1392$ & 8.1 \\
Kyocera SN282 & $2103 / 1330$ & 11.3 & $2103 / 1320$ & 6.1 \\
\hline
\end{tabular}

In order to determine if there were any issues with acoustic vibration, baseline combustor configuration tests were performed. The measured frequency-dependent impedance was incorporated in a thermo-acoustic model, which predicted that at $100 \%$ power, system instability most likely exists near $480 \mathrm{~Hz}$. Due to the high stiffness and low density, the first natural frequency of the ceramic can is $1605 \mathrm{~Hz}$; therefore well above the excitation frequency. 


\section{CERAMIC VANE DESIGN AND ANALYSIS}

As stated in [4], there are two major reasons for selecting a vane ring rather than individual vanes: cost of manufacturing and reduction of sealing area. The primary loading on the ceramic vane ring is thermal in nature and transients during start-up and shutdowns present the worst cases. Therefore, the focus of the more recent work was to reduce the high stresses during transient conditions by design changes. The effects of platform thickness and attachment ring location on transient stresses were evaluated parametrically. The analysis also accounted for the presence of an environmental barrier coating (EBC) on the vane. A significant reduction in the transient stress from $59 \mathrm{ksi}$ to $26 \mathrm{ksi}$ was achieved when the attachment ring was relocated towards the trailing edge and the outer platform cooling was modified.

Detailed transient and steady state thermal analysis was performed on the aero-optimized airfoil designs. The steady state and transient thermal stresses in the vane ring were found to be acceptable for both average inlet and hot-streak conditions. The hot-streak and average inlet steady state stresses were found to be 25.3 and $13.9 \mathrm{ksi}$, respectively. The transient stress (in the hot streak zone) peaked to $25.9 \mathrm{ksi}$ at the trailing edge fillet on the inner platform, 8 seconds into trip shut-down (Figure 4).
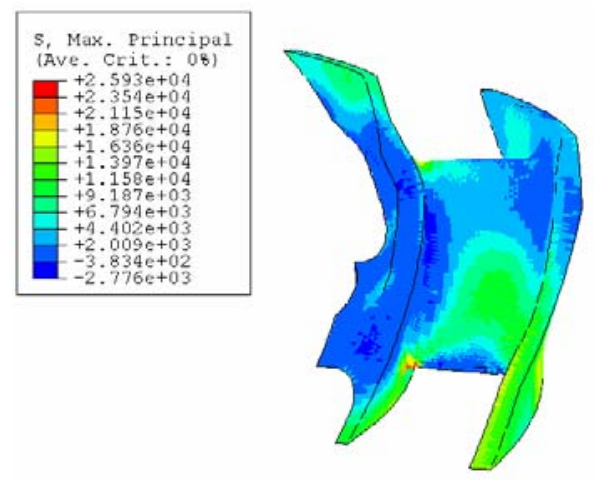

Figure 4: Thermal stress during trip shutdown after 8 seconds

Ceramic reliability analysis using NASA's CARES/Life [12] predicted a probability of fast fracture failure of $\sim 1$ in $1,000,000$ for individual vanes under steady state hot streak condition. Scaling the analysis to the entire vane ring predicted a failure probability of 1 in 100,000. The structural analysis was repeated to include the attachment tab (and the pressure loading on it) on the inner platform of the vane ring. The internal tab led to an increase in the stress to $34.5 \mathrm{ksi}$ and the resulting probability of failure was predicted as 1.4 in 10,000 vane rings. No slow crack growth nor creep life was assessed so far.

The final vane ring design was released for fabrication at Kyocera Industrial Ceramics Corp (KICC) in Vancouver, WA. Kyocera's silicon nitride grade SN282 was selected for its high creep resistance at high temperature, which is a key issue for turbine vanes due to the presence of hot streaks from the combustor that exceed the average turbine inlet temperature by a considerable margin. Vane ring blanks were dry pressed and underwent a pre-sinter operation to prepare them for bisque machining (Figure 5a). A bisque machining approach was developed to enable machining of the complex vane ring geometry, which consisted of 15 vanes joined by integral inner and outer platforms. As a prelude to actual bisque machining of vane rings, a plastic model was machined using the CAM program to ensure that all surfaces could be accessed, and that there were no errors in CAM programming.

A total of three bisque fired SN282 were pre-sinter machined followed by sintering. The yield on the components was outstanding, with all three being free of any shrinkage cracks, major distortion, or other defects. This yield is unusual in typical initial prototyping of large silicon nitride turbine components. Both throat width measurements and limited contact coordinate measurements indicated that the flow areas between each vane were within $4 \%$ of the original CAD model. One of the three vane rings had minor chip outs, which were deeper than the anticipated final diamond grinding envelope. The other two components were deemed acceptable for engine environment/gas generator testing.

At the time of this writing, all three vane rings are undergoing diamond grinding of their attachment regions. All areas outside the actual gaspath will be diamond ground to ensure high dimensional tolerance with mating metallic components and seals. It is anticipated that one or two of the vane rings will undergo steady state and trip shutdown transient testing in UTRC's ST5 gas generator rig during calendar year

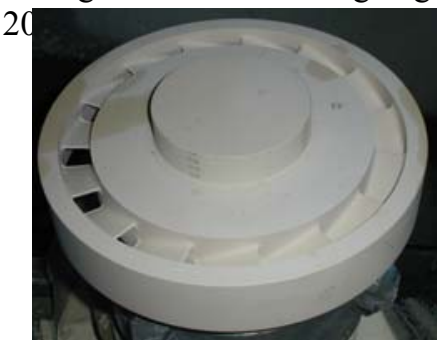

a)

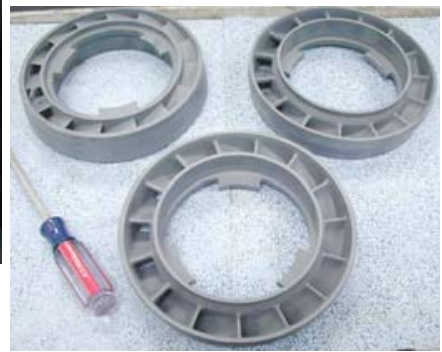

(b)
Figure 5: (a) Bisque machined vane ring; (b) Three vane rings after final processing

\section{CERAMIC INTEGRALLY BLADED ROTOR}

An integrally bladed rotor (IBR), rather than individual inserted blade design was chosen for cost and reduction of contact area between ceramic and metal interfaces. The latter represents a considerable saving in machining of contact surfaces and elimination of high contact stresses. The previous paper [4] focused on steady state thermal and stress analysis and reducing stress at the disc bore. This paper summarizes the efforts to reduce the stresses at disc rim under steady state conditions and stress during engine transients. 


\section{Steady State Disc Rim and Blade Root Stress}

The two highly stressed areas of the IBR are disc rim and the root of the blade. A series of sensitivity studies was performed to reduce rim and blade root stress. The rim stress is mainly caused by the uneven radial deflections at the leading edge and the trailing edge of the rim. The blade was joined with the disc and a root fillet radius was added. The radial stress in the base of the blade was found to be unevenly distributed. The rotor was reshaped and re-optimized to reduce and balance rim deflection (Figure 6). The blade was then stacked so the center of gravity of the blade cross sections lay on a radial line.

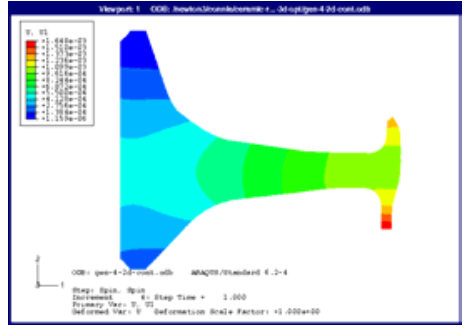

(a)

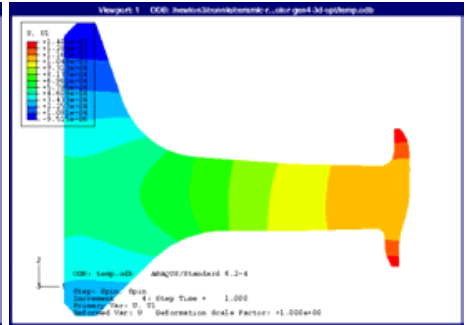

(b)
Figure 6: Plot of disc deflection for (a) original and (b) modified disc designs

The peak radial root stress was reduced by approximately 5 ksi. The high blade root radial stress was not entirely eliminated because untwisting of the blade causes some of the radial root stress variation. Figure 7 is a plot of the maximum principal stress in the rotor stress in the root of the blade.

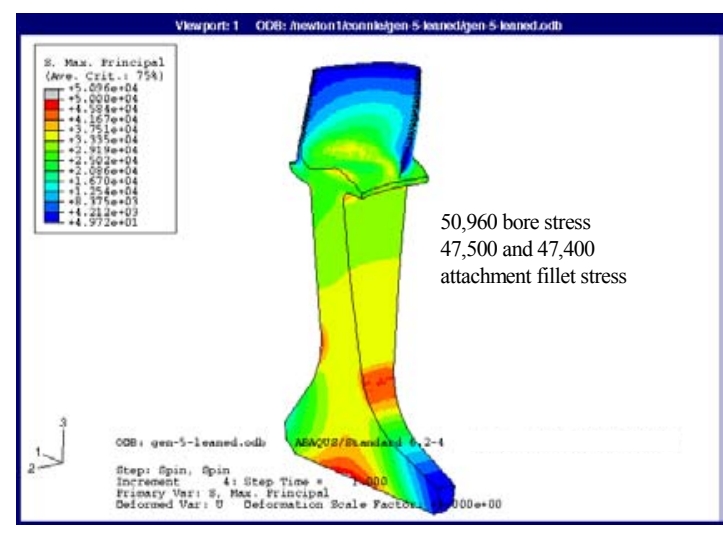

Figure 7: Plot of IBR stress after shape optimization

Significant hoop stress was also found in the blade root fillet. A series of studies were performed to gain an understanding into the cause of the root fillet stress and these studies have not been concluded.

Aero-thermal transient analysis data for convective heat transfer coefficients, blade sink temperature at tip, mid-span and root, and rotational velocity were provided as a function of time. Transient structural analyses of the IBR design were performed using this data. The results were examined for thermal transients that may cause locally high stress.

\section{Cold Start Up}

This analysis for cold start-up was performed for 100 seconds of operation, assuming that all the hardware has an initial temperature of $-10^{\circ} \mathrm{F}$. One concern was that the blades would become hot quickly while attached to a rotor hub that was still low in temperature, leading to high thermal stresses. The start up simulated is from a stationary rotor to idle. The final rotor $\mathrm{rpm}$ is $50 \%$ of max power and the idle blade sink temperature is approximately $1200^{\circ} \mathrm{F}$ lower than the temperature at maximum power. Figure 8 shows a plot of rotor maximum principle stress as a function of start up time.

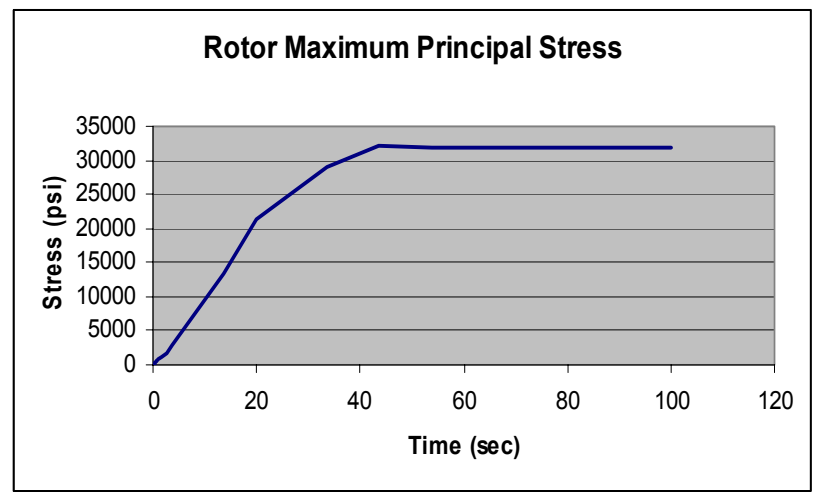

Figure 8: Cold start-up rotor maximum principal stress as a function of time

\section{Emergency Trip Shut Down}

In this analysis the rotor is operating at full power at the start of the simulation. The initial blade mid-span sink temperature is $1902^{\circ} \mathrm{F}$ and the initial rotor speed is $50,352 \mathrm{rpm}$, which represent the highest stress state. The stress diminishes as the rotational speed decreases and the thermal gradients are reduced. Figure 9 is a plot of maximum principle stress as a function of time. The start-up and shut down analysis suggests that the transient stresses are lower that what are expected at full power conditions. 


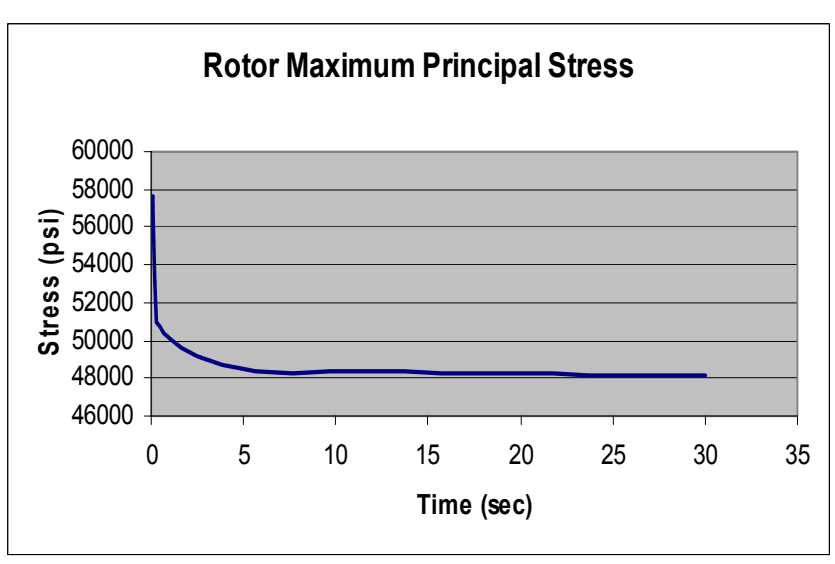

Figure 9: Emergency shutdown maximum principal stress as a function of time

\section{Ceramic IBR Life Prediction}

The NASA CARES/Life code [9] was used to predict the probability of failure for the final IBR design. NT154 silicon nitride from Saint Gobain Ceramics was selected as the material for IBR. For this material, as-processed material has a different strength and Weibull distribution than longitudinally or transversely ground material. Additionally, the strength and Weibull modulus is a function of temperature. Since the IBR will have all three types of surfaces as well as a temperature distribution during operation, the FEA model was partitioned into three sets to more accurately predict the probability of failure. Figure 10 shows the partitioning of the FEA model for ceramic life prediction.
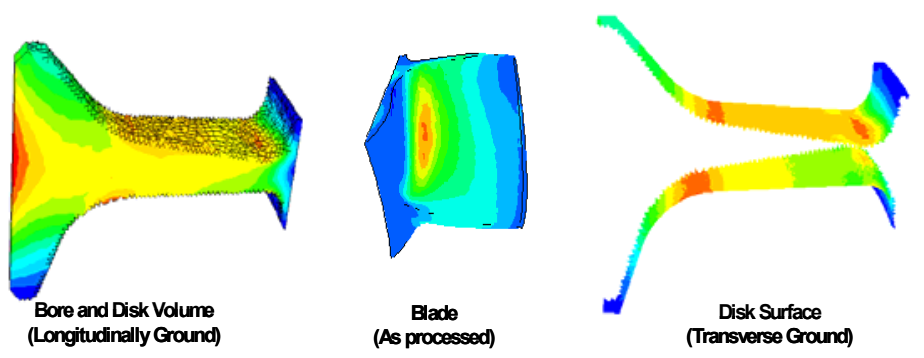

Figure 10: IBR FEA model partitioned into three sets for CARES reliability analysis

Table 2 contains a summary of the fast fracture reliability results. It is apparent from examining the table that the cold spin case has the highest probably of failure. The cold spin conditions would only be encountered during rotor proof testing. The high probability of failure is due to the large hoop stress in the rim. This stress is greatly reduced as the rotor heats up and develops a thermal gradient. The probability of failure of the blade and rim would be reduced to approximately $0.1 \%$ if the blade surfaces were machined. This would obviously have an adverse effect on overall IBR cost. In all cases the probability of failure is controlled by the blade and rim.
Table 2: Fast Fracture Failure Probability of IBR under Four Loading Conditions

\begin{tabular}{|c|c|c|c|c|c|}
\hline \multirow{2}{*}{ IBR Location / Strength } & \multirow{2}{*}{$\begin{array}{l}\text { Charac. Strength ksi } \\
\text { (Weibull Modulus) }\end{array}$} & \multicolumn{4}{|c|}{ Probability of Failure } \\
\hline & & Cold Spin & Hot Spin & $\begin{array}{l}\text { Transient } \\
\text { Shut-down }\end{array}$ & $\begin{array}{l}\text { Transien } \\
\text { Start-up }\end{array}$ \\
\hline $\begin{array}{l}\text { Bore and Disk Volume / } \\
\text { Longitudinal ground }\end{array}$ & $90.79(14.73)$ & 4.32E-05 & $1.51 \mathrm{E}-04$ & 1.11E-04 & $2.00 \mathrm{E}-08$ \\
\hline $\begin{array}{c}\text { Disk Surface / } \\
\text { Transverse ground }\end{array}$ & $71.44(14.14)$ & $3.78 \mathrm{E}-04$ & $1.46 E-03$ & 1.19E-03 & 3.10E-07 \\
\hline $\begin{array}{c}\text { Blade / } \\
\text { As processed }\end{array}$ & $30.71(8.93)$ & 3.71E-01 & $1.17 \mathrm{E}-01$ & 1.10E-01 & $9.61 \mathrm{E}-04$ \\
\hline $\begin{array}{l}\text { Combined Probability of } \\
\text { Failure for IBR }\end{array}$ & - & 3.71E-01 & 1.18E-01 & 1.11E-01 & 9.61E-04 \\
\hline
\end{tabular}

\section{CERAMIC SHROUD}

Due to the low thermal expansion of silicon nitride materials, the ceramic IBR of ST5+ would grow thermally approximately $1 / 3$ that of the metallic ST5 compressor turbine rotor. In addition, the low density and high stiffness of the ceramics makes the ST5+ ceramic IBR expand less than the ST5 metallic rotor under centrifugal forces. Combining these two factors together, a large gap could be expected between the ceramic IBR and the metal shroud. This could result in severe blade tip flow losses that can be translated to low turbine and engine efficiency.

To assess the effect of such loss, a tip clearance analysis was conducted for three shrouds: metal shroud, $\mathrm{SiC}$ and $\mathrm{Si}_{3} \mathrm{~N}_{4}$ shrouds. These analyses included checking pinch points, where clearance might go to zero or interference, during startup. Aero thermal heat transfer to the shroud, and its effect on shroud absolute temperature was also determined and added to the analysis.

The analysis showed that if a metal shroud is used with the ceramic rotor, excessive leakage would ensue due to the large tip clearance of $0.0261 \mathrm{in}$. However if a ceramic shroud is employed, the tip clearance is reduced to $0.0085 \mathrm{in}$ for $\mathrm{SiC}$ and 0.0062 in for $\mathrm{Si}_{3} \mathrm{~N}_{4}$. For small engines such as ST5+, a 0.001 in tip clearance equates $0.3 \%$ turbine efficiency. Therefore, use of a ceramic shroud may result in a $0.45 \%$ increase in turbine efficiency.

Four ceramic design concepts for the turbine shroud were generated and down selected to two. Detailed thermal and stress analyses were performed to determine which of the two concepts would be better as the final design. Due to the high rotation speed of the rotor blades, heat transfer coefficients for the shroud were determined as a function of the engine axial length only. Sink temperature variation in the circumferential direction assumed the same profile as predicated by CFD at the exit of the scroll. Considering the averaging effect resulting from the rotor blade rotation, such a profile represents a worse case.

Thermal distortion of the shroud support, i.e., the turbine support casing or the vane ring outer platform, strongly influences thermal stress in the shroud. Steady state thermal analysis showed that the OD platform of the vane grows radially by 0.0158 in under hot streak conditions and 0.014 in under average conditions. This means the maximum vane ring outer 
platform distortion is 0.0018 in, comparable to the 0.0015 in turbine support casing distortion. Under the worst thermal loading case, i.e. the hot streak conditions, the peak thermal stress is just over $10 \mathrm{ksi}$ in the shroud (see Figure 11).

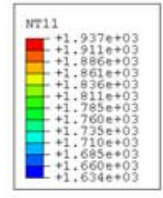

$2-3$

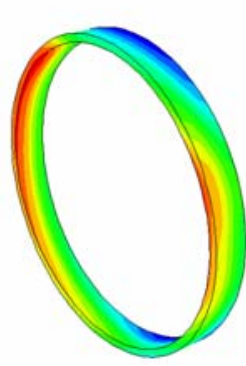

(a)
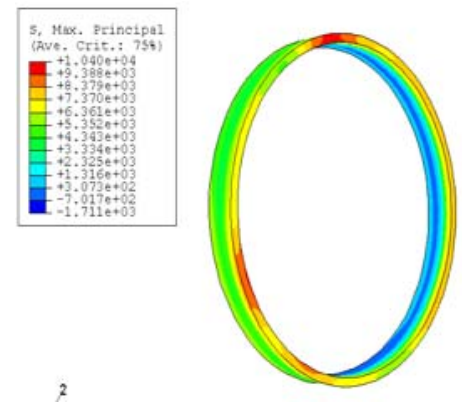

(b)
Figure 11: (a) Temperature distribution and (b) thermal stress distribution of the turbine shroud under hot streak conditions

A second major design concern is the relative thermal deformation between the shroud and its support during engine operation. To analyze this, thermal growth of the casing and the ceramic shroud during startup and shutdown was predicted. During the $-10 \mathrm{~F}$ cold start, the turbine support casing is expected to shrink 0.015 " more than the ceramic shroud, which means that a cold build clearance of at least 0.015 " is needed. At steady state, the casing grows 0.010 " more than the shroud, while during shutdown, the thin shroud reacts to gas temperature drop quickly, widening the gap between the shroud and the casing to 0.025 ". Therefore the overlap between the tab on the shroud and the slot on the casing should be greater than 0.015 " to maintain shroud support by the casing.

Contact stress considerations narrowed the design down to the one shown below. Because of the overall low stress in the shroud, siliconized silicon carbide $(\mathrm{SiSiC})$ was considered. Figure 12 shows the initial manufacturing attempt by Schunk Co in Gissen, Germany.

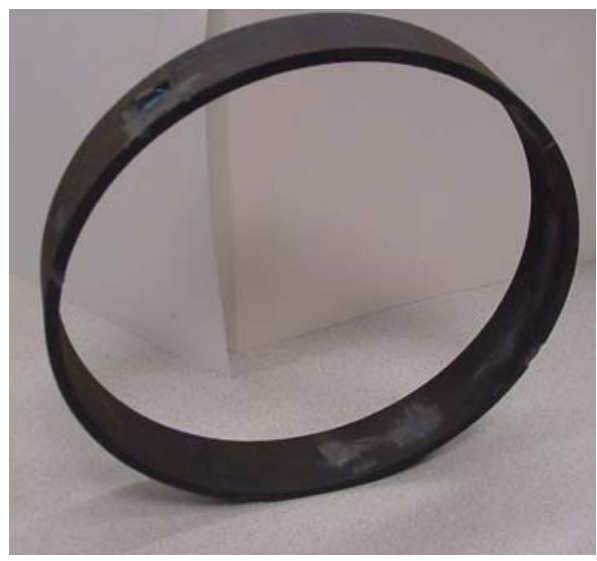

Figure 12: Ceramic turbine tip shroud

\section{SUMMARY AND CONCLUSIONS}

Significant progress has been made in designing the ceramic components for ST5+ micro-turbine engine. It is believed that the three stationery components- combustor can, first stage vane ring and turbine shroud can meet the design requirements. However, it remains a challenge to design the ceramic IBR with acceptable stress and reliability. Prototype ceramic vane rings and turbine tip shrouds have been made and two of the silicon nitride vane rings meet the standards for rig testing.

\section{ACKNOWLEDGEMENTS}

The authors would like to thank DOE for its financial support and Debbie Haught of the DOE Office of Power Technologies and Stephen Waslo of the DOE Chicago Operations Office for their programmatic support. They also wish to acknowledge the technical support from their colleagues at Pratt \& Whitney Canada.

\section{REFERENCES}

[1] Stauffer, J, 2003, August 14, 2003, "Blackout:Updated Sequence of Events", Cambridge Energy Research Associates Report

[2] U.S. Department of Energy, http://www.eere.energy.gov/ der/microturbines/microturbines.html\#advanced

[3] Rosfjord,T., "Advanced Microturbine Systems", Progress Report for Period October 6, 2000 to December 31, 2000, for US Department of Energy.

[4] Shi, J., V. Vedula, J. Holowczak, C. E. Bird, S. S. Ochs, L. Bertuccioli and D. J. Bombara, 2002, "Preliminary Design of Ceramic Components for the ST5+ Advanced Microturbine Engine", ASME GT-2002-30547, ASME TURBOEXPO 2002, June 3-6, 2002, Amsterdam, The Netherlands

[5] Smith, K.O. and Fahme, A, 1996, "Experimental assesment of the emissions benefits of a ceramic gas turbine combustor", ASME Turbo Expo 1996, Paper 96-GT-318

[6] Brewer,D., Ojard,G. and Gibler,M., 2000, "Ceramic Matrix combustor liner rig test", ASME Turbo Expo 2000, Munich, ASME 2000-GT-0670

[7] Verrilli, M.J., D. Brewer, 2002, "Characterisation of CMC fastners exposed in a combustor liner rig test", ASME GT2002-30459

[8] Igashira, K., Matsuda, Y., 2001, "Development of the advanced combustor liner composed of CMC/GMC hybrid composite material", ASME 2001-GT-0511

[9] Mikami, T., et al , 1996, "Status of the development of the CGT301, a 300KW Class Ceramic Gas Turbine", ASME 96GT-252.

[10] Tatsumi, T., et al, 1999, "Development summary of the 300kw ceramic gas turbine CGT302", ASME 99-GT-105

[11] Tanaka,R, T. Tatsumi, Y. Ichikawa, K. Sanbonsugi, 2001, "Development of the Hybrid Gas Turbine (1st year summary)", ASME 2001-GT-0515

[12] Nemeth, N.N., Janosik, L.A, Gyekenyesi, J.P., "Ceramics Analysis and Reliability Evaluation of Structures/Life Prediction Program, Users and Programmers Manual", NASA Glenn Research Center, 1993. 
Presented at the $28^{\text {th }}$ International Conference on Advanced Ceramics \& Composites, Cocoa Beach, FL, January 25-29, 2004

\section{CERAMIC COMBUSTOR DESIGN FOR ST5+ MICROTURBINE ENGINE}

Jun Shi, Venkata Vedula, Ellen Sun, David Bombara, John Holowczak, William Tredway, Alex Chen, Catalin Fotache

United Technologies Research Center

411 Silver Lane, East Hartford, CT 06108

\section{ABSTRACT}

Ceramic combustor liners require no film cooling on the hot-side and minimal backside cooling, due to their high temperature capability. The hotter combustor walls lead to minimal "wall quenching" and better carbon monoxide (CO) oxidation because less cooling is applied. A ceramic combustor can was designed for the ST5+ microturbine engine to improve the engine performance and emissions. The can was designed with special attention to attachment methods that minimize thermal stresses due to the large difference in thermal expansion coefficients between metallic and ceramic materials. Detailed thermal and stress analyses were performed to guide design decisions that lead to optimal component reliability and manufacturability. This paper gives a detailed account of the design and analysis associated with the ceramic combustor can.

\section{INTRODUCTION}

World population growth and the rise in living standards have increased the demand for electricity substantially over the last two decades. The increased demand for electric power has put on a strain over the electricity grids, most of which are dated and over-stretched for their capacity. This is best exemplified by recent massive blackout in North America highlighted the vulnerability of the current electric grid system for reliable distribution of electric power 1. The blackout on August 14, 2003, affected 50 million people in eight U.S. states and eastern Canada. Billed as the worst blackout in America's history, it cost at least $\$ 6$ billion in economic and other losses.

The U.S. Department of Energy (DOE) had foreseen the potential problems with antiquated power distribution systems and initiated an Advanced Microturbine Systems program ${ }^{2}$. Under this program, electric generators driven by high efficiency microturbine engines are developed to provide electric power local to power demands, thereby relieving the reliance on electricity grids that are already congested and are costly to maintain and upgrade. United Technologies Research Center and Pratt and Whitney recognized the market potential for microturbine engines for distributed power generation and were awarded a DOE contract to develop a high thermal efficiency $(>40 \%)$ and low installed cost $(<\$ 500 / \mathrm{kW})$ ST5 + microturbine with a power output of $400 \mathrm{~kW}$.

A key improvement to the advanced microturbine is application of structural ceramics to hot gas path components: combustor, first stage turbine vanes, integrally bladed rotor (IBR), and turbine tip shroud. Together, these ceramic components account for 3\% increase in engine thermal efficiency. A picture of the ST5+ microturbine with its major components is shown in Figure 1. Engine specifications and design of turbine components have been published previously ${ }^{3}$. This paper describes the design and analysis of the ceramic combustor can.

Combustors in gas turbine engines are subjected to severe thermal loading generated by the combustion process. The current metal combustor can in gas turbines are either film cooled or impingement cooled (more 
recent engines) to maintain structural integrity under severe thermal loading. In both cases, the cooled combustor wall leads to local quenching of $\mathrm{CO}$ burnout, thereby resulting in high $\mathrm{CO}$ emissions. In addition, active film cooling of the combustor wall introduces flow losses (pressure loss) that reduce the thermal efficiency of the engine. These effects become more pronounced in a lean premixed combustor system that operates at a lower temperature and has very limited air available for liner cooling. By using high temperature ceramic materials, $\mathrm{CO}$ wall quenching due to film or impingement cooling, as well as associated flow losses can be eliminated ${ }^{4}$. Since a ceramic combustor wall operates at a higher temperature than a metal combustor wall, it helps to stabilize combustion process, especially at part-load conditions for lean premixed combustion, which is prone to combustion instability and flameout.

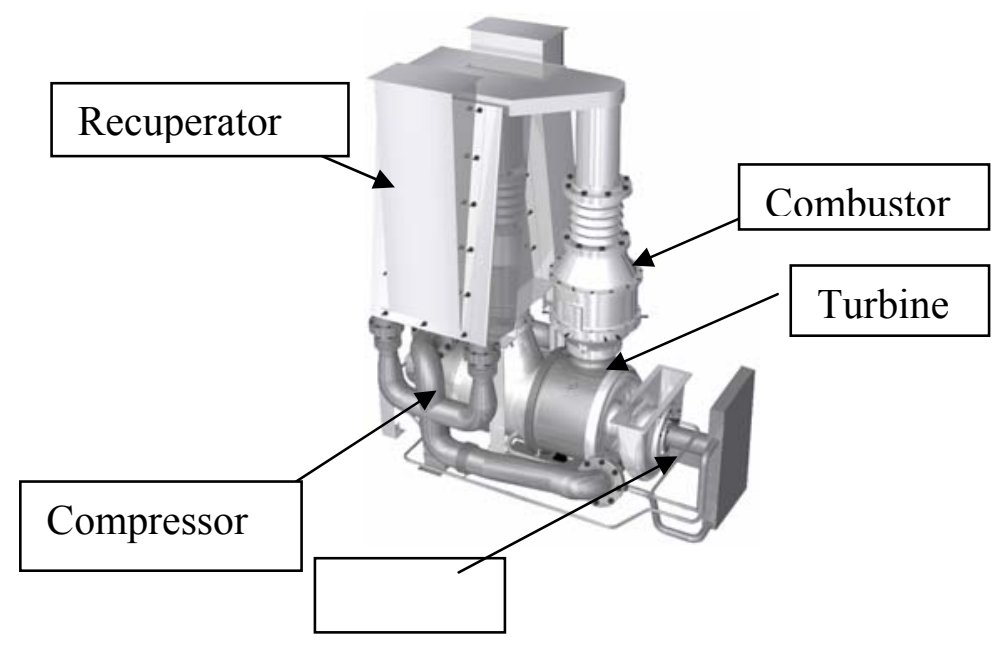

Figure 1: ST5+ Microturbine

\section{MATERIAL SELECTION}

In the current program, six ceramic materials were considered for the microturbine combustor, four monolithic ceramics; silicon carbide $(\mathrm{SiC})$, silicon nitride $\left(\mathrm{Si}_{3} \mathrm{~N}_{4}\right)$, siliconized silicon carbide (SiSiC), alumina $\left(\mathrm{Al}_{2} \mathrm{O}_{3}\right)$, and two ceramic matrix composites (CMCs)-Oxide/Oxide and $\mathrm{SiC} / \mathrm{SiC}$. Although CMC combustors have been successfully demonstrated for industrial gas turbine engines, $5,7,8$, their cost were found to be prohibitive for the cost sensitive microturbine. In addition, the small size and low stress expected in the microturbine combustor warranted monolithic ceramics as past engine experience has illustrated ${ }^{9,10,11}$. As a result, CMCs were not pursued for the ST5+ microturbine combustor. Alumina was not pursued due to low thermal shock resistance.

\section{ATTACHMENT DESIGN AND ANALYSIS}

The ST5+ microturbine engine has a single silo type combustor (see Figure 1). The current metal combustor in the baseline configuration is coated with thermal barrier coating (TBC) and is impingement cooled to withstand the high temperature and corrosive combustion environment. The silo combustor is connected to a combustor transition duct (CTD) that turns a vertical combustion gas flow into horizontal flow that goes into the turbine. Such a turning leads to high thermal loading on the CTD and since ST5+ engine is recuperated, there is concern that there may be insufficient cooling for the CTD. A use of ceramic combustor is advantageous since the combustor would need less cooling air (compared to a metal one) and if required, more cooling could be diverted to the CTD to ensure its mechanical integrity. 
The current metal can is supported at the fuel nozzle and is free to slide at its exit in and out of the combustion transition duct to minimize thermal stress. The ceramic combustor adopted the same arrangement at exit, but special attention was paid to the attachment method at the fuel nozzle end in order to minimize thermal stress resulting from the thermal expansion difference between the metal support and the ceramic combustor.

A number of concepts were proposed during the concept design phase. Two ceramic combustor cans were down-selected for preliminary and detail designs. Both ceramic cans are deigned with a flange at the fuel nozzle end for attachment (see Figure 2). One design has a right angle flange, while the other design has a 45degree flange. The ceramic cans are clamped down to a metal support through a wave spring that purports to absorb the thermal expansion mismatch between the can and the metallic support. At the interface between the ceramic can and the metal supports, ceramic seals with metal overbraid are inserted to avoid stress concentration by point contact and allow some relative movement.
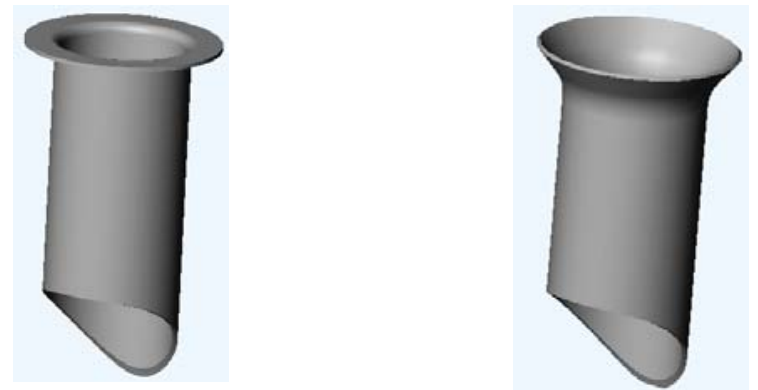

\section{Figure 2: Two Ceramic Combustor Attachment Methods}

Extensive thermal and stress analyses were performed to ascertain the temperature and thermal $/$ mechanical stress. The temperature and maximum principal stress distributions are shown in Figure 3. The temperature is lower at the flange area, necessary for attachment, but higher at the main combustor can body. The temperature difference between metal and ceramic at attachment generates substantial thermal stress and insulation material was added to minimize heat flow from the ceramic can to the metal support, thereby raising temperature at the ceramic can attachment area while still maintaining a low temperature for the metal support.

The final results for the candidate ceramic materials for both designs are summarized in Table 1 . The ceramic can design with a 45 degree flange has a lower thermal stress than the 90 degree flange design because of its lower constraint on the thermal expansion of the hotter main ceramic can body.
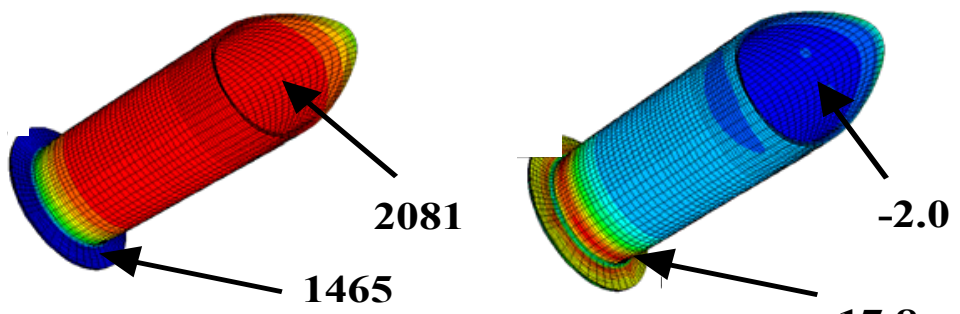

17.8

Figure 3: (a) Temperature distribution $(F)$ and (b) maximum principal stress (ksi) in SiC ceramic combustor can 
Table 1: Maximum Temperature and Stress in Two Ceramic Combustor Designs

\begin{tabular}{|c|cc|cc|}
\hline \multirow{2}{*}{ Material } & \multicolumn{4}{c|}{ Design } \\
\cline { 2 - 5 } & \multicolumn{2}{|c|}{ Flange } & \multicolumn{2}{c|}{ Taper } \\
\cline { 2 - 5 } & $\begin{array}{c}\text { Max./Min. Max. Stress } \\
\text { Temp (F) }\end{array}$ & $\begin{array}{c}\text { Max./Min. } \\
\text { (Ksi) }\end{array}$ & $\begin{array}{c}\text { Max. Stress } \\
\text { (ksi) }\end{array}$ \\
\hline Honeywell AS800 & $2103 / 1330$ & 14.6 & $2103 / 1320$ & 7.9 \\
Hexoloy SA SiC & $2081 / 1465$ & 17.8 & $2080 / 1457$ & 7.8 \\
CoorsTek SCRB-210 & $2090 / 1391$ & 16.6 & $2090 / 1392$ & 8.1 \\
Kyocera SN282 & $2103 / 1330$ & 11.3 & $2103 / 1320$ & 6.1 \\
\hline
\end{tabular}

The monolithic ceramics were ranked according to their strength, resistance to thermal shock, and cost of manufacturing. Si-SiC was eliminated because of its low strength at room and elevated temperatures. In addition, $\mathrm{SiSiC}$ was also found to be prone to creep at stress and temperature regime expected for the ceramic combustor can. In-situ toughened $\mathrm{Si}_{3} \mathrm{~N}_{4}$ offers the highest strength and toughness, but it is more costly than $\mathrm{SiC}$. Considering that the ceramic combustor is not as highly stressed as ceramic turbine vanes and blades, $\mathrm{SiC}$ was selected as the primary candidate material for combustor can.

Eigen value frequency analysis was also performed to determine if the thermo-acoustic and structural frequencies might lead to resonance. Baseline combustor configuration test was performed and the measured frequency-dependent impedance was incorporated in a thermo-acoustic model, which predicted that at $100 \%$ power, system instability most likely exists near $480 \mathrm{~Hz}$. The analysis predicted that the vibration frequencies for the first three bulk modes for combustor were 1605,2731 , and $3648 \mathrm{~Hz}$ due primarily to the fact that CMC's have high stiffness and low density. The vibration modes are shown in Figure 4. The first two frequencies are lower than $3000 \mathrm{~Hz}$ where thermo-acoustic frequencies are active, indicating that there is adequate dynamic excitation margin and resonance will not be an issue.
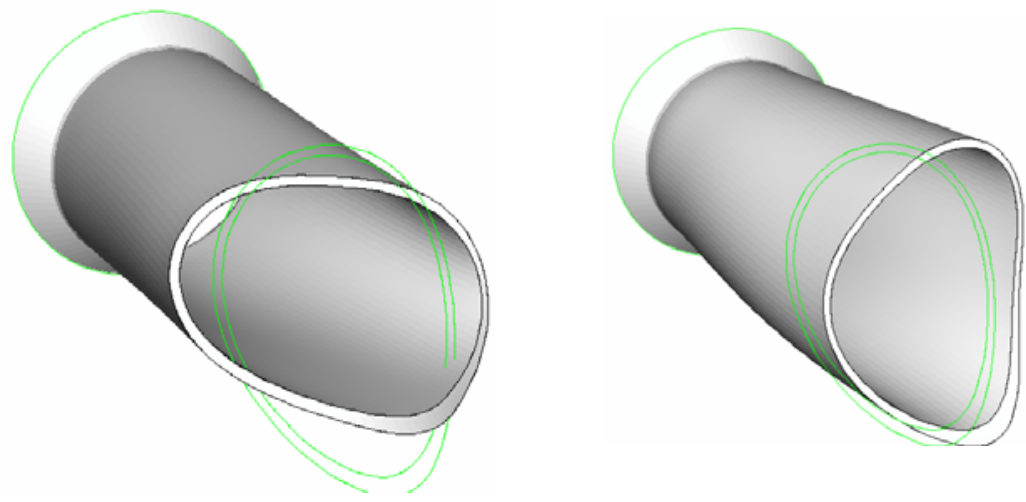

Figure 4: Vibration modes: Eigen value analysis (amplified displacements)

In addition to the combustor can material selection and design, there are several other elements under development to ensure that the overall combustor module can achieve the required life and performance. One such key element is a wave spring in the attachment design. The wave spring is used to mitigate the thermal 
stress that may built-up between the ceramic combustor can and the metal support under engine operating conditions when both expand thermally, but by different amount. The major concern was that the spring may not be able to maintain the clamping load due to creep, mainly due to high recuperated air temperature $(\sim 1130 \mathrm{~F})$. To verify the creep strength, wave springs were placed in a furnace and a constant load was applied to simulate service condition. The first set of wave springs were made of INCONEL X750 and they showed substantial creep deformation under load and temperature. A second set of wave springs were made using a more creep resistant Nickel based superalloy (IN718) and tested under same conditions. Unfortunately, the springs showed unacceptable creep deformation again. The springs were then redesigned to reduce stress and more temperature resistance materials were also considered. Ceramic rope seal is another important element of the low stress attachment design. To ensure its integrity under engine conditions, a special testing rig was set up to simulate actual thermal and mechanical loadings. Fatigue tests were run up to 1 million cycles and no visible damage was observed on the seals.

The other key element in the use of silicon carbide based materials in the gas turbine environments is the development and use of protective environmental barrier coatings (EBC's). EBC's are required because of the accelerated oxidation of $\mathrm{SiC}$ and subsequent volatilization of silica in the high temperature high-pressure steam environment. EBC systems for silicon carbide fiber reinforced silicon carbide composites ( $\mathrm{SiC} / \mathrm{SiC} \mathrm{CMC}$ 's) were first developed under NASA HSCT Program ${ }^{12}$. The multi-layer coating system typically consists of a silicon bond layer, a mullite containing intermediate layer and a top layer of a celsian-based complex silicate (such as barium strontium aluminum silicate - BSAS). The effectiveness of such multi-layer coating systems have been demonstrated via $>50,000$-hour field tests in industrial gas turbine engines under different DOE programs. Coating trials were performed to apply the multi-layer EBC to the ST5+ combustor liner. The plasma spray parameters were optimised to ensure high quality EBC coatings. Preliminary coating tests showed that a modified EBC process could be applied successfully to the combustor liner. The coating fixtures and parameters that were established during coupon trials were refined. A dense BSAS based coating with desired and uniform thickness was demonstrated on the inner surface of a SiC Hexoloy cylinder with the same ID (circa 6 inches) and similar length (circa 13 inches) as that of the advanced microturbine combustor liner (Figure 4).

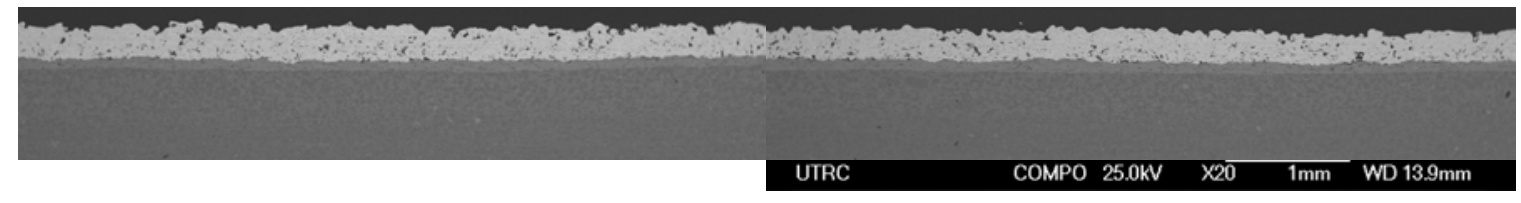

\section{SUMMARY}

Figure 5: Cross-section view of EBC on the ID surface of a 6" SiC Hexoloy cylinder

Significant progress has been made in designing the ceramic combustor for ST5+ microturbine engine. It is believed that the ceramic combustor can meet the thermal and stress design requirements. The ceramic combustor can was designed with special attention to attachment methods that minimize thermal stresses due to the large difference in thermal expansion coefficients between metallic and ceramic materials. Detailed thermal and stress analyses were performed to that lead to optimal component reliability and manufacturability.

\section{ACKNOWLEDGEMENTS}

The authors would like to thank DOE for its financial support and Debbie Haught of the DOE Office of Power Technologies and Stephen Waslo of the DOE Chicago Operations Office for their programmatic support. They also wish to acknowledge the technical support from their colleagues in Pratt \& Whitney Canada. 


\section{REFERENCES}

Stauffer, J., 2003, August 14, 2003, Blackout: Updated Sequence of Events, Cambridge Energy Research Associates Report

2 U.S. Department of Energy, http://www.eere.energy.gov/der/microturbines/microturbines.html \#advanced

3 Shi, J., V. Vedula, J. Holowczak, C. E. Bird, S. S. Ochs, L. Bertuccioli and D. J. Bombara, 2002, Preliminary Design of Ceramic Components for the ST5+ Advanced Microturbine Engine Paper ASME GT-2002-30547, ASME TURBOEXPO 2002, June 3-6, 2002, Amsterdam, The Netherlands

4 Smith, K.O. and Fahme, A, 1996, Experimental assessment of the emissions benefits of a ceramic gas turbine combustor, ASME Turbo Expo 1996, Paper 96-GT-318

5 Price, J., et al, 2001, Ceramic Stationary Gas Turbine Development Program-eighth annual summary, ASME Turbo Expo Paper, 2001-GT-0517

6 Brewer,D., Ojard,G. and Gibler,M., 2000, Ceramic Matrix combustor liner rig test, ASME Turbo Expo 2000, Munich, ASME 2000-GT-0670

7 Verrilli, M.J., D. Brewer, 2002, Characterisation of CMC fastners exposed in a combustor liner rig test, ASME GT-2002-30459

8 Igashira, K., Matsuda, Y., 2001, Development of the advanced combustor liner composed of CMC/GMC hybrid composite material, ASME 2001-GT-0511

9 Mikami, T., et al , 1996, Status of the development of the CGT301, a 300KW Class Ceramic Gas Turbine, ASME 96-GT-252

10 Tatsumi, T., et al, 1999, Development summary of the $300 \mathrm{kw}$ ceramic gas turbine CGT302, ASME 99-GT105

11 Tanaka,R, T. Tatsumi, Y. Ichikawa, K. Sanbonsugi, 2001,Development of the Hybrid Gas Turbine (1st year summary),ASME 2001-GT-0515

12 Eaton, H.E., Linsey, G.D., Sun, E.Y., More, K.L., Kimmel, J.B., Price, J.R., and Miriyala, N., "EBC Protection of $\mathrm{SiC} / \mathrm{SiC}$ Composites in the Gas Turbine Combustion Environment - Continuing Evaluation and Refurbishment Considerations", 2001-GT-0513, 2001, ASME TURBOEXPO 2001, Land, Sea and Air, New Orleans, LA, 2001 


\begin{tabular}{|c|c|c|c|}
\hline TO: & Bill Tredway (UTRC) & FROM: & $\begin{array}{l}\text { Ara Vartabedian } \\
\text { Vimal Pujari } \\
\text { Gregg Wayman } \\
\text { Norm Paille }\end{array}$ \\
\hline Subject: & UTRC Microturbine Rotor Program Report & DATE: & $12 / 7 / 06$ \\
\hline
\end{tabular}

\section{Introduction}

Silicon nitride offers excellent thermo-mechanical properties such as high strength and creep resistance at elevated temperatures, low co-efficient of thermal expansion and high thermal shock resistance. This makes it a suitable candidate material for high temperature gas turbine components such as integrally bladed rotors (IBR), vanes and combustor liners. At Saint-Gobain in the last two decades, extensive effort was directed towards the development of high temperature silicon nitride based ceramic materials (NT154), net shape forming processes and prototype component field evaluations.

Currently, members of the Fine Ceramics R\&D team have been involved with improving the NT154 material and forming process. The technology is being used to deliver small quantities of gas turbine components (rotors and vane rings) to customers. Saint-Gobain Advanced Ceramics in East Granby, CT, a manufacturer of silicon nitride bearing balls, was asked to assist in delivering these components by handling the furnacing process steps for the NT154 material.

As part of the Microturbine rotor program with United Technologies (UTRC), the manufacturing process, to produce $\phi 3.9 "$ NT154 radial flow rotors (Ingersoll-Rand Design), was explored. The delivery of up to 10 rotors was the goal of the program. The plan is for UTRC to spin test the rotors to evaluate reliability.

\section{Radial Flow Rotor Fabrication}

The NT154 silicon nitride component fabrication process has been developed over the past couple years in the production of radial and axial turbine rotors. The process includes forming the component in the green state. Once formed, the component goes through the typical NT154 furnacing process. Saint-Gobain Advanced Ceramics in East Granby, CT, a manufacturer of silicon nitride bearing balls, has assisted in the furnacing. Depending upon the size and complexity of the component, the process is modified to result in a crack-free, dense part. Portions of the component may then be dense machined (diamond ground).

\section{Green Forming}

Eight rotors were successfully green formed (Figure 1). The dimensional accuracy of the green rotors was measured by CMM and calipers (Table I). Complete dimensional information was collected on only three of the green rotors due to equipment availability. The data that was collected indicates very good part-to-part consistency and accuracy with a maximum deviation from nominal of 0.003 ”. 
Table I: CMM on Green Formed Radial Microturbine Rotors

\begin{tabular}{|c|c|c|c|c|c|c|c|c|c|c|}
\hline & & & & & $\begin{aligned} \text { Actu } \\
\end{aligned}$ & & & & & \\
\hline & Nominal (Inches) & 154-33B-MT3 & 154-33B-MT4 & 154-33B-MT5 & 154-37B-MT1 & 154-38B-MT1 & 154-38B-MT2 & 154-39B-MT1 & 154-39B-MT2 & From Nominal (Inches) \\
\hline $\begin{array}{l}\text { Total Height } \\
\end{array}$ & 3.739 & 3.736 & 3.736 & 3.737 & & & 3.737 & & & 0.003 \\
\hline 2nd Plane & 3.405 & 3.402 & 3.402 & 3.402 & & & 3.131 & & & 0.003 \\
\hline 3rd Plane & 3.071 & 3.069 & 3.068 & 3.069 & & & & & & 0.003 \\
\hline Blade Underside Plane Height & 1.453 & 1.452 & 1.454 & 1.454 & & & calipers & calipers & calipers & 0.001 \\
\hline Top Shaft OD & 0.477 & 0.477 & 0.476 & 0.476 & measured & measured & & & & 0.001 \\
\hline Bottom Shaft OD & 0.954 & 0.953 & 0.954 & 0.953 & & & 0.955 & 0.955 & 0.955 & 0.001 \\
\hline Blade Tip OD & 4.691 & 4.692 & 4.692 & 4.692 & & & & & & 0.001 \\
\hline Offset Between Top Shaft and Blade Tip OD & 0.000 & 0.002 & 0.002 & 0.001 & & & & & & \\
\hline $\begin{array}{l}\text { Offset Between Bottom Shaft and Blade Tip OD } \\
\text { Blade Tip OD Roundness }\end{array}$ & $\frac{0.000}{0.000}$ & $\frac{0.001}{0.000}$ & $\frac{0.001}{0.001}$ & $\frac{0.000}{0.000}$ & & & & & & \\
\hline $\begin{array}{l}\text { Blade II OD Roundness } \\
\text { Blade Underside Plane Flatness }\end{array}$ & 0.000 & 0.000 & 0.000 & 0.000 & & & & & & \\
\hline
\end{tabular}
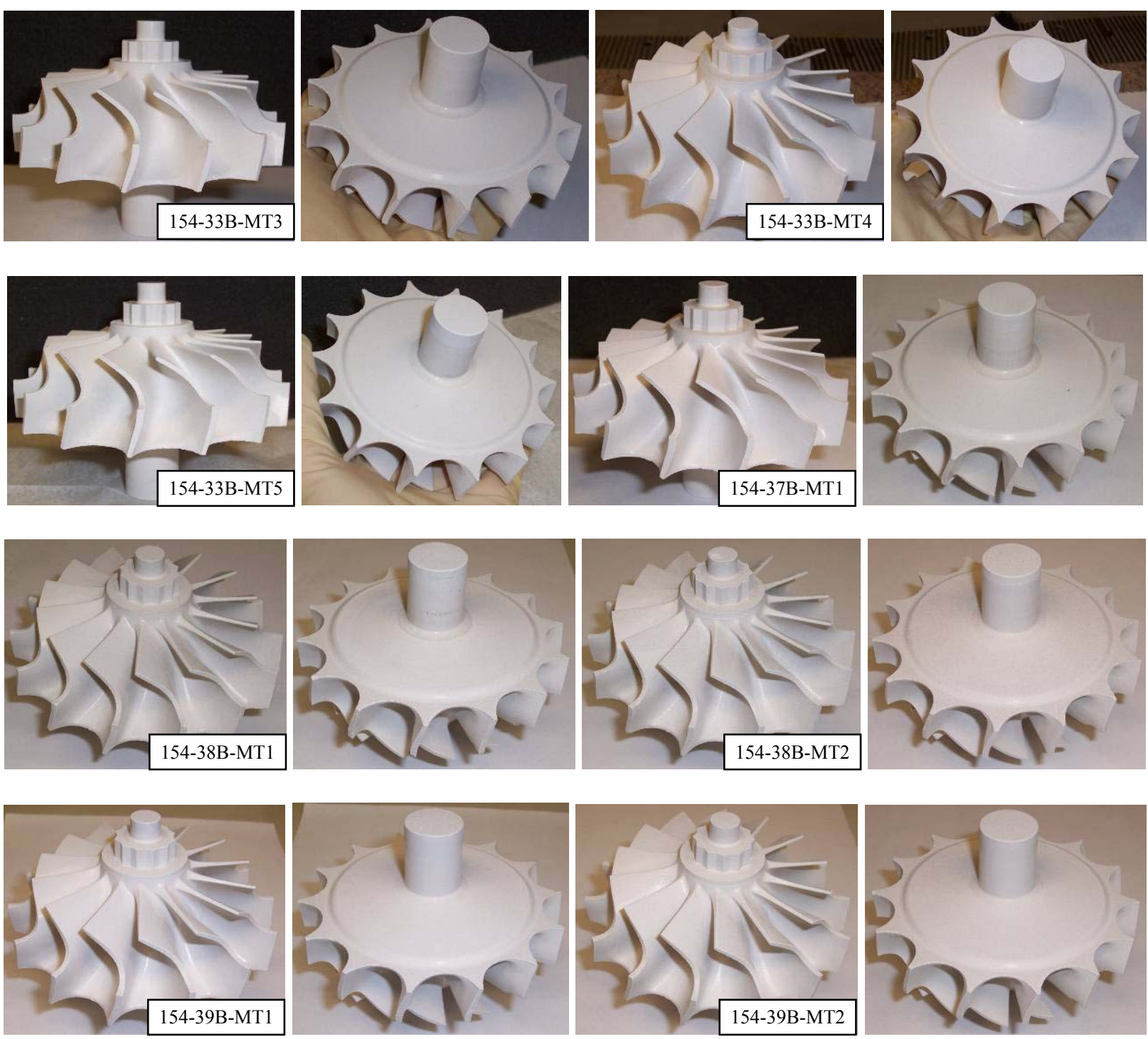

Figure 1: Green Formed Radial Rotors

Furnacing

As mentioned previously, Saint-Gobain Advanced Ceramics in East Granby, CT has assisted in the furnacing of these rotors in addition to other gas turbine components. The furnacing steps, as part of the NT154 process, are being done in East Granby, on furnaces qualified previously. NRDC personnel continue to lead the activity. Per the standard procedure, the rotors were densified by hot isostatic pressing (HIP). Co-processed NT154 tiles were included with the rotors for property characterization. 


\section{Final Analysis}

Once completed, the dense rotors (Figure 2) and co-processed tiles were fully characterized. Microfocus x-ray was completed on rotor 154-33B-MT3 only and showed no signs of cracking. As mentioned previously, there were blade chipping issues with a few of the rotors in the green state, caused by handling during processing. These defects are shown in Figure 2.

Dimensional measurements were completed by CMM to determine final dimensions and average shrinkage experienced during densification (Table II). Based on the data, the dimensions of the eight dense rotors deviated by up to \pm 0.014 ". The average linear shrinkage, which factored in many dimensional measurements, saw a variation of $\pm 0.23 \%$ across the eight rotors. It is expected that the variation can be tightened in the future by improved powder control and larger powder batch sizes.

Table II: CMM on Dense Radial Microturbine Rotors

\begin{tabular}{|c|c|c|c|c|c|c|c|c|c|c|}
\hline & Nominal (Inches) & 154-33B-MT3 & 154-33B-MT4 & 154-33B-MT5 & $\begin{array}{r}\text { Actual } \\
\text { 154-37B-MT1 }\end{array}$ & $\begin{array}{l}\text { (Inches) } \\
\text { 154-38B-MT1 }\end{array}$ & 154-38B-MT2 & 154-39B-MT1 | & 154-39B-MT2 & $\begin{array}{c}\text { Maximum Part-to-Part } \\
\text { Variation (Inches) }\end{array}$ \\
\hline Total Height & 3.085 & 3.086 & 3.084 & 3.069 & 3.080 & 3.077 & 3.076 & 3.067 & 3.065 & \pm 0.010 \\
\hline Blade Underside Plane Height & 1.199 & 1.198 & 1.195 & 1.192 & 1.199 & 1.197 & 1.200 & 1.194 & 1.194 & \pm 0.004 \\
\hline Top Shaft OD & 0.394 & 0.392 & 0.393 & 0.392 & 0.394 & 0.393 & 0.394 & 0.393 & 0.393 & \pm 0.001 \\
\hline Bottom Shaft OD & 0.787 & 0.787 & 0.786 & 0.784 & 0.787 & 0.785 & 0.785 & 0.785 & 0.784 & \pm 0.002 \\
\hline Blade Tip OD & 3.870 & 3.894 & 3.890 & 3.882 & 3.890 & 3.877 & 3.879 & 3.867 & 3.865 & \pm 0.014 \\
\hline Offset Between Top Shaft and Blade Tip OD & 0.000 & 0.001 & $\overline{0.002}$ & 0.001 & 0.001 & 0.000 & 0.001 & 0.003 & $\overline{0.004}$ & \\
\hline Offset Between Bottom Shaft and Blade Tip OD & 0.000 & 0.004 & 0.001 & 0.001 & 0.002 & 0.001 & 0.003 & 0.002 & 0.001 & \\
\hline Blade Tip OD Roundness & 0.000 & 0.002 & 0.002 & 0.006 & 0.005 & 0.001 & 0.002 & 0.002 & 0.000 & \\
\hline Blade Underside Plane Flatness & 0.000 & & & & & & 0.002 & 0.000 & 0.001 & \\
\hline
\end{tabular}

The surface finish of the as-processed dense rotors was measured with profilometry using a $10 \mu \mathrm{m}$ stylus and $8 \mathrm{~mm}$ path lengths (Table III). The measurements followed the same procedure as used on the green rotors.

Particular attention should be paid to the surface finish of the blade surfaces. Up to four blade paths and four blades were measured per rotor. The average blade surface roughness was generally in the 50-60 $\mu$ in range with two rotors being outside that range 

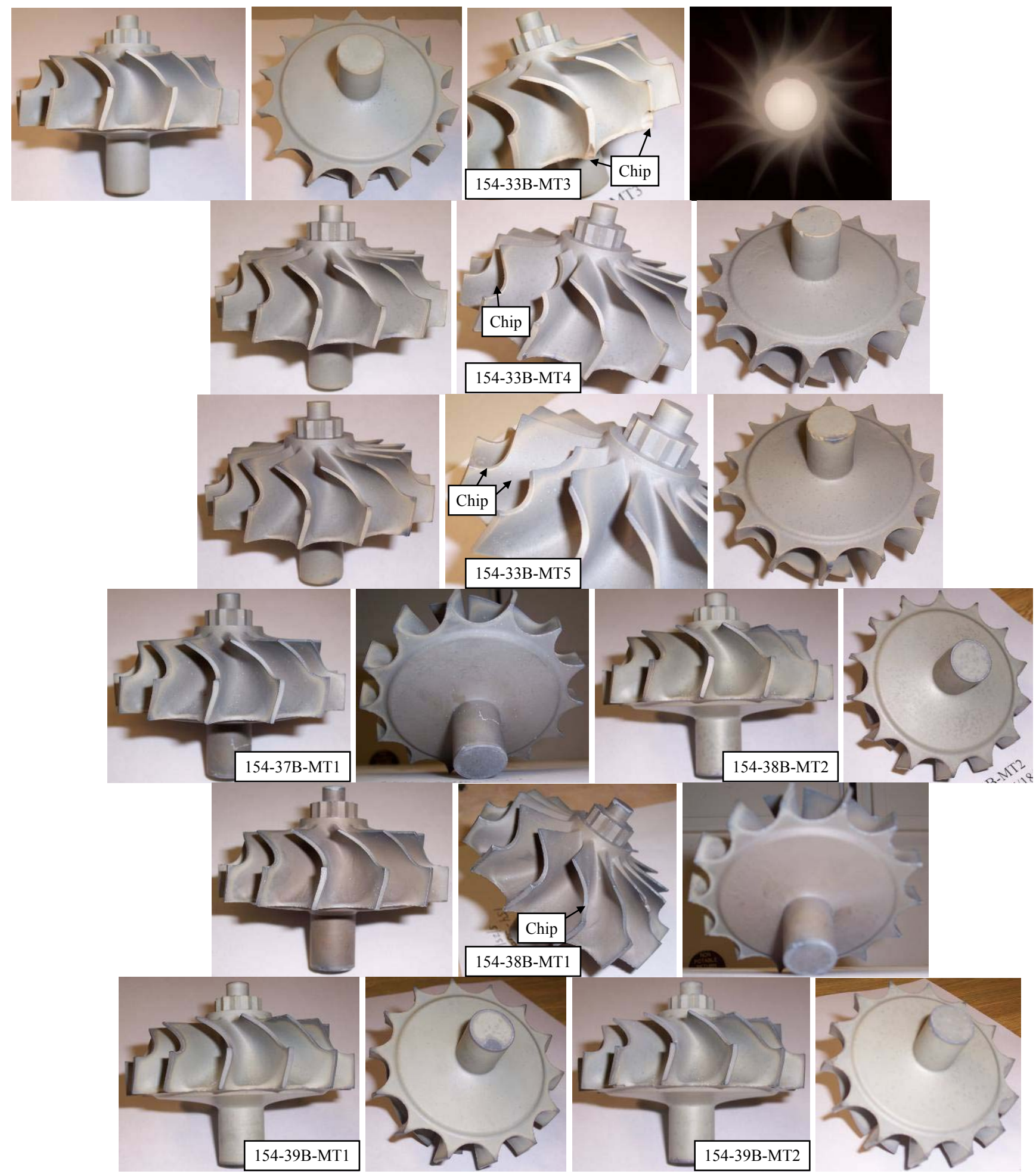

Figure 2: Dense Radial Rotors 
Table III: Profilometry of Dense Rotor Surfaces

\begin{tabular}{|c|c|c|c|c|c|c|c|c|}
\hline & \multicolumn{4}{|c|}{$\operatorname{Ra}(\mu$-in) } & \multicolumn{4}{|c|}{ Rt $(\mu \mathrm{m})$} \\
\hline & Blades & 2nd and 3rd Planes & Bottom Face & Bottom Shaft & Blades & 2nd and 3rd Planes & Bottom Face & Bottom Shaft \\
\hline $\begin{array}{l}154-33 \mathrm{~B}-M T 3 \\
154-33 \mathrm{~B}-M T 4 \\
154-33 \mathrm{~B}-M T 5\end{array}$ & $\begin{array}{c}55 \\
\text { not measured } \\
\text { not measured }\end{array}$ & 35 & 34 & 40 & 13 & $\begin{array}{l}9 \\
9\end{array}$ & 9 & 11 \\
\hline 154-37B-MT1 & \begin{tabular}{|l|}
52 \\
\end{tabular} & 42 & 51 & & 11 & 8 & 13 & \\
\hline 154-38B-MT1 & 58 & 52 & 57 & & 14 & 9 & 15 & \\
\hline 154-38B-MT2 & 73 & 96 & 79 & & 18 & 20 & 23 & \\
\hline 154-39B-MT1 & 52 & 52 & 104 & & 13 & 14 & 25 & \\
\hline 154-39B-MT2 & 80 & 58 & 78 & & 19 & 13 & 21 & \\
\hline
\end{tabular}

Several properties were measured on dense co-processed tiles to help ensure the quality of the rotors. These properties (Table IV), with the exception of rotor density, were destructive in nature and therefore could not be completed on the rotors. The data shown in Table IV is for the six rotors that were suitable for delivery to United Technologies.

The rotor densities are fairly consistent and typical for NT154. The robust process used helps to maintain this consistency. The data on the co-processed tiles did have some variation although the values are within the range for the material.

Table IV: Rotor and Co-processed Tile Final Properties

\begin{tabular}{|c|c|c|c|c|c|}
\hline & \multirow[b]{2}{*}{$\begin{array}{l}\text { Rotor Density } \\
(\mathrm{g} / \mathrm{cc})\end{array}$} & \multicolumn{4}{|c|}{ Co-Processed Tiles } \\
\hline & & $\begin{array}{l}\text { Toughness* } \\
\left(\mathrm{MPa}^{*} \mathrm{~m}^{1 / 2}\right)\end{array}$ & $\begin{array}{c}\text { Room Temperature } \\
\text { Flexural Strength }(\mathrm{MPa})^{\star *}\end{array}$ & $\begin{array}{l}\text { 1200C Flexural } \\
\text { Strength }(\mathrm{MPa})^{\star *}\end{array}$ & $\begin{array}{c}\text { Phase Analysis } \\
\% \beta-S i 3 N 4 \\
\end{array}$ \\
\hline 154-33B-MT3 & 3.230 & 5.53 & 901 & 554 & 94 \\
\hline 154-37B-MT1 & 3.217 & 4.28 & 839 & 593 & 79 \\
\hline 154-38B-MT1 & 3.220 & 4.52 & 812 & 592 & 89 \\
\hline 154-38B-MT2 & 3.224 & 4.04 & 973 & 666 & 89 \\
\hline 154-39B-MT1 & 3.224 & 4.39 & 891 & 615 & 72 \\
\hline 154-39B-MT2 & 3.220 & $4.39^{\star \star \star}$ & 947 & 719 & 76 \\
\hline
\end{tabular}

*Toughness by indentation crack length method

${ }^{* *}$ Four point flexure (ASTM C1161-2002)

${ }^{* * *}$ Value is co-processed tile in a separate HIP crucible

The six rotors, shown in Table IV, have been delivered to United Technologies (UTRC). UTRC plans to spin test the rotors to a pre-determined proof test speed. If the rotor survives, UTRC may apply its current Environmental Barrier Coating (EBC) and re-spin the coated rotor. The objective would be to evaluate the integrity of the coating and determine any residual stresses that it may impart on the base rotor. 


\section{Previous Data on Radial Design Rotors}

Four NT154 radial rotors, of the same design discussed previously in this report, were produced in 2003 and 2004. The average surface roughness for these rotors was 30-40 $\mu$ in making the as-processed finish slightly better than the current rotors. Two of these rotors were sent to Oak Ridge National Lab (ORNL) for mechanical property evaluation. Another rotor was spin tested at Test Devices in Hudson, MA.

\section{Biaxial Flexure Testing}

ORNL conducted biaxial (ball on ring) flexure testing on samples machined from the blade and hub locations. The $\$ 7 \mathrm{~mm} \times 1 \mathrm{~mm}$ samples were either fully machined or preserved an as-processed (AP) surface on one side. The results of the room temperature testing, for one of the rotors, are shown in Figure 3 . The data suggests that very good properties have been achieved in the rotors. There does appear to be some drop-off in the measured AP strength in the blade location. The AP blade samples have a natural curvature which possibly impacts the test data. There may also be some differences in the as-processed surface properties although surface roughness data does not support this.
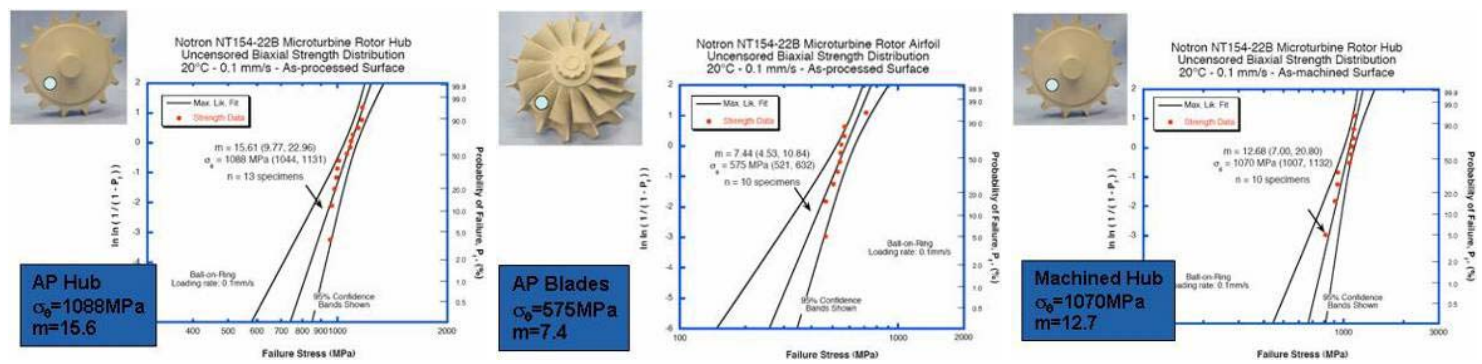

Figure 3: Room Temperature Biaxial Flexure Data for NT154 Radial Rotor

\section{$\underline{\text { Spin Testing }}$}

One of the rotors produced in 2004 was spin tested at Test Devices in Hudson, MA. The rotor has an anticipated design speed of 97,500rpm in the application. The attachment to the arbor and balancing was conducted at Test Devices. A final unbalance of $0.048 \mathrm{~g}$-in was achieved by minimal machining of three blade tips.

The room temperature test was run in vacuum up to $143,330 \mathrm{rpm}$, the maximum speed achievable with the equipment/setup used. The rotor survived the testing without failure. Based on FEA analysis (Figure 4$)^{1}$, the rotor experienced stresses up to 490MPa $(2.16 \times 225.5)$ during the testing. The maximum stress location was on the as-processed surface at the root of the blades.

\footnotetext{
${ }^{1}$ Kesseli et al, "Advancements in the IR PowerWorks Employing a Ceramic Turbine Rotor”, IGTI Conference, Atlanta, June 16, 2003.
} 


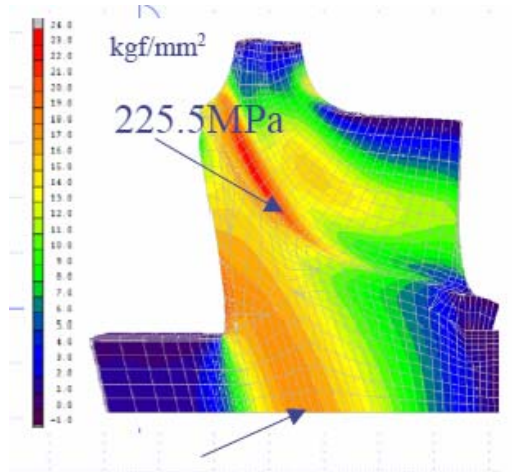

172.9MPa

Figure 4: Spin Test FEA for 97,500rpm

\section{Conclusion}

As part of a contract with United Technologies, six $\phi 3.9 "$ NT154 silicon nitride radial flow rotors have been produced and delivered. Dimensional, surface finish and property data are presented in this report. In addition, mechanical property and spin test data for rotors of the same design, produced in 2003/2004, are included. 


\title{
ASME Turbo Expo 2007 Power for Land, Sea, and Air May 14-17, 2007, Montreal, Canada
}

GT2007-27935

\section{RELIABILITY PREDICTION OF MONOLITHIC STRUCTURAL CERAMICS WITH UNCERTAINTIES}

\author{
X. Luo, G.V. Srinivasan, and W.K. Tredway \\ United Technologies Research Center, East Hartford, CT 06108
}

\begin{abstract}
Reliability prediction of monolithic structural ceramics involves stress analysis through Finite Element Analysis and a probability of failure prediction code such as CARES that considers the strength of ceramics as a statistical (Weibull) distribution. Though the strength is considered as a statistical distribution, stress in a given volume or surface element is discrete in current practice. However, uncertainties in FEA input such as material properties or boundary conditions make the predicted stress uncertain, thereby resulting in predicted reliability being uncertain as well. A probabilistic framework has been developed for reliability prediction to estimate component reliability by treating the uncertainties in loading, boundary conditions, and material properties as random variables. The framework consists of an automated, closed loop process integrating algorithms for assessing failure probability due to general randomness. Efficient and accurate computational methods for reliability analysis have been implemented in the framework for significant savings in computation time. The methodology is demonstrated on a gas turbine component. The analysis shows that reliability is compromised significantly by a design based on mean values of the random parameters, while an overly conservative design based on worst case scenario will result in rejection of too many components at unnecessarily high proof test loads. This method ultimately leads to the determination of an optimum proof test level to assure component reliability amidst several sources of uncertainties in reliability prediction.
\end{abstract}

\section{INTRODUCTION}

The unique properties of advanced ceramics such as hightemperature strength, environmental resistance, and low density provide the potential for greatly increased fuel efficiency and reduced weight and emissions in aerospace and industrial gas turbine engine applications. Consequently, research and development activities have focused on improving ceramic material processing and properties as well as on establishing a sound design methodology. Being brittle with no plasticity makes these materials vulnerable for catastrophic failure. Variability in size and distribution of inherent flaws in ceramics makes their failure probabilistic in nature. Therefore, optimization of design requires the ability to accurately predict a component's load resistance and reliability. It is economically prohibitive to test a statistically significant number of ceramic components in actual operating environments for the intended life-time to obtain the reliability. Hence a probabilistic model based on physics of failure has to be used to predict reliability of these components. Methods of quantifying reliability in ceramics and the corresponding failure probability have been investigated by few [1-4]. The result of one such effort led by NASA Glenn (formerly NASA Lewis) Research Center is a computer software named CARES (Ceramics Analysis and Reliability Evaluation of Structures) [5]. This CARES software is used in this study for reliability determination.

The reliability evaluation methodology combines linear elastic fracture mechanics theory that relates strengths of ceramics to size, shape, and orientation of critical flaws; a characteristic flaw size distribution function that accounts for the size effect on strength via the weakest-link concept; and a timedependent strength degradation caused by sub-critical crack growth.

\section{Current Practice in Determining Ceramic Component Reliability}

Inherent in this methodology is that the component integrity is a function of the entire field solution for stresses and is not based only on the most highly stressed point (contrary to metals). Hence stress state prediction for the whole component via Finite Element Analysis (FEA) is required. Probabilistic 
failure evaluation of the component is made possible by appropriate scaling of the fracture strength distribution from test specimens under laboratory conditions to complex shaped components experiencing multi axial stress state. In addition, strength of the ceramic component is affected by its surface area and volume. The Weibull parameters for surface flaws were obtained from four-point bend strength data and parameters for volume flaws were obtained from uni-axial tension tests as a function of temperature using standard specimen geometries in laboratory testing. Fractography of failed specimens was performed to ascertain the failure source from a volume or surface flaw. The sub-critical crack growth parameters were determined from dynamic fatigue or stress rupture tests. From these lab-scale data, the reliability of a component with complex geometry and loading is then predicted [5]. The process is captured in Fig 1.

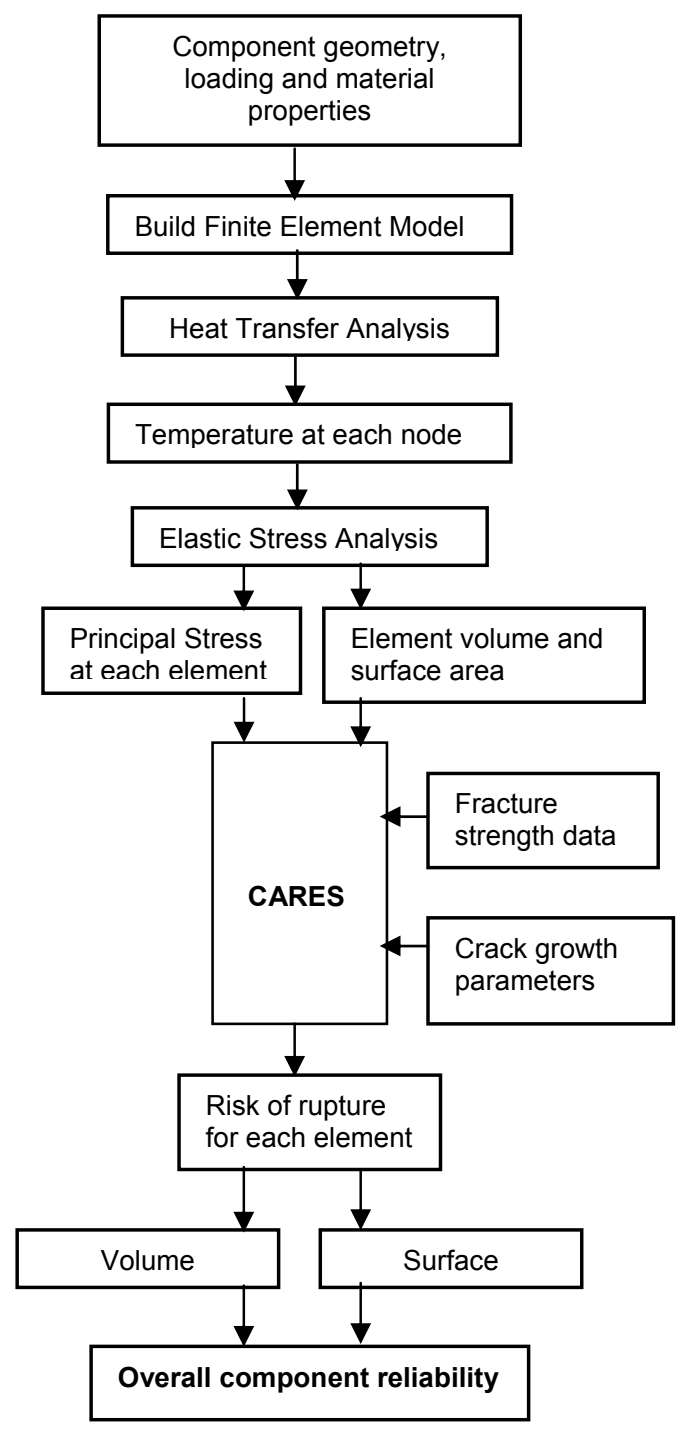

Figure 1. Flow chart illustrating the current reliability evaluation methodology using CARES [5]
The reliability prediction process described for structural ceramics described above is traditionally practiced in industry. Here the failure prediction is probabilistic since the strength of material is input as a probabilistic (Weibull) distribution. But, the predicted state of stress from finite element modeling in the material is deterministic. The predicted stress state is also probabilistic as uncertainty in modeling exists which induces uncertainty in reliability prediction.

\section{Incorporating uncertainty in Reliability Prediction}

In designing with ceramics (as with other materials), designers are confronted with numerous uncertainties in modeling and material property variability. The designer must consider manufacturing tolerances (geometry), variability in loads (engine operating conditions), material properties (thermal conductivity, specific heat, elastic modulus, Poisson's ratio, thermal expansion, etc.), and boundary conditions (constraints or load/displacement dependent boundary conditions, etc.) during design to ensure that products are reliable and safe. To address these random variations in traditional (deterministic) design, safety factors have traditionally been used. Safety factors have been established for mature applications and materials, like bridges, aircraft parts etc. Choosing a factor of safety for new and novel application and materials can be subjective, and either may lead to a very conservative design or compromise reliability. The reliability-based design approach uses probabilistic methods to account for uncertainties and expected variations in consistent objective fashion.

Each random variable is assigned a probability distribution. In general, the distribution can be defined by a mean, a standard deviation, and a distribution type. Some distributions will require bounds or additional shape parameters. If the relevant data exists, the distribution may be found from data by standard statistical methods. However, frequently the structural analyst or the design engineer only has a rough notion of the mean and perhaps the standard deviation. Even though these statistics must be estimated, this approach still provides more accurate results than using safety or knockdown factors [6], which can in some cases stack up in the analysis process to yield over-conservative and consequently uneconomical designs. Although the predicted reliability or probability of failure is necessarily approximate, the probabilistic approach will still provide very useful information in the form of sensitivity factors. The sensitivity factors, which are by-products of the probabilistic analysis, tell the analyst which sources of uncertainty are contributing most to the uncertainty in the predicted performance. Thus, it is possible to determine which variables should be better controlled to attain the best improvement in product reliability. Alternatively, one can determine which tolerances could be relaxed without substantially affecting product reliability. 


\section{Analysis Method}

A number of methods are available to perform probabilistic analysis. One of them involves random sampling of inputs and obtains response as a distribution. Monte-Carlo Simulation (MCS) and the Response Surface Analysis (RSA) thru exploration of design space are based on this sampling technique. The other method, known as Fast Probability Integration (FPI) technique, involves repeated evaluation of the failure criteria, which requires repeated computations. These methods are described below.

\section{Monte Carlo Simulation (MCS):}

MCS generates samples of each random variable from supplied distributions, and runs the deterministic model at each combination. The whole distribution of input distributions is swept in a random fashion. Thus, the response is also obtained as a distribution. Mean values and probabilities are then obtained directly from the response distribution.

\section{Response Surface (RS):}

The RS method fits a surface to the response quantity (usually by first sampling the response using Design of Experiments techniques) then uses MCS on the surface to perform the probabilistic analysis. The surface can be refit in critical areas of the response to improve the accuracy of the results.

The above techniques have been used for probabilistic analysis for ceramics [7, 8]. In either of the methods mentioned above, a large number of computational runs are required since this is based on random sampling of inputs over the entire range defined. For example, to determine probability of failure in the range $10^{-2}$ to $10^{-3}$, typically $10^{4}$ to $10^{5}$ runs are required [9]. Hence MCS is best for problems that execute relatively quickly and has practical limitation when it comes to executing finite element calculations involving large number of nodes, which will be typical of a ceramic component for application in gas turbine engines. Hence advanced fast probabilistic techniques that can find solution in fewer simulation runs with acceptable accuracy have to be adopted.

\section{Fast Probability Integration (FPI) Techniques:}

Failure or success in probabilistic analysis are called limitstates and are modeled using a limit-state equation (sometimes called a performance function). The most common form of the limit-state is $\mathrm{g}=\mathrm{R}-\mathrm{S}$ where $\mathrm{R}$ is a resistance or capacity and $\mathrm{S}$ is applied load or stress. Examples of a limit-state are the stress at a particular location (S) exceeding the characteristic fracture stress $(\mathrm{R})$, or the calculated probability of survival (R) being less than the desired product reliability $(\mathrm{S})$. When the limit-state function evaluates to less than zero, the system is considered to have failed.
The fast probability integration methods calculate the failure probability using the first/second-order Taylor expansion of the limit-state function at the most probable point (MPP). The first order Taylor expansion method is called the First Order Reliability Method (FORM), while the second first order Taylor expansion method is called the Second Order Reliability Method (SORM).

In the first order reliability method, the limit state of interest is approximated by a linearized function at the most probable failure point. An optimization routine is used to locate this point iteratively. Hasofer and Lind [10] introduced the "generalized safety index"', a set of reduced variables are defined as:

$$
u_{i}=\frac{x_{i}-\mu_{X_{i}}}{\sigma_{X_{i}}}, \quad(i=1,2, \cdots, n)
$$

where $\mu_{\mathrm{Xi}}$ and $\sigma_{\mathrm{Xi}}$ are the mean and standard deviation of random variable $\mathrm{x}_{\mathrm{i}}$, respectively, and the original limit state $g(x)$ can thus be transformed to a reduced variable space $g(u)$.

The generalized safety or reliability index is defined as the shortest distance from the limit state failure surface to the origin in the reduced variable space as:

$$
\beta=\operatorname{Min}\left[\sqrt{u^{\mathrm{T}} u}\right]=\sqrt{\left(u^{*}\right)^{T}\left(u^{*}\right)} \quad \text { subject to } \mathrm{g}(\mathrm{u})=0
$$

where the $\left\{\mathrm{u}_{\mathrm{i}}^{*}\right\}$ are the values of the reduced random variables corresponding to the shortest distance $\beta$ in the U-space as illustrated in Figure 2. In the context of structural reliability, the corresponding $\mathbf{u}^{*}$ is called the design point or the checking point. The Hasofer-Lind reliability index provides a reasonable estimate of structural safety, which is invariant to the formulation of limit states.

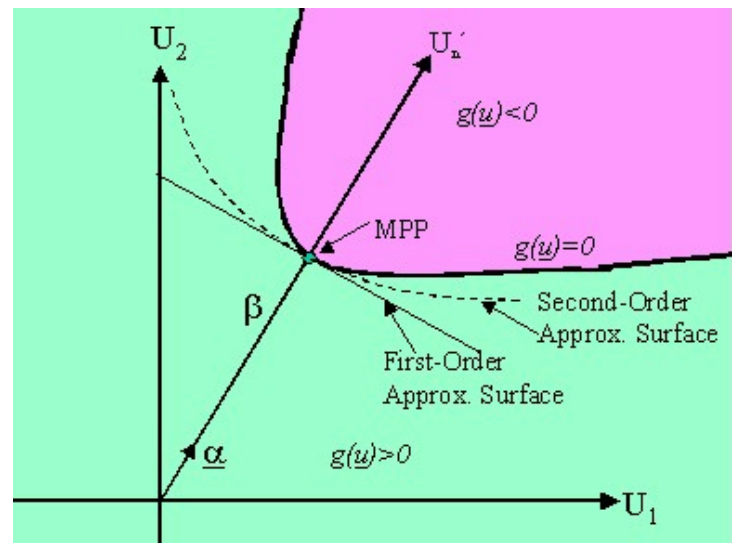

Figure 2. Illustration of MPP search and reliability index 
FORM/SORM methods give satisfactory results because the majority of failure probability is contributed from the probability density of the failure domain around the MPP.

The major advantages of FPI are summarized as follows:

- Great numerical efficiency (50-100 times faster than MCS); ability to capture the response distribution in fewer runs compared to thousands of runs in MCS

- Capable of probabilistic sensitivity analysis without significant numerical efforts

- Capable of assessing small and large probability of failure

- Capable of predicting important region for robust design (MPP)

- Capable of handling a large number of random variables

FORM is preferred for evaluating small probabilities because it often requires the least number of analysis cycles (i.e., FE analysis runs). A typical component's FE model may contain thousands of nodes, and each iteration can be very time consuming. Therefore, FORM offers the best potential to minimize the number of iterations. This FORM methodology has been validated in many structural reliability investigations $[11,12]$. After reviewing all available methodologies, FORM appears to be the best algorithm for reliability evaluation of ceramics with uncertainties.

\section{SIMULATION CONFIGURATION}

The probabilistic algorithm selects the inputs for simulation in proper order dictated by the algorithm used. The change or choice of different set of input values of the random variables for the subsequent iteration are a function of response gathered from the previous iteration. Hence to utilize FORM, the operation has to be a closed loop process. In order to facilitate a continuous closed loop operation, different software containing the finite element simulation (ANSYS),

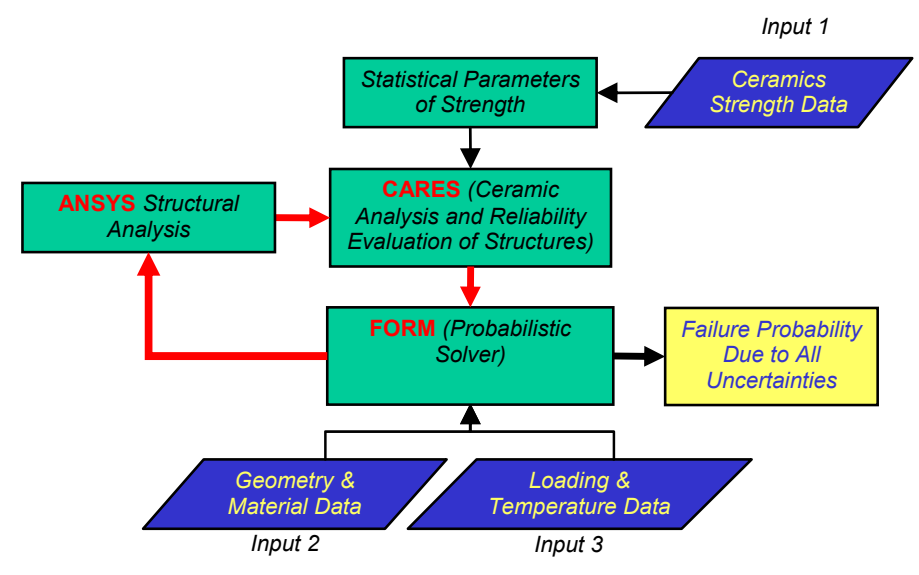

Figure 3. Schematic illustrating the closed loop simulation
The reliability prediction code (CARES), and a code containing the FORM algorithm have been linked thru appropriate scripts / commands. The implementation is schematically shown in Figure 3. The iteration process stops when the solution is converged and the result is a distribution of predicted reliability or probability of failure.

\section{METHODOLOGY DEMONSTRATION SIMULATION RESULTS}

For methodology demonstration purposes, a fictitious design closely representing a ceramic gas turbine component (shroud) and corresponding loading conditions are considered. The dimensions of this cylinder are: $203 \mathrm{~mm}$ o.d., $25.4 \mathrm{~mm}$ length, and $6.35 \mathrm{~mm}$ wall thickness. Material properties close to sintered silicon carbide are assigned and are shown in Table 1 [13]. Though the material properties are actually temperature dependent, they are taken as independent of temperature here for demonstration purpose. The component is thermally loaded with a hotter convective boundary condition on the inner diameter (bulk temperature 1 and film transfer coefficient 1) and a cooler condition on the outer diameter (bulk temperature 2 and film transfer co-efficient 2). The resulting steady state temperature on the component is also shown in Figure 4 for the mean values of model input shown in Table 1 .

Table 1. Input for Finite Element Analysis

\begin{tabular}{|c|c|c|c|c|}
\hline \multirow[t]{2}{*}{ Category } & \multirow{2}{*}{$\begin{array}{l}\text { Random } \\
\text { Variable }\end{array}$} & \multicolumn{3}{|c|}{ Range } \\
\hline & & $-3 \sigma$ & Mean & $+3 \sigma$ \\
\hline Geometry & Thickness, mm & & 6.35 & \\
\hline \multirow[t]{4}{*}{$\begin{array}{l}\text { Boundary } \\
\text { Condition }\end{array}$} & $\begin{array}{l}\text { Convective } \\
\text { Bulk Temp, } \\
\mathrm{T}_{\text {hot }}{ }^{\circ} \mathrm{C}\end{array}$ & 1204 & 1316 & 1427 \\
\hline & $\begin{array}{l}\text { Film Transfer } \\
\text { Co-eff., } \mathrm{H} 1 \text {, } \\
\mathrm{kW} / \mathrm{m}^{2} /{ }^{\circ} \mathrm{C}\end{array}$ & 123 & 164 & 204 \\
\hline & $\begin{array}{l}\text { Convective } \\
\text { Bulk Temp., } \\
\mathrm{T}_{\text {cold }}{ }^{\circ} \mathrm{C}\end{array}$ & 538 & 659 & 760 \\
\hline & $\begin{array}{l}\text { Film Transfer } \\
\text { Co-eff., } \mathrm{H} 2 \text {, } \\
\mathrm{kW} / \mathrm{m}^{2} /{ }^{\circ} \mathrm{C}\end{array}$ & 40.8 & 61.3 & 81.8 \\
\hline \multirow[t]{6}{*}{$\begin{array}{l}\text { Material } \\
\text { Properties }\end{array}$} & $\begin{array}{l}\text { Modulus, E } \\
\times 10^{9}, \mathrm{~Pa}\end{array}$ & 386 & 400 & 414 \\
\hline & CTEx $10^{-6} /{ }^{\circ} \mathrm{C}$ & 3.24 & 3.69 & 4.14 \\
\hline & Poisson's Ratio & $\mathrm{n} / \mathrm{a}$ & 0.23 & $\mathrm{n} / \mathrm{a}$ \\
\hline & $\begin{array}{l}\text { Thermal } \\
\text { Conductivity, } \\
\left(\mathrm{W} / \mathrm{m} /{ }^{\circ} \mathrm{C}\right)\end{array}$ & $\mathrm{n} / \mathrm{a}$ & 41.5 & $\mathrm{n} / \mathrm{a}$ \\
\hline & $\begin{array}{l}\text { Specific Heat, } \\
\mathrm{J} / \mathrm{g} /{ }^{\circ} \mathrm{C}\end{array}$ & $\mathrm{n} / \mathrm{a}$ & 0.94 & $\mathrm{n} / \mathrm{a}$ \\
\hline & Density, $\mathrm{g} / \mathrm{cm}^{3}$ & $\mathrm{n} / \mathrm{a}$ & 3.1 & $\mathrm{n} / \mathrm{a}$ \\
\hline
\end{tabular}


The steady state nodal temperatures are used as a loading condition in elastic stress analysis. The principal stress distribution is shown in Figure 5 for the mean values of input shown in Table 1.

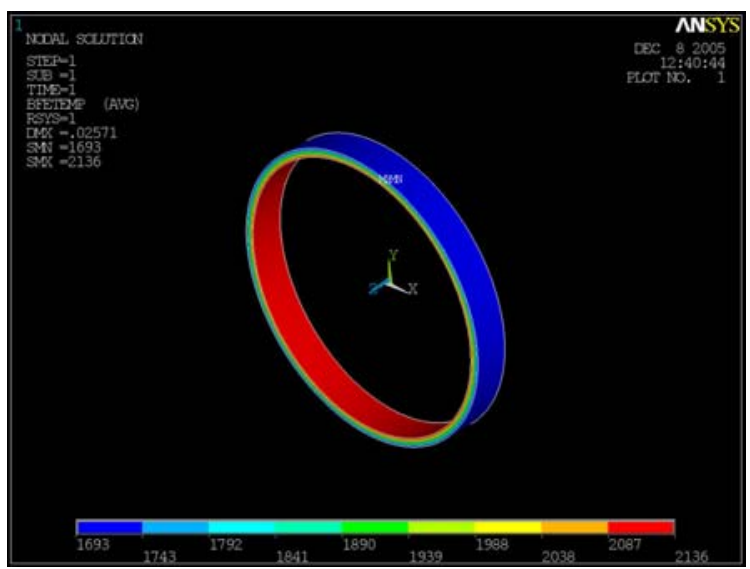

Figure 4. Steady state temperature profile resulting from convective thermal loads

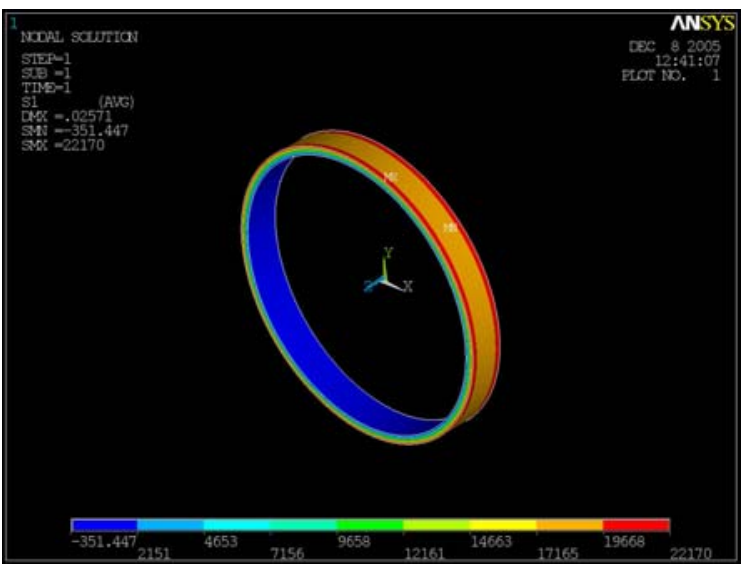

Figure 5. Principal stress distribution in the component.

Uncertainties in gas temperature and film transfer coefficient as boundary conditions in thermal analysis (input 2), elastic modulus and coefficient of thermal expansion as material properties in stress analysis (input 3) are included for demonstration of the methodology. Uncertainties in other input may also exist, but for demonstration purposes, only few are considered. However, the methodology will be able to address them all during a realistic design stage. Only a single value is shown in Table 1 for the parameter for which uncertainty is not considered. The uncertainties are represented as a normal distribution, values for mean, and $-3 \sigma$ and $+3 \sigma$ of the distribution are shown in Table 1 for the variables for which uncertainties are considered (where $\sigma$ is the standard deviation). Though the ranges given in the uncertainty distribution are assumed here for demonstration purposes, such levels of uncertainty are not unreasonable for gas turbine boundary conditions and material properties.
The Weibull modulus has been taken to be 9 (averaged over the temperature range) and characteristic strength as $37 \mathrm{ksi}$ representing volume flaws from uni-axial tension test for $\mathrm{SiC}$ [13]. These values are taken as input into CARES (the characteristic strength has to be normalized over the effective volume), and are assumed to be independent of temperature. Though uncertainty in slow crack growth parameters are not considered in this exercise, uncertainty in these parameters can be accounted for in an actual design exercise.

Before considering uncertainties, a deterministic stress analysis was done by taking only the mean values and a corresponding probability of failure is determined using CARES. The probability of failure corresponding to mean input values was 0.004 . Then the probability of failure for worst case stress state was calculated thru deterministic method. The input values corresponding to the worst case situation corresponding to maximum stress is shown in red in Table 1. The probability of failure for worst case was determined to be 0.49 .

The probability of failure has been obtained as a distribution when uncertainties in model input are considered. The resulting cumulative distribution of failure probability is shown in Figure 6. It took only 7 iterations of simulations to generate the distribution curve shown in Figure 6.

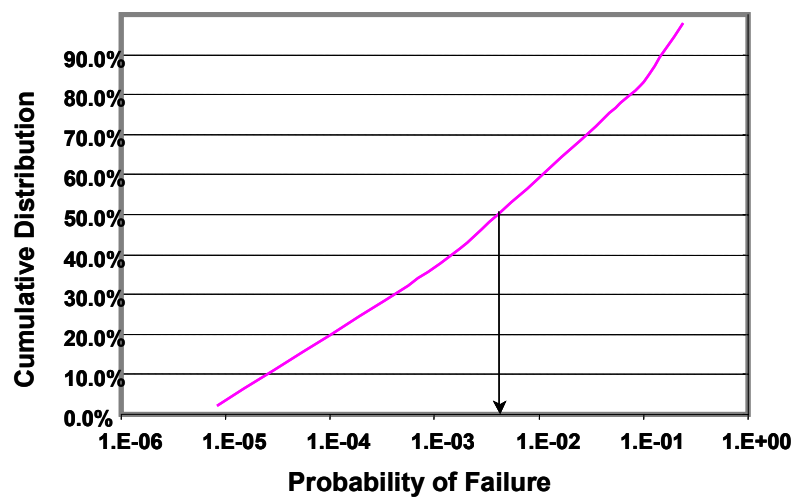

Figure 6. Predicted probability of failure shown as a cumulative distribution due to uncertainties in modeling input.

Since the distribution has been taken as symmetrical everywhere, the deterministic prediction using mean input values and the mean from the distribution obtained from the probabilistic solver should agree. The mean probability of failure from the distribution obtained using the probabilistic solver (corresponding to $50 \%$ confidence in Figure 6) is very close to the probability of failure determined deterministically (0.004) taking only mean values for input. This verifies the accuracy of the probabilistic solver used to obtain the 
distribution of probability of failure due to uncertain input values in the thermal stress model.

The FORM algorithm used also captures sensitivity of statistical parameters contributing to failure prediction. The relative contribution or rank ordering of uncertainties in parameters is shown in Figure 7. In this example, uncertainty in thermal boundary conditions and material coefficient of thermal expansion appears to have more influence on uncertainty in reliability prediction.

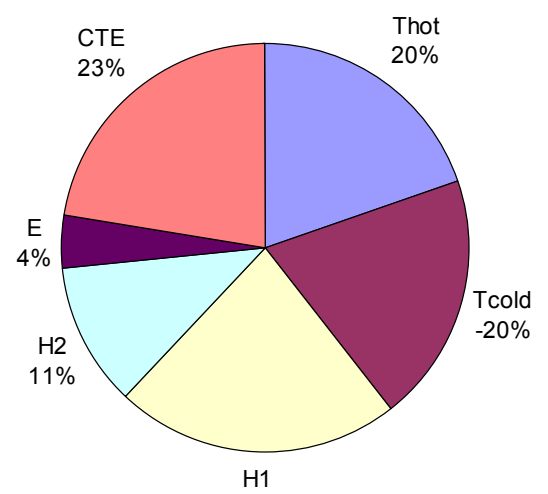

Figure 7. Sensitivity ranking of uncertainties in model input

Though only few input parameters are chosen as random variables in this example for demonstration, the method is certainly applicable to actual design where more input parameters will have to be treated as random variables. This slightly enhances the complexity in coding or scripting and increases the number of iterations, but both are achievable within reasonable limits.

\section{DISCUSSION}

Uncertainties governing the probability of failure have implications on design and selection of proof stress level. Since the predicted probability of failure itself is a distribution when uncertainties in model input are considered, the $\mathrm{Y}$ axis in the cumulative distribution shown in Figure 6 can be interpreted as confidence of prediction due to uncertainties in model input. Figure 8 is reproduced from Figure 6 where the $\mathrm{X}$ axis is linear instead of logarithmic. Table 2 lists probability of failure obtained from deterministic approach for mean input values and extreme condition input values. Also shown in Table 2 is the predicted probability of failure with $95 \%$ confidence when considering uncertainties in model inputs thru the probabilistic approach.

As shown in this example, one would expect the probability of failure to be 0.004 when mean input values are taken for prediction. If the actual boundary conditions or material properties are unfavorably different than the mean value considered for prediction, then the resulting failure probability will be higher than 0.004; that is more parts are likely to fail in service than predicted. In this case, the reliability is compromised. Since the predicted reliability with $95 \%$ confidence is 0.2 , it suggests that the compromise in reliability can be as high as 196 more parts failing per 1000 .

\section{Table 2. Probability of Failure determined through different approaches}

\begin{tabular}{|l|r|}
\hline \multicolumn{1}{|c|}{$\begin{array}{c}\text { Treatment of } \\
\text { Model Input }\end{array}$} & $\begin{array}{c}\text { Probability } \\
\text { of failure }\end{array}$ \\
\hline Deterministic, Mean value & 0.004 \\
\hline Deterministic, extreme value & 0.49 \\
\hline Probabilistic, at 95\% confidence & 0.2 \\
\hline
\end{tabular}

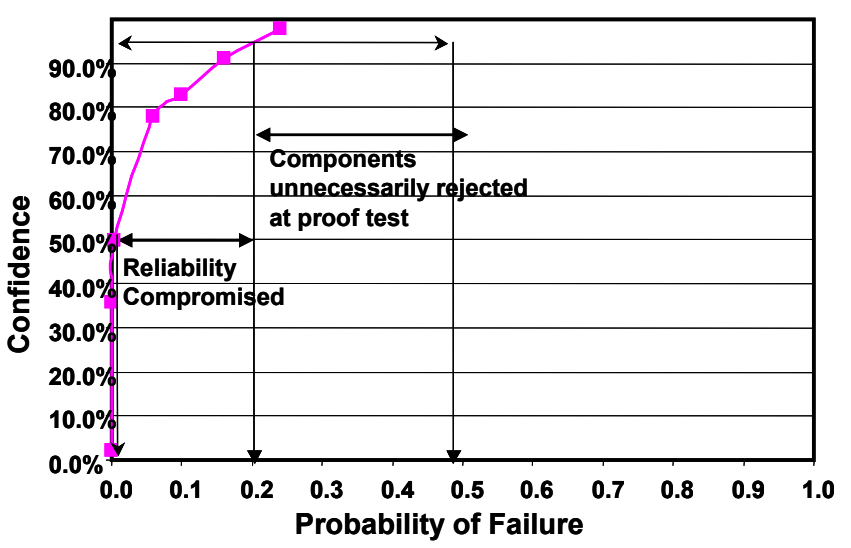

Figure 8. Cumulative distribution of probability of failure due to uncertainties in model input.

A conservative approach will be to predict probability of failure using only extreme conditions. Based on this approach, the predicted probability of failure is 0.49 (from Table 2). Since this level of probability of failure can not be accepted in service, the parts would have to be proof screened prior to shipment. Since the parts are likely to be proof screened at or near use stress level (corresponding to worst case stress prediction), nearly $49 \%$ of parts are expected to fail at proof screening. This may be too conservative. The likelihood of all factors considered at the extreme condition occurring simultaneously in reality is going to be very small. Reliability with $95 \%$ confidence may be adequate and provides enough conservatism since uncertainties are already taken into account. In this case, the proof stress level can be reduced appropriately and nearly $30 \%$ good components can be saved.

The sensitivity analysis helps the design engineer to focus their effort on better quantification of the most sensitive uncertain input parameters to the model. The design engineer also can pay attention to the design such that the range of uncertainty in critical parameters can be reduced to enable robust design. 


\section{CONCLUSION}

A fast and efficient probabilistic method has been demonstrated in predicting probability of failure taking uncertainties in model prediction into account. The probabilistic analysis enables reliability prediction with quantifiable confidence. The sensitivity analysis can be used to manage critical parameters effectively. This in turn allows optimization of design while considering uncertainties to obtain a robust design and proper selection of a proof test level to assure product reliability while minimizing parts rejected at proof screening.

\section{ACKNOWLEDGEMENT}

We thank Dr. Zaffir Chaudhry, United Technologies Research Center, for valuable discussion and suggestions. This work was partly funded by Department of Energy.

\section{REFERENCES}

1. A.G. Evans, "Aspects of the Reliability of Ceramics for Engine Applications", in Fracture in Ceramic Materials, Ed. A.G. Evans, Noyes Publications, 1984, ISBN 0-81551005-5

2. M.van Roode, M. K. Ferber,. D. W. Richerson, "Ceramic Gas Turbine Design and Test Experience" ASME, New York, 2002, ISBN 0-7918-0181-0

3. N. N. Nemeth., L. M. Powers., L. A. Janosik, and J. P. Gyekenyesi, "Time-Dependent Reliability Analysis of Monolithic Ceramic Components Using the CARES/LIFE Integrated Design Program," Life Prediction Methodologies and Data for Ceramic Materials, ASTM STP 1201, C. R. Brinkman, and S. F. Duffy, Eds., American Society for Testing and Materials, Philadelphia, 1993, pp. 390-408
4. B. Schenk, A. D. Peralta, P. Brehm, and M. N. Menon, "A New Probabilistic Approach for Accurate Fatigue Data Analysis of Ceramic Materials", J. Eng. for Gas Turbines and Power, 2000, Vol. 122, Issue 4, pp. 637-645

5. N. N. Nemeth., L. M. Powers., L. A. Janosik, and J. P. Gyekenyesi, "Ceramics Analysis and Reliability Evaluation of Structures Life Prediction Program (CARES/LIFE) Users and Programmers Manual," NASA TM-106316.

6. R. E. Melchers,, STRUCTURAL RELIABILITY: Analysis and Prediction, John Wiley \& Sons, New York, 1987.

7. S. Reh, T. Palfi, and N. N. Nemeth, "Probabilistic Analysis Techniques Applied to Lifetime reliability Estimation of Ceramics", JANNAF $39^{\text {th }} \mathrm{CS} / 27^{\text {th }} \mathrm{APS} / 21^{\text {st }}$ $\mathrm{PSHS} / 3^{\text {rd }}$ MSS Joint Subcommittee Meeting, Colorado Springs, Colorado, Dec. 1-5, 2003.

8. R. H. Carter, and O. M. Jadaan, "The Effects of Incorporating Sysstem Level Variability into the Reliability Analysis for Ceramic Components," Ceram. Eng. Sci. Proc., Vol. 26, pp 253-260, 2005.

9. O. Ditlevsen, and H. O. Madsen, Structural Reliability Methods, John Wiley, 1996.

10. A. M. Hasofer and N. C. Lind, "Exact and Invariant Second Moment Code Format," Proceedings of ASCE, Journal of the Engineering Mechanics Division, Vol. 100, No. EM1, pp. 1111-121, 1974.

11. I.R. (Wally) Orisamolu and X. Luo, "Probabilistic Assessment of Corrosion Effects on the Damage Tolerance of Aircraft Structures", AIAA-97-1070-CP, 1997

12. D. S. Riha, B. H. Thacker, H. R. Millwater, Y.- T.. Wu, and M. P. Enright, "Probabilistic Engineering Analysis using the NESSUS Software" AIAA-2000-1512, 2000.

13. Hexoloy SA SiC technical data from Saint-Gobain Ceramics, http://www.hexoloy.com/hexoloy_data-sheets 


\title{
Development and Evaluation of Environmental Barrier Coatings for Si-based Ceramics
}

\author{
Tania Bhatia, Venkat Vedula, Harry Eaton, Ellen Sun, John Holowczak and Gary Linsey \\ United Technologies Research Center \\ East Hartford, CT, USA.
}

\section{ABSTRACT}

Environmental barrier coatings (EBCs) are being developed for silicon carbide ( $\mathrm{SiC}$ ) based composites and monolithic silicon nitride $\left(\mathrm{Si}_{3} \mathrm{~N}_{4}\right)$ to protect against the accelerated oxidation and subsequent silica volatilization in high temperature, high-pressure steam environments encountered in gas turbine engines. While EBCs for silicon carbide $\left(\mathrm{EBC}_{\mathrm{SiC}}\right)$ have been demonstrated in combustor liner applications, efforts are ongoing in the development of EBC systems for silicon nitride $\left(\mathrm{EBC}_{\mathrm{SiN}}\right)$. The challenges of adapting $\mathrm{EBC}_{\mathrm{SiC}}$ to monolithic $\mathrm{Si}_{3} \mathrm{~N}_{4}$ are discussed in this paper. Progress in the area of $\mathrm{EBC}_{\mathrm{SiN}}$ including development and performance during field tests and tests simulating engine conditions are reviewed.

\section{INTRODUCTION}

Silicon-based monolithic ceramics (Silicon Carbide and Silicon Nitride) and ceramic-matrix composites (CMCs) are attractive materials for use in gas turbine engine hot sections due to their high temperature mechanical and physical properties as well as lower density than metals. Potential gas turbine ceramic components include combustor liners, vanes, rotors and shrouds. One of the key material requirements for these components is that they withstand high temperatures and pressures for extremely long duration under steam-rich environments. Steamstability has been shown to be a problem in $\mathrm{SiO}_{2}$ forming ceramics $\left(\mathrm{SiC}\right.$ and $\left.\mathrm{Si}_{3} \mathrm{~N}_{4}\right)$ [1-5] due to the accelerated oxidation and recession of silicon carbide and silicon nitride owing to the formation of volatile $\mathrm{Si}(\mathrm{OH})_{4}$ species in high temperature exposure to steam.

Environmental Barrier Coatings (EBCs) have been developed for $\mathrm{SiC} / \mathrm{SiC} \mathrm{CMCs}$ and are key to realizing the potential of Si-based materials for high temperature gas turbine applications [6]. EBCs developed for SiC CMCs have been successfully deployed for protection of CMC combustor liners in Solar Centaur 50S engines and have accumulated over 50,000 hours of engine tests at temperatures in the $1150^{\circ} \mathrm{C}$ $1200^{\circ} \mathrm{C}(2100-2200 \mathrm{~F})$ range [6-9]. Results on the environmental protectiveness of $\mathrm{EBC}_{\mathrm{SiC}}$ when applied to $\mathrm{Si}_{3} \mathrm{~N}_{4}$ have been discussed by Sun et. al [10] and More et. al [11]. This paper discusses some important challenges that affect the direct application of the $\mathrm{EBC}_{\mathrm{SiC}}$ to $\mathrm{Si}_{3} \mathrm{~N}_{4}$ based both on experimental results and finite element analysis on coated components. 


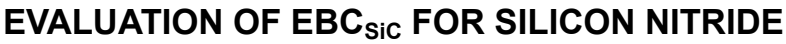

Evaluation of the $\mathrm{EBC}_{\mathrm{SiC}}$ for $\mathrm{Si}_{3} \mathrm{~N}_{4}$ involved using existing coating and process technology associated with the $\mathrm{EBC}_{\mathrm{SiC}}$ and then modifying and optimizing this technology for application to different gas turbine grades of silicon nitride (AS800, SN88, SN282). The $\mathrm{EBC}_{\mathrm{SiC}}$ coating is fully described in the literature [6-11]. It can be described generally as a two or three layer system on a silicon carbide monolith or composite substrate consisting of a bond coat layer of silicon, a top layer of an alkaline earth aluminosilicate based on strontium and barium with a celsian structure and an intermediate layer of mullite blended with the top layer composition (ref. Fig. 1). Processing of these systems is accomplished by thermal spray.

Specimens of the $\mathrm{EBC}_{\mathrm{SiC}}$ coated AS800 silicon nitride were sent to Oak Ridge National Laboratory (ORNL) for exposure to the Keiser Rig for testing in $1.5 \mathrm{~atm}$ steam at $1200^{\circ} \mathrm{C}$ $\left(2200^{\circ} \mathrm{F}\right)$ for $2000 \mathrm{hrs}$ duration [11]. Readers are referred to Ref. 12 for details on the Keiser Rig facility which was used to measure the effectiveness of the EBC system as a steam/oxygen permeation barrier. Figure 2 shows a representation of the coated silicon nitride coupon after $1200^{\circ} \mathrm{C}\left(\sim 2200^{\circ} \mathrm{F}\right)$ exposure. No oxidation of the silicon nitride surface was seen, very little silica formation had occurred on the surface of the silicon, and the $\mathrm{EBC}_{\mathrm{SiC}}$ coating remained relatively unaffected by the exposure. The through thickness cracks observed in Fig. 2 are present in the as-processed state and are caused by CTE mismatch between the coating and the substrate.

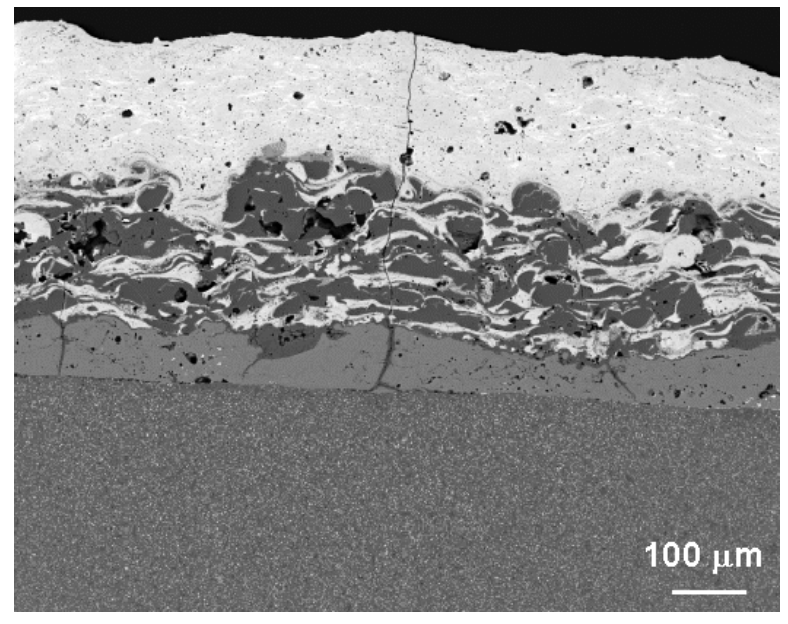

Figure 2. $\mathbf{E B C}_{\mathrm{SiC}}$ coated AS800 post test ORNL Keiser rig $-2000 \mathrm{hrs}, 1200^{\circ} \mathrm{C}\left(2200^{\circ} \mathrm{F}\right)$, $1.5 \mathrm{~atm}$ steam showing no oxidation of AS800 surface [11].

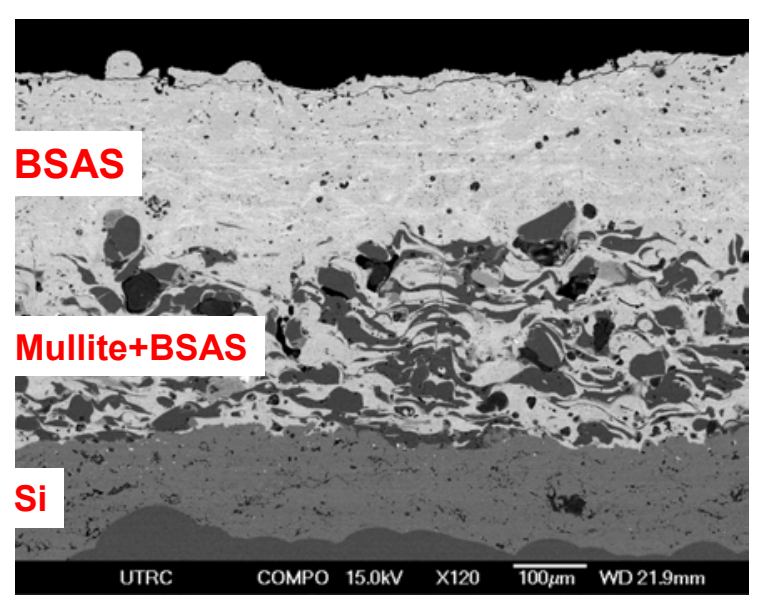

Figure 1. State of the art $\mathrm{EBC}_{\mathrm{SiC}}$ consisting of 3-layers; a Si bond coat, a blended intermediate layer and a top layer based on barium, strontium aluminosilicate (BSAS).

\section{MODELING OF SOLAR TURBINES VANE PROOF TEST}

The objective of this work was to predict the effect of the environmental barrier coating (EBC) on thermal stresses and life of Solar Turbines ceramic stationary gas turbine (CSGT) vanes for Centaur 50S engine exposed to proof testing. The work included finite element analysis (FEA) of the thermal gradients and the resulting stresses in CSGT vanes during steady state and transient proof testing conditions; life prediction of vanes 
using probabilistic CARES/Life analysis; and effects of substrate and EBC properties on thermal stresses in the vanes.

Proof testing is a technique where ceramic components are over-stressed prior to use and those that fail or give indication of fracture initiation are discarded. It is an effective method to truncate the component strength distribution at or above the design stress. Solar Turbines, Inc. has a thermal gradient proof test rig to screen out low strength vanes before they are introduced into engine tests. The conditions for vane proof test were derived from Solar Turbines steady state finite element analysis (for additional details on the proof test, see Ref. 13). About $90 \%$ of silicon nitride vanes manufactured by Kyocera Ceramics (SN282), NGK Ceramics (SN88), and Honeywell Ceramic Components (AS800) passed the Solar Turbines proof test in the uncoated condition. Two of the SN282 (Kyocera) vanes that passed the proof test were coated with the $\mathrm{EBC}_{\mathrm{SiC}}$ and subjected to the same test conditions again. The vanes failed the proof test and fractured into two pieces during heat-up prior to reaching the full temperature gradient required by the test. Figure 3 shows the vanes before and after the proof test. The failure appears to be a typical thermal shock failure in fast fracture under high thermal stresses, possibly at the trailing edge.
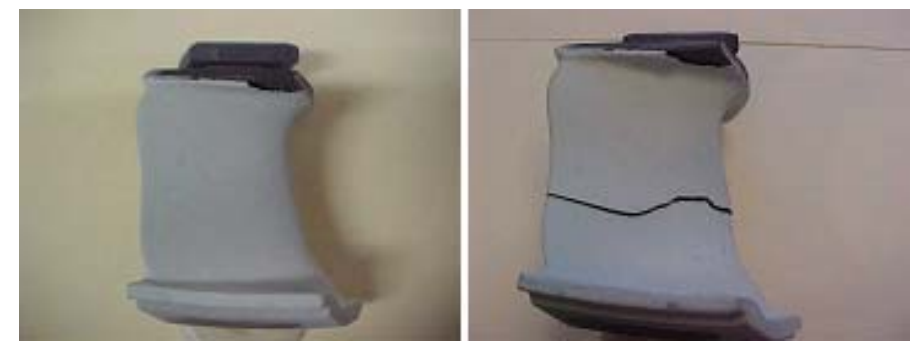

Figure 3. $\mathbf{E B C}_{\text {SiC }}$ coated Solar Turbines vanes before and after the thermal shock proof test.

The structural analysis was performed to determine the effect of the EBC on the thermal gradients and the resulting stresses in the EBC and vanes. The stresses in vanes were then used to predict the probability of failure of the vanes under test conditions.

The FEA was performed using ABAQUS Version 6.2 (HKS, Inc.). The solid model of the vane (ProE file) and the thermal boundary conditions; heat transfer coefficients (h) and sink temperatures, $(\mathrm{T}(\operatorname{sink}))$, as a function of location on vane were provided by Solar Turbines. The boundary conditions for the thermal shock proof test were provided by Solar Turbines and they closely match the engine conditions. In order to analyze the effect of the EBC on the temperature gradients and stresses, a 15-mil coating solid model was developed by UTRC. The coating solid model was attached to the vane in the EBCvane analysis using tie constraints.

Temperature dependent material data (elastic modulus, thermal expansion, thermal conductivity, and heat capacity) were used for the silicon nitride vanes. The EBC is a 3-layer coating of silicon, mixed oxide layer (Mullite+BSAS), and BSAS layer. Since the thermal conductivity of silicon is much higher than that of mixed oxide and BSAS layers, it would have minimal effect on the thermal gradients. The Si layer may however effect the thermal stresses due to its elastic-plastic response, especially at high temperatures. The properties of Mullite+BSAS and BSAS layers are very similar. Therefore, as a first approximation, the silicon layer is ignored and the 15-mil coating is assumed to be composed of BSAS. Since the properties of plasma-sprayed BSAS were not available, properties of dense BSAS were used in the analysis. The coefficients of thermal expansion (CTE) are likely to have a significant influence on the thermal stresses in the EBC and the vanes. Figure 4 shows the coefficient of thermal expansion (CTE) for SN282, AS800, and the $\mathrm{EBC}$ (dense BSAS). 
The finite element analysis of the uncoated SN282 silicon nitride vane was performed using the thermal boundary conditions and temperature dependent material properties. Figure 5 shows the temperature distribution and maximum principal stress on the vane in steady state condition. The maximum temperature in the vane $\left(1300^{\circ} \mathrm{C} / 2376^{\circ} \mathrm{F}\right)$ was at mid-span and the minimum temperature was $640^{\circ} \mathrm{C}\left(1185^{\circ} \mathrm{F}\right)$. The thermal results were then used to predict the stresses in the vane. The maximum principal stress at the trailing edge (TE) of the vane was $245 \mathrm{MPa}(35.5 \mathrm{ksi})$.

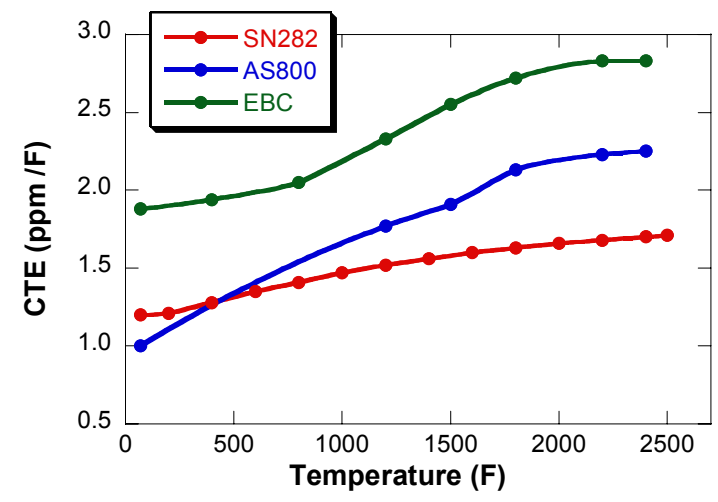

Figure 4. CTEs of Silicon Nitride (SN282 and AS800) and EBC (dense BSAS)

The analysis was repeated with a 15 -mil EBC on the vane. While the EBC coated component is cooled from the annealing temperature to room temperature (RT), below a certain stress-free temperature, residual stresses are developed in the $\mathrm{EBC}$ and vane due to CTE mismatch. The coating will be under tensile residual stresses (due to higher CTE) and the substrate will be under compression. However, during cooling from the annealing temperature, part of the residual stresses can be relieved by cracking. When the vane and EBC are heated to operating condition, the stress-state is reversed and the $\mathrm{EBC}$ is in compression and vane surface in tension.
The analysis was performed for two extreme cases to determine the effect of residual stresses on the stresses during operation. In the first scenario, it is assumed that above certain elevated temperature (called stress-free temperature), the substrate and coating have zero thermal stress and when the system is cooled to RT, residual stresses are developed due to difference in material's CTEs. In the second scenario, it is assumed that the residual stresses during cooling from annealing temperature are fully relieved, either by micro-cracking or local plastic deformation, and therefore at room temperature, the $\mathrm{EBC}$ and vane are stress-free. Figure 6(a) shows the temperature gradients in the EBC at steady state and Figure 6(b) shows the temperature distribution in the vane underneath the $\mathrm{EBC}$ for the first scenario. The maximum temperature in the $\mathrm{EBC}$ was $1323^{\circ} \mathrm{C}\left(2413^{\circ} \mathrm{F}\right)$ and that in the substrate was $1289^{\circ} \mathrm{C}\left(2352^{\circ} \mathrm{F}\right)$. Compared to the case of no EBC layer, the $\mathrm{EBC}$ provides a temperature difference of $13^{\circ} \mathrm{C}\left(24^{\circ} \mathrm{F}\right)$. The EBC surface temperature is higher than that of silicon nitride due to much lower thermal conductivity. Figure 7 shows the corresponding thermal stresses in the vane. In the second scenario described above, the stresses calculated are those generated during the heat-up from RT to operation $\left(\sim 1300^{\circ} \mathrm{C} / \sim 2400^{\circ} \mathrm{F}\right)$. The stress at the trailing edge for this case is $364 \mathrm{MPa}(52.8 \mathrm{ksi}), \sim 49 \%$ higher than that predicted for without EBC case. Table 1 lists the analysis steps and maximum and minimum temperatures and stresses in the vane and EBC for both cases. The most likely scenario is that a part of the residual stress will be relieved by local cracking to between 260 to $364 \mathrm{MPa}$ (37.8 to $52.8 \mathrm{ksi}$ ), an increase of $6-49 \%$ compared to no EBC case depending on the degree of cracking. In addition to the stresses in silicon nitride, as shown in Table 1, the tensile stresses in EBC can also be fairly high (172 $\mathrm{MPa} / 25 \mathrm{ksi}$ ) and these stresses can initiate cracking in the coating itself or at the coatingvane interface during the cool-down after annealing. 
Table 1. Temperatures and Stresses in vanes and EBC

\begin{tabular}{|c|c|c|c|c|c|}
\hline \multirow{2}{*}{ Vane Analysis } & \multirow{2}{*}{ Analysis Step } & \multicolumn{2}{|c|}{ Temperatures (F) } & \multirow{2}{*}{$\begin{array}{l}\text { Location of } \\
\text { Max. Stress }\end{array}$} & \multirow{2}{*}{$\frac{\text { Max. Princ. Stres }}{\text { SN282 }}$} \\
\hline & & Vane & EBC & & \\
\hline No EBC & RT to operation & $2376 / 1185$ & - & Vane TE & 35.5 \\
\hline With EBC: 1 Step Analysis & $R T$ to operation & $2352 / 1191$ & 2413/1255 & Vane TE & 52.8 \\
\hline With EBC: 2 Step Analysis & $\begin{array}{c}\text { APS to } R T \\
\text { RT to operation }\end{array}$ & $\begin{array}{c}\text { RT } \\
2352 / 1191\end{array}$ & $\begin{array}{c}\text { RT } \\
2413 / 1255\end{array}$ & $\begin{array}{l}\text { Coating } \\
\text { Vane TE }\end{array}$ & $\begin{array}{c}23-25 \\
37.8\end{array}$ \\
\hline
\end{tabular}

In order to quantify the effect of substrate CTE on the stresses, the FEA of vanes was repeated with the properties of AS800. Table 1 shows the stresses in the vane with and without the EBC coating. As can be seen, the maximum stress without the EBC is higher in AS800 than that in SN282. This is expected due to higher CTE of AS800 compared to SN282. The effect of the EBC on AS800 vane stresses is reverse of that observed in the case of SN282. The maximum stress decreases from 340 to $325 \mathrm{MPa}$ (49.4 to $47.2 \mathrm{ksi}$ ). This is likely due to fact that the CTE of AS800 has a better match to the CTE of the EBC than SN282 (Figure 4). The analysis suggests that the substrate CTE has a significant influence on the stresses in the vanes.

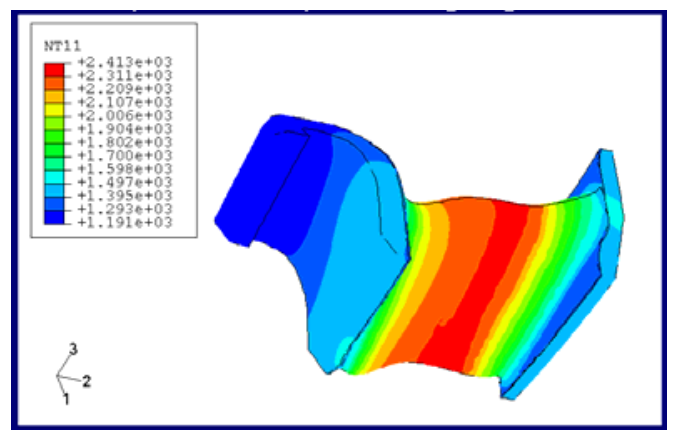

(a)

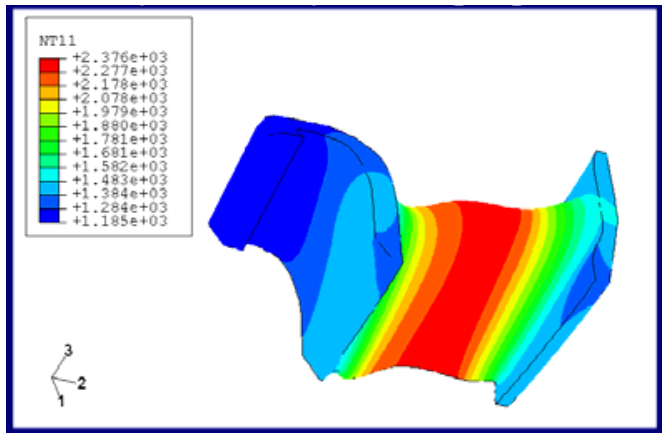

(a)

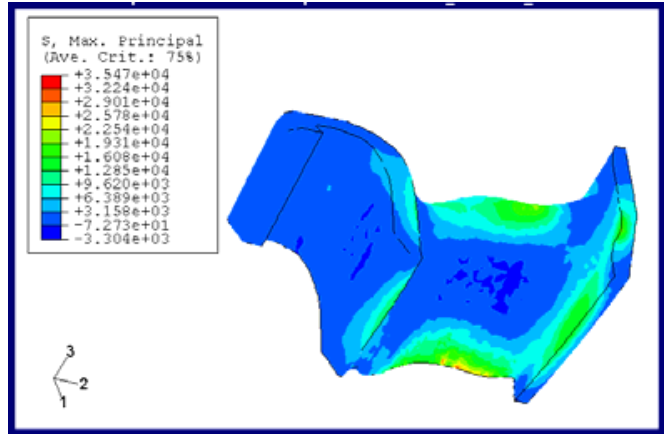

(b)

Figure 5. (a) Temperature distribution in uncoated SN282 vane at steady state condition and (b) Maximum principal stress (psi) distribution. Maximum stress is located at the trailing edge.

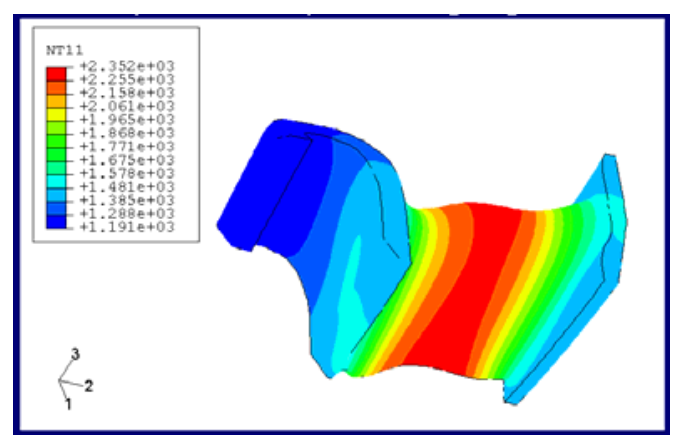

(b)

Figure 6. Temperature distribution in EBC coated SN282 vane at steady state condition (in ${ }^{\circ} \mathrm{F}$ ). (a) in EBC (b) in substrate under EBC 
The likelihood of failure of the SN282 vanes was calculated using as-processed properties obtained from Kyocera [RT Strength: $634 \mathrm{MPa} / 92 \mathrm{ksi}$, Weibull modulus $\mathrm{m}=10$ and $1400^{\circ} \mathrm{C}\left(2552^{\circ} \mathrm{F}\right)$ Strength: $468 \mathrm{MPa} / 68 \mathrm{ksi}, \mathrm{m}=10$ ]. The overall probability of failure of the vane was calculated using the CARES/Life code from NASA Glenn Research Center. The vanes were assumed to fail due to volume flaws in fast-fracture and Weibull principal of independent action (PIA) was selected as the fracture criterion. The probability of failure was calculated using the asprocessed strength of SN282, assuming that the EBC does not lead to any substrate strength debit. The failure probability was found to increase from 3.1E-04 to 7.3E-03 using RT strength values and from $6.3 \mathrm{E}-03$ to $1.4 \mathrm{E}-01$ using $2552^{\circ} \mathrm{F}$ strength data, for without and with the $\mathrm{EBC}$ respectively.

The failure of the coated SN282 vanes prompted UTRC and Oak Ridge National Laboratory (ORNL) to evaluate the effect of the EBC on substrate strength (see next sections). In one early study, the room temperature 4-point bend strength of the coated SN282 samples was found to be only $130 \mathrm{MPa}(19 \mathrm{ksi})$ indicating a significant debit in strength $(\sim 80 \%)$ due to the EBC. (However later work at ORNL indicated greater RT strengths, see Fig. 10.) For a 130 MPa (19 ksi) RT strength, the CARES/Life analysis predicts the probability of failure of coated vanes to be 1.0 (Table 2). At elevated temperature the probability will be between 0.14 and 1.0 depending on the extent of strength debit.

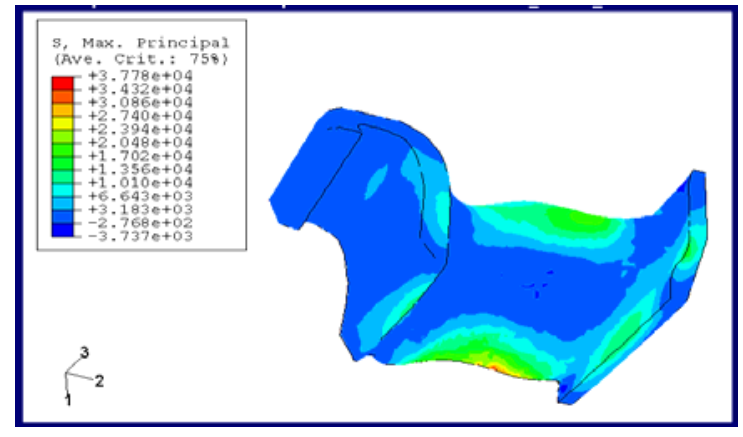

Figure 7. Maximum principal stress (psi) in coated SN282 vane at steady state condition.

\section{Table 2. Failure probability of vanes with and without the EBC}

\begin{tabular}{|c|c|c|c|c|}
\hline \multirow{2}{*}{\multicolumn{2}{|c|}{ Material/ Property }} & \multicolumn{2}{|c|}{ As-processed SN282 } & \multirow{2}{*}{ SN282 with EI } \\
\hline & & No-EBC Nozzle & Nozzle with EBC & \\
\hline \multirow{2}{*}{ Strength (ksi) } & RT & 92 & 92 & 19 \\
\hline & $2552 \mathrm{~F}$ & 68 & 68 & Not Available \\
\hline \multicolumn{2}{|l|}{ Max. Stress (ksi) } & 35.5 & $37 . .8$ & 37.8 \\
\hline $\begin{array}{c}\begin{array}{l}\text { Weibull Modulus } \\
\text { (estimate) }\end{array} \\
\end{array}$ & $\mathrm{RT} / 2552 \mathrm{~F}$ & 10 & 10 & 10 \\
\hline \multirow{2}{*}{$\begin{array}{l}\text { Over-all Vane Failure } \\
\text { Probability }\end{array}$} & RT & 3.10E-04 & $7.30 \mathrm{E}-03$ & $1.00 \mathrm{E}+00$ \\
\hline & $2552 \mathrm{~F}$ & $6.30 \mathrm{E}-03$ & $1.40 \mathrm{E}-01$ & ----- \\
\hline
\end{tabular}

Source: As-processed SN282 Strength from Kyocera Industrial Ceramics Corp. SN282 with EBC strength data from ORNL

The above analysis used hot-pressed BSAS properties for the EBC. In reality, the plasmasprayed EBC will be porous and will have lower conductivity and elastic modulus. In order to determine the effect of the EBC properties on thermal stresses in the vane, the analysis was repeated with half the thermal conductivity and half the stiffness of hot pressed BSAS values. Half values correspond to $\sim 30 \%$ porosity uniformly distributed in the coating. The remaining properties of the substrate and boundary conditions were the same as before. Table 3 shows the effects of properties of the $\mathrm{EBC}$ on the stresses.

The stress drop in the EBC is expected since the stiffness is half that of the substrate, the stresses 
will scale similarly. The analysis suggests that the properties of the EBC can affect the stresses in vane also due to modulus mismatch.

The transient analysis was performed on the vane using the boundary conditions provided by Solar Turbines. A stress free temperature of $1000^{\circ} \mathrm{C}$ $\left(1832^{\circ} \mathrm{F}\right)$ was assumed for the transient analysis. The stresses during the transient heating are very similar ( 344-351 MPa/ 50-51 ksi) for with and without the EBC coating and the maximum stress occurs after 14 and 9 secs respectively. The maximum stress location is the trailing edge (close to mid-span). Figure 8 shows the temperature and stress variations with time. The corresponding steady state stresses were 260 and $245 \mathrm{MPa}$ (37.8 and $35.5 \mathrm{ksi}$ ) for with and without the EBC. Interestingly, Solar Turbines reported failure of the coated vanes after $\sim 15 \mathrm{~s}$ into the test and the predicted time at which maximum stress occurs during the transient matches the experimental proof test failure time very well.

Table 3. Effect of coating properties on stresses in vane and coating

\begin{tabular}{|c|c|c|c|c|c|}
\hline \multirow{2}{*}{ Coating Properties } & \multirow{2}{*}{ Analysis Step } & \multicolumn{2}{|c|}{ Temperatures (F) } & \multirow{2}{*}{$\begin{array}{l}\text { Location of } \\
\text { Max. Stress }\end{array}$} & \multirow{2}{*}{$\begin{array}{l}\text { Max. Prin } \\
\text { Stress (ks }\end{array}$} \\
\hline & & Vane & EBC & & \\
\hline \multirow{2}{*}{ Dense BSAS } & APS to RT & RT & RT & Coating & $23-25$ \\
\hline & $\mathrm{RT}$ to operation & $2352 / 1191$ & $2413 / 1255$ & Vane TE & 37.8 \\
\hline \multirow{2}{*}{ Porous BSAS } & APS to RT & RT & RT & Coating & $12-13$ \\
\hline & $\mathrm{RT}$ to operation & $2330 / 1194$ & $2421 / 1254$ & Vane TE & 33.4 \\
\hline
\end{tabular}

Porous BSAS refers to coating with half the thermal conductivity and stiffness as dense BSAS.

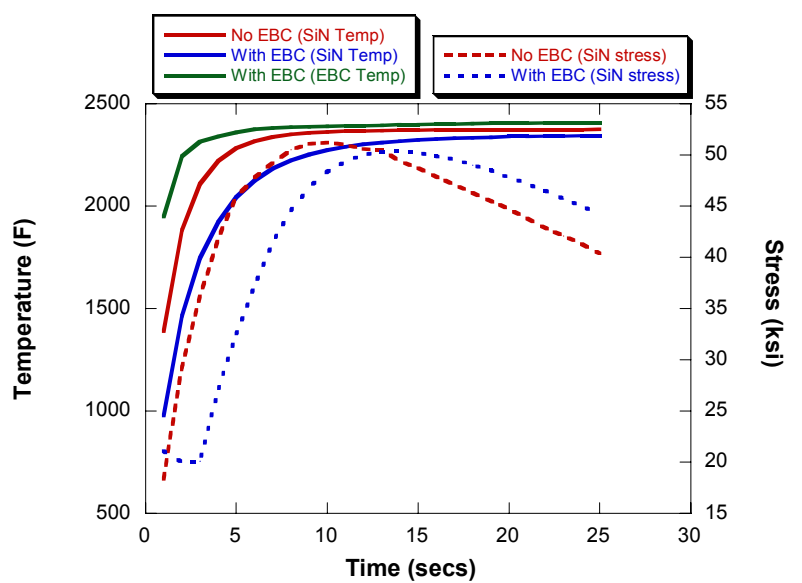

Figure 8. Maximum temperature and stress in $\mathrm{EBC}$ and $\mathrm{SN} 282$ silicon nitride ( $\mathrm{SiN}$ ) during the transient heat-up.

\section{COUPON-LEVEL PROPERTY CHARACTERIZATION AT ORNL}

Proof tested $\mathrm{EBC}_{\mathrm{SiC}}$ coated Solar Turbines vanes that had failed (Figure 9) and AS800 and SN282 coupons coated with the $\mathrm{EBC}_{\mathrm{SiC}}$ were submitted by Solar Turbines and UTRC to ORNL for mechanical property test evaluation to assess changes in strength as the result of application of the baseline $\mathrm{EBC}_{\mathrm{SiC}}$ coating. Figures 10-12 are data generated at ORNL based on RT testing of vane coupons and RT and elevated temperature testing of bend bar coupons respectively. Test results in all cases show a very significant debit of 60 to $70 \%$ in bend strength at RT due to application of the $\mathrm{EBC}_{\mathrm{SiC}}$ coating ("w/EBC" and "w/oEBC" refer to calculation of the fracture stress either by including the thickness of the EBC or not i.e., assumes whether or not the coating provides any load bearing contribution, however, in both cases the EBC coating is present on the silicon nitride). There is no significant difference in the debit whether the test coupon is fabricated from the vane or determined by use of a bend bar. For the $1204^{\circ} \mathrm{C}\left(2200^{\circ} \mathrm{F}\right)$ test conditions the debit appears to be reduced significantly especially for testing at a load rate of $30 \mathrm{MPa} / \mathrm{s}(4.4 \mathrm{ksi} / \mathrm{s})$ where the debit is only $\sim 10 \%$ assuming that the coating provides no load 
bearing contribution. At $1204^{\circ} \mathrm{C}\left(2200^{\circ} \mathrm{F}\right)$ and at a load rate of $0.003 \mathrm{MPa} / \mathrm{s}(4.4 \mathrm{E}-04 \mathrm{ksi} / \mathrm{s})$ the debit is $\sim 30 \%$ implying sensitivity to the atmosphere in comparison to the $30 \mathrm{MPa} / \mathrm{s}(4.4$ $\mathrm{ksi} / \mathrm{s}$ ) load rate. Both conditions, however, show less debit than at RT (60\% to $70 \%$ debit).

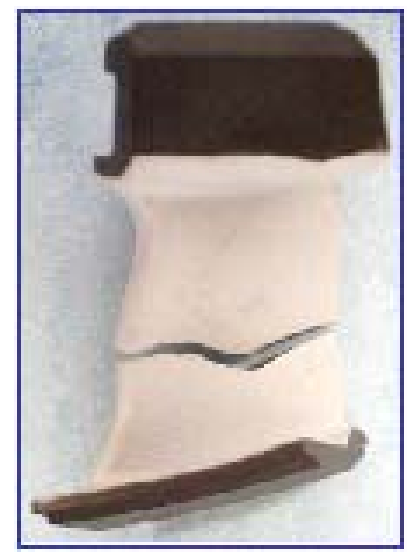

Figure 9. $\mathrm{EBC}_{\mathrm{SiC}}$ coated Solar Turbines vane post proof test showing mid-span failure.

The following conclusions were made based on the structural analysis and life prediction of Solar Turbines vanes and mechanical characterization at ORNL:

1. The thermal stresses are strongly dependent on CTE mismatch between the $\mathrm{EBC}$ and substrate and weakly dependent on elastic modulus mismatch.

2. The maximum stress location for both steady state and transient condition is vane trailing edge (mid-span).

3. Transient stresses during heating are $\sim 35 \%$ higher than the steady state stresses in the vanes. The time at which the transient stress peaks $(\sim 15$ secs $)$ matches with the experimental observation of vane failure during heat-up.

4. The thermal stress increases by 6 to $48 \%$, depending on the residual stress relaxation, when the $\mathrm{EBC}_{\mathrm{SiC}}$ is applied to silicon nitride vanes.

5. The probability of failure of coated SN282 vanes is $100 \%$ due to significant strength debit of the substrate by the coating process.

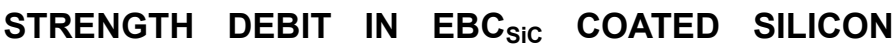 NITRIDE}

In an attempt to further our understanding of the apparent debit observed in the strength of the $\mathrm{EBC}_{\mathrm{SiC}}$ coated Solar Turbines vanes, UTRC studied the flexure strength behavior of AS800 silicon nitride at room temperature under several conditions. Test coupons of nominal size $8 \times 0.4$ $\mathrm{x} 0.3 \mathrm{~cm}$ were made from AS800 and tested in four-point bending. The mechanical behavior was characterized by varying the following parameters:

1. Material surface: As-processed and machined surfaces

2. Grit blast conditions

3. Effects of heat treatment and heat treat atmosphere

4. Effects of individual EBC layers: Bond coat, bond coat plus intermediate coat, and three layer-coated surfaces.

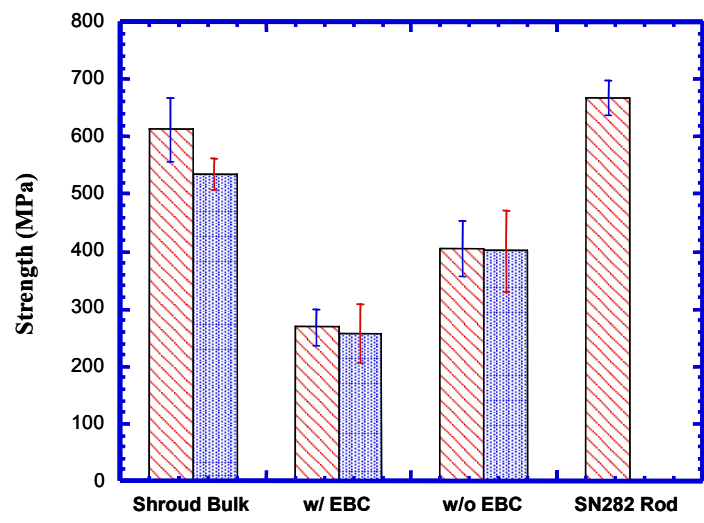

Figure 10. ORNL RT strength testing of $E B C_{S i C}$ coated Solar Turbines $S N 282$ vanes $($ red $=$ vane $\# 9$, and blue = vane \#11) post proof test failure. "w/EBC" and "w/oEBC" refer to strength calculation including or not thickness of coating both conditions have EBC coating on silicon nitride.

Strength measurements of the as-processed and as-machined (no subsequent heat treatment) surfaces of the AS800 bend bars showed RT 
strengths and standard deviations of $785 \pm 52$ and $737 \pm 40 \mathrm{MPa}(114 \pm 7.5$ and $107 \pm 5.8 \mathrm{ksi})$ respectively, roughly a $6 \%$ decrease in strength due to machining flaws but still within $10 \%$ of the nominal, as-processed strength value for AS800.

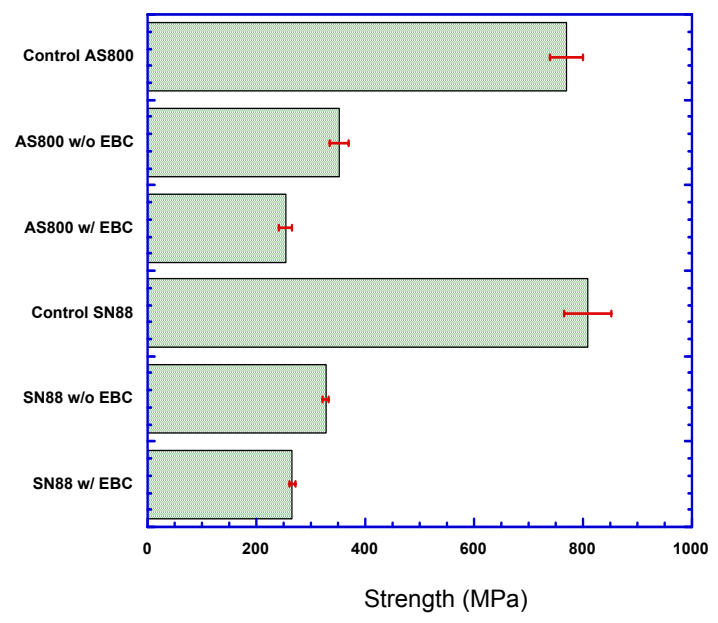

Figure 11. $\mathrm{EBC}_{\mathrm{SiC}}$ coated $\mathrm{AS800}$ and $\mathrm{SN} 88$ bend bars @RT. "W/EBC" and "w/oEBC" refer to strength calculation including or not thickness of coating - both conditions have EBC coating on silicon nitride.

As part of the coating application, grit blasting is used to clean the surface. Grit blasting the asprocessed surface with either quartz, silicon, or alumina, all in the size range of 150 microns or finer, resulted in fracture strengths of $\sim 847$, $\sim 834, \sim$ and $756 \mathrm{MPa}(\sim 123, \sim 121$, and $\sim 110 \mathrm{ksi})$ respectively for roughly $+8 \%,+7 \%$, and $-2 \%$ changes in strength, all still within $10 \%$ of the nominal as-processed strength value for AS800. For the machined surface condition, alumina grit blasting resulted in a strength of $\sim 716 \mathrm{MPa}(\sim$ $104 \mathrm{ksi}$ ) again roughly a 2 to $3 \%$ decrease in strength or very similar results to the asprocessed condition.

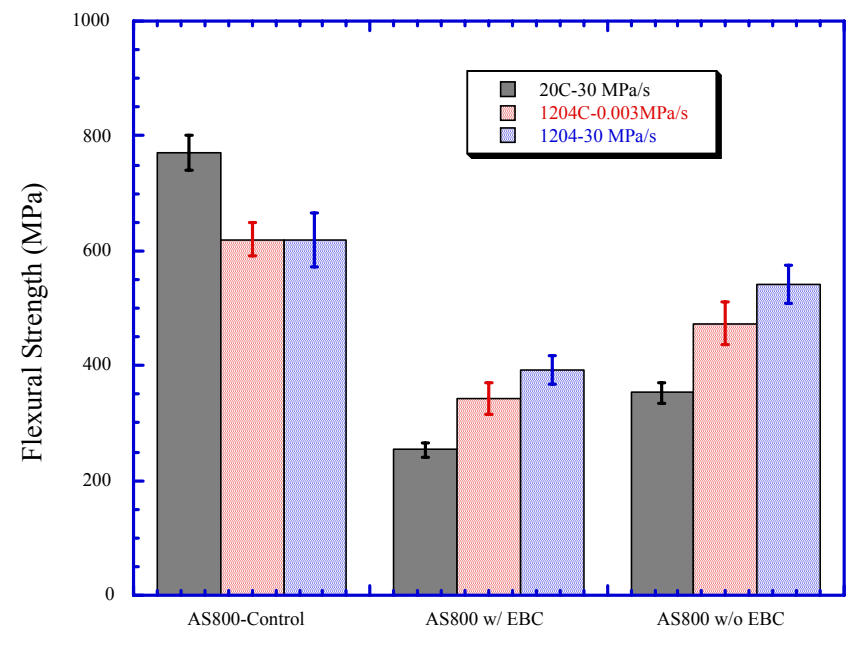

Figure 12. EBC $_{\mathrm{SiC}}$ coated AS800 bend bars @RT and $1204^{\circ} \mathrm{C}\left(2200^{\circ} \mathrm{F}\right)$. "W/EBC" and "w/oEBC" refer to strength calculation including or not thickness of coating - both conditions have EBC coating on silicon nitride.

During the coating application process, the substrate is exposed to both elevated temperatures during processing and to a subsequent heat treatment in air. Measurements of as-processed surface after heat treatment in air showed a strength of $688 \mathrm{MPa}(99.9 \mathrm{ksi})$ for a loss in strength of $\sim 13 \%$ while the machined surface showed a loss of $17 \%$. Measurements of the alumina grit blasted, as-processed condition after exposure to the heat treat conditions showed a strength of $613 \pm 23 \mathrm{MPa}(89.0 \pm 3.4 \mathrm{ksi})$, a decrease of $\sim 22 \%$ in strength. The same measurements made on alumina grit blasted specimens exposed to the heat-treat conditions in $\mathrm{N}_{2}$ showed a strength of $\sim 730 \mathrm{MPa}(\sim 106 \mathrm{ksi})$ almost the same value as the grit blasted only condition. For the machined surface condition, alumina grit blasting plus heat treat in air resulted in a strength of $572 \pm 43 \mathrm{MPa}(83 \pm 6.3$ $\mathrm{ksi}$ ), a $22.5 \%$ reduction in the machined surface strength, very similar to the as-processed surface condition. The effect of heat-treatment on the grit blasted, machined surfaces in $\mathrm{N}_{2}$ was not evaluated. The conclusion however is that although grit-blasting does cause some debit in 
strength, a subsequent heat treatment in furnace air results in much higher reduction in the strength of AS800 silicon nitride.

The role of fluence in grit blasting was also examined in this study. Fluences at $150 \mathrm{~m} / \mathrm{s}(492$ $\mathrm{f} / \mathrm{s}$ ) impact velocity ranging from $14.2 \mathrm{~g} / \mathrm{cm}^{2}$ to $426 \mathrm{~g} / \mathrm{cm}^{2}$ produced no significant variation in strength debit for either the condition of grit blasting alone or for grit blasting plus heat treatment. Figure 13 shows the effects of grit blasting fluence on normalized bend strength.

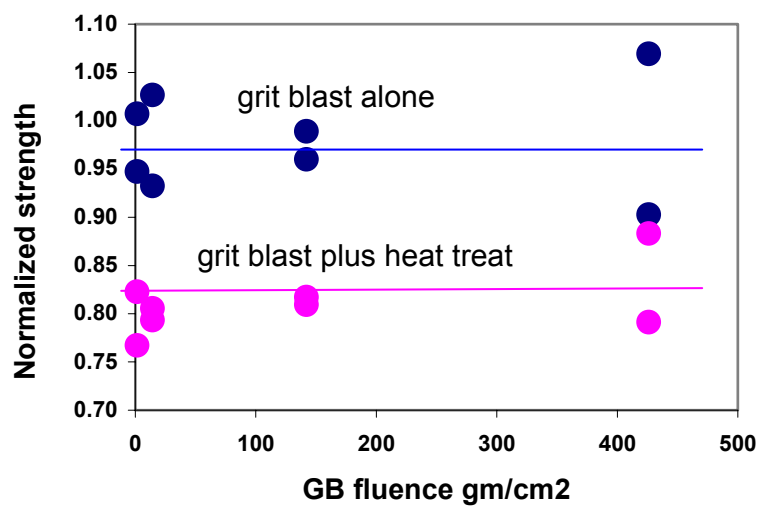

Figure 13. Effects of grit blast (GB) fluence $\left(\mathrm{gm} / \mathrm{cm}^{2}\right)$ on strength of AS800.

The next set of experiments was performed to study the effects of the EBC layers on strength of AS800. Application of 125 microns of silicon metal to a grit blast surface of the AS800 and using a subsequent $1250^{\circ} \mathrm{C}\left(2285^{\circ} \mathrm{F}\right) / 24 \mathrm{hr}$ heat treat in air resulted in a strength of $310 \mathrm{MPa}(45$ ksi) for the as-processed surfaces and $317 \mathrm{MPa}$ (46 ksi) for the machined surfaces representing roughly a $60 \%$ reduction in non-EBC coated strength and roughly a $50 \%$ decrease in strength over the grit blasted and heat treated values. Strength of the AS800 having the three-layer EBC was approximately the same value at 317 $\mathrm{MPa}$ (46 ksi). There was no significant effect due to increasing the thickness of silicon layer to 250 microns or due to the effect of the silicon layer plus only the intermediate layer. Figure 14 is a Weibull plot of the room temperature strength of uncoated and coated AS800 in four point bending.

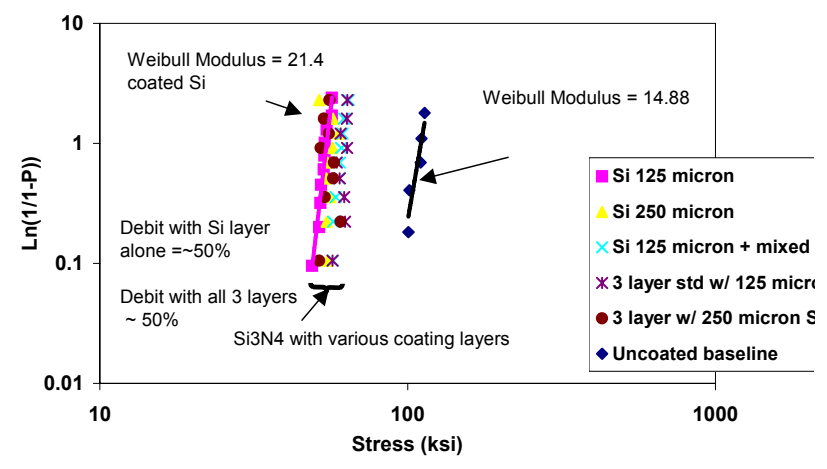

Figure 14. Weibull plot of uncoated and coated AS800. Baseline refers to uncoated AS800 strength data, and the other data refer to various coated samples.

\section{SUMMARY}

The effectiveness of the $\mathrm{EBC}_{\mathrm{SiC}}$ on silicon nitride was studied and it is concluded that while the EBC provided adequate environmental protection, the CTE mismatch caused room temperature substrate strength degradation that is presently unacceptable for the components considered. The study was based on structural analysis and life prediction performed on Solar Turbines vanes to understand the mechanical behavior of coated silicon nitride components. In summary, tests of silicon nitride gas turbine components showed a limited applicability of EBCs that were developed for silicon carbide composites to silicon nitride components. It demonstrates the need for the development of new coating systems specifically tailored to silicon nitride.

\section{ACKNOWLEDGMENTS}

This work and the efforts leading to it would not have been possible without the guidance and support of the Office of Naval Research (ONR) Dr. Steven Fishman; the Department of Energy (DoE) Power Technologies - Deborah Haught and Steven Waslo; and the National Air and Space Administration (NASA) - Dave Brewer, 
Joe Shaw and Bob Draper. Thanks are due to other United Technologies Research Center personnel Greg Ojard, Shanti Nair (University of Massachusetts), Bill Tredway, Thomas Lawton, Mark Hermann, Steve Gore, Bob Barth, Roy Wong, Bob Brown, Chuck Burila, Bruce Laube. The authors also thank collaborators Jeff Price, Josh Kimmel, Mark Van Roode, and Oscar Jimenez at Solar Turbines Inc.; Karren More, Peter Tortorelli, Matt Ferber and H.T.Lin at Oak Ridge National Laboratory.

\section{REFERENCES}

1. Opila, E.J., and Hann R.E. Jr, 1997, "Paralinear Oxidation of CVD SiC in Water Vapor”, J. Am. Ceram. Soc., 80 (1), pp. 197-205.

2. Opila, E.J., Fox, D.S., and Jacobson, N.S., 1997, "Mass Spectrometric Identification of Si-O$\mathrm{OH}(\mathrm{g})$ Species from the Reaction of Silica with Water Vapor at Atmospheric Pressure", J. Am. Ceram. Soc., 80 (4), pp. 1009-12

3. Opila E.J., Smialek, J.L., Robinson, R.C., Fox, D.S., and Jacobson, N.S., 1999, "SiC Recession Caused by $\mathrm{SiO}_{2}$ Scale Volatility under Combustion Conditions: II, Thermodynamcis and Gaseous-Diffusion Model", J. Am. Ceram. Soc., 82 (7), pp. 1826-34.

4. Robinson, R.C., and Smialek, J.L., 1999, "SiC Recession Caused by $\mathrm{SiO}_{2}$ Scale Volatility under Combustion Conditions: I, Experimental Results and Empirical Model", J. Am. Ceram. Soc., 82 (7), pp. 1817-25.

5. Smialek, J.L., Robinson, R.C., Opila, E.J., Fox, D.S., and Jacobson, N.S., 1999, "SiC and $\mathrm{Si}_{3} \mathrm{~N}_{4}$ Recession Due to $\mathrm{SiO}_{2}$ Scale Volatility Under Combustor Conditions", Adv. Composite Mater., 8, 1, pp.33-45.

6. Eaton, H.E., Linsey, G.D., More, K.L., Kimmel, J.B., Price, J.R., and Miriyala, N., 2000, "EBC Protection of $\mathrm{SiC} / \mathrm{SiC}$ Composites in the Gas
Turbine Combustion Environment", ASME Paper GT-2000-631.

7. Eaton, H.E., and Linsey, G.D.; 2002, "Accelerated oxidation of SiC CMC's by Water Vapor and Protection via Environmental Barrier Coating Approach", J. Eur. Ceram. Soc, 22, pp 2741-2747.

8. More, K.L., Tortorelli, P.F., Walker, L.R., Kimmel, J.B., Miriyala, N., Price, J.R., Eaton, H.E., Sun, E.Y., and Linsey, G.D., 2002, "Evaluating Environmental Barrier Coatings on Ceramic Matrix Composites after Engine and Laboratory Exposures", ASME Paper GT-200230630 .

9. Miriyala, N., Kimmel, J., Price, J., More, K., Tortorelli, P., Eaton, H., Linsey, G., and Sun, E., 2002, "The Evaluation of CFCC Liners After Field Testing in a Gas Turbine -III", ASME Paper GT-2002-30585.

10. Sun, E., Eaton, H., Holowczak, J., and Linsey, G., 2002, "Development and Evaluation of Environmental Barrier Coatings for Silicon Nitride", ASME Paper GT-2002-30628.

11. More, K.L., Tortorelli, P.F., and Walker, L.R., "Verification of an EBC's Protective Capability by First-Stage Evaluation in a High Temperature, High-Pressure Furnace”, ASME Paper GT-200338923.

12. More, K.L., Tortorelli, P.F., Ferber, M.K., Walker, L.R., Keiser, J.P., Brentnall, W.B., Miralya, N., and Price, J.B., 1999, "Exposure of Ceramics and Ceramic Matrix Composites in Simulated and Actual Combustor Environments", ASME Paper 99-GT-292.

13. vanRoode, M., Price, J.R., Richerson, D.W., Parthasarathy, V., and Graves, G.A.; 2001, "Ceramic Stationary Gas Turbine Program - 
Monolithic Ceramic Component Development

Summary", ASME Paper GT-2001-0457. 


\title{
GT 2007-27685
}

\section{ENVIRONMENTAL BARRIER COATINGS FOR MONOLITHIC SILICON NITRIDE - BOND COAT DEVELOPMENT}

\author{
Tania Bhatia, G.V. Srinivasan, Sonia V. Tulyani, Robert A. Barth, \\ Venkat R. Vedula and William K. Tredway \\ United Technologies research Center, East Hartford, CT, USA
}

\begin{abstract}
Environmental barrier coatings (EBCs) are being developed for silicon carbide ( $\mathrm{SiC}$ ) based composites and monolithic silicon nitride $\left(\mathrm{Si}_{3} \mathrm{~N}_{4}\right)$ to protect against the accelerated oxidation and subsequent silica volatilization in high temperature highpressure steam environments encountered in gas turbine engines. It has been found that the application of EBCs developed for SiC-based composites $\left(\mathrm{EBC}_{\mathrm{SiC}}\right)$ to monolithic silicon nitride results in a loss of room temperature mechanical strength of the monolithic substrate. In this paper, we discuss the development of a bond coat system tailored for monolithic silicon nitride that helps retain the strength of the substrate. Some of the unique requirements and challenges associated with the processing of non-line-of-sight EBCs for $\mathrm{Si}_{3} \mathrm{~N}_{4}$ will also be discussed. Preliminary results from coating of airfoils will be presented.
\end{abstract}

\section{INTRODUCTION}

Silicon-based ceramics (monolithic silicon carbide and silicon nitride) and ceramic-matrix composites (CMCs) are attractive materials for use in gas turbine engine hot sections due to their high temperature mechanical and physical properties as well as lower density than metals. Potential gas turbine ceramic components include combustor liners, vanes, rotors and shrouds. One of the key material requirements for these components is that they withstand high temperatures and pressures for extremely long durations under steam-rich environments. Steam stability has been shown to be a problem in $\mathrm{SiO}_{2}$ forming ceramics $\left(\mathrm{SiC}\right.$ and $\left.\mathrm{Si}_{3} \mathrm{~N}_{4}\right)$ [1-5] due to the accelerated oxidation and recession of silicon carbide and silicon nitride owing to the formation of volatile $\mathrm{Si}(\mathrm{OH})_{4}$ species in high temperature exposure to steam.

Environmental Barrier Coatings (EBCs) have been developed for $\mathrm{SiC} / \mathrm{SiC} \mathrm{CMCs}$ and are key to realizing the potential of Si-based materials for high temperature gas turbine applications [6]. EBCs developed for $\mathrm{SiC} / \mathrm{SiC} \mathrm{CMCs}$ have been successfully deployed for protection of CMC combustor liners in Solar Centaur 50S engines and have accumulated over 75,000 hours of engine tests at temperatures in the $1150-1200{ }^{\circ} \mathrm{C}(2100-2200 \mathrm{~F})$ range [6-10]. Engine tests provide valuable insights and lessons that guide the development of a newer generation of coatings [6-10].

Early attempts at adapting the EBC developed for $\mathrm{SiC}\left(\mathrm{EBC}_{\mathrm{SiC}}\right)$ for silicon nitride have shown that coating provides adequate environmental protection to the substrate [11-13]. However, the coating results in an undesirable reduction in the strength of the ceramic substrate caused by the CTE mismatch between the coating and substrate [13]. It was also shown that the mechanical property knockdown contributed to the failure of $\mathrm{EBC}_{\mathrm{SiC}}$ coated SN 282 vanes during proof testing by Solar Turbines Inc. $[13,14]$. It was clear that a new coating system needed to be developed for $\mathrm{Si}_{3} \mathrm{~N}_{4}$ components. 
Coatings tailored specifically for $\mathrm{Si}_{3} \mathrm{~N}_{4}$ are currently being developed by UTRC under programs funded by DOE and ONR. This paper discusses the development of a bond coat system that helps retain the strength of EBC-coated silicon nitride.

\section{NOMENCLATURE}

BSAS Barium Strontium Aluminosilicate

CMC Ceramic Matrix Composite

CSGT Ceramic Stationary Gas Turbine

CTE Coefficient of Thermal Expansion

CVD Chemical Vapor Deposition

DOE U.S. Department of Energy

EBC Environmental Barrier Coating

EPM Enabling Propulsion Materials

IBR Integrally Bladed Rotor

IGT Industrial Gas Turbine

NASA National Aeronautics and Space Administration

NIST National Institute for Standards and Technology

OOF Object Oriented Finite Element Analysis

ONR Office of Naval Research

$\mathrm{SiC} / \mathrm{SiC}$ Silicon Carbide Fiber Reinforced Silicon Carbide Matrix CMC

$\mathrm{Si}_{3} \mathrm{~N}_{4} \quad$ Silicon Nitride

SN282 Gas turbine grade silicon nitride by Kyocera Industrial Ceramics Corp.

Solar Solar Turbines Inc.

UTRC United Technologies Research Center

\section{EMPHASIS ON THE DEVELOPMENT OF NON-LINE- OF-SIGHT COATINGS}

In the initial phase of the coating development, the complexity and small size of the monolithic silicon nitride components that needed to be coated were considered. A typical integral vane ring and integrally bladed rotor (IBR) that needs an EBC is shown in figure 1a. Most of the prior experience in EBC development consisted of plasma sprayed coatings and it appeared that existing thermal spray technologies might not be suitable to coat the components of interest. A feasibility study was performed to determine if air plasma spray technique could be used to coat complex shaped engine components such as an integral vane ring. The study was based on a simple analytical approach that considered the ability of a plasma gun to coat "hidden" areas (vanes and platforms) by calculating the angle at which the spray gun approached the component without "gouging" using the ST5+ vane ring design developed under the DOE Advanced Microturbine contract [14]. The quality of coating as a function of gun-angle was independently assessed by thermal spraying a cylinder. The other factors that weighed in on the final feasibility assessment included fixtures, cost, coating uniformity and existing mini-gun technologies. It was established that air plasma spray could not be used to apply environmental barrier coatings (EBCs) of acceptable quality to an integral vane ring assembly. Figure $1 \mathrm{~b}$ is a pictorial representation of the approach used to assess the relative "accessibility" of the plasma plume to the component. Subsequent coating development for silicon nitride focused on non-line of sight coating methods. The processing routes found most promising were slurry coatings and chemical vapor deposition (CVD).

\section{BOND COAT DEVELOPMENT}

Early work on the development of EBC for silicon nitride $\left(\mathrm{Si}_{3} \mathrm{~N}_{4}\right)$ was done under the NASA EPM, DOE CSGT and DOE/ONR funded EBC for Silicon Nitride programs. The EBC developed for silicon carbide ( $\mathrm{SiC}$ ) has been demonstrated to be ineffective for $\mathrm{Si}_{3} \mathrm{~N}_{4}$ as it caused a debit in room temperature strength of the base material by over $50 \%$ [13]. Figure 2 shows the reduction in strength when the 3-layer state-of-the-art $\mathrm{EBC}_{\mathrm{SiC}}$ is applied to silicon nitride (AS800). A similar strength debit was also seen on other grades of silicon nitride and at elevated temperature the debit in strength was $\sim 15 \%$. The primary mechanism causing the reduction in the strength of silicon nitride has been identified to be the thermal mismatch between the coating and 
silicon nitride [13]. It was also found that the application of the silicon bond coat alone to the substrate (with or without a top layer) results in about $50 \%$ debit in room temperature strength of the substrate indicating that a coating architecture with silicon as bond coat applied on to $\mathrm{Si}_{3} \mathrm{~N}_{4}$ is undesirable[13]. The silicon coatings are typically very well bonded to the substrate and the CTE mismatch cracks (as observed) are expected to interact with the pre-existing cracks in the ceramic resulting in a significant reduction in fracture strength of the ceramic.
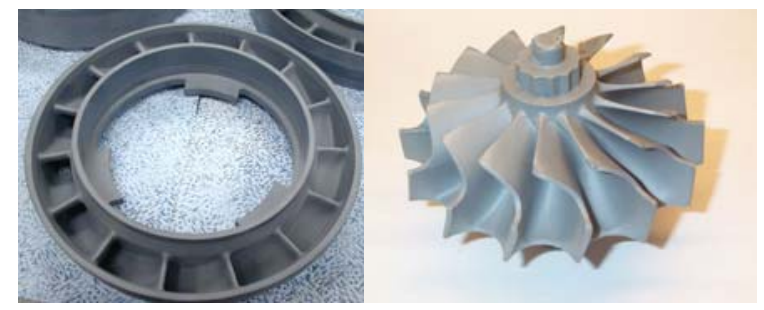

(a)

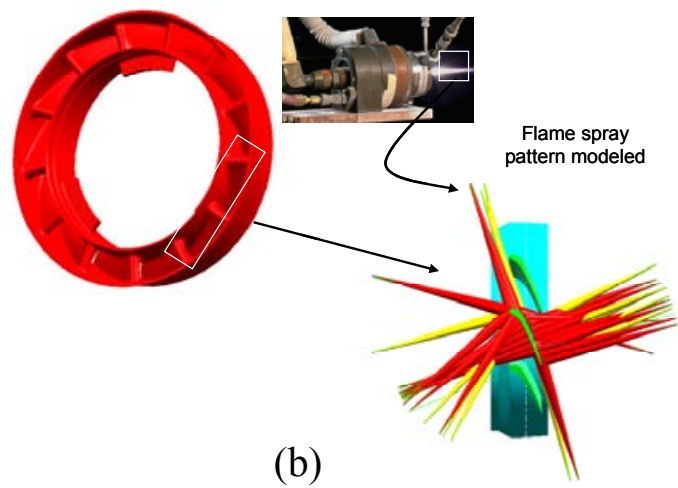

Figure 1: (a) Typical $\mathrm{Si}_{3} \mathrm{~N}_{4}$ gas turbine components. (b) Study of the feasibility of thermal spraying an integral vane ring.

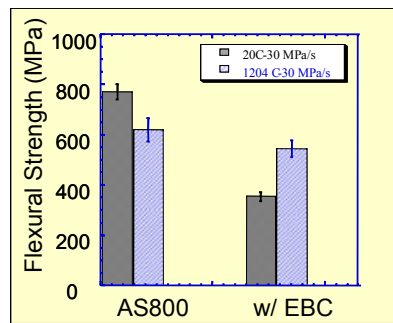

(a)

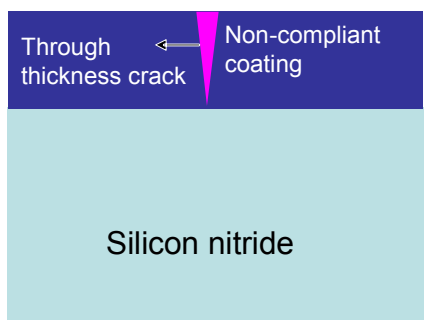

(b)

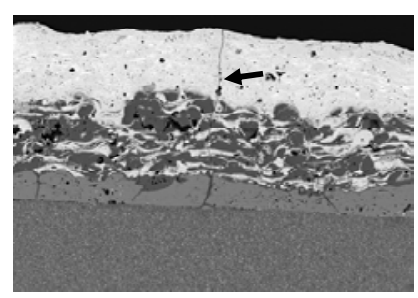

(c)

Figure 2: (a) Effect of BSAS-based EBC coating on strength of $\mathrm{Si}_{3} \mathrm{~N}_{4}$. (b) Schematic mechanism of strength reduction. (c) Microstructure of $B S A S E B C$ on $\mathrm{Si}_{3} \mathrm{~N}_{4}$ that shows the flaws in the coating.

Further efforts were made to understand the mechanism for the strength debit of the substrate using numerical modeling. When a thin layer of silicon is deposited on a silicon nitride substrate and the system is cooled from a stress-free temperature of $1000^{\circ} \mathrm{C}\left(1832^{\circ} \mathrm{F}\right)$, the in-plane tensile residual stress in silicon given by the following equation:

$$
[\sigma=\mathrm{E} \Delta \alpha \Delta \mathrm{T} /(1-\mathrm{v})]
$$

where $\mathrm{E}$ is the modulus of silicon, $\Delta \alpha$ is the difference in CTE of silicon and silicon nitride, $\Delta \mathrm{T}$ is the temperature difference and $v$ is the Poisson's ratio, which is of the order of $26 \mathrm{ksi}(=179 \mathrm{MPa})$. Although the exact value of fracture strength of silicon is unknown, it is governed by processing flaws and cracking is always observed in the silicon layer (see figure 2c). It is therefore believed that the residual stress in Si exceeds its strength. Further it is found that the magnitude of tensile stress in silicon is fairly independent of thickness of silicon layer, and thickness and moduli of intermediate and top layers, as long as thickness of coating layers is at least an order of magnitude lower than the substrate thickness (which is typically the case in most applications), as shown in Figure 3.

A variety of coating architectures were considered with an objective to drive down the residual stress in the silicon layer. Some of the architectures are 
shown in Figure 4. The thermophysical properties of the layers were varied and it was found that if the CTE of the materials was varied within $4 \mathrm{ppm} / \mathrm{C}$ of $\mathrm{Si}_{3} \mathrm{~N}_{4}$, the residual stress in the silicon layer did not decrease to levels much lower than 23-25 ksi.

In addition to the stress analyses, micromechanical fracture modeling was also conducted to explain the effects of residual stress in the Si layer on flaw creation, propagation and interaction with preexisting flaws in silicon nitride.

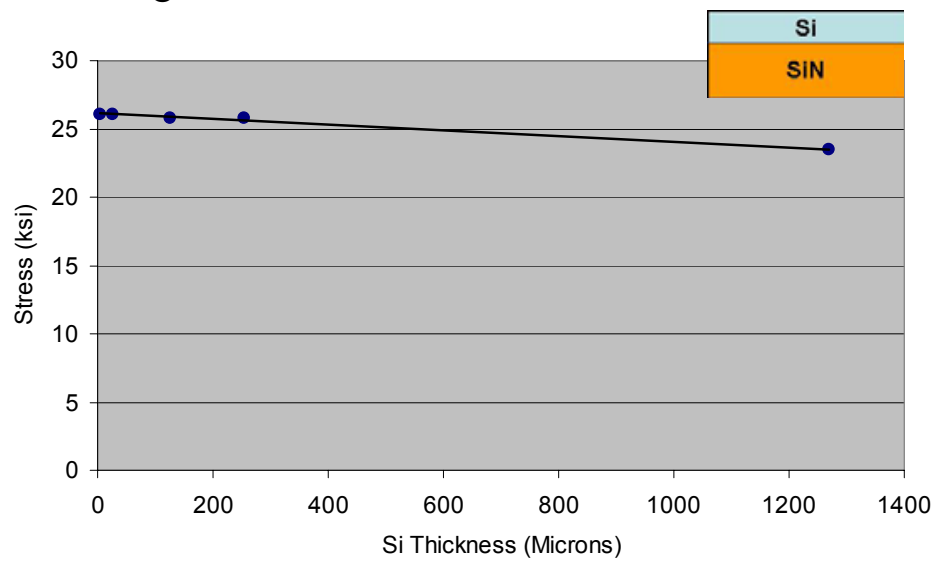

Figure 3: Calculation of residual stress in Si layer on monolithic $\mathrm{Si}_{3} \mathrm{~N}_{4}$. The stress in the coating is fairly independent of the coating thickness.
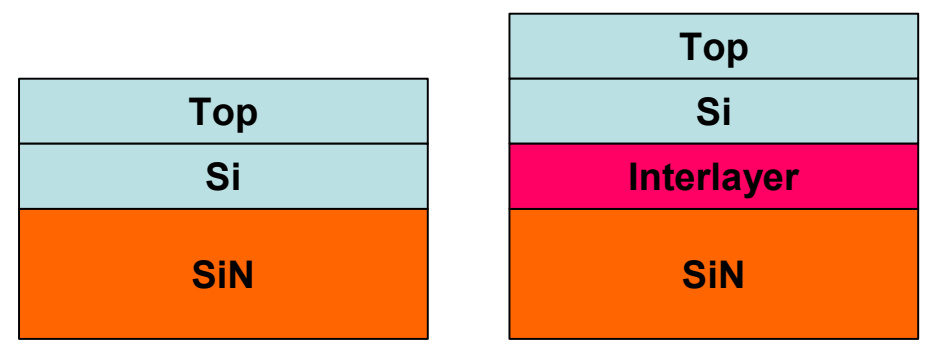

Figure 4: Various architectures considered to drive down residual stress in the Si-layer of the coating.

OOF, an object oriented finite element analysis code developed at NIST[15], was used to investigate the response of the coated substrate to thermal loads. The program performs thermoelastic calculations in two dimensions (plane strain or plane stress) using 3node triangular elements. Several "smart" meshing schemes based on energy minimization are available to mesh curved features, such as grain boundaries. A digital image of a microstructure, either from an optical/electron microscope or a result of a computer simulation, can be used for analysis. Based on this data, a finite element grid with associated material properties is generated on which mechanical and/or thermal loading can be applied. A solution is then obtained for the specified boundary conditions, distortion, and temperature change. The calculations were done assuming plane stress $\left(\sigma_{33}=0\right)$ and free boundary conditions to mimic unconstrained cooling of a thin plate from its sintering temperature.

A typical coating microstructure (Figure 5) was imported into the OOF code, digitized for thermal analysis and then subjected to a temperature change of $1000^{\circ} \mathrm{C}\left(1832^{\circ} \mathrm{F}\right)$. The calculated global stresses were similar to that obtained from equaltion 1 [Figure 3].

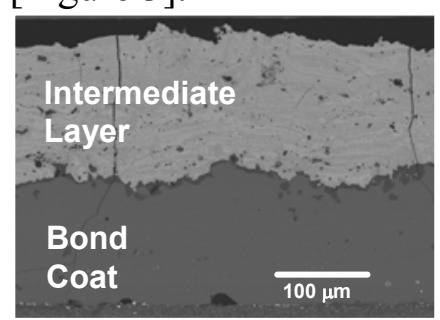

Typical EBC

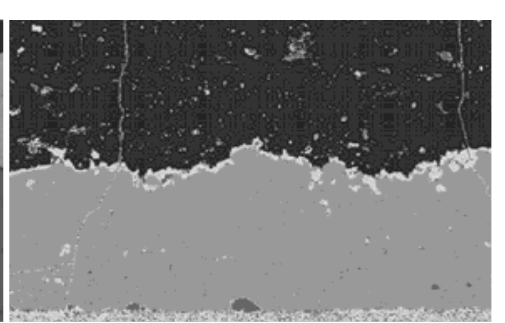

Digitized Microstructure

\section{Figure 5: EBC coating microstructure and digitized image for $O O F$ analysis}

In addition to the calculation of the residual stresses, the elements in the OOF code are designed to fail under a Griffith-like strain energy based criterion. The elements crack when the required surface energy can be supplied by the stored strain energy per crack extension $(\Delta \mathrm{L})$, i.e.,

$$
\frac{1}{2} \sigma_{i j}^{\text {elem }} \varepsilon_{i j}^{\text {elem }} A_{\text {elem }} / \Delta L \geq 2 \gamma
$$

where $\gamma$ is the surface energy of the cracked interface.

The analysis involves the following steps:

a. Thermal and mechanical loads are applied and the microstructure is equilibrated to determine stress/strain distribution.

b. The energy balance is computed and if an element satisfies the energy criterion for cracking, the stiffness of the element is set to zero. 
c. The microstructure is re-equilibrated and the stress distribution is re-calculated.

d. The procedure is repeated until no more elements mutate or one or more cracks become unstable, causing fracture into two or more fragments.

A parametric study was undertaken to develop an understanding of the effects of material properties on residual stresses and crack initiation and propagation using simple geometries. An example of such an analysis is shown in Figure 6. The simulation results indicated that crack propagation and arrest were strongly dependent on relative surface energies and residual stresses. Further, it was found that using a low modulus interlayer between $\mathrm{Si}_{3} \mathrm{~N}_{4}$ and silicon could help in isolating the flaws in the coating from the pre-existing flaws in $\mathrm{Si}_{3} \mathrm{~N}_{4}$.

As predicted by the OOF approach, it was observed that a low modulus oxide inter-layer between $\mathrm{Si}_{3} \mathrm{~N}_{4}$ and Si successfully solved the problem of substrate strength retention. The interlayer is applied using a dip coating process and the Si layer is applied by CVD. The coating was found to help retain the strength of $\mathrm{Si}_{3} \mathrm{~N}_{4}$ as is shown in figure 7. The two bars in figure $7 \mathrm{a}$ represent $35 \mu \mathrm{m}$ and $70 \mu \mathrm{m}$ thick silicon layers. The inter-layer approach has been used for Si thicknesses up to $100 \mu \mathrm{m}$ with successful retention of baseline strength. Figure $7 \mathrm{~b}$ shows a typical microstructure of the bond coat system. A well adhered gas tight top layer is expected to provide the steam protection required in the gas turbine environment.

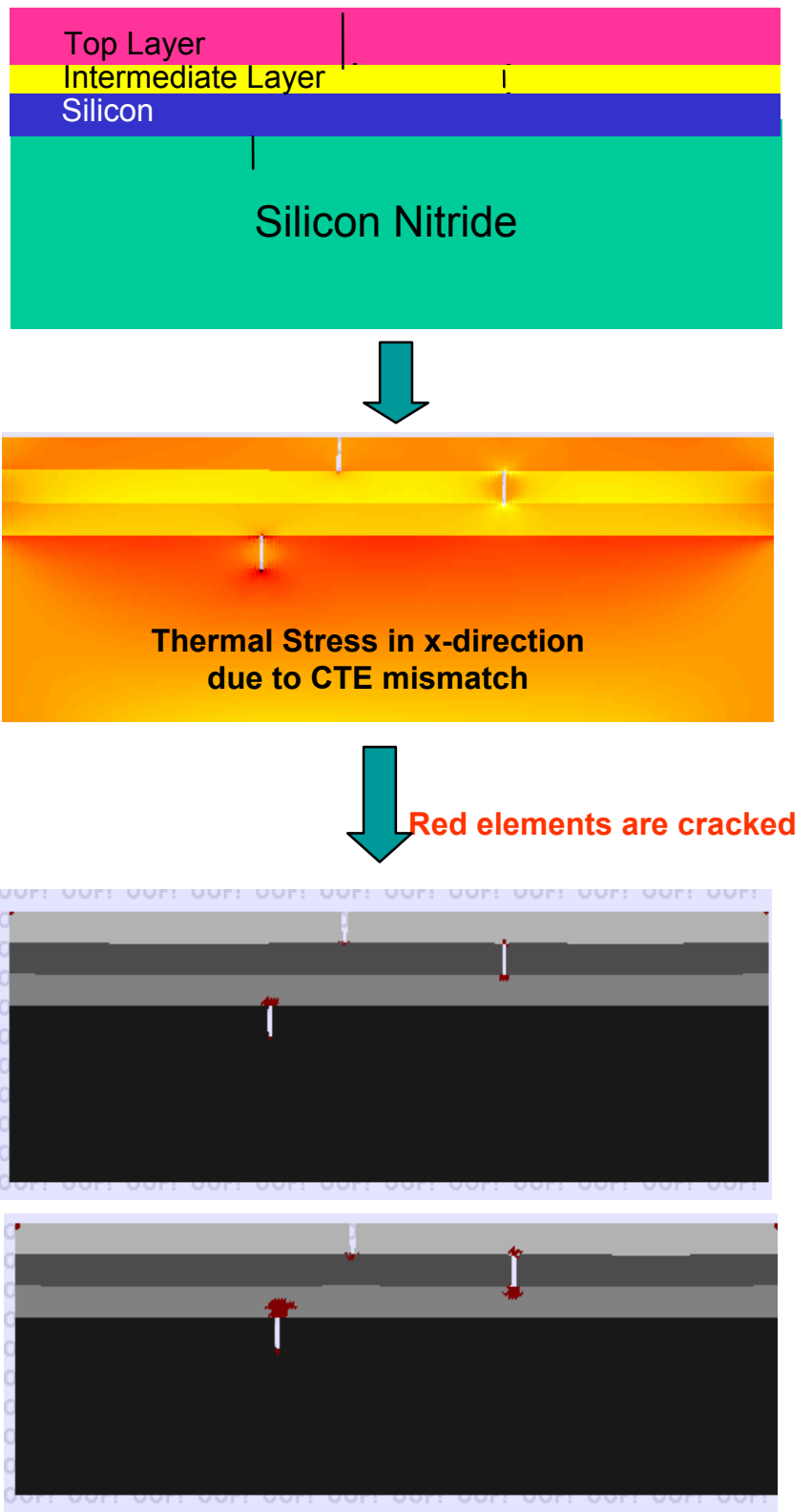

Figure 6: Residual stresses and cracking in EBC coated substrates using OOF 


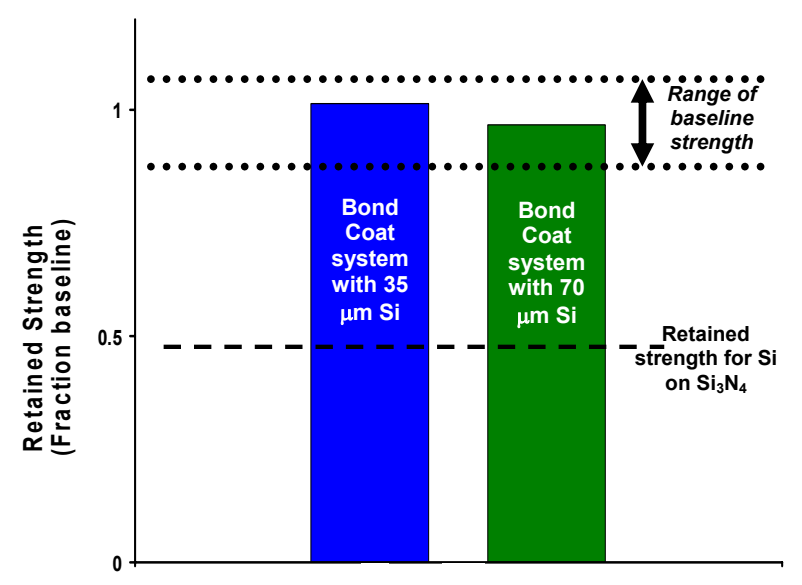

(a)

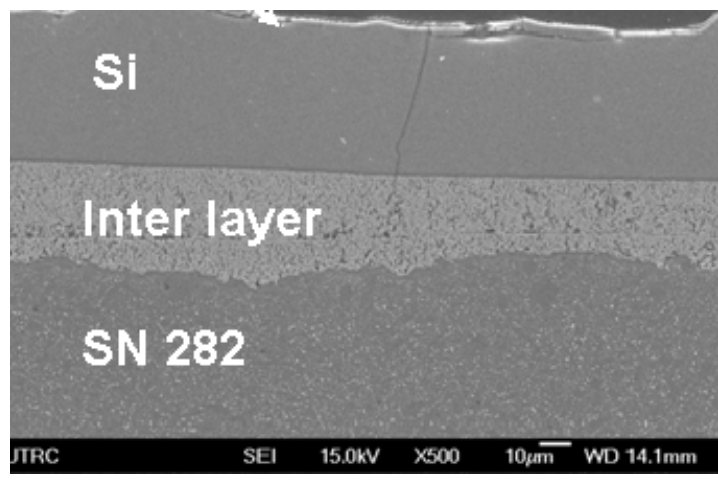

(b)

Figure 7: (a) Retained strength of silicon nitride using an oxide interlayer between silicon nitride and Si bond coat. (b) Microstructure of the bond coat system that retains baseline substrate strength.

Weibull analysis and fractographic investigation were performed to understand the nature and distribution of strength controlling defects, and verify the effectiveness of the interlayer. The Weibull plot of the cumulative probability of failure with bend strength for as received silicon nitride and silicon nitride samples coated with the new bond layer system ( $\mathrm{Si}$ and interlayer) is shown in Figure 8. The Weibull distribution is given as

$$
P_{f}=1-\exp \left[-\left(\frac{\sigma}{\sigma_{c}}\right)^{m}\right]
$$

where $\mathrm{P}_{\mathrm{f}}$ is cumulative probability of failure, $\sigma$ is the order parameter or strength at which probability of failure is to be determined, $\sigma_{c}$ is the scaling parameter of the distribution and also known as characteristic strength, $m$ is the shape parameter of the distribution and is also known as the Weibull Modulus [16]. The Weibull distribution parameters $\left(\sigma_{\mathrm{c}}\right.$ and $\left.\mathrm{m}\right)$ were determined from regression fit.
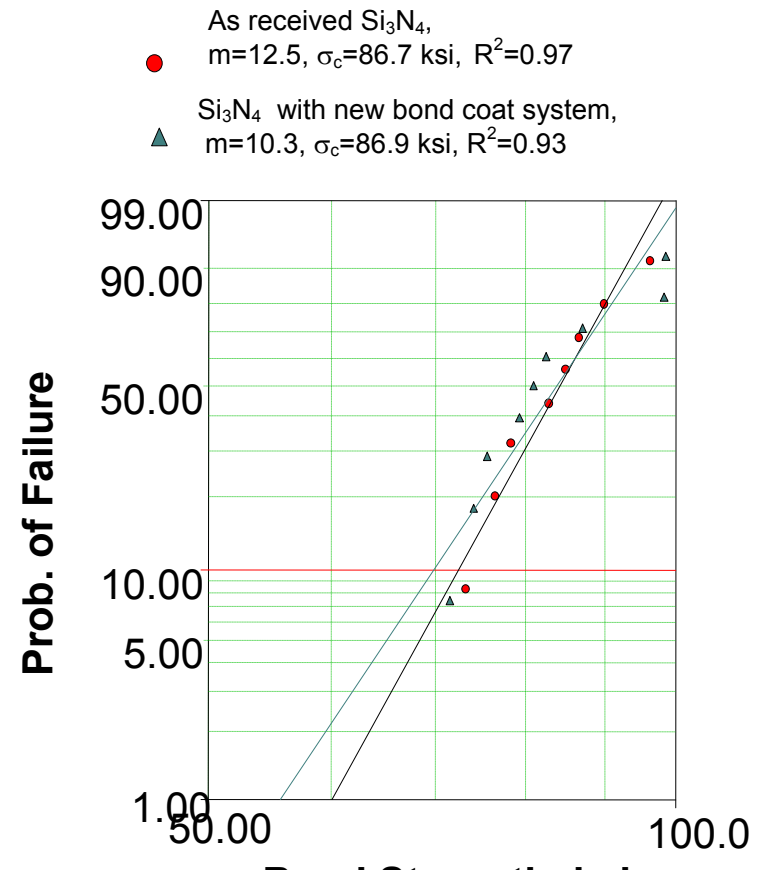

Bend Strength, ksi

Figure 8: Strength of samples fractured in four point bending shown as Weibull distribution

The Weibull modulus and characteristic strength for the as received silicon nitride samples are 12.5 and $86.7 \mathrm{ksi}$, respectively. The Weibull modulus and characteristic strength for silicon nitride with bond coat system are 10.3 and $86.9 \mathrm{ksi}$, respectively. The distributions of the two sets of data are similar both in magnitude and in scatter. The regression analysis shows similar degree of fit for both sets of samples as judged from the $\mathrm{R}^{2}$ value. The Weibull analysis suggests that both sets of samples contain flaws of nearly the same size and distribution.

Fractographic analysis indicates that the nature of strength limiting flaws in the uncoated substrate and the substrate with the bond coat system remains unchanged. Figures $9 \mathrm{a}$ and $\mathrm{b}$ show fracture surfaces of coated and uncoated SN282 as observed under a low magnification stereo microscope. The failure 
strength of as received silicon nitride is $86.6 \mathrm{ksi}$, while the failure strength of the coated silicon nitride is $81.4 \mathrm{ksi}$. The fracture origin for both samples, as marked in the figure 9 , is from the silicon nitride surface as judged by the fracture mirror and crack branching pattern. The magnitude of fracture mirror radius is also same for both the samples, $\sim 300 \mu$ each.
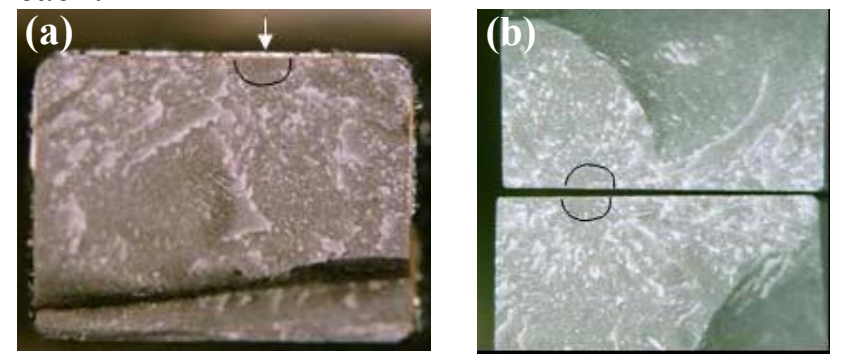

Figure 9: (a) Fracture surface of as received silicon nitride that failed at $86.6 \mathrm{ksi}$ in bend test. (b)

Fracture surface of as silicon nitride coated with the compliant laer and Si that failed at $81.4 \mathrm{ksi}$ in bend test

The fracture mirror radius is directly proportional to crack size from which the fracture initiated [17]. The local stress at failure is hence inversely proportional to the square root of fracture mirror radius. Since the failure strength determined from testing and the fracture mirror sizes are nearly the same for both samples shown in figure 9, the local stresses at failure are also the same. This implies that the bond coat system on silicon nitride does not contribute to any additional local stresses and isolates the interaction of residual stress in silicon layer from preexisting flaws in silicon nitride. It is thus demonstrated that the bond coat system neither creates a different critical flaw population nor does it affect the stress intensity factor associated with original flaw population present in the as received material.

\section{SCALE-UP EFFORTS IN PREPARATION OF COATING DEMONSTRATIONS}

As outlined earlier, coating of integral components requires non-line-of-sight coating methods. Slurry based coating techniques offer the promise of being low cost and versatile with respect to composition unlike most vapor routes such as CVD. Unfortunately, the slurry coating technology to make relatively thick and high density coatings for environmental protection is not mature. Reference 18 lays out the important principles of slurry development with focus on EBCs. It is clear from the discussion captured in references 18 and 19 that one of the most critical parameters that govern the ability to obtain uniform and crack free coatings of the desired thickness is slurry rheology. The references cited explain the importance and methodology of $\mathrm{pH}$ selection, binder selection, and binder content as a function of starting powders.

In the current study, the principles of slurry stabilization and viscosity control outlined in references 18 and 19 were utilized to optimize slurries for dip coating. The composition of interest was the ceramic interlayer discussed in the previous section. Slurry viscosity was critically dependent upon $\mathrm{pH}$, binder and solid loading. It was also found that coating coverage and uniformity at the coupon level could not be used to guide slurry optimization as component geometries played an important role in determining coating quality as will be obvious in the following discussion. Also, dip coating trials on prototype components plays an important role in the development of uniform coatings and offers the opportunity for a number of sub-scale tests needed to validate the coating before engine tests.

Efforts at scale-up were focused on two classes of components: (1) single SN282 blades for burner rig tests, and; (2) integral turbine components (integrally bladed rotors and integral vane rings) in order to closely understand the challenges of coating complex geometries. Dip coating the single silicon nitride blades helped in optimization of slurries and designing fixtures to hold and manipulate the components during the dip coating process. Figure $10 \mathrm{a}$ is a picture of an EBC coated blade before a burner rig testing. The blade was burner rig tested in the UTRC facility described in reference 10. The flame from the burner impinged upon the blade and the material temperature on the leading edge was in excess of $2400 \mathrm{~F}\left(1315^{\circ} \mathrm{C}\right)$. The approximate hot time was 2 minutes and the blade was subsequently cooled for 1 minute. As is seen from figure 10b, there was no observable damage after 50 thermal cycles. Similar burner rig testing will be used to qualify the coating as the final coating architecture and process is down selected. 
(a)
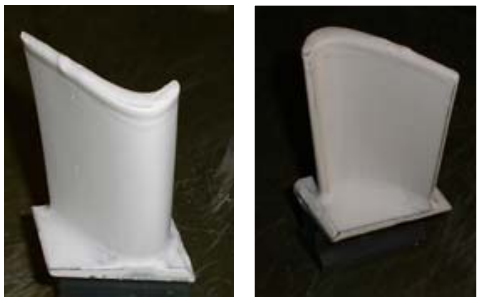

(b)

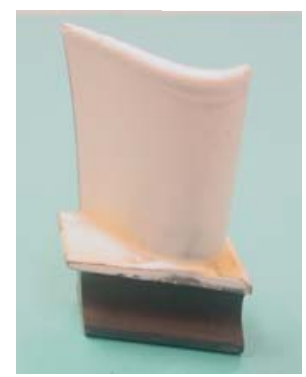

Figure 10: Slurry coated SN282 blade. (a) Before and (b) After burner rig testing to $2400 \mathrm{~F}$ (50 cycles)

When integral vane rings or rotors were dipped, the drip issues were found to be much less severe than in the single blade. It was decided to focus scale-up on the integral components since they are more relevant to the ongoing programs at UTRC. A dip coated integral rotor before firing is shown in Figure 11. Another particular dip trial on an integral vane ring prototype similar to one described in figure 1 is shown in figure 12 . It can be seen from the figure that the airfoils and platforms have fairly uniform coverage with the coating. In order to understand the variability of coating thickness on the component and "quantify" coating quality, a white light fringe projection technique (described in reference 20) was used extensively to map the contours of the component before and after coating application. This was used to map coating thickness in the different areas of the component. The areas in the fillets were found to be particularly difficult to coat adequately. Efforts are ongoing to improve slurry characteristics to improve coating coverage to achieve uniform coatings.

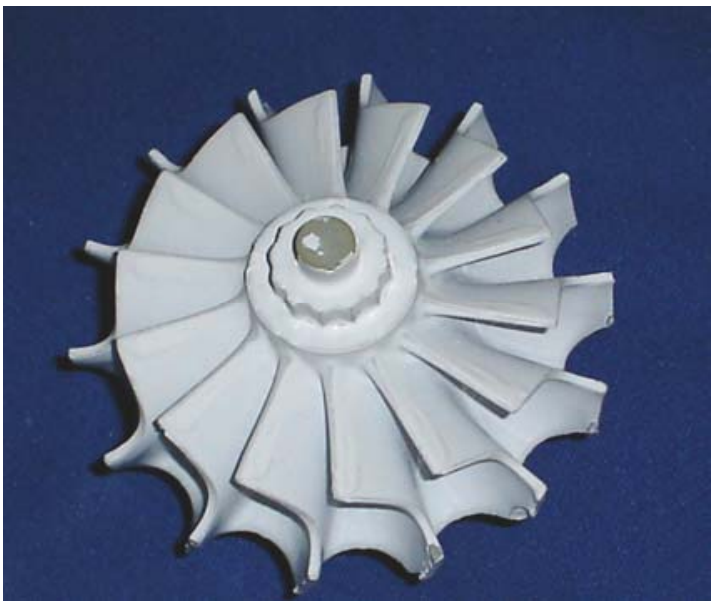

Figure 11: Integrally bladed NT154 microturbine rotor after dip coating in an oxide slurry.
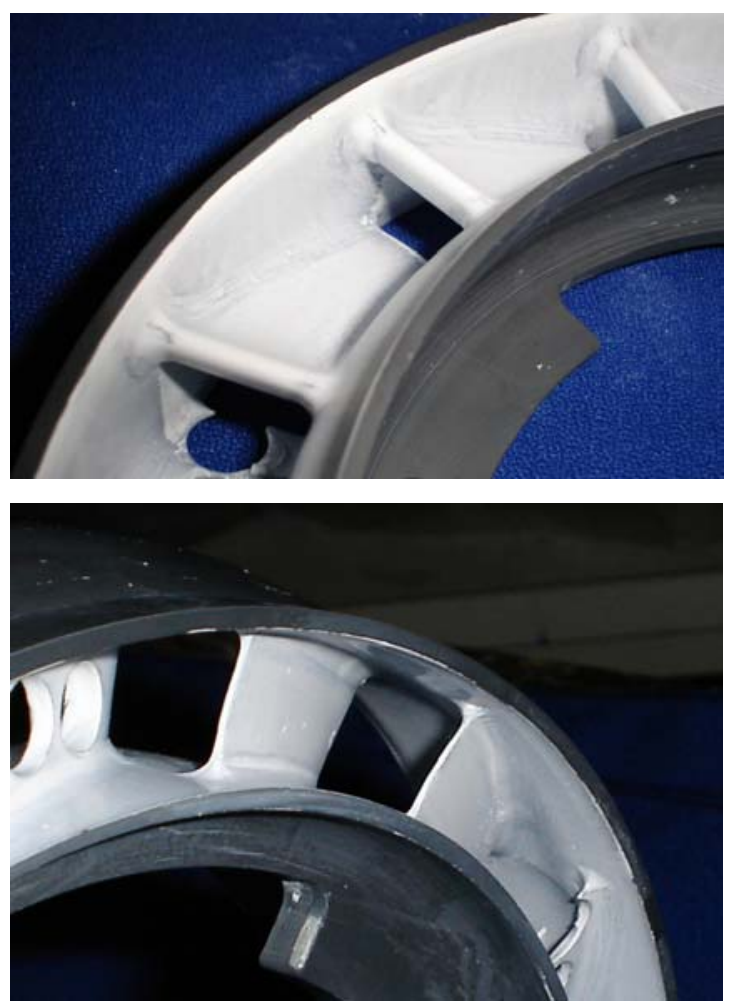

Figure 12: Coating of integral vane ring to demonstrate scalability of the process

\section{SUMMARY}

A new bond coat system consisting of a low modulus ceramic inter layer and a CVD Si layer helps retain the baseline strength of monolithic silicon nitride. It has been found that the coating does not adversely affect the pre-existing flaws in silicon nitride and the 
interlayer is effective in isolating the residual stress in the Si layer from the substrate. It has also been determined that the coating solutions for monolithic silicon nitride need to focus on non-line-of-sightmethods in order to coat integral components of relevance. Efforts are ongoing to demonstrate the environmental protectiveness of a complete coating system tailored for silicon nitride processed by nonline-of-sight methods.

\section{ACKNOWLEDGMENTS}

This work and the efforts leading to it would not have been possible without the guidance and support of the Office of Naval Research (ONR) - Dr. Dave Shifler and Dr. Steven Fishman; the Department of Energy (DOE) - Deborah Haught and Don Geiling. Thanks are due to Mark Bliek of Bolton Works, Bolton, CT and other United Technologies Research Center personnel: Tahany El-Wardany, Owen Donahue, Mark Herman, John Holowczak, Wayde Schmidt, Tom Lawton and Jodi Vecchiarelli. Thanks are also due to Beth Armstrong of Oak Ridge National laboratories for her insight and discussions on slurry stabilization.

\section{REFERENCES}

1. Opila, E.J., and Hann R.E. Jr, 1997, "Paralinear Oxidation of CVD SiC in Water Vapor”, J. Am. Ceram. Soc., 80 (1), pp. 197205.

2. Opila, E.J., Fox, D.S., and Jacobson, N.S., 1997, "Mass Spectrometric Identification of $\mathrm{Si}-\mathrm{O}-\mathrm{OH}(\mathrm{g})$ Species from the Reaction of Silica with Water Vapor at Atmospheric Pressure", J. Am. Ceram. Soc., 80 (4), pp. 1009-12

3. Opila E.J., Smialek, J.L., Robinson, R.C., Fox, D.S., and Jacobson, N.S., 1999, "SiC Recession Caused by $\mathrm{SiO} 2$ Scale Volatility under Combustion Conditions: II, Thermodynamcis and Gaseous-Diffusion Model", J. Am. Ceram. Soc., 82 (7), pp. 1826-34.

4. Robinson, R.C., and Smialek, J.L., 1999, "SiC Recession Caused by $\mathrm{SiO} 2$ Scale Volatility under Combustion Conditions: I,
Experimental Results and Empirical Model", J. Am. Ceram. Soc., 82 (7), pp. 1817-25.

5. Smialek, J.L., Robinson, R.C., Opila, E.J., Fox, D.S., and Jacobson, N.S., 1999, "SiC and Si3N4 Recession Due to $\mathrm{SiO} 2$ Scale Volatility Under Combustor Conditions", Adv. Composite Mater., 8, 1, pp.33-45.

6. Eaton, H.E., Linsey, G.D., More, K.L., Kimmel, J.B., Price, J.R., and Miriyala, N., 2000, "EBC Protection of $\mathrm{SiC} / \mathrm{SiC}$ Composites in the Gas Turbine Combustion Environment", ASME Paper GT-2000-631.

7. Eaton, H.E., and Linsey, G.D.; 2002, "Accelerated oxidation of $\mathrm{SiC}$ CMC's by Water Vapor and Protection via Environmental Barrier Coating Approach", J. Eur. Ceram. Soc, 22, pp 2741-2747.

8. More, K.L., Tortorelli, P.F., Walker, L.R., Kimmel, J.B., Miriyala, N., Price, J.R., Eaton, H.E., Sun, E.Y., and Linsey, G.D., 2002, "Evaluating Environmental Barrier Coatings on Ceramic Matrix Composites after Engine and Laboratory Exposures", ASME Paper GT-2002-30630.

9. Miriyala, N., Kimmel, J., Price, J., More, K., Tortorelli, P., Eaton, H., Linsey, G., and Sun, E., 2002, "The Evaluation of CFCC Liners After Field Testing in a Gas Turbine -III", ASME Paper GT-2002-30585.

10. Bhatia, T., Eaton, H.E., Sun,E.Y., Lawton T.H., and Vedula, V.R. "Advanced Environmental Barrier Coatings for $\mathrm{SiC} / \mathrm{SiC}$ Composites", , ASME GT2005-68241, Reno, 2005.

11. Sun, E., Eaton, H., Holowczak, J., and Linsey, G., 2002, "Development and Evaluation of Environmental Barrier Coatings for Silicon Nitride", ASME Paper GT-2002-30628.

12. More, K.L., Tortorelli, P.F., and Walker, L.R., "Verification of an EBC's Protective Capability by First-Stage Evaluation in a High Temperature, High-Pressure Furnace", ASME Paper GT-2003-38923. 
13. Bhatia, T., Vedula, V.R., Eaton, H.E., Sun, E.Y., Holowczak, J.H., and Linsey, G.L., "Development and Evaluation of Environmental Barrier Coatings for Si-based Ceramics", ASME Paper GT2004-54092.

14. Tredway W.K., Shi, J., Holowczak, J.H., Vedula, V., Bird, C, Ochs, S, Bertuccoioli, L., and Bombara, D, "Design of Ceramic Components for an Advanced Micro-Turbine Engine" ASME Paper GT2004-54205

15. S. A. Langer, E. R. Fuller, Jr., and W. C. Carter, "OOF: An Image-based Finite Element Analysis of Material Microstructures", Computing Sci. Eng., 3 [3] 15-23 (2001).

16. Weibull, W., "A Statistical Theory of the Strength of Materials", Ingeniors Vertenskaps Akademien Handlinger, vol. 151, pp. 1-45, 1939

17. Kirchner, H.P., and Conway, J., "Fracture Mechanics of Crack Branching in Ceramics", in Advances in Ceramics, Vol. 22: Fractography of Glasses and Ceramics, Ed. by Verner, J.R., and frechette, V.D., The Amer. Ceram. Soc., 1988

18. Kirby, G.H, Cooley, K.M., and Armstrong, B.L., "Tailored Rheological Behavior of Mullite and BSAS Suspensions Using a Cationic Polyelectrolyte", by ASME Paper GT 2005-, 2005

19. Armstrong, B. L., "Slurry Deposition of Environmental Protection Systems," presented at the Environmental Barrier Coatings Workshop, Nashville TN, November 16, 2005.

http://www.ornl.gov/sci/de materials/docum ents/BLAEBC111605final.pdf

20. de Groot, P., and Deck,L, "Surface Profiling by Analysis of White-light Interferograms in the Spatial Frequency Domain " Journal of Modern Optics, Vol. 42 (2); pp 389-401, 1995 
